\title{
Evaluation Strategies for Risk Assessment and Usability of Medical Plasma Sources in Dermatology
}

\author{
Doctoral Thesis
}

\author{
In partial fulfillment of the requirements for the degree \\ "Doctor rerum naturalium (Dr. rer. nat.)" \\ in the Molecular Medicine Study Program \\ at the Georg-August University Göttingen
}

submitted by

Regina Tiede

born in Karabulak, Kasachstan

Göttingen, 30.05.2017 



\section{Members of the Thesis Committee}

\section{Supervisor:}

Prof. Dr. med. Steffen Emmert

University Medical Center Rostock, Clinic for Dermatology and Venereology

18057 Rostock

First member of the thesis committee:

Prof. Dr. med. Michael P. Schön

University Medical Center Göttingen, Clinic for Dermatology, Venereology and Allergology

37075 Göttingen

Second member of the thesis committee:

Prof. apl. Prof. Dr. Wolfgang Viöl

University of Applied Sciences and Arts

Fraunhofer IST Application Center for Plasma and Photonic

37085 Göttingen

Third member of the thesis committee:

Prof. Dr. Hubertus Jarry

University Medical Center Göttingen, Dept. of Clinical and Experimental Endocrinology

37075 Göttingen

Date of Disputation: 04.08.2017 





\section{Affidavit}

Herewith I declare that my doctoral thesis entitled

"Evaluation Strategies for Risk Assessment and Usability of Medical Plasma Sources in Dermatology"

has been written independently with no other sources and aids than quoted.

30.05.2017

Date

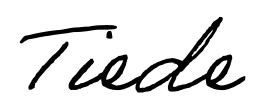

Signature (Regina Tiede) 


\section{Thank You}

Supervisor

Members of the Thesis Committee

Cooperation Partners

Financial Support

Colleagues

Special thank you to my beloved family, who always supports me.
Prof. Dr. med. Steffen Emmert

Prof. Dr. med. Michael P. Schön

Prof. Dr. Wolfgang Viöl

Prof. Dr. Hubertus Jarry

INP Greifswald

HAWK Göttingen

DIN

IFS

German Federal Ministry of Economic Affairs and Energy; NormPlas

(01FS12003)

Sabine Smolorz

Miriam Mann \& Sander Bekeschus

Petra Rieper \& Steffen Schubert

Antje Apel \& Stina Schiller

Andreas Helmke

Erich M. Staudacher 


\section{Table of Contents}

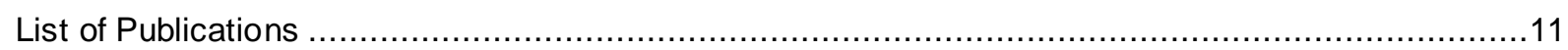

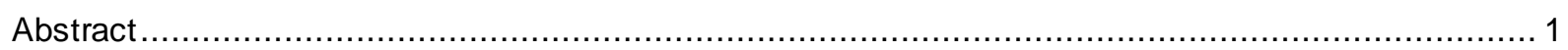

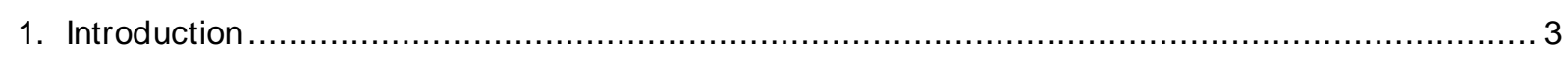

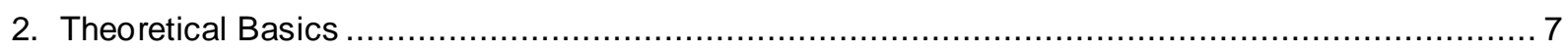

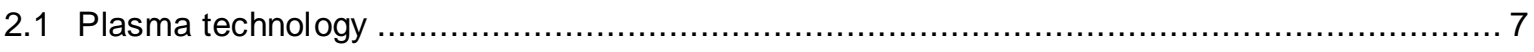

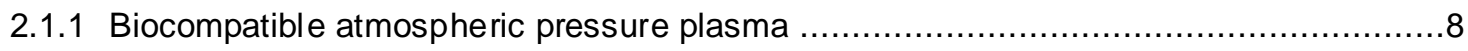

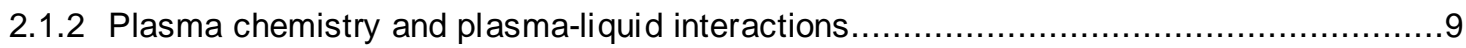

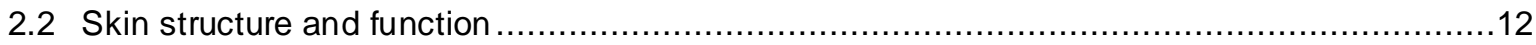

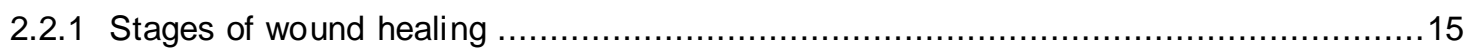

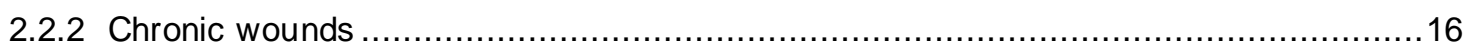

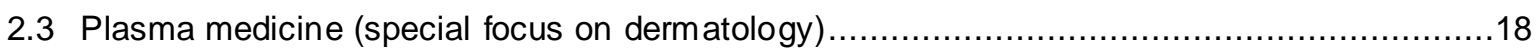

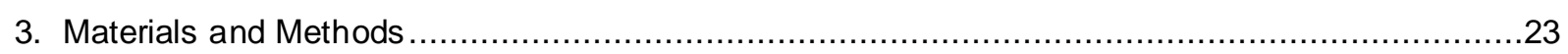

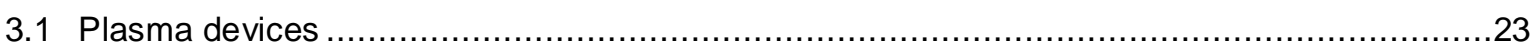

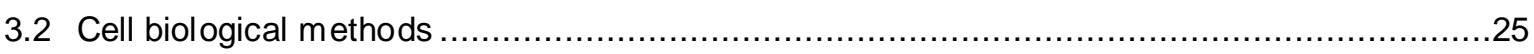

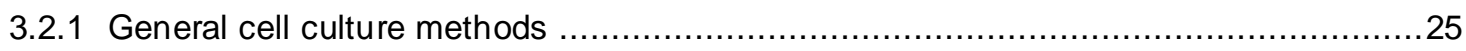

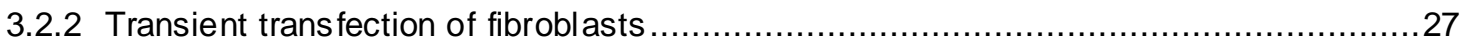

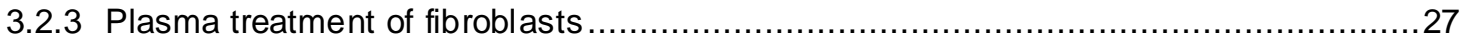

3.2.4 Treatment of fibroblasts with $\mathrm{H}_{2} \mathrm{O}_{2}$ and different radiations .............................28

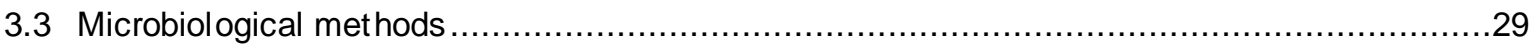

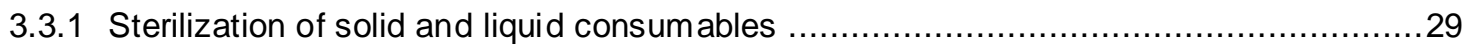

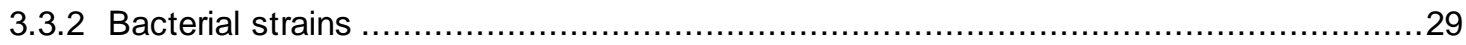

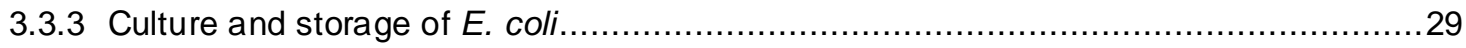

3.3.4 Preparation of chemically-competent $E$. coli................................................ 30

3.3.5 Transformation of plasmid DNA into chemically-competent $E$. coli ........................... 30

3.3.6 Amplification and preparation of plasmid DNA in E. coli ..........................................

3.3.7 Quality control of generated competent cells .............................................. 31

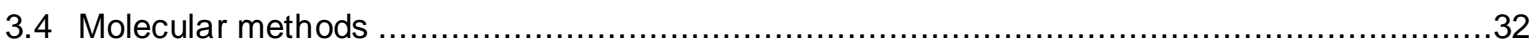

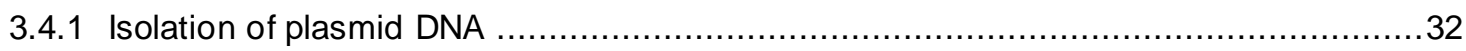

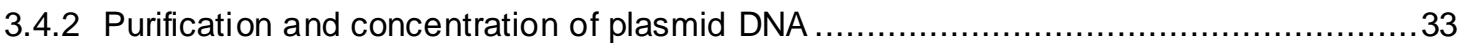

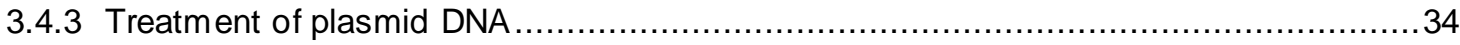

3.4.4 DNA separation via agarose gel electrophoresis ............................................... 34

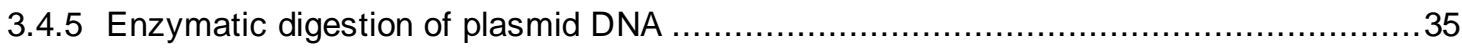

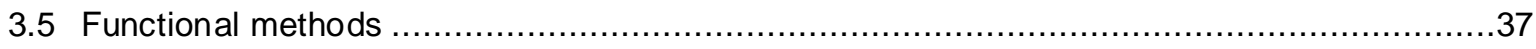




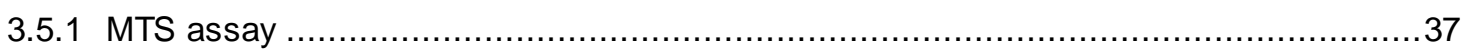

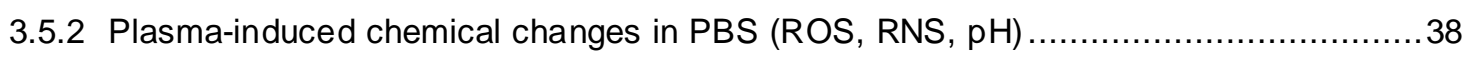

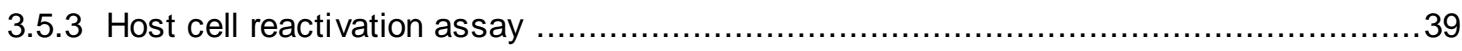

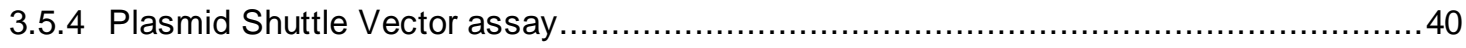

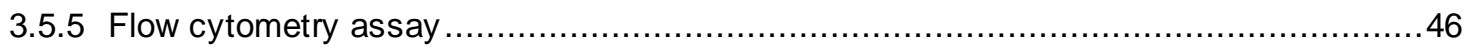

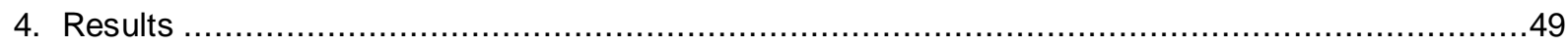

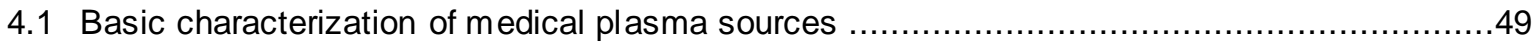

4.1.1 Physico-technical characterization of APPs and safety in use ........................49

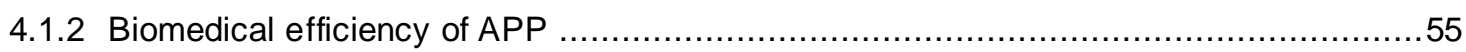

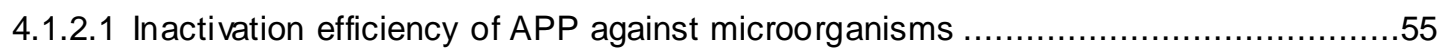

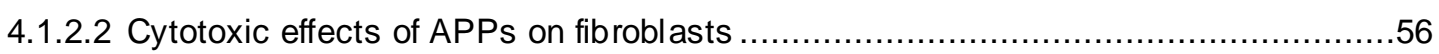

4.1.2.3 APP-dependent generation of reactive species and $\mathrm{pH}$ changes .....................60

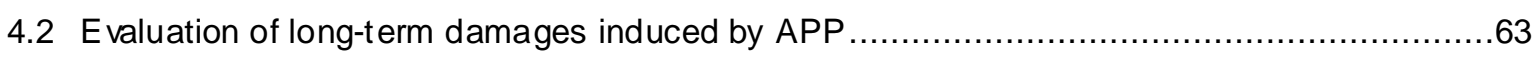

4.2.1 Indirectly measured genotoxicity of APP on plasmid DNA $\ldots \ldots \ldots \ldots \ldots \ldots \ldots \ldots \ldots \ldots \ldots \ldots$

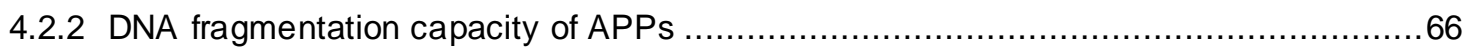

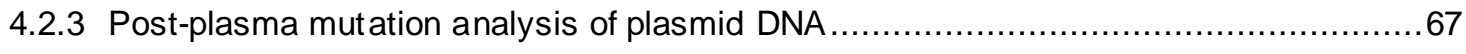

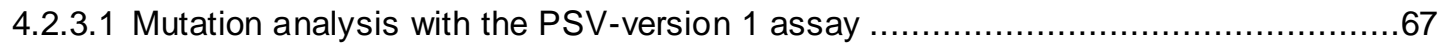

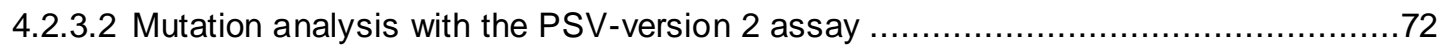

4.2.4 Flow cytometric analyses of genomic DNA damages in fibroblasts .....................74

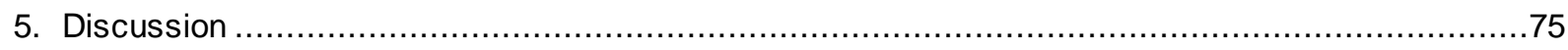

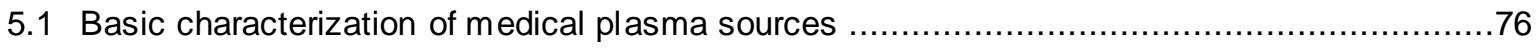

5.1.1 Physico-technical parameters and medical treatment requirements .....................76

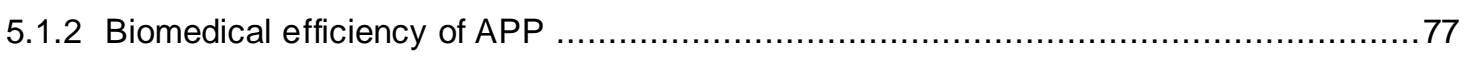

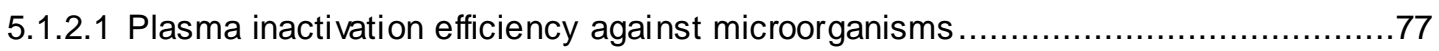

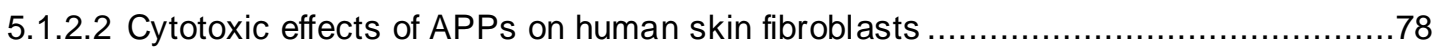

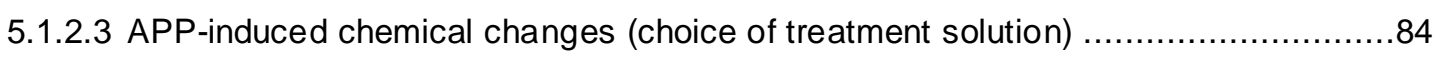

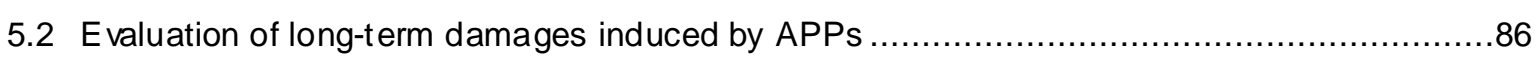

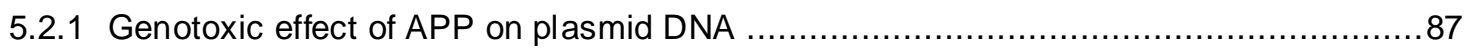

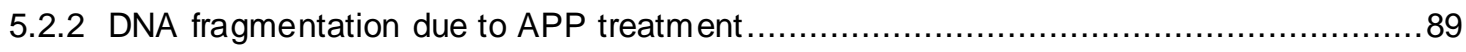

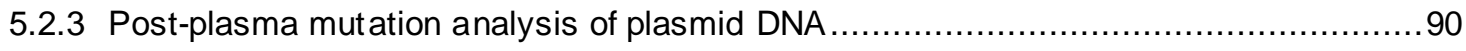

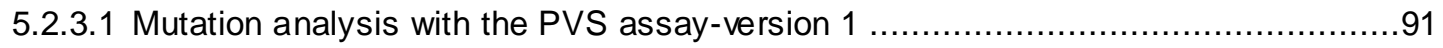

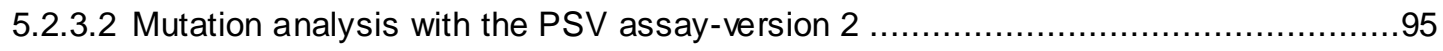

5.2.4 Flow cytometric analysis of DNA damages in human fibroblasts......................99

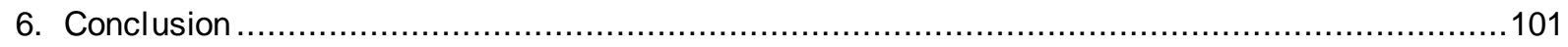

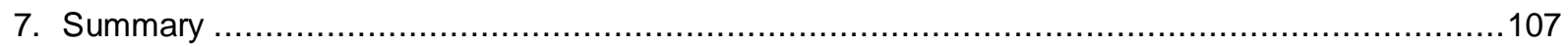




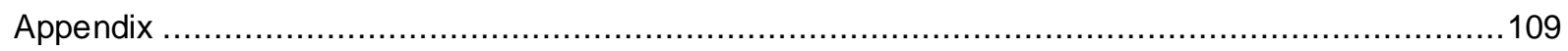

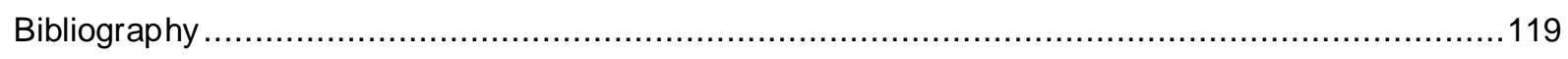

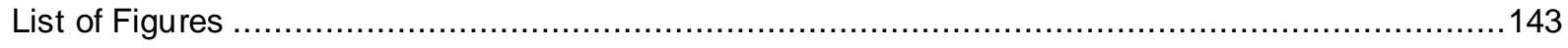

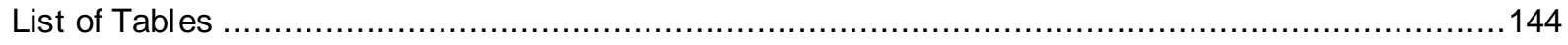

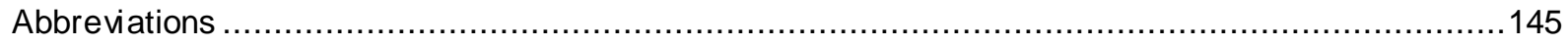

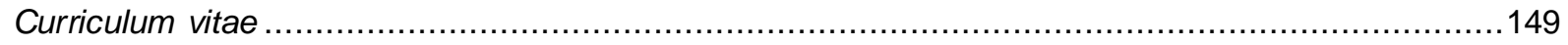


$-x-$ 


\section{List of Publications}

\section{Scientific publications}

\section{la. Thesis related, peer-reviewed publications}

1. $\quad$ Tiede $R^{*}$, Hirschberg J*, Viöl W, Emmert S (2016) A $\mu$ s-Pulsed Dielectric Barrier Discharge Source: Physical Characterization and Biological Effects on Human Skin Fibroblasts. Plasma Process and Polymers, 13:775-787.

2. Mann MS*, Tiede $\mathrm{R}^{*}$, Gavenis K, Daeschlein G, Bussiahn R, Weltmann K-D, Emmert S, von Woedtke T, Ahmed R (2016) Introduction to DIN-specification 91315 based on the characterization of the plasma jet kINPen ${ }^{\circledR}$ MED. Clinical Plasma Medicine, 4, 35-45.

3. Tiede R, Hirschberg J, Daeschlein G, von Woedtke T, Viöl W, Emmert S (2014) Plasma Applications: A Dermatological View. Contribution to Plasma Physics, 54:118-130.

\section{Ib. Thesis related publications without peer-review}

4. Tiede R, Helmke A, Wandke D, Viöl W, Emmert S (2015) PlasmaDerm ${ }^{\circledR}$ : kaltes Atmosphärendruckplasma als Spitzeninnovation. Spitzenforschung in der Dermatologie. Innovation und Auszeichnungen, 70-80.

5. DIN SPEC 91315 (2014) General requirements for medical plasma sources. Beuth-Verlag.

6. Tiede R, Mann M, Viol W, Daeschlein G, Welz C, Wolff H, von Woedtke T, Lademann J, Emmert S (2014) Plasmamedizin in der Dermatologie. HAUT, 6:228-233.

7. Schiller S, Schubert S, Lehmann J, Seebode C, Smolorz S, Tiede R, Apel A, Laspe P, Emmert $S$ (2014) Von seltenen genetischen Erkrankungen lernen: Hautkrebs und DNA Reparatur, Ichthyosen und epidermale Differenzierung sowie kaltes Atmosphärendruckplasma als neue Therapiemodalität. Spitzenforschung in der Dermatologie, 62-70.

\section{Ic. Other peer-reviewed publications}

8. Daly KC, Bradley S, Chapman PD, Staudacher EM, Tiede R, Schachter J (2015) Space Takes Time: Concentration Dependent Output Codes from Primary Olfactory Networks Rapidly Provide Additional Information at Defined Discrimination Thresholds. Frontiers in Cellular Neuroscience, 9:article 515.

9. $\quad$ Tiede R, Krautwald K, Fincke A, Angenstein F (2011) NMDA dependent mechanisms only affect the BOLD response in the rat dentate gyrus by modifying local signal processing. Journal of Cerebral Blood Flow and Metabolism, 32:570-584. 


\section{Thesis related book contributions}

10. Tiede R, Emmert S (2016) Kapitel 6: Plasmabehandlung von Wunden. Metelmann HR, von Woedtke T, Weltmann K-D: Plasmamedizin, Springer-Verlag.

11. Tiede R, Emmert S. Plasmabehandlung zur Wundheilung, für Neurodermitis und Psoriasis sowie Plasma-Anwendungssicherheit. Uni-Med. Klinik Buchbeitrag; accepted.

12. Tiede R, Isbary G, Emmert S. Treatment of ulceration and wounds. Metelmann HR, von Woedtke T, Weltmann K-D: Comprehensive Clinical Plasma Medicine. Springer-Verlag; in progress. 


\section{Abstract}

This body of work provides descriptions of test systems, which can be used for a detailed assessment of physical, non-thermal atmospheric pressure plasma (APP) devices with regard to bio-medically relevant performance parameters. To establish and perform experiments, two different plasma sources were used: the plasma jet type kINPen ${ }^{\circledR}$ MED and a $\mu$ s-pulsed volume dielectric barrier discharge (DBD) device. On the basis of a general physico-technical characterization of the two sources, evaluation strategies were developed to comparatively study (1) immediate cell damages after APP treatments and (2) to test if APPs cause genetic alterations in cellular DNA. Since the dermatological use of APP devices was of major interest in this thesis, different human skin fibroblast lines were used for plasma experiments. With the test systems, cell-type dependent effects of APP can be compared; moreover, a direct comparison of plasma-type dependent effects is also feasible.

The first part of this thesis presents common test systems for the basic physical characterization, which include measurements of electric current, gas temperature and resulting thermal output, ultraviolet (UV) radiation, and emission of potentially unhealthy gases. Based on these measurements, a risk assessment was possible, which indicate that the two sources can be safely used as medical tools, but also exhibit plasma-specific handling and application requirements. Furthermore, a number of bio-medically relevant performance parameters of the sources were investigated: inactivation efficiency against pathogens, cytotoxicity on human skin fibroblasts, and chemical changes of plasma-treated phosphate buffered saline (PBS) solution. The results demonstrated that the impact of APPs on cells differ due to their different physical and chemical properties. Most, but not all, of the test systems presented here were published in the context of a cooperation with other groups as German DIN-Specification 91315.

The second part of the thesis presents test systems for the assessment of long-term damages. The genotoxic and mutagenic effects of plasmas on isolated and cellular deoxyribonucleic acid (DNA) were examined with different techniques: host cell reactivation assay, DNA separation via gel electrophoresis, plasmid shuttle vector assay, and flow cytometry based on staining of phosphorylated histone proteins. The assessment of possible plasma-induced long-term damages is of utmost importance because some of the plasma components, like reactive oxygen species (ROS) and UV radiation, are well known to affect DNA. Particularly in dermatological therapies of wounds, potential mutagenic side effects induced by plasma application would lead to serious health risks, since the skin of patients will be directly exposed to plasma and, thus, also proliferative cells in the wound area. 
The level of impact of the two plasma sources on cells and isolated DNA was compared. At same treatment durations, plasma jet treatments usually induced stronger effects than DBD applications. In particular, a higher cytotoxicity and genotoxicity was observed. However, only a tendency towards a mutagenic effect was seen. In contrast, in experiments on plasmid DNA, which was located inside the cells during plasmatreatments, no mutagenic effect was detected for either of the two sources. But, an increased formation of double strand breaks in genomic DNA could be demonstrated.

Calculations of plasma doses within given treatment durations revealed that in same time periods the plasma jet transfers higher energy densities to the treatment object than the DBD plasma. On the other hand, the DBD plasma was shown to generate much higher ROS and RNS concentrations during the same treatment time. In some parts these findings can explain the observations in this thesis. It is, however, assumed that mainly ROS and UV radiation are responsible for the different effects of the two plasma sources.

With the assays presented here, a valuable basis for a more detailed evaluation of different plasma jet systems and volume DBD devices with regard to their medical usability is created. Moreover, such APP sources can now be characterized and their desired therapeutic applications can be assessed on a standardized, quantitative basis. 


\section{Introduction}

In the last years, intensive research was done on the various effects of biocompatible physical plasma on living organisms and tissues whereby the awareness of its beneficial properties in medical applications became increasingly clear. From this research, the new and interdisciplinary field of plasma medicine evolved. In this field, physicists, engineers, medical doctors, and biologists cooperate closely with the purpose of using plasma as a medical tool to treat and alleviate symptoms or even cure diseases. One of the first milestones in plasma medicine was the production of non-thermal plasma under atmospheric conditions, also known as biocompatible or cold plasma. The temperature of such plasmas is usually below $40^{\circ} \mathrm{C}$, which is a prerequisite for the treatment of heat sensitive materials, living organisms, or whole tissues. Before that, thermal plasmas have been used as standard practice in medicine, e.g. to cauterize tissues, coagulate blood, or for sterilization and decontamination of thermally stabile materials [1-4]. Now, many studies focus on the effects of components generated in non-thermal and biocompatible atmospheric pressure plasma (APP) on living prokaryotic or eukaryotic cells, cell structures and components, benign and malignant tissues of plants, animals, and humans.

Particularly in dermatology, plasma is thought to be a new medical hope for the treatment of numerous skin diseases. Researchers find more and more evidence that plasma stimulates and supports healing processes of the skin in many different ways [5-9]. This is because physical APPs contain various biologically and chemically active components, such as reactive oxygen species (ROS), reactive nitrogen species (RNS), electrons, ions, and neutral molecules. Moreover, artificial optical radiations, which include ultraviolet (UV) radiation as well as electric currents, are produced in the plasma. During plasma treatment, all these elements are acting simultaneously; they may reinforce or diminish one another by interactions and, thus, lead to numerous effects. The plasma cocktail, meaning the composition of the plasma elements, strongly depends on the way plasma is produced. Changing the working gas, power supply, or electrode configuration greatly influences plasma composition [10]. Nowadays, many research groups have developed their own individual plasma source, which is why each device has unique physical properties. For this reason, a comparison of experimental results based on different plasma sources and different experimental setups is not possible. Only if the experimental procedures are standardized, meaning that same test assays, treatment conditions, and organism or tissues are used, a comparison of the biological impacts of different plasmas is scientifically reasonable. In addition, with regard to medical applications of APP sources another aspect is immensely important: the safety in use. Each individual plasma component or element bears its own risk factor. General risk factors originating from plasma include in particular: plasma temperature, radiation, ROS and RNS, emission of toxic 
gases, and electric currents. If plasma temperature is too high, this can cause burns, high doses of UV radiation may induce the development of skin cancer, and electrical currents could lead to electric shocks. Even though these risks are well-known in the plasma community and have already been discussed in several reviews [7-9], basic criteria for the use of medical plasma sources and guidelines for their safe use are still missing.

\section{Aims of the study}

The first aim of this study was to define generally accepted, plasma specific standards and basic safety criteria for medical plasma sources. In collaboration with others, this was achieved by creating and publishing a German DIN ('Deutsches Institut für Normung')-Specification document (DIN-SPEC 91315) titled "General requirements for plasma sources in medicine" [11]. Physical efficiency measurements and some biological experiments from my thesis are part of this DIN-SPEC. In the document test systems are introduced that are appropriate for a first, general evaluation of physico-technical performance characteristics of plasma sources (i.e. plasma temperature, thermal output, artificial optical radiation, UV radiation, gas emission, and electric current), as well as general bio-medically relevant effects (i.e. inactivation efficiency against microorganisms, cytotoxicity on human skin cells, and chemical changes of plasma-treated liquids). This allows a basic evaluation of the biomedical potential of APP sources. In addition, a general characterization will indicate if a plasma device is suitable as therapeutic tool and may even reveal the best application field for a specific device; this applies especially to new plasma sources in the early stages of their development. Furthermore, based on a standard characterization according to DIN-SPEC 91315, biological effects caused by different plasmas can be compared. Such tests will provide a quantitative basis to identify the best and most appropriate application(s) for individual sources.

The basic biomedical characterization described in DIN-SPEC 91315 mainly aims at direct and at short-term effects of therapeutic plasma applications. However, plasma-induced long-term damages are also of great interest, especially in the field of dermatology where the skin of patients is exposed to plasma and most treatments require repetitive applications during the therapeutic process. Plasmaincludes components that are widely known to be mutagenic, e.g. UV radiation and different ROS. UV radiation is able to generate deoxyribonucleic acid (DNA) photoproducts like cyclobutane pyrimidine dimer (CPD) or and pyrimidine-(6-4)-pyrimidone dimer $(6,4 \mathrm{PP})[12-16]$, while strong oxidative ROS like the hyperoxide anion $\left(\mathrm{O}_{2}{ }^{\bullet}\right)$ and the hydroxyl radical $\left(\mathrm{OH}^{\bullet}\right)$ oxidize DNA molecules leading to oxidative DNA lesions, strand breaks, or other DNA modifications [17-19]. Moreover, other components of plasma like RNS, and discharge currents potentially have an impact on the biological system of a skin cell. Therefore, the second major aim of this thesis was to establish test systems to study long-term effects on human skin cells induced by plasmaapplications. Both, the genotoxic and the mutagenic effect of APP treatments on human skin fibroblasts was studied using the host cell reactivation (HCR) 
assay, agarose gel electrophoresis, the plasmid shuttle vector (PSV) assay, and a flow cytometry assay based on $\mathrm{Y}-\mathrm{H} 2 \mathrm{~A} . \mathrm{X}$ staining.

The third aim of this project was to develop test systems and experimental settings that can be easily adjusted to as many different plasma devices as possible. Therefore, two different types of APP sources were chosen: the kINPen ${ }^{\circledR}$ MED as plasma jet device and a $\mu$ s-pulsed volume dielectric barrier discharge (DBD) source. Both types of plasma devices are known to be suitable for skin applications and have previously been used for experimental biomedical applications [9, 10, 20-25]. On the basis of the assays established in this thesis, a direct comparison of these two sources with regard to their physical efficiencies and biomedical effects is possible. 
$-6-$ 


\section{Theoretical Basics}

In this chapter necessary background information about important aspects of this work is provided. Since the project was performed in the interdisciplinary field of plasma medicine physical, chemical, medical, and, of course, biological knowledge is presented in three main sections. The first section 'Plasma technology' includes a short introduction of the physical term plasma and how it can be produced, followed by a more detailed description of biocompatible atmospheric pressure plasmas and important chemical kinetics of plasma-liquid interactions. The second section provides dermatological background information about the structure and function of the skin and the process of wound healing with a focus on human fibroblast cells. In the last section, some of the current research areas in plasma medicine are introduced. In addition, the current state of knowledge about beneficial effects of APP for dermatological applications is summarized.

\subsection{Plasma technology}

Plasmais defined as partially or completely ionized gas, in which some electrons are separated from their atomic union. Viewed as a whole, plasma is electrically quasi-neutral and conductive. In 1879 Sir William Crookes first described this state as "radiant matter" [26] followed by the introduction of the term plasma by Irvin Langmuir in 1928 [27]. From a cosmological point of view, the most matter of the visible universe exists in the physical plasma state; e.g. cosmic orbs such as suns and stars, but also solar corona, stellar winds, and shining interstellar clouds. On earth, the plasma state is visible as natural phenomena like the aurora borealis or lightening in thunderstorms. Plasma can be produced by high energy inputs to a neutral gas; e.g. by radiation energy (e.g. UV or thermal excitation), strong electric fields, or kinetic energy [28]. Consequently, plasma comprises the highest enthalpy of all physical states (Fig. 1).

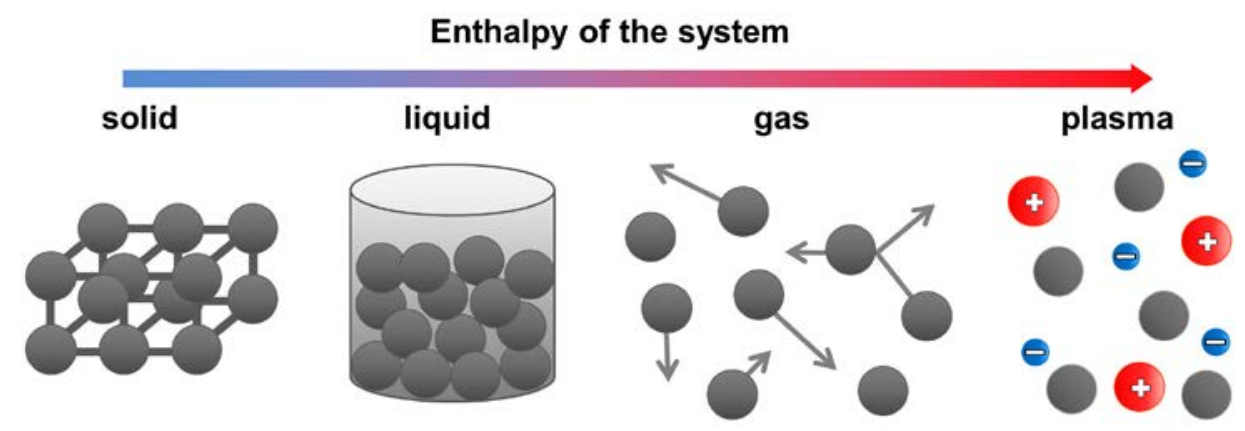

Figure 1: Schematic illustration of the four physical states

With increasing enthalpy of the system, the physical state of matter of atoms (grey spheres) changes from solid, to liquid, to gas, and finally to the plasma state where electrons (negative blue spheres), ions (positive red spheres), and neutral atoms coexist. 
Depending on the production of the plasma, it can exist in two basic forms: non-thermal and thermal plasma.

In thermal or equilibrium plasma electrons, ions, and neutrals have almost the same temperature. Due to the high electron temperature $\left(T_{e}\right)$ of about $10,000 \mathrm{~K}$, the ion temperature $\left(T_{i}\right)$ and the neutral gas temperature $\left(T_{n}\right)$ in such equilibrium plasmas can reach several hundred or thousand degrees $\left(T_{e} \approx T_{i} \approx\right)$ [29]. The electron density in thermal plasmas is very high $\left(10^{21}-10^{26} / \mathrm{m}^{3}\right)$ [28]. Via so called inelastic collisions of electrons with heavy particles (ions, neutrals) in the gas, reactive species are produced. Simultaneously, elastic collisions of electrons and heavy particles increase the plasma temperatures [28]. This kind of plasmas are commonly used in industrial processes such as metal cutting and welding or surface coating by plasma spraying [30-32], but are also found in mercury or Xenon arc lamps for example.

Non-thermal or non-equilibrium plasma is characterized by different temperatures of electrons (extremely hot) compared to ions and uncharged particles (around room temperature; $T_{e} \gg T_{i}$ and $T_{e} \gg T_{n}$ with $\left.T_{i} \approx T_{n}\right)$. The electron density is low $\left(<10^{19} / \mathrm{m}^{3}\right)$ and mainly inelastic collisions and only few elastic collisions of electrons and heavy particles take place [28].

Plasma can be also classified according to the pressure levels in which the plasma is produced: low-, high-, or atmospheric-pressure plasma. In this work only non-thermal plasma devices which operate under atmospheric pressure were utilized.

\subsubsection{Biocompatible atmospheric pressure plasma}

Biocompatible APPs are usually generated by electrical excitation of a neutral gas or a gas mixture, which produces many different chemically and biologically active components. In contrast to low- or high- pressure plasma production, there is no need for complex and costintensive vacuum systems or chambers to maintain the pressure conditions. Accordingly, portable APP systems with handheld application devices can be designed.

APPs for biomedical applications are mostly generated by applying high voltages to electrodes facing each other. Due to this arrangement the gas between the electrodes is partially ionized. One way to keep the plasma at low temperature is to electrically isolate at least one electrode with a dielectric cover [33]. Generated charge carriers (electrodes and ions) are thereby prevented from flowing off to the respective electrode and thus accumulate at the dielectric layer. This also prevents the generation of arc discharges across the discharge gap [34]. When high voltages are applied to the electrodes plasma ignites in so called microdischarges or microfilaments, through which the charge carriers are transported to the opposite electrode within a few nanoseconds. Microfilaments are spatially and temporally distributed between the electrodes and thus lead to a rather inhomogeneous type of discharge [35]. DBD devices with such configurations are also called volume DBDs. The electrons and ions generated in the 
discharge interact with other molecules in the gas generating radicals, metastable products, excited molecules, and atoms. Excited molecules, i.e. $\mathrm{N}_{2}$, can spontaneously emit photons due to relaxation. This leads to the characteristic glow of plasmas whereby the color of the emitted light depends on the gas being excited.

In this study a volume DBD was used, which runs under burst mode with short high voltage pulses in the microsecond range and, therefore, will be called $\mu$-pulsed volume DBD device. This source only consists of one electrode covered by a dielectric whereby the treated material acts as counter electrode. The air between the electrode and the treated object is ionized to produce the plasma.

The other source used during this project was a plasma jet type. It includes a dielectric layer, which separates a pin and a round electrode. Argon gas is directed through the small tunnel between the electrodes and a high voltage with a very high repetition frequency of about $1 \mathrm{MHz}$ is applied to the electrodes. Rare gases like helium or argon are preferably used for operating plasma jet sources, because lower energy inputs are necessary for plasma ignition [36]. Moreover, it stabilizes the discharge and species composition generated in the plasma is more accurately definable. Through admixture of $\mathrm{O}_{2}$ or other molecules, the production of desired reactive species can be controlled [36, 37]. Also, shielding gases can be used to build a defined atmosphere around the plasma jet to modify and regulate species mixture in the effluent [3840]. However, using ambient air instead of noble gases would increase the amount of generated reactive species [41].

There are other possible configurations of electrodes for plasma devices and a wide range of power supplies that can be used to ignite the plasma (from direct current, alternating current, radio frequency to microwaves). Furthermore, different operating modes are possible, i.e. burst mode and continuous mode, which also will affect plasma physics. More detailed information about APP sources preferably used for biomedical applications can be obtained in the following comprehensive reviews $[8,10,42]$.

\subsubsection{Plasma chemistry and plasma-liquid interactions}

Chemical kinetics of plasma-liquid interactions is of special interest regarding biological and medical studies where tissue or cells are exposed to plasma because they are surrounded by an aqueous milieu. In in-vitro studies on cell cultures for example, a thin liquid layer covering the cells is often required to prevent dehydration of the cells during plasma treatments [4347]. In dermatological treatments of wounds, plasma constituents will initially react with molecules in the wound liquid and produce reactive species. In general, highly energetic particles in the plasma-liquid interface will react quickly with nearby molecules and, therefore, may not directly hit the cells. In contrast, long-living species are more likely to reach the cells via diffusion. 
It was already demonstrated that depending on the composition of the liquid surrounding the cells during plasma treatment different cellular responses can be induced [21] showing that individual plasma-liquid interactions took place. Moreover, plasma chemistry and, therefore, plasma-liquid interactions strongly depend on physical settings of the plasma source and the process gas used for ignition of the plasma [48]. In this context, electron temperature has to be mentioned as a key parameter that determines which types of reactive species are produced and in which concentrations certain species occur. Some researchers use computational model simulations to calculate possible reaction paths and predict generated species in and around plasmas $[40,49,50]$.

Even though the two plasma sources used in this project are driven with different working gases (kINPen ${ }^{\circledR}$ MED source is driven with argon gas and the $\mu$ s-pulsed DBD source ignites in ambient air) basic plasma chemistry of the two plasmas overlap since both interact with same molecules or atoms in ambient air and aqueous solutions. The reactions listed below are selected examples for possible reaction paths with important end products in and around the plasmas. In order to allow an approximate complete consideration, hundreds of reactions must be considered $[40,50]$.

As one of the first reactions, free electrons may react with $\mathrm{H}_{2} \mathrm{O}$ (Eq. 1-3), $\mathrm{N}_{2}$ (Eq. 4), or $\mathrm{O}_{2}$ (Eq. 5 and 6):

$$
\begin{aligned}
& e+\mathrm{H}_{2} \mathrm{O} \rightarrow \mathrm{H}+\mathrm{OH}+\mathrm{e} \\
& e+\mathrm{H}_{2} \mathrm{O} \rightarrow \mathrm{O}^{-}+\mathrm{H}_{2} \\
& e+\mathrm{H}_{2} \mathrm{O} \rightarrow \mathrm{OH}^{-}+\mathrm{H} \\
& e+\mathrm{N}_{2} \rightarrow e^{+} 2 \mathrm{~N} \\
& e+\mathrm{O}_{2} \rightarrow \mathrm{O}_{2}^{-} \\
& e+\mathrm{O}_{2} \rightarrow \mathrm{O}^{-}+\mathrm{O}^{-}
\end{aligned}
$$

In case of the plasma jet, Ar in its ground state is being ionized within the plasma by inelastic collisions with highly energetic electrons leading to an excited argon gas atom ( $\mathrm{Ar}^{\star} ; \mathrm{Eq} .7$ ):

$$
\mathrm{e}+\mathrm{Ar} \rightarrow \mathrm{e}+\mathrm{Ar}^{\star}
$$

The energy from excited $\mathrm{Ar}^{\star}$ can dissociate other molecules in the air surrounding the plasma jet (i.e. reacts with $\mathrm{H}_{2} \mathrm{O}, \mathrm{N}_{2}$, or $\mathrm{O}_{2}$; Eq. 8-10):

$$
\begin{aligned}
& \mathrm{Ar}^{\star}+\mathrm{H}_{2} \mathrm{O} \rightarrow \mathrm{Ar}+\mathrm{OH}+\mathrm{H} . \\
& \mathrm{Ar}^{\star}+\mathrm{N}_{2} \rightarrow \mathrm{Ar}+2 \mathrm{~N}, \\
& \mathrm{Ar}^{\star}+\mathrm{O}_{2} \rightarrow \mathrm{Ar}+2 \mathrm{O},
\end{aligned}
$$

Furthermore, reactions with other impact partner (IM) in the vicinity of the plasma take place that lead to the formation of long-living species in APPs like $\mathrm{O}_{3}$ (Eq. 11) and $\mathrm{H}_{2} \mathrm{O}_{2}$ (Eq. 12):

$$
\mathrm{O}+\mathrm{O}_{2}+\mathrm{IM} \rightarrow \mathrm{O}_{3}+\mathrm{IM}
$$




$$
2 \mathrm{OH}+\mathrm{IM} \rightarrow \mathrm{H}_{2} \mathrm{O}_{2}+\mathrm{IM} \text {. }
$$

Also, other biologically important molecules like different nitric oxides are generated, for example $\mathrm{NO}$ (Eq. 13 and 14), $\mathrm{NO}_{2}$ (Eq. 15), and $\mathrm{NO}_{3}$ (Eq. 16):

$$
\begin{aligned}
& \mathrm{N}+\mathrm{O}_{2} \rightarrow \mathrm{NO}+\mathrm{O}, \\
& \mathrm{N}+\mathrm{OH} \rightarrow \mathrm{NO}+\mathrm{H}, \\
& \mathrm{O}+\mathrm{NO}+\mathrm{IM} \rightarrow \mathrm{NO}_{2}+\mathrm{IM}, \\
& \mathrm{O}+\mathrm{NO}_{2}+\mathrm{IM} \rightarrow \mathrm{NO}_{3}+\mathrm{IM},
\end{aligned}
$$

In liquid environments $\mathrm{NO}_{2}^{-}$and $\mathrm{NO}_{3}^{-}$can also be formed via the products $\mathrm{HNO}_{2}$ and $\mathrm{HNO}_{3}$ (Eq. 17-19 and Eq. 20-22, respectively):

$$
\begin{aligned}
& \mathrm{NO}+\mathrm{OH}+\mathrm{IM} \rightarrow \mathrm{HNO}_{2}+\mathrm{IM}, \\
& \mathrm{HNO}_{2}+\mathrm{OH}^{-} \rightarrow \mathrm{NO}_{2}^{-}+\mathrm{H}_{2} \mathrm{O} \\
& \mathrm{HNO}_{2}+\mathrm{H}_{2} \mathrm{O} \rightarrow \mathrm{NO}_{2}^{-}+\mathrm{H}_{3} \mathrm{O}^{+}, \\
& \quad \mathrm{NO}_{2}+\mathrm{OH}+\mathrm{IM} \rightarrow \mathrm{HNO}_{3}+\mathrm{IM}, \\
& \quad \mathrm{HNO}_{3}+\mathrm{OH}^{-} \rightarrow \mathrm{NO}_{3}{ }^{-}+\mathrm{H}_{2} \mathrm{O} \\
& \mathrm{HNO}_{3}+\mathrm{H}_{2} \mathrm{O} \rightarrow \mathrm{NO}_{3}{ }^{-}+\mathrm{H}_{3} \mathrm{O}^{+} .
\end{aligned}
$$




\subsection{Skin structure and function}

The human skin is one of the biggest and functionally seen the most extraordinary organ of the body. As barrier to the external world it incessantly communicates and adapts to environmental influences, while at the same time protecting us against external damages by toxic agents, microorganisms, mechanical insults, and UV radiation. Moreover, it is involved in essential body functions like thermoregulation, skin hydration, sensory perception, and immune defense [51]. This highly dynamic organ undergoes constant change as cells from deeper layers are moving towards upper layers to replace shedding cells. The skin is divided into three structural layers (from apical to basal):

1. The epidermis as the outermost layer serves as chemical and physical barrier between the interior and the exterior environment.

2. The dermis is responsible for oxygen and nutrient supply to the epidermis and gives structural support to the skin.

3. The subcutis is an important storage of fat.

\section{Epidermis}

The epidermis mainly consists of keratinocytes that build a stratified squamous epithelium. During the migrating from the basal to the top layer of the epidermis, keratinocytes undergo a terminal differentiation including structural and physiological alterations, which usually take about 28 to 30 days. The main product that is synthesized by the keratinocytes is keratin. According to the types of keratin proteins produced and differences in keratin maturation, five separate layers are defined in the epidermis (Fig. 2) [52]:

1) The stratum basale comprises proliferative keratinocytes that are connected with each other by desmosomes. At the base, the cells are attached via hemidesmosomes to a thin membrane, which is called the basal laminar. This membrane functionally separates the dermis from the epidermis $[53,54]$. Melanocytes that produce the pigment melanin to provide protection against UV radiation are also present in this layer, as well as mechanoreceptor cells; the Merkel cells that often are associated with sensory nerve endings. On fingers and toes, these cells are present in particularly large numbers [52].

2) In the stratum spinosum keratinocytes are in their early differentiation phase when they build characteristic short and spiky extensions of their surfaces. Now, other keratin proteins are expressed (Fig. 2). In this layer the majorities of Langerhans cells are located but are also present in all other epidermal layers. They are premature antigen-presenting dendritic cells that are important for immunological responses of the skin [52]. 


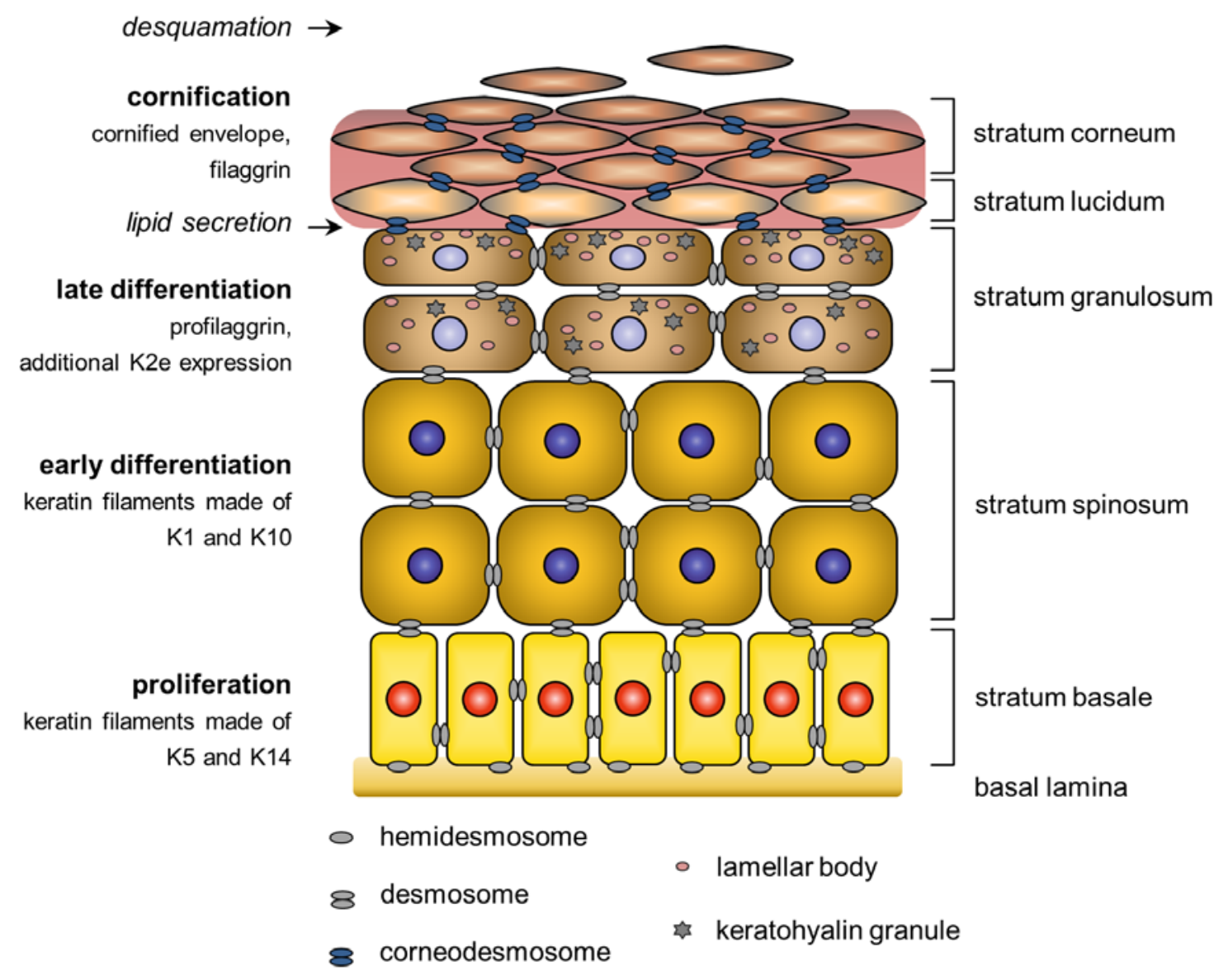

Figure 2: Schematic illustration of epidermal layers

Each epidermal layer (right side) comprises keratinocytes in different developmental stages from proliferative cells at the basal lamina up to corneocytes that descale from the skin. In each stage (written in bolt letters; left side) keratinocytes express different keratin proteins and are characterized by other structural proteins and complexes.

3) In the stratum granulosum keratinocytes form and accumulate lamellar bodies that contain lipids as main component [55]. Furthermore, keratinocytes produce keratohyalin granules predominantly filled with the precursor protein profilaggrin [52].

4) The stratum lucidum is a very thin layer between the stratum granulosum and corneum, which is more pronounced on palms and soles. At this stage, keratinocytes lose their nuclei and other organelles [52] and secrete the content of the lamellar bodies via exocytosis to form impermeable membrane stacks in the extracellular space that serve as water barrier.

5) Mature keratinocytes form the most apical layer of the epidermis; the stratum corneum. Profilaggrin is now dephosphorylated and proteolysed into multiple filaggrin monomers, which associate with keratin intermediate filaments to form tight bundles of parallel aligned filaments. This process causes a highly insoluble keratin matrix and further compression of the cells. Together with a number of other structural proteins, the keratin matrix deposit at the cytoplasmic membrane and thereby form the cross-linked cornified envelope. The 
cells are now terminally differentiated, non-viable, and are called corneocytes connected through corneodesmosomes [52]. They are continuously scaled from the skin, a process which is called desquamation.

\section{Dermis}

The dermis is a strongly vascularized tissue and highly pervaded by nerves and lymphatic systems. It is subdivided into two layers, stratum papillare and stratum reticulare, which cannot be sharply distinguished from each other. The stratum papillare is located directly underneath the epidermis and owes its name from cone shaped loops of collagen fibers rising as connective-tissue papillae into depressions of the epidermis. Melanocytes and high numbers of mast cells are found in this layer. At this interface the dermis serves as supply zone for the epidermis, which itself does not contain any blood vessels. The stratum reticulare is a denser and irregularly arranged connective tissue.

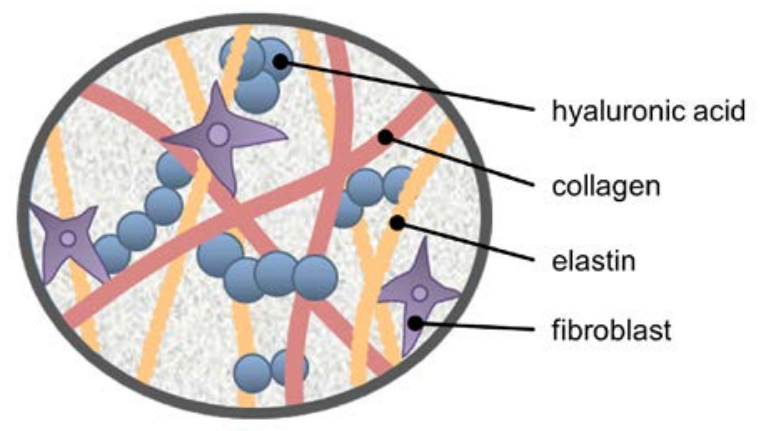

Figure 3: Structural arrangement of the connective tissue in the dermis

Fibroblasts express the major connective tissue components, e.g. hyaluronic acid, collagen, and elastin.

Fibroblasts represent the major cell type of the dermis. They synthesize proteoglycans, hyaluronic acid, glycoproteins, elastin and collagen (after secretion collagen polypeptide chains self-assemble to collagen fibrils in the extracellular space by polymerization process), which make up the extracellular matrix (Fig. 3). This provides tear strength and elasticity to the skin. Furthermore, the dermis comprises sweat glands, hair follicles and sensory cells, such as the Meissner corpuscles (fast-adapting pressure receptors) and Ruffini corpuscles (slowly adapting receptors for perception of stretch and shear) [52]. In response to skin injuries fibroblasts proliferate and the secretion of cytokines is reinforced, which is why fibroblasts play a crucial role in wound healing processes.

\section{Subcutis}

The subcutis is a loosely arranged and fatty connective tissue. It serves as shock absorber, and is important for thermal insulation and energy storage. The subcutaneous tissue contains numerous blood and lymph vessels, sweat glands and hair roots. Moreover, it is pervaded by a dense nervous network, the endings of which are spreading to all layers of skin. The different sensory cells transduce stimuli like pain, warmth, cold, and pressure. The sensory cell type Pacinian corpuscle is located in the subcutis. They respond to fast changes of stimuli and especially are responsible for vibration perception [52]. 


\subsubsection{Stages of wound healing}

Normal wound healing includes highly dynamic but strictly directed biological processes, like coagulation, inflammation, matrix synthesis and deposition, angiogenesis, and remodeling [56]. Immediately after skin injuries the endogenous immune defense is activated simultaneously with various skin cells, including fibroblasts. Numerous growth factors, cytokines, and integrins are released that initiate and coordinate the complex healing process. Major phases in wound healing are described sequentially. However, only the most important cell types and molecular factors, which are affected by plasma applications, are mentioned and described. In general, three main phases of wound healing are defined [57]:

\section{Hemostasis and inflammation}

Damage to blood vessels leads to an influx of thrombocytes into the wound region. They clump together after contact with collagen to stop the bleeding, which is called coagulation. The activated thrombocytes subsequently secrete many different signaling substances, such as cytokines that initiate the inflammation process. Chemo-attractants, for example plateletderived growth factor (PDGF), interleukin (IL)-1, tumor necrosis factor- $\alpha$ (TNF- $\alpha$ ), and transforming growth factor (TGF)- $\beta$ are secreted by thrombocytes. These factors attract neutrophil granulocytes, macrophages, fibroblasts, and smooth muscle cells. The growth factor TGF- $\beta$ further activates macrophages to secrete various signal molecules (different fibroblast growth factors (FGFs), ILs, PDGF, and TNF- $\alpha$ ). In the further course of the inflammation phase, neutrophils clean the wound by removing eliminated bacteria, destroyed matrix components like collagen, as well as dead cells using matrix metalloproteinase (MMP) and elastase [57, 58]. Mast cells release specific amines and enzymes that digest surrounding vessels to enhance cell migration and transport into the wound. This also causes water deposition and typical inflammatory symptoms such as swelling and redness occur [59,60]. At the same time, monocytes differentiate into specific wound macrophages in response to the release of the cytokine interferon- $\gamma$ (IFN- $\gamma$ ) by fibroblasts. They are responsible for further thorough cleaning of the wound and additional ejection of PDGF and TGF- $\beta$ to boost the chemotaxis of fibroblasts and muscle cells into the wound bed [61]. To recruit more macrophages and fibroblasts, additional chemo-attractants are being released by macrophages: TNF- $\alpha$, IL- 6 , granulocyte colony-stimulating factor (G-CSF), and granulocyte-macrophage colony-stimulating factor (GM-CSF). Subsequently, fibroblasts also release IL-6, G-CSF, and GM-CSF [57].

\section{Proliferation}

Cell-cell junctions (desmosomes) and cell-substrate junctions (hemidesmosomes) are decomposed so that keratinocytes can migrate into the injured tissue in order to rebuild the epidermal layers. Fibroblasts also migrate into the wound and begin to proliferate and deposit new extracellular matrix components; proteoglycan and fibronectin. Furthermore, fibroblasts 
are stimulated by macrophages to express IL-6 and FGF10, which leads to the initiation of epithelialization by activating proliferation and migration of keratinocytes. In addition, fibroblasts but also macrophages release proteases that transform the inactive TGF- $\beta$ into the active form. This in turn stimulates fibroblast proliferation and collagen synthesis and simultaneously inhibits the collagenase activity [57,60]. Active fibroblasts, immune cells, and macrophages continue to secret cell-type specific sets of signal molecules (inter alia growth factors, integrins, keratins, chemokines, and MMPs) to further sustain the directed remodeling of the tissue.

\section{Maturation and remodeling}

In the final phase of wound healing the different skin layers as well as connective tissue and blood vessels are completely rebuilt. Macrophages now produce IL-10 that inhibits the invasion of neutrophil granulocytes and reduces the secretion of IL-1 $\beta$, monocyte chemoattractant protein (MCP)-1, macrophage inflammatory protein (MIP)-1 $\alpha$, IL-6, and TNF- $\alpha$ [62]. In addition, other growth factors (e.g. epidermal growth factor (EGF), TGF- $\alpha$, vascular endothelial growth factor (VEGF), bFGF, and TGF- $\beta$ ) are released by fibroblasts, macrophages, keratinocytes, endothelial cells, and thrombocytes required for remodeling of connective tissue, enhanced angiogenesis in the wound area, and the correct formation of epidermal layers. Environmental factors in the wound bed like $\mathrm{pH}$, oxygen partial pressure, and increased lactate values play a major role in the recruitment of new blood vessels [60, 63].

\subsubsection{Chronic wounds}

Chronic wound conditions occur when wounds do not heal in a proper way. Wounds are classified as chronic when they persist for over three months without signs of healing or when they are not completely cured after 12 months [64]. They are characterized by a malfunction to progress through the normal phases of wound healing and remain in a pathological inflammation phase. This leads to a delayed, incomplete, and uncoordinated healing process. In most cases chronic wounds are a result of vascular diseases leading to ischemia, such as the lower leg ulcer ulcus cruris. Other causes include metabolic, neuropathic, genetic or hematological pathology, dermatosa, as well as severe mechanically, thermally, or chemically induced skin injuries [65]. Often, chronic wound conditions are accompanied by bacterial and/or fungal infections whereby the process of healing is further strongly inhibited [56, 66, 67]. Bacteria may even build a biofilm shielding the wound. As a result of pathogenic overgrowth and infection other complications may arise, like abscess formation, gangrene, or sepsis [68]. The abnormal inflammatory profile includes excessive numbers of neutrophils in the wound bed that express degradative MMPs and elastase; thus, the concentrations of these enzymes are too high in the wound. Moreover, there is an imbalance between MMPs and their inhibitor proteins (i.e. tissue inhibitors of metalloproteinase (TIMP)), which favors degradation 
of collagen and elastase. In addition, also too high numbers of inflammatory cells are present in the wound and, therefore, excessive amounts of inflammatory cytokines like TNF- $\alpha$ are released [69]. Pro-proliferative factors (e.g. PDGF) and matrix depositing factors (e.g. TGF- $\beta$ ) are reduced though [70]. All these factors influence the functionality of fibroblasts. Because of the high degradation rate of collagen by MMPs for example, fibroblasts fail in depositing enough extracellular matrix. Furthermore, some fibroblasts show an impaired migration behavior and a reduced response to growth factors [68]. In general, proteases and radicals persist in the wound and mitogenic activity of cells is suppressed. Some fibroblasts differentiate to myofibroblasts important for wound contraction in the later phases of wound healing and scar formation. Sometimes, deregulated fibroblasts show an uncontrolled and excessive synthesis of collagen, which cannot be efficiently deposited in the extracellular matrix leading to fibrosis [60]. 


\subsection{Plasma medicine (special focus on dermatology)}

The first study, in which an APP glow discharge was used for the bacterial inactivation of Pseudomonas fluorescens HK 44, was conducted in 1996 [71]. Because the strong inactivation efficiency was evident, many other researchers focused on decontamination and sterilization effects of plasma against a broad spectrum of different microorganisms. In the beginning of the 21th century more researchers expanded the knowledge about plasma-cell interactions on mammalian cells. In 2003 researchers reported that plasma treatments with a plasma needle of eukaryotic cells do not necessarily induce cell death but under mild treatment conditions rather lead to the detachment of cell-cell and cell-substrate connections [72]. This effect was reversible, i.e. after some hours cells attach and connect again. It was suspected that ROS and RNS produced in the plasma were mainly responsible for cell detachment by damaging cell adhesion molecules like integrins and cadherins.

Over the next years, more and more plasma researchers focused on detailing dose dependent effects of plasma treatments. The term plasma dose refers to the energy density, which is transferred to a treatment target and is specified with the unit $\mathrm{J} / \mathrm{cm}^{2}$. The plasma dose can be either varied by treatment duration with plasma or by changing physical setting like input power or voltage, which in turn alter the composition of bioactive components such as the concentration of reactive species for example. In the simplest way results of plasma dose dependent studies can be summarized as follows: Very high plasma doses result in increased numbers of apoptotic and also necrotic cells [73]. Medium doses of plasma can evoke apoptosis [74]. Low doses of plasmalead to cell detachment from substrate and dissolved cellcell interactions. However, cells remain viable, and after some time reattach and proliferate again [74-76]. In some cell types, very low doses even induce higher proliferation rates [44, $74,77]$.

The controlled induction of apoptosis in eukaryotic cells opened up new therapeutic applications for plasma, for example the selective killing of cancer cells [78]. Different cellular mechanisms underlying apoptosis were already described, such as DNA damages (including strand breaks), cell cycle checkpoint arrest, mitochondrial dysfunction, or up- and downregulation of apoptosis affecting proteins, for example an accumulation of the tumor suppressor protein p53 [21, 79-84]. Most importantly, studies indicate that cancer cells are in general more vulnerable to plasma applications than healthy cells. Therefore, nowadays cancer therapy with plasma seems conceivable [81, 85-87]. In-vivo experiments on mice indeed demonstrated that plasma applications inhibited tumor growth without damaging the surrounding healthy tissue and, therefore, increased the survival rate of the animals [85]. Here again, reactive species, especially ROS, are thought to play a major role in triggering apoptosis in cancer cells [85, 88-90]. 
Besides cancer medicine, other medical research fields like dentistry, cosmetic medicine, and especially dermatology steadily gained interest during the last decade. In dentistry, for instance, plasma is used to break up and remove biofilms on implant materials or in root canals $[91,92]$. Moreover, in combination with $\mathrm{H}_{2} \mathrm{O}_{2}$, plasma treatment efficiently is able to bleach tooth [93]. Cosmetic plasma applications involve treatments of diseases like acne, as well as treatments to improve the aesthetic appearance of the skin, i.e. scars and wrinkles [94-96]. Severe bacterial or fungal skin infections that play a fundamental role in widespread skin diseases such as atopic dermatitis and other eczema or chronic wounds are of special concern in dermatology and, therefore, are in focus of medical plasma therapy. In the following section more information on dermatological plasma applications is provided.

The vast number of new potential therapeutic applications with APPs led to the introduction of the new term 'plasma medicine' in 2007 with announcing the first 'International Conference on Plasma Medicine' [97]. The term summarizes all non-destructive plasma treatments of mammalian cells and/or tissue to modify cell responses for specific therapeutic purposes.

\section{Dermatological applications of biocompatible APP (state of knowledge)}

Due to its physical propagation and properties cold APP seems to be perfectly applicable on the skin; it adapts to uneven surfaces and can transfer biologically active components into small cavities. Some reviews were already dedicated to dermatological plasma applications in which a number of skin diseases are suggested that could be beneficially treated with plasma treatments $[7,9,23,98]$. The most important findings regarding beneficial plasma effects for dermatological therapies are presented below.

\section{Differential effects of plasma on eukaryotic and prokaryotic cells}

The well-known strong antimicrobial and antiviral properties of plasma play a crucial role in plasma medicine. Given the threat of ever rising bacterial resistance to antibiotics the disinfecting and sterilizing properties of APP are of particular interest in plasma medicine. It has already been widely demonstrated that within seconds or minutes of plasma application the treated skin or material can be efficiently but gently cleaned from bacteria, fungi, viruses, and spores [42, 99-104]. Even methicillin-resistant Staphylococcus aureus (MRSA) and other resistant pathogens are rapidly inactivated and killed by plasma $[105,106]$. Moreover, biofilms can be broken up and removed [107]. Because of these remarkable properties, APP is more and more used as medical tool for the therapy of highly infected or chronic wound conditions. Some clinical trials on ulcers showed a higher reduction of bacterial load and a quicker improvement of wounds after plasma treatments than after standard wound care [108-110]. Comparing the sensitivity of bacteria and mammalian cells to plasma applications it was already occasionally shown that bacteria are more susceptible to same plasma doses than eukaryotic cells. In Wende et al. [111] for example, a self-developed in-vitro wound model was 
developed to study the selective effect of plasma on eukaryotic and prokaryotic cells. Therefore, a two dimensional cell culture of keratinocytes was covered with agarose gel, scratches were induced, and the scratches were then inoculated with Staphylococcus epidermidis (S. epidermidis). After a $40 \mathrm{~s}$ exposure to the plasma jet source, keratinocytes started to grow into the scratch whereas in untreated control samples scratches even increased in size [111]. In another study, a commercially available full thickness reconstructed human skin model (EpiDermFT) was used for the same approach. The skin was injured and the wounds were infected with Staphylococcus aureus (S. aureus). Tissue samples were covered with phosphate buffered saline (PBS) and the liquid plasma electrode of the plasma source was held into the PBS for plasma application. 1 and 2 minutes (min) of plasmatreatment significantly reduced bacterial colonization without causing tissue damage [112]. Furthermore, small pieces of porcine skin from biopsies were colonized by two different MRSA strains, Escherichia coli (E. coli), or $S$. aureus to examine the decolonization efficiency of the FlatPlasSter (plasma box) and miniFlatPlasSter (portable handpiece) device [105]. Results indicated a plasma treatment time dependent and species dependent elimination of the different bacterial strains and further revealed neither epidermal, nor dermal abnormalities for treatment durations up to $8 \mathrm{~min}$. It is argued that bacteria are less effective in compensating high intracellular ROS levels and in repairing ROS and/or UV triggered DNA damages. Also, the smaller size of bacteria compared to mammalian cells may be an explanation, because the same dose of a toxic agent would lead to a faster injury of small bacterial cells than big mammalian cells. To sum up, eukaryotic cells may cope better with external stress induced by plasma treatments than prokaryotic cells [113].

\section{Plasma-induced increase of cell proliferation}

The antibacterial effect of plasma treatment is not the only reason for an enhanced wound healing. In the work of Kalghatgi et al. [44] low doses of plasma $\left(30 \mathrm{~s} \bumpeq 3.9 \mathrm{~J} / \mathrm{cm}^{2}\right)$ resulted in a twofold higher proliferation rate of porcine aortic endothelial cells compared to untreated cells. They further demonstrated that the release of FGF2 was elevated in plasma-treated cells and, therefore, assumed that proliferation enhancement was promoted by FGF2 release. Moreover, their results suggest that the increased FGF2 release resulted from cells with sub-lethal membrane damages induced by plasma generated ROS [44]. Similar results were obtained by Ngo et al. [77]. The immortalized mouse fibroblast cell line L292 responded to very short plasma applications $(5,10$, and $15 \mathrm{~s})$ with an about three times higher proliferation rate than non-exposed cells. In addition, cell migration increased. Both phenomena were correlated with elevated FGF7 release of cells and high ROS levels in cells' surrounding medium [77]. APP treatments also may trigger differentiation in eukaryotic cells. Chondrogenic and osteogenic cells that already started their differentiation process could be for example 
stimulated by plasma to produce intracellular ROS, which likely accelerated the process of differentiation [114].

\section{Acidification due to plasma treatment}

The human skin has a pH between 6 and 4 . Such acidic environments are detrimental for many bacteria; pH values below 6 inhibit bacterial growth [115]. Thus, the low pH of the skin contributes to the natural barrier function. When the skin is injured interstitial fluids with almost neutral $\mathrm{pH}$ come in contact with the skin and, therefore, increase the $\mathrm{pH}$ value in wounds. Consequently, the natural $\mathrm{pH}$ of this skin area is disturbed, which simultaneously facilitates bacterial accumulation. As a natural body response to bacterial colonization the $\mathrm{pH}$ shifts back to an acidic milieu in wounds. This is one of the reasons why the $\mathrm{pH}$ value in general plays an important role in wound healing $[115,116]$. Studies showed that the inactivation efficiency of plasma against bacteria was strongest for acidified solutions in which the bacteria were suspended [117-119]. Furthermore, lipid film surfaces taken from human foreheads could be acidified by volume DBD plasma application. It was hypothesized that the conversion of $\mathrm{NO}_{2}$ molecules generated in the DBD plasma into nitric or nitrous acids drives such pH changes [120]. This is consistent with another study where non-buffered physiological saline was treated with a surface DBD device for up to $30 \mathrm{~min}\left(\hat{=} 110 \mathrm{~J} / \mathrm{cm}^{2}\right)$, which caused a pH decrease from 7 to about 2. Again, it was assumed that RNS like NO are mainly responsible for decreasing $\mathrm{pH}$ values [117]. Taken together, the acidification property of APPs can be used to clean infected wounds and to limit bacterial growth in general. The natural healing process of the skin can thereby be supported.

\section{Plasma-induced changes in gene expressions of wound-related factors}

The few clinical APP studies in which chronic wounds were exposed to plasma showed that additional plasma treatments in addition to the standard wound care efficiently decreased bacterial contaminations of the wounds, which will support wound healing [108-110]. Nonetheless, this is only one mode of action regarding the improvement of healing processes. In order to understand the underlying mechanisms of plasma supported wound healing in more detail, gene expression analyses of wound healing related proteins were performed.

In Barton et al. [121] complementary DNA (CDNA) and quantitative real-time polymerase chain reaction (qPCR) were used to investigate down- or upregulation of various ribonucleic acids (RNAs) in immortal human skin keratinocytes (HaCaT). Results showed an upregulation of a number of angiogenesis promoting factors, e.g. VEGF-A which enhances angiogenesis in damaged tissues $[122,123]$ and prostaglandin-endoperoxide synthase 2 (PTGS2) which is expressed in early stages of wound healing and activates cell proliferation [124, 125]. In addition, elevated RNA levels of the GM-CSF were detected after plasma treatments. GM-CSF 
enhances keratinocyte proliferation, increases angiogenesis via VEGF upregulation, and leads to the recruitment of leukocytes and Langerhans cells [126-128].

Furthermore, plasma treatments stimulated the up-regulation of heparin-binding EGF-like growth factor (HBEGF) [121], which is a protein that can regulate keratinocytes proliferation and regeneration upon skin damage $[129,130]$, MMP-9 that is important for reorganization of tissue [131, 132], and FGF10 that is known to stimulate proliferation and migration of keratinocytes [133]. The messenger RNA (mRNA) syntheses of the anti-inflammatory cytokine IL-6 was mostly influenced by plasma treatments (29-fold upregulation) [121].

Elevated productions of different cytokines and growth factors were also shown by Arndt et al. [46] in cultured primary human dermal fibroblast cells exposed to the MicroPlaSter $\beta$ device. Namely, higher amounts of IL-6, IL-8, MCP-1, TGF-ß1 and TGF-ß2 were observed on mRNA and protein levels. This indicates for a plasma-induced enhancement of the immune defense during wound healing. In addition, in-vivo animal experiments were conducted in this work using mice with artificially generated wounds. A daily treatment of $2 \mathrm{~min}$ over a period of 10 days with the MicroPlaSter $\beta$ source led to significantly accelerated wound closure in mice. Interestingly, increased protein amounts of MCP-1 and IL-6 but no changes in TGF-ß1 and TGF-ß expressions were recorded in treated tissues. Morphologically, a thicker epidermal layer and denser structure of collagen fibers were observed, which correspond with higher mRNA levels of collagen type 1 and alpha-smooth muscle actin (alpha-SMA) in the dermal tissue of mice [46].

\section{Tissue tolerable plasma treatments}

At this time, to the best of my knowledge, no side effects such as burns were detected following plasma application. Experiments on mice, ex-vivo studies on porcine skin, and human skin biopsies, as well as in-vitro studies on living human cells neither showed histological injuries, nor increased amounts of necrotic cells [43, 105, 111, 134-136]. Furthermore, during and after clinical trials with patients suffering from chronic wounds no side effects, like pain or deterioration of wounds were reported [108-110]. The same has been shown for intact skin treatments: Daeschlein et al. [137] applied different plasmas (i.e. pulsed APP jet, non-pulsed APP jet, and DBD) to finger cups of volunteers and observed no harmful effects on skin barrier functions examined with a transepidermal water loss (TEWL) recording device. This makes clear that APP sources can be tuned and adjusted so that plasma applications of the skin are well tolerable for humans. Still, adjustments of plasma devices for biomedical use are more or less performed after the principle of trial and error. This is because the physical-chemical kinetics in the plasma and their resulting biomedical efficiencies are not yet completely understood. 


\section{Materials and Methods}

In this chapter first the main structure of the two plasma sources is presented, followed by detailed descriptions of cellular, molecular, and functional methods. A complete list of all materials is in addition provided in the appendix I.

\subsection{Plasma devices}

The plasma jet device kINPen $^{\circledR}$ MED was developed by neoplas tools $\mathrm{GmbH}$ and INP ('Leibniz-Institut für Plasmaforschung und Technologie') in Greifswald, DE. It consists of a pen-shaped hand held device and a control unit for gas and power supply (50 VA at 230 V, $50 \mathrm{~Hz}$ ) [138]. The hand-held unit comprises a ceramic capillary tube that includes a metallic pin electrode and is surrounded by a ring electrode at the distal tip of the device (Fig. 4a). Argon gas (Argon N46, purity of 99.996\%; Air Liquid, Düsseldorf, DE) is directed through the capillary with a flow rate of 5 standard liter per minutes (s/m). High voltages of up to $3 \mathrm{kV}$ (peak to peak) are applied to the pin electrode at a repetition frequency of about $1 \mathrm{MHz}$. The device operates in a burst mode with a repetition rate of $2.5 \mathrm{kHz}$ (duty cycle: $50 \%$ ). The gas is partially ionized by high voltages and directed outwards of the hand held device forming a so-called effluent at the tip. The effluent propagates into the air in form of bullets. The kINPen ${ }^{\circledR}$ MED was the first plasma jet worldwide that obtained a CE-certification as medical device (class lla) for the use on patients.

The other source used in this thesis was a $\mu$ s-pulsed volume DBD provided by the HAWK ('Hochschule für angewandte Wissenschaft und Kunst'), Göttingen, DE. This DBD device was developed for laboratory use only. However, it is similar to the PlasmaDerm ${ }^{\circledR} \mathrm{VU}-2010$ (CINOGY GmbH, Duderstadt, DE), which was already used in a clinical trial on the therapy of venous leg ulcer [110] and is the first volume DBD device worldwide, which is classified as CEcertified medical tool in class lla. The $\mu$ s-pulsed DBD device comprises a handpiece and a power supply (Power Supply 3045/15; EA-Electronic GmbH, Essen, DE). The nozzle of the handpiece consists of an electrode (diameter: $10 \mathrm{~mm}$ ) that is covered by a $1 \mathrm{~mm}$ thick ceramic dielectric $\left(\mathrm{Al}_{2} \mathrm{O}_{3}\right.$; Fig. $\left.4 \mathrm{~b}\right)$. High voltages of about $9.9 \mathrm{kV}$ are applied to this electrode at a frequency of $300 \mathrm{~Hz}$. The plasma is ignited when the treatment object is set approximately $1 \mathrm{~mm}$ away from the nozzle so that it can act as counter electrode. As described in Tiede et al. [47], PBS solution (cf. appendix 1.5) was used as counter electrode in fibroblast experiments. Grounding was achieved by installing a copper strip (CFT-25/10M; Conrad Electronic SE, Hirschau, DE) near the DBD tip. One end of the copper strip was directed into the PBS solution and the other end was connected to an earthing clip in a socket. 
a

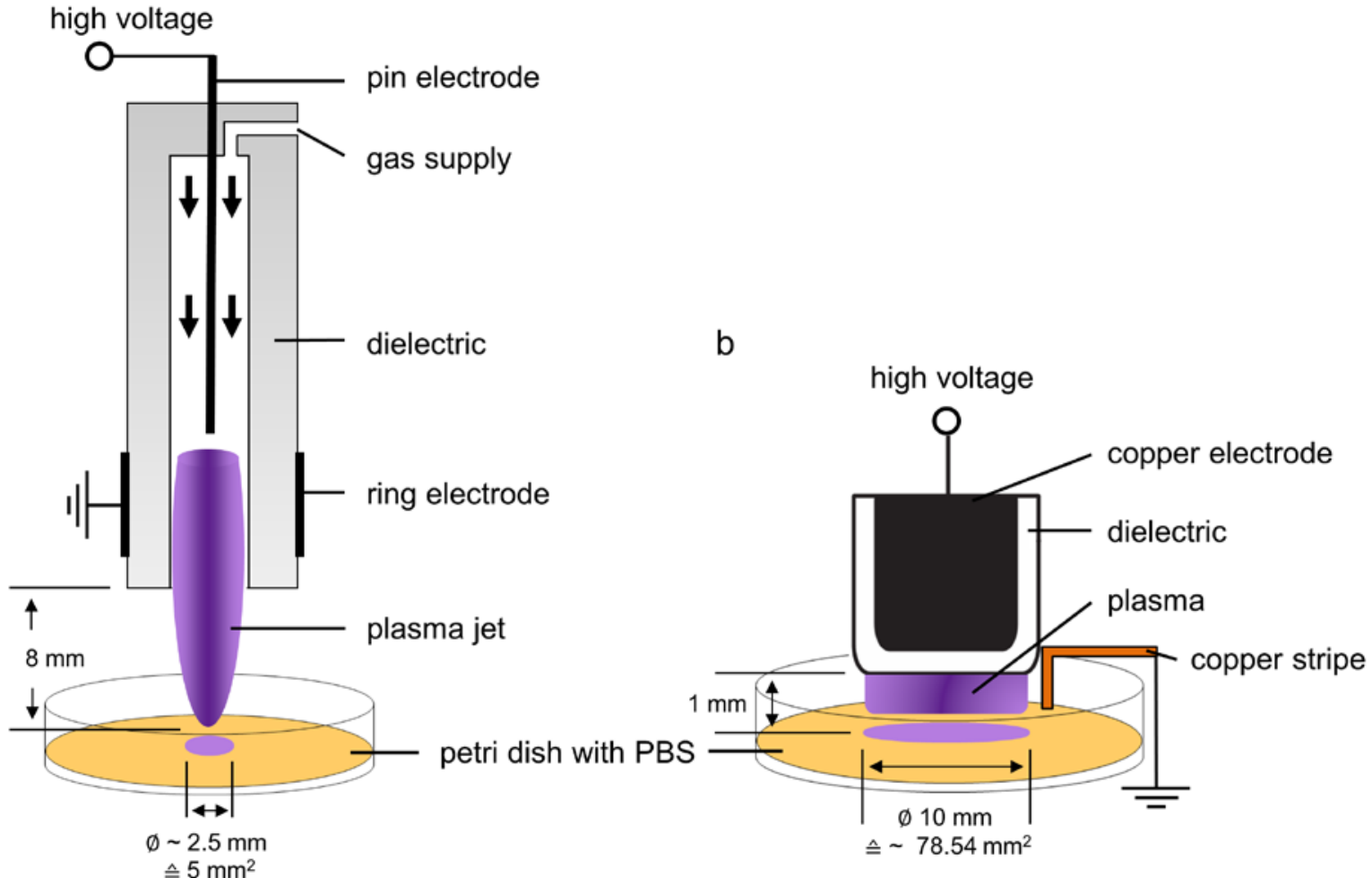

Figure 4: Schematic illustration of the two plasma sources

The general and simplified structures of the KINPen ${ }^{\circledR}$ MED nozzle (a) and the tip of the $\mu$ s-pulsed DBD source (b) are presented in geometrical relationship to a treatment object (petri dish). Distances from nozzle and tip to the treatment object and the resulting exposure areas of the plasmas are presented. 


\subsection{Cell biological methods}

\subsubsection{General cell culture methods}

\section{Cell lines}

Two different adherent human skin fibroblast cell lines were used for establishing and performing test assays to evaluate effects of different plasma sources:

i. $\quad \mathrm{GM00637}(\mathrm{GM})$

ii. $\quad$ primary fibroblast (PF)

During all experiments vital cells were handled under sterile conditions.

The GM cell line (Coriell Institute, Camden New Jersey, USA) is a SV40 virus-transformed immortalized cell line. The cells were cultured in Dulbecco's modified Eagle's medium (DMEM; PAA Cölbe, DE) at $37 \mathrm{C}, 5 \% \mathrm{CO}_{2}$, and a humidity of $90 \%$, and split twice a week into fresh $175 \mathrm{~cm}^{2}$ cell culture flasks (Greiner bio-one, Frickenhausen, DE) at a ratio of 1:4.

PF cells were isolated from healthy skin punch biopsies of donors. Skin samples were incubated in PBS containing 5\% Penicillin-Streptomycin (P/S; PAA Coelbe, DE) for at least $30 \mathrm{~min}$ at $4{ }^{\circ} \mathrm{C}$. Superfluous fat was removed and skin samples were cut into $1-4 \mathrm{~mm}^{2}$ small pieces with a scalpel (Feather, Osaka, JP). Three to five tissue pieces were transferred into a $175 \mathrm{~cm}^{2}$ flask, incubated at room temperature for $15 \mathrm{~min}$ to enhance tissue adhesion, and carefully flooded with $25 \mathrm{~mL}$ DMEM supplemented with $10 \%$ fetal bovine serum (FBS; Biochrom AG, Berlin, DE) and 1\% P/S (culture DMEM; cf. appendix 1.5). Flasks were then cultured in a $\mathrm{CO}_{2}$-incubator (MCO-18AIC; Sanyo, München, DE) at $37^{\circ} \mathrm{C}$, with $5 \% \mathrm{CO}_{2}$, and 90\% humidity for approximately 1-2 weeks until exclusively fibroblast cells were proliferating. Cells were transferred into new flasks for further growth and split once a week at a ratio of 1:2.

\section{Passaging of fibroblasts}

Fibroblasts were divided and passaged (transposed to new flasks) at 90\% confluence; with $100 \%$ defined as the largest possible area of the flask base covered by cells. Flasks were rinsed with $10 \mathrm{~mL}$ PBS to remove any residual FBS, as well as dead cells. Cells were incubated with $4 \mathrm{~mL}$ Trypsin/EDTA (Biochrom AG, Berlin, DE) for $5 \mathrm{~min}\left(37^{\circ} \mathrm{C}, 5 \% \mathrm{CO}_{2}, 90 \%\right.$ humidity) to dissociate them from flask base. Trypsin activity was stopped by adding $10 \mathrm{~mL}$ FBScontaining culture medium. Cells were centrifuged for $5 \mathrm{~min}$ at 1000 rounds per minute (rpm) in a centrifuge (Mikro 220; Hettich, Tutllingen, DE), the supernatant discarded, and the pellet re-suspended in about $30 \mathrm{~mL}$ of medium for transferring them into new $175 \mathrm{~cm}^{2}$ flasks. 


\section{Cryo-preservation of fibroblasts}

Fibroblasts had to be regularly frozen and stored in liquid nitrogen for maintenance of the cell culture. Therefore, cells were collected from cell culture flasks using Trypsin/EDTA as described above and centrifuged for $5 \mathrm{~min}$ at $1000 \mathrm{rpm}$. The supernatant was discarded and the pellet re-suspended in culture DMEM. Cell number of the cell solution was determined (cf. below) and adjusted to $4 \cdot 10^{5}$ cells/mL by adding culture DMEM. Then, same volume of freezing medium (cf. appendix I.5) was added. Precooled cryo tubes (Greiner bio-one, Frickenhausen, DE) were filled with $1 \mathrm{~mL}$ solution each and stored overnight at $-80^{\circ} \mathrm{C}$ (Ultra low MDF-U73V; Sanyo, Müchen, DE) in a cryo box (Nunc; Wiesbaden, DE) filled with isopropanol to ensure a constant cooling rate $\left(-1^{\circ} \mathrm{C} / \mathrm{min}\right)$. On the next day, the cryo tubes were transferred into a liquid nitrogen container (Apollo Biosafe; Messer Greisheim, Bad Siden, DE) for cryo-preservation at $-196^{\circ} \mathrm{C}$.

\section{Re-culturing of fibroblasts}

In order to re-seed frozen cells, a cryo tube was held under running tap water to thaw the cells a little bit and subsequently wiped off with $70 \%$ ethanol (Merck, Darmstadt, DE). Then, $1 \mathrm{~mL}$ of culture DMEM was added and gently mixed to completely thaw cells. Subsequently, the cell solution was poured into $10 \mathrm{~mL}$ culture medium, centrifuged for $5 \mathrm{~min}$ at $1000 \mathrm{rpm}$, and the supernatant discarded. The pellet was re-suspended in $10 \mathrm{~mL}$ culture medium and transferred to a fresh culture flask. On the following day, culture DMEM was completely replaced with fresh culture medium to remove dead cells.

\section{Cell counting}

Cells were harvested as described above and re-suspended in culture medium. $10 \mu \mathrm{L}$ of the cell suspension was mixed with $90 \mu \mathrm{L}$ of trypan blue and $10 \mu \mathrm{L}$ of this solution (1/10 dilution factor) was added to a Neubauer counting chamber (Brand, Wertheim, DE). Four $0.01 \mathrm{~cm}^{2}$ corner squares with a depth of $0.01 \mathrm{~cm}$ were counted, which correspond to a volume of $0.0001 \mathrm{~mL}$. The concentration of cell number per $\mathrm{mL}$ is defined with:

$$
\text { concentration }(\text { cells } / \mathrm{mL})=\frac{\text { number of cells }}{\text { number of squares } \mathrm{x} \text { dilution factor } \mathrm{x} \text { volume }(\mathrm{mL})}
$$

which can be simplified to

$$
\text { concentration }(\text { cells } / \mathrm{mL})=\text { number of cells } \times 25000 \text {. }
$$

Afterwards the chamber was cleaned with water and $70 \%$ ethanol. 


\subsubsection{Transient transfection of fibroblasts}

Chemical transfections of GM or PF cells were achieved by using the non-liposomal lipid Attractene Transfection Reagent (Qiagen, Hilden, DE). This reagent forms complexes with plasmid DNA that can be assimilated by eukaryotic cells via endocytosis. Cells were seeded in different densities depending on cell line and assay: For HCR assays 40,000 GM cells and 30,000 PFs were seeded per well in 12-well-plates (Greiner bio-one, Frickenhausen, DE), whereas for the PSV assay 250,000 GMs were seeded in $35 \mathrm{~mm}$ cell culture dishes (Th. Geyer, Renningen, DE). Cells were then incubated for adhering overnight. On the next day, either $58.4 \mu \mathrm{L}$ or $90.5 \mu \mathrm{L}$ of non-supplemented DMEM was mixed with either $100 \mathrm{ng}$ (renilla) and $150 \mathrm{ng}$ (firefly) or $250 \mathrm{ng}$ (pSP189) of plasmid DNA (cf. appendix 1.7 for firefly and renilla plasmids; cf. 3.5.4 for pSP189 plasmid) in round-bottom tubes with snap caps (BD Bioscience, Heidelberg, DE), respectively. Either $0.6 \mu \mathrm{L}$ or $4.5 \mu \mathrm{L}$ of Attractene reagent were added to the DMEM-plasmid mix, instantly vortexed (on the Vibrofix VF1 Electronic; IKA Labortechnik, Staufem, DE) for several seconds and incubated for $15 \mathrm{~min}$ at room temperature. During that time, medium was removed from wells and cell dishes and cells covered with $500 \mu \mathrm{L}$ or $2 \mathrm{~mL}$ of fresh culture DMEM for the HCR or PSV assay, respectively. Then, the transfection mix (60 $\mu \mathrm{L}$ for HCR assay and $100 \mu \mathrm{L}$ for PSV assay) was added drop by drop into wells or dishes and incubated $\left(37^{\circ} \mathrm{C}, 5 \% \mathrm{CO}_{2}, 90 \%\right.$ humidity) for 5 hours (h). Afterwards, the transfection solution was replaced by either $\sim 1 \mathrm{~mL}$ or $\sim 4 \mathrm{~mL}$ of fresh culture medium and the cells further incubated for $72 \mathrm{~h}$.

\subsubsection{Plasma treatment of fibroblasts}

On the day before plasma treatment, fibroblasts were seeded in $35 \mathrm{~mm}$ cell culture dishes in $2 \mathrm{~mL}$ of culture DMEM in a density of 250,000 for GM and 100,000 for PF cells. On the following day, culture medium was removed, cells were rinsed with PBS, and covered with $1 \mathrm{~mL}$ of PBS. Plasma applications were performed in a source dependent manner to achieve the best possible treatment.

\section{Plasma treatment with the kINPen ${ }^{\circledR}$ MED}

The jet was positioned centrally and exactly $8 \mathrm{~mm}$ above the bottom of the cell culture dish. The argon gas streamed out of the device with a gas flow rate of $5 \mathrm{~s} / \mathrm{m}$ leading to a circulation of the PBS in the dish like a swirl. Thus, cells in the middle of the dish were directly exposed to the plasma jet, while cells that were lying closer to the rim were exposed indirectly.

\section{Plasma treatment with the $\mu \mathrm{s}-$ pulsed volume DBD}

The nozzle of this device was placed $1 \mathrm{~mm}$ above the PBS surface to ensure a uniform discharge. For grounding of samples, a cooper strip was placed into the PBS solution, so that it did not touch the bottom of the dish, and connected to an earthing clip in a socket. During 
plasma treatment, culture dishes were constantly moved with $40 \mathrm{rpm}$ by an Orbital Shaker (Standard 1000 Orbital Shaker; WWR International bvba, Geldenaakesbaan, BE) to reach the largest treatment area possible.

The next steps were performed in the same way for both plasma sources: Immediately after plasma application (at the most $2 \mathrm{~min}$ later), $3 \mathrm{~mL}$ of DMEM supplemented with $13 \%$ FBS (DMEM-13\%F; cf. appendix I.5) were added to each dish and cells incubated $\left(37^{\circ} \mathrm{C}, 5 \% \mathrm{CO}_{2}\right.$, $90 \%$ humidity) for different times depending on the performed assay; $48 \mathrm{~h}$ for MTS (3-(4,5dimethylthiazol-2-yl)-5-(3-carboxymethoxyphenyl)-2-(4-sulfophenyl)-2H-tetrazolium) tests, $72 \mathrm{~h}$ for PSV assays, and $24 \mathrm{~h}$ for flow cytometry experiments.

It is worth noting that the PBS solution was left in the cell culture dishes after plasma exposure to exclude the removal of loose, but still viable, cells. Many researchers performed cell viability assays without taking into account that most cell types treated with low to medium plasma doses or short application times detach from their substrate as one of the first cell responses $[45,74]$. Thus, loose cells float in the treatment solution. If the solution is immediately replaced by fresh medium, cells, which are still viable, will be removed. The here presented protocol avoids this circumstance.

\subsubsection{Treatment of fibroblasts with $\mathrm{H}_{2} \mathrm{O}_{2}$ and different radiations $\mathrm{H}_{2} \mathrm{O}_{2}$ treatment of fibroblasts}

As positive control for MTS assays, cells were incubated for 30,60, 90, and $180 \mathrm{~s}$ with a 60, 75 , or $90 \mu \mathrm{M}$ concentrated $\mathrm{H}_{2} \mathrm{O}_{2}$-solution (Merck, Darmstadt, DE) in PBS. Corresponding to plasma treatments, $3 \mathrm{~mL}$ of fresh DMEM-13\%F was added and dishes were incubated for $48 \mathrm{~h}$ before performing the MTS assay (cf. 3.5.1).

\section{UVC irradiation of GM cells}

During PSV experiments, samples of GM cells were exposed to $2.5,5$, and $7.5 \mathrm{~mJ} / \mathrm{cm}^{2}$ of UVC radiation at a wavelength of $254 \mathrm{~nm}$ as positive control using the UVC 500 crosslinker (Amersham Bioscience, Glattburg, $\mathrm{CH}$ ).

\section{X-ray irradiation of GM cells}

For flow cytometric analyses X-ray irradiations were performed as positive control for the induction of double strand break (DSB) events in cells. Using the RS225 X-Ray Box (Gulmay Medical LTD, Camberley, Surrey, UK) GM cells were exposed to different doses of X-rays: i.e. $1,3,5,7$, and 9 gray (Gy). 


\subsection{Microbiological methods}

\subsubsection{Sterilization of solid and liquid consumables}

Non sterile buffers, solutions, bacterial media, plastic pipette tips, and S1 laboratory waste were autoclaved (in autoclave DE-65; Systec, Wettenberg, DE) for $20 \mathrm{~min}$ at three bar and $121^{\circ} \mathrm{C}$. Glass pipettes and miscellaneous glassware were washed in a dish washer (Miele professional; Miele, Gütersloh, DE) at $40^{\circ} \mathrm{C}$. Glass pipettes were then sealed with cotton wadding (Brand, Wertheim, DE) using a tamping machine (Tecnomara, Tecnoplug; Integra Bioscience, Fernwald, DE) and subsequently sterilized at $190^{\circ} \mathrm{C}$. Other glassware and pipette tips were dried at $70^{\circ} \mathrm{C}$ for at least $4 \mathrm{~h}$ (in Memmert SL 50; Willi Fischer KG, Frankfurt, DE). Temperature-sensitive buffers and liquids were sterilized using syringes (Braun, Melsungen, DE) and sterile filter paper (Sarstedt, Nümbrecht, DE).

\subsubsection{Bacterial strains}

Two different $E$. coli strains were used during the thesis:

i. $\quad \mathrm{DH} 5 \alpha$ [139]:

$\mathrm{F}^{-}$endA1, hsdR17 $\left(\mathrm{r}_{\mathrm{K}^{-}}, \mathrm{m}_{\mathrm{K}}{ }^{+}\right)$, glnV44 (synthetic name of supE44), thi-1, $\lambda^{-}, \operatorname{rec} A 1$, gyrA96, relA1, deoR, $\Delta$ (lacZYA-argF)U169, ф80dlacZAM15, nupG

ii. MLB100 [140]:

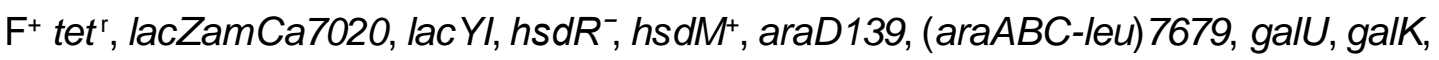
rpsL, thi

\subsubsection{Culture and storage of E. coli}

$200 \mu \mathrm{L}$ of frozen E. coli culture (cf. storage conditions below) of the strains DH5 $\alpha$ or MLB100 were poured into $200 \mathrm{~mL}$ of fresh double yeast medium (dYT; cf. appendix I.5) without antibiotics and grown overnight at $37^{\circ} \mathrm{C}$ in an incubator shaker (Shaker Thermotron; Infors, Bottmingen, SZ) at $200 \mathrm{rpm}$. On the next day, $5 \mathrm{~mL}$ of $E$. coli culture were added to $100 \mathrm{~mL}$ of dYT medium and incubated for $2 \mathrm{~h}\left(37^{\circ} \mathrm{C}, 170 \mathrm{rpm}\right)$. Then, $25 \mathrm{~mL}$ of this preparatory culture were mixed with $500 \mathrm{~mL} \mathrm{dYT} \mathrm{medium} \mathrm{and} \mathrm{incubated} \mathrm{until} \mathrm{the} \mathrm{optical} \mathrm{density} \mathrm{(OD)} \mathrm{reached} \mathrm{a}$ value of about $0.5-0.6$ measured at $600 \mathrm{~nm}$ with the DU $640^{\circledR}$ Spectrophotometer (Beckmann, München, DE); this indicates the logarithmic growth phase. Pure dYT medium served as control for the OD 600 measurements. For long-term storage of the DH5a and MLB100 cells, $850 \mu \mathrm{L}$ of the main culture were shortly vortexed with $150 \mu \mathrm{L}$ glycerol (Merck, Darmstadt, DE), shock frozen in liquid nitrogen, and then stored at $-80^{\circ} \mathrm{C}$. 


\subsubsection{Preparation of chemically-competent E. coli}

The competence of bacteria describes their ability to take up DNA that is free floating in the surrounding medium. This requires the process of transformation, i.e. uptake of foreign DNA by prokaryotic cells. E. coli bacteria do not take up foreign DNA easily and, hence, the uptake rate (transformation rate) of plasmid DNA would be very low. By physical or chemical manipulation of bacteria's membrane, plasmid DNA attaches more easily to the membrane and penetrates the cell through generated pores. By this method competent cells can be produced that are necessary for the replication of recombinant plasmid DNA, so for amplification of the plasmid DNA.

First, main cultures of DH5a or MLB100 were prepared as previously described (cf. 3.3.3). All following steps were performed on ice and with precooled cells, solutions, and supplies. $50 \mathrm{~mL}$ of main culture were centrifuged for $20 \mathrm{~min}$ at $4^{\circ} \mathrm{C}$ and $3000 \mathrm{rpm}$ (Sorval RC 6+ centrifuge; Thermo Scientific, Waltham, US) and the supernatant was discarded. The pellet was re-suspended with $50 \mathrm{~mL}$ of $50 \mathrm{mM} \mathrm{CaCl}_{2}$-solution (Merck, Darmstadt, DE) and incubated on ice for $30 \mathrm{~min}$. This bacterial solution was centrifuged $\left(20 \mathrm{~min}, 4^{\circ} \mathrm{C}, 3000 \mathrm{rpm}\right.$ ) and the supernatant discarded, again. Afterwards, the pellet was carefully re-suspended in $10 \mathrm{~mL}$ of $\mathrm{CaCl}_{2}$-glycerol solution (cf. appendix I.5). The resulting bacterial cultures (50 $\mu \mathrm{L}$ of $\mathrm{DH} 5 \alpha$ and $200 \mu \mathrm{L}$ of MLB100) were aliquoted in $-20^{\circ} \mathrm{C}$ precooled reaction tubes (Eppendorf, Hamburg, $\mathrm{DE})$, shock frozen in liquid nitrogen, and frozen at $-80^{\circ} \mathrm{C}$.

\subsubsection{Transformation of plasmid DNA into chemically-competent E. coli}

$50 \mu \mathrm{L}$ of chemically-competent MLB100 or DH5a cells in reaction tubes were slowly defrosted on ice, supplemented with $50 \mathrm{ng}$ of plasmid DNA, and incubated for $30 \mathrm{~min}$ on ice. Subsequently, the reaction tubes were placed into a thermal block (Thermomixer 5436; Eppedorf, Hamburg, DE) for exactly $45 \mathrm{~s}$ at $42{ }^{\circ} \mathrm{C}$ to generate a heat shock, followed by incubation on ice for $2 \mathrm{~min}$. Then, $450 \mu \mathrm{L}$ of dYT or LB medium (cf. appendix I.5) without antibiotics was added to the cells. For recovery, the culture was transferred to $15 \mathrm{~mL}$ tubes with filter (Greiner bio-one, Frickenhausen, DE) and incubated for $1.5 \mathrm{~h}$ in an incubator shaker $\left(37^{\circ} \mathrm{C}, 170 \mathrm{rpm}\right)$.

In the course of the PSV experiments, transformed MLB100 cells with pSP189 plasmids were spread on LB agar plates containing IPTG (isopropyl- $\beta$-D-thiogalactopyranosid), X-Gal (5-Brom-4-chlor-3-indoxyl- $\beta$-D-galactopyranosid), and ampicillin (cf. appendix 1.5) for blue/white selection (cf. 3.5.4). After recovery, $150 \mu \mathrm{L}$ of bacterial cultures were used for plating. Agar plates were incubated for $20 \mathrm{~h}$ at $37^{\circ} \mathrm{C}$. If the blue color of the colonies was still very bright, plates were further incubated at room temperature in the dark for some hours or overnight. Then, mutation analysis was performed, starting with counting the blue and white 
colonies on the plates, picking white and bright blue colonies for colony polymerase chain reaction (PCR), and further sequencing (cf. 3.5.4).

\subsubsection{Amplification and preparation of plasmid DNA in E. coli}

For plasmid amplification dYT, LB medium, and LB agar plates were supplemented with $100 \mathrm{mg} / \mathrm{L}$ ampicillin (Sigma-Aldrich, München, DE) according to the required resistance on the plasmids used in this project (firefly, renilla, pUC19, and pSP189).

Only chemically-competent DH5a cells were used to amplify firefly, renilla, and pUC19 plasmids (cf. appendix I.7). Following the transformation of cells with the desired plasmid, $300 \mathrm{~mL}$ of LB medium containing ampicillin were inoculated with transformed cells and incubated overnight in the incubator shaker $\left(200 \mathrm{rpm}\right.$ at $\left.37^{\circ} \mathrm{C}\right)$. On the next day, cultures were divided into $50 \mathrm{~mL}$ tubes (Greiner bio-one, Frickenhausen, DE) and centrifuged for $10 \mathrm{~min}$ and $4000 \mathrm{rpm}$. The supernatant was discarded and the pellets used for midi or maxi preparation of plasmids with the NucleoBond ${ }^{\circledR}$ Xtra MiDi/Maxi Plus Kit (Machery-Nagel, Düren, DE; cf. 3.4.1).

For PSV experiments, stock solutions of pSP189 plasmids were produced using only MLB100 cells. After transformation, the bacterial suspensions were plated on LB agar plates containing IPTG, X-Gal, and ampicillin. Here, it is very important to use at least six large LB agar plates (145 mm; Greiner bio-one, Frickenhausen, DE) to ensure that the variability of the signature sequences on the pSP189 plasmid is preserved. On the next day bacteria with ampicillin resistance were able to grow on plates. Colonies were collected by washing the plates with dYT medium. The bacterial solution was divided into $50 \mathrm{~mL}$ tubes, centrifuged for $10 \mathrm{~min}$ at $4000 \mathrm{rpm}$, and pellets further used for midi scale preparation (cf. 3.4.1).

\subsubsection{Quality control of generated competent cells}

To guarantee an adequate transformation efficiencies a quality control was performed every time new competent cells were produced. $50 \mu \mathrm{L}$ of competent cells were mixed with $5 \mathrm{ng}$ native pUC19 or $50 \mathrm{ng}$ of pSP189 plasmid DNA and transformed (cf. 3.3.5). 50, 100 and $150 \mu \mathrm{L}$ of this pre-culture were spread on LB agar plates containing ampicillin (cf. appendix 1.5) and incubated overnight at $37^{\circ} \mathrm{C}$. On the next day, colonies were counted and the colony forming unit (CFU) per $\mu \mathrm{g}$ DNA calculated. When the transformation efficiency was about $10^{6} \mathrm{CFU} / \mu \mathrm{g}$, competent cells were further used for experiments. 


\subsection{Molecular methods}

\subsubsection{Isolation of plasmid DNA}

Plasmid DNA had to be isolated from E. coli after plasmid amplification (cf. 3.3.6) and also from GM cells during the PSV assay (cf. 3.5.4).

\section{Plasmid isolation from $E$. coli}

In general, plasmid isolation was performed using the alkaline lysis [141]. As a first step bacteria carrying the plasmid were grown under selective antibiotic conditions (LB or dYT medium supplemented with $100 \mathrm{mg} / \mathrm{L}$ ampicillin). Then, cells were centrifuged and the pellet re-suspended in a solution with EDTA (ethylenediaminetetraacetic acid), Tris- $\mathrm{HCl}$, glucose, and RNase A. EDTA protects DNA from degradation by DNase and destabilizes the cell wall by binding bivalent cations like $\mathrm{Mg}_{2}{ }^{+}$and $\mathrm{Ca}_{2}{ }^{+}$that are essential for cell wall integrity and the activity of DNase in cells. Glucose is included in the solution to prevent cells from bursting, RNase to digest cellular RNA, and Tris-HCl buffers the solution. Afterwards, the lysis buffer is added to the cells. It contains ionic SDS (sodium dodecyl sulfate) - this destroy the murein sacculus and the cytoplasmic membrane - and $\mathrm{NaOH}$, which generates a strong alkaline $\mathrm{pH}$ shift (to a pH of about 12). This $\mathrm{pH}$ shift denaturize hydrogen bonds between complementary DNA strands (chromosomal DNA as well as plasmid DNA). By adding a solution containing potassium acetate, the $\mathrm{pH}$ shifts back to 7 . In this stage, plasmid DNA can re-nature easily due to their small and circular conformation, while separated strands of genomic DNA (which are already fragmented due to previous steps) only partially re-nature and may bind undirected with wrong complementary strands. This leads to a chaotic DNA accumulation that furthermore stick together with denatured cellular proteins and SDS due to hydrophobic interactions and consequently a white precipitate is formed. These complexes and $\mathrm{NaOH}$ can be easily removed by centrifugation. Double stranded plasmid DNA is now dissolved in the supernatant, which is transferred to a vertical glass tube packed with silica that binds the intact plasmid DNA.

To isolate lager amounts of plasmid DNA (i.e. after plasmid amplification of firefly, renilla, and pUC19) from MLB100 or DH5a cells, the NucleoBond ${ }^{\circledR}$ Xtra MiDi/Maxi Kit was used according to the user's manual. For that, bacteria were transformed (cf. 3.3.5) and overnight cultures prepared (cf. 3.3.3). For amplification of the pSP189 plasmid only the NucleoBond ${ }^{\circledR}$ Xtra MiDi Plus Kit (Machery-Nagel, Düren, DE) was used and isolation performed according to instructions of low-copy plasmids. Here, transformed cells were grown overnight on big agar plates $(145 \mathrm{~mm})$. At a time, colonies of at least six plates were collected and incubated for $16-20 \mathrm{~h}$ in $400 \mathrm{~mL}$ of LB medium in an incubator shaker at $37^{\circ} \mathrm{C}$. 


\section{Plasmid isolation from fibroblasts}

The alkaline lysis method was also used to isolate plasmid DNA from GMs. As first step, fibroblasts were detached from cell culture dishes by removing the medium, adding $500 \mu \mathrm{L}$ of Accutase (Biochrom AG, Berlin, DE), and incubation for $5 \min \left(37^{\circ} \mathrm{C}, 5 \% \mathrm{CO}_{2}, 90 \%\right.$ humidity). Cells were then collected in $5 \mathrm{~mL}$ reaction tubes and dishes washed with $500 \mu \mathrm{L}$ of PBS to catch remaining cells. For one treatment condition three dishes with fibroblasts were prepared and cells pooled in one reaction tube. After a centrifugation for $30 \mathrm{~s}$ at $1300 \mathrm{rpm}$, the supernatant was discarded and the following steps were performed as described in the manual, starting with adding the lysis buffer.

With the NucleoSpin ${ }^{\circledR}$ Plasmid Kit (Machery-Nagel, Düren, DE), smaller amounts of plasmid DNA from GM cells were isolated according to manufacturer's instructions for low copy plasmids.

\subsubsection{Purification and concentration of plasmid DNA}

\section{Purification of plasmid DNA}

After midi or maxi preparations, eluated plasmid DNA had to be purified, which was done by precipitation with ethanol in mild acidic conditions ( $\mathrm{pH}$ : 5.2) achieved by using sodium acetate. Ethanol is much less polar than DNA or water. By adding ethanol to the DNA solution, the solubility of the DNA in water is reduced [142]. The low pH further reduces solubility because the negatively charged DNA is partially saturated with sodium ions and partially protonated. At some point, when enough ethanol is added, the electrical attraction between DNA phosphate groups and positive ions becomes strong enough to form stable ionic bonds [143].

To the DNA solution, 1/10 volume of $3 \mathrm{M}$ sodium acetate (Sigma-Aldrich, München, DE) and 2.5 volumes of $96 \%$ ethanol (analytical grade) was added and intensively vortexed. The solution was then centrifuged for $30 \mathrm{~min}$ at $14000 \mathrm{rpm}$, the supernatant discarded, and $300 \mu \mathrm{L}$ of $70 \%$ ethanol added to wash the pellet. The solution was centrifuged for $10 \mathrm{~min}$ at $14000 \mathrm{rpm}$, followed by removing the ethanol and drying the pellet on a thermal block for $5 \mathrm{~min}$ at $42{ }^{\circ} \mathrm{C}$ while tubes were left open. Finally the pellet is re-suspended in $250 \mu \mathrm{L}$ water.

To purify pSP189 plasmids isolated from GM cells, only the Wizard ${ }^{\circledR}$ SV Gel and PCR CleanUp System (Promega, Fitchburg, US) were used whereby adsorption of the DNA is also achieved with alcohol and mild acid conditions via polar interactions. Here, DNA is bound to silica gel and proteins are denaturized by chaotropic salts, which are then washed out of the matrix. Finally, DNA is eluated in $50 \mu \mathrm{L}$ double distilled water $\left(\mathrm{ddH}_{2} \mathrm{O}\right)$. 


\section{DNA concentration measurements}

The DNA concentration was determined using the NanoVuePlus ${ }^{\circledR}$ (GE Healthcare, Buckinghamshire, UK). $2 \mu \mathrm{L}$ of DNA sample was measured at $260 \mathrm{~nm}$ absorption. Autoclaved $\mathrm{ddH}_{2} \mathrm{O}$ (same water as used for DNA eluation) served as blank. The concentration was calculated by the device using the standard conversion factor for DNA (50). DNA purity was tested by measuring the quotient of $O D_{260} / \mathrm{OD}_{280}$ that had to be between 1.7 and 2.0 for further use.

\subsubsection{Treatment of plasmid DNA}

\section{Plasma treatment}

To analyze the direct genotoxic effect of APP only purified and isolated DNA dissolved in $\mathrm{dd}_{2} \mathrm{O}$ was used. In the course of the HCR assay firefly plasmid was treated with plasma to induce DNA adducts and/or fragmentation. For gel electrophoresis plasma-treated firefly plasmid was used to investigate the fragmentation potential of the APP. Also, the pSP189 vector was treated with plasma during performance of version 1 of the PSV assay. In all these cases, $300 \mu \mathrm{L}$ of the plasmid solution were placed into one well of a 12 well-plate. Treatment conditions for the two sources were the same as already described in section 3.2.4. Afterwards, plasmid DNA solutions were stored at $-20^{\circ} \mathrm{C}$ until further use.

\section{UV irradiation of plasmid DNA}

Plasmids were exposed to UV radiation as positive control. For HCR experiments, $300 \mu \mathrm{L}$ of firefly plasmid were irradiated with either UVB at a wavelength of $312 \mathrm{~nm}$ (BioLink BLX 312; LTF-Labortechnik, Wasserburg, DE) or UVC radiations $(254 \mathrm{~nm})$ in 12 -well-plates. The following doses were applied to firefly plasmid solutions: $50,100,250,500,750$, and $1 \mathrm{~mJ} / \mathrm{cm}^{2}$ of UVB and $5,10,25,50,75 \mathrm{~mJ} / \mathrm{cm}^{2}$ of UVC.

UVC irradiations of pSP189 plasmid solutions were equally performed; but exclusively with $75 \mathrm{~mJ} / \mathrm{m}^{2}$.

\subsubsection{DNA separation via agarose gel electrophoresis}

Via agarose gel electrophoresis negatively charged DNA molecules can be simply separated according to their conformation (supercoiled, circular, or linear) and by their size while migrating through an electric field. To make a $1 \% \mathrm{gel}, 0.4 \mathrm{~g}$ of LE agarose powder (Biozym, Oldendorf, DE) was mixed with $40 \mathrm{~mL}$ of $1 x$ Tris/Borate/EDTA (TBE) buffer (cf. appendix I.5). The solution was heated in a microwave (NN-5253; Panasonic, Hamburg, DE) until it boiled and the powder was dissolved. Afterwards, $2 \mu \mathrm{L}$ of HDGreen Plus DNA Stain (Intas, Göttingen, $\mathrm{DE}$ ) was added to gel solution that intercalates into the DNA and that can be visualized by exposure to UV radiation. Then, the gel was gently poured into an electrophoresis chamber (Hardware \& service, Friedland, DE) and an electrophoresis comb was pressed into the gel 
near the upper edge. The gel was dried for $15 \mathrm{~min}$ at room temperature and the whole agarose chamber was filled with 1x TBE buffer. Then, the comb was carefully removed, which generates small loading chambers in the gel. DNA samples (usually 100-200 ng DNA content) were mixed with $2.5 \mu \mathrm{L}$ of $6 \mathrm{x}$ DNA Loading Dye (Thermo Scientific, Braunschweig, DE) and, together with $4 \mu \mathrm{L}$ of two differentially large DNA weight ladders (Thermo-Scientific, Braunschweig, DE), i.e. 100 base pairs (bp) and 1 kilo base pairs (kb), filled into the small loading chambers (ad most $10 \mu \mathrm{L}$ per chamber). Afterwards, the whole electrophoresis chamber was connected to a power supply (Mini Power Rack P20; Biometra, Göttingen, DE) generating an electric field with a voltage of about $90 \mathrm{~V}$. DNA fragments were visualized by fluorescence of the HDGreen stain with a gel documentation system (Gel iX 20 Imager; Intas, Göttingen, DE). In this work, gel electrophoresis was used for analytical investigations of fragmentation rates of APP-treated plasmid DNA (firefly plasmid). $250 \mathrm{ng}$ and $750 \mathrm{ng}$ DNA were used per sample of DBD treated or jet-treated samples, respectively. Also, the technique was utilized for testing PCR products during PSV experiments. Therefore, $7.5 \mu \mathrm{L}$ of PCR products were mixed with $2.5 \mu \mathrm{L}$ 6x DNA Loading Dye. This mix and a $100 \mathrm{bp}$ DNA weight ladder were then separated in the gel with the same settings as above.

\subsubsection{Enzymatic digestion of plasmid DNA}

\section{BamHI}

Restriction enzyme digestion with BamHI (10 U/ $\mu \mathrm{L}$; Thermo-Scientific, Braunschweig, DE) was performed to verify the linearized form of the firefly plasmid in agarose gel electrophoresis. The firefly plasmid includes only one site at which BamHI can cut the plasmid [144] and, thus, the digestion solution mainly consists of the linearized form of the plasmid. When running this sample in a gel it should create one band at the size of the plasmid (4863 bp). According to the protocol recommended for $\mathrm{BamHl}$, the digestion solution included $2 \mu \mathrm{L} \mathrm{BamHI} 5 \mu \mathrm{L}$ Tango Buffer 10x (Thermo-Scientific, Braunschweig, DE), $2 \mu \mathrm{g}$ DNA (corresponded to about $8 \mu \mathrm{L}$ ), and $35 \mu \mathrm{LddH} \mathrm{H}_{2} \mathrm{O}$. The solution was incubated for $1 \mathrm{~h}$ at $37^{\circ} \mathrm{C}$ and subsequently prepared for gel electrophoresis.

\section{Dpnl}

Digestion of the pSP189 plasmid was required during PSV experiments using the enzyme Dpnl 10U/ $\mu \mathrm{L}$ (Thermo-Scientific, Braunschweig, DE). This was done after isolation of pSP189 DNA from GM cells (cf. 3.4.1). The enzyme belongs to type II restriction endonucleases and recognizes methylated adenosines in the 5'-GA^TC-3' sequence to further catalyze the double strand cut at this DNA site. Only bacteria express the appropriate enzyme to methylate the plasmids in this form, whereas all replicated plasmids in human cells lose their methylated adenosines. Thus, only the originally used pSP189 DNA during transfection into GM cells was degraded by Dpnl digestion. Thus, only replicated pSP189 plasmids were further used for 
experiments. $44 \mu \mathrm{L}$ of DNA samples were mixed with $1 \mu \mathrm{L}$ of Dpnl enzyme and $5 \mu \mathrm{L}$ of the recommended Tango Buffer 10x. Samples were incubated for $1 \mathrm{~h}$ at $37^{\circ} \mathrm{C}$ followed by heat inactivation of the enzyme at $80^{\circ} \mathrm{C}$ for $20 \mathrm{~min}$. Afterwards, DNA solutions were purified with the Wizard ${ }^{\circledR}$ SV Gel and PCR Clean-Up System by Promega according to manufacturer's instructions and the DNA concentration measured (cf. 3.4.2). Purified DNA samples were further used for blue/white selection and sequence analysis of mutated pSP189 plasmids (cf. 3.5.4).

\section{EXo-SAP}

Before the PCR products could be sequenced in the course of PSV assays, remaining deoxynucleotides (dNTPs) and primers in samples had to be removed. Therefore, samples were digested with the Exo-SAP-mix (New England Biolabs, Ipswich, US) containing Exonucelase I to remove primers and Shrimp Alkaline Phosphatase to degrade unincorporated dNTPs. $5 \mu \mathrm{L}$ PCR product and $2 \mu \mathrm{L}$ Exo-SAP-mix (prediluted in a ratio of $1: 4$ in $\mathrm{dd}_{2} \mathrm{O}$ ) were mixed on ice and incubated for $30 \mathrm{~min}$ at $37^{\circ} \mathrm{C}$, then $15 \mathrm{~min}$ at $80^{\circ} \mathrm{C}$, and finally for $3 \mathrm{~min}$ at $95^{\circ} \mathrm{C}$. 


\subsection{Functional methods}

\subsubsection{MTS assay}

To study the cytotoxic effect of plasma on skin fibroblasts the common MTS assay was carried out with the use of the kit CellTiter $96^{\circledR}$ AQeuos One Solution Cell Proliferation Assay (Promega, Mannheim, DE). The assay is based on the MTS tetrazolium compound that can be mitochondrially metabolized by viable cells into a dark purple or aubergine colored formazan product. The product is soluble in culture medium and the amount of the metabolized product can be photometrically measured representing the cell viability rate. The assay is generally used for examining cell proliferation in response to intracellular triggers or signaling molecules like growth factors, cytokines, or nutrients, but also for analyzing cytotoxic effects of agents or pharmaceutical compounds. However, the protocol of manufacturer had to be adjusted for APP applications. The experimental procedure that worked best is described below.

After seeding cells in culture dishes, they were exposed to the different plasmas (cf. 3.2.4). Plasma jet applications were performed for 10, 30, 60, 90, and $180 \mathrm{~s}$, which corresponds to plasma doses of $31,92,184,275,551 \mathrm{~J} / \mathrm{cm}^{2}$ (cf. 4.1.1). These treatment durations were sufficient to reach the lethal dose $50 \%$ (LD50; meaning that $50 \%$ of the cells cannot metabolize the tetrazolium dye anymore) and lower values of cell viability. Using the $\mu s-p u l s e d$ DBD source for same treatment durations, corresponding plasma doses are 4, 11, 23, 34, and $69 \mathrm{~J} / \mathrm{cm}^{2}$. However, extended application times were required to reach same viability values as in jet treatments. Therefore, additional durations of 270 and $360 \mathrm{~s}\left(\hat{=} 103\right.$ and $\left.137 \mathrm{~J} / \mathrm{cm}^{2}\right)$ for GM cells and further 480 and $600 \mathrm{~s}\left(\triangleq 183\right.$ and $229 \mathrm{~J} / \mathrm{cm}^{2}$ ) for PFs were used. For each plasma treatment duration, two independent culture dishes were prepared. Treated cells were incubated for $48 \mathrm{~h}\left(37^{\circ} \mathrm{C}, 5 \% \mathrm{CO}_{2}, 90 \%\right.$ humidity) before the PBS-DMEM mix covering the cells was replaced by $1 \mathrm{~mL}$ of fresh complete DMEM. $200 \mu \mathrm{L}$ of MTS solution were added to each dish, followed by an incubation for $2 \mathrm{~h}\left(37^{\circ} \mathrm{C}, 5 \% \mathrm{CO}_{2}, 90 \%\right.$ humidity). Then, $120 \mu \mathrm{L}$ of each dish were transferred into one well of a 96-well-plate (Greiner bio-one, Frickenhausen, DE) and the absorption measured at $450 \mathrm{~nm}$ with an ELISA Reader (Tecan, Männdorf, DE). Simultaneously, with plasma-treated samples, untreated samples were prepared as negative control. These cells were treated exactly the sameway (washing with PBS, $1 \mathrm{~mL}$ PBS covering cells before $3 \mathrm{~mL}$ DMEM-13\%F was added) but without the plasma treatment. As positive control, cells were incubated in different concentrations of $\mathrm{H}_{2} \mathrm{O}_{2}$-solution in PBS (cf. 3.2.4).

To study the impact of reactive species or biologically active agents on plasma-induced cytotoxic effects, the same assay was performed in an indirect approach. Here, $1 \mathrm{~mL}$ of PBS solution was treated with plasma in a cell culture dish without cells. Afterwards, this PBS 
solution was added to cells for $5 \mathrm{~min}$. Then, $3 \mathrm{~mL}$ of fresh DMEM-13\%F was added to each dish.

\section{Analysis of MTS results}

The collected raw absorption data from the ELISA reader were first corrected for background fluorescence by subtracting the 'no-cell' control (absorption data of DMEM-13\%F and MTS solution alone) from all absorption values detected. All corrected data were averaged over the experiments and then normalized to the averaged negative control (untreated cells defined as $100 \%$ cell viability). Direct and indirect experiments were repeated for several times with following sample sizes:

- direct plasma treatment of GMs with $n=30$

- $\quad$ direct plasma treatment of PFs with $n=24$

- $\mathrm{H}_{2} \mathrm{O}_{2}$ treatments with $\mathrm{n}=24$

- $\quad$ indirect plasma treatment with $\mathrm{n}=18$

The standard deviation (SD) was calculated using Excel software (Microsoft Office 2010). Statistical analyses were performed with SigmaPlot 12.0 software. For all normally distributed datasets (Shapiro-Wilk with $P>0.05$ ), the one-sided t-test for two samples with unequal variance was used. If the normality test failed, the Mann-Whitney $U$ Test was used.

\subsubsection{Plasma-induced chemical changes in PBS (ROS, RNS, pH)}

The generation of reactive species in APP plays a major role for a lot of plasma-induced effects. Therefore, the production of certain reactive species was quantified in a plasma-treated PBS solution; $\mathrm{NO}_{2}{ }^{-}$and $\mathrm{NO}_{3}{ }^{-}$representative for $\mathrm{RNS}$ and $\mathrm{H}_{2} \mathrm{O}_{2}$ representative for ROS production. Furthermore, it was analyzed to which extent the $\mathrm{pH}$ of the solution changed after plasma treatments. $1 \mathrm{~mL}$ of PBS was treated with plasma in $35 \mathrm{~mm}$ cell dishes for same durations used in the MTS tests (cf. section above). Measurements of reactive species and $\mathrm{pH}$ changes in PBS using the $\mathrm{KINPen}^{\circledR}$ MED device were kindly performed for this thesis by Sander Bekeschus from the INP in Greifswald. For the use of the $\mu$ s-pulsed DBD, reactive species concentrations were measured by Joanna Hirschberg from the HAWK in Göttingen. The $\mathrm{pH}$ measurements after DBD treatments of PBS were performed by me with a $\mathrm{pH}$ meter (Lab pH Electrode LE438; Mettler-Toledo AG, Schwerzenbach, CH).

Sample sizes of these measurements are as follows:

- $\quad$ reactive species measurement after jet applications with $n=2$

- $\quad$ reactive species measurement after DBD applications with $n=6$

- $\quad \mathrm{pH}$ measurements after jet or DBD applications with $\mathrm{n}=2$ 


\subsubsection{Host cell reactivation assay}

The HCR assay is commonly used to quantify the relative DNA repair capacity of fibroblast cells of damaged reporter plasmid DNA. Simultaneously, genotoxic effects of substances or agents can be indirectly investigated with this method. The assay is based on the firefly plasmid, which includes a non-replicating reporter gene [145] coding for the firefly luciferase enzyme [144]. In this study, purified firefly plasmid DNA was dissolved in $\mathrm{ddH}_{2} \mathrm{O}$ and treated with plasma, UVC, or UVB radiation (cf. 3.4.3). Untreated or treated firefly plasmids were then co-transfected with renilla plasmids (coding for renilla luciferase) using the Attractene reagent (cf. 3.2.2). The co-transfection with renilla plasmid was required for normalization. After $72 \mathrm{~h}$ of incubation $\left(37^{\circ} \mathrm{C}, 5 \% \mathrm{CO}_{2}, 90 \%\right.$ humidity) cells were washed with PBS and lysed for $45 \mathrm{~min}$ at room temperature with $80 \mu \mathrm{L} /$ well of passive lysis buffer (included in the Dual-Luciferase Reporter Assay System; Promega, Mannheim, DE). Then, cells were scraped off and $40 \mu \mathrm{L}$ solution from each well were transferred to 96 well Glomax ${ }^{\mathrm{TM}}$ Micoplates (Promega, Mannheim, DE). The enzyme expressions of both luciferases were measured by the Glomax ${ }^{\top M}$ 96 Microplate Luminometer (Promega, Mannheim, DE) using substrates from the Dual-Luciferase Reporter Assay System. The device, one after another, adds $80 \mu \mathrm{L}$ of corresponding luciferase substrates for firefly (beetle luciferine) and renilla (coelenterazine) to each well and quantifies the luminescence as relative light units (RLUs). This represents the according enzyme activity.

\section{Analysis of HCR results}

To analyze the reporter gene expression of firefly luciferase, firefly RLU data within each experiment were first normalized to renilla RLU values by dividing firefly RLU values with RLU data of renilla within each well. Then, the values of these corrected data were averaged over same treatment modalities and converted into percent, whereby averaged RLUs of the untreated control plasmids were defined as $100 \%$. Finally, mean percent values of experiments were averaged.

The different treatment modalities included different sample sizes:

- $\quad$ jet applications of GMs with $n=12$

- $\quad$ jet applications of PFs with $n=9$

- DBD applications of GMs and PFs with $\mathrm{n}=15$

- UVC irradiations of GMs with $\mathrm{n}=15$

- UVC irradiations of PFs with $n=12$

- UVB irradiations of GMs and PFs with $n=12$

SD values were calculated (Excel; Microsoft Office 2010) and statistical analyses were done as previously described for the MTS analysis (cf. 3.5.1). 


\subsubsection{Plasmid Shuttle Vector assay}

The PSV assay was performed for a detailed analysis of plasma-induced mutagenic alterations and genotoxic effects. Here, the low-copy plasmid pSP189 (generous gift of Kenneth $\mathrm{H}$. Kraemer; National Cancer Institute, Bethesda, MD, USA), including the supF-tRNA gene and a signature sequence, was essential (Fig. 5).

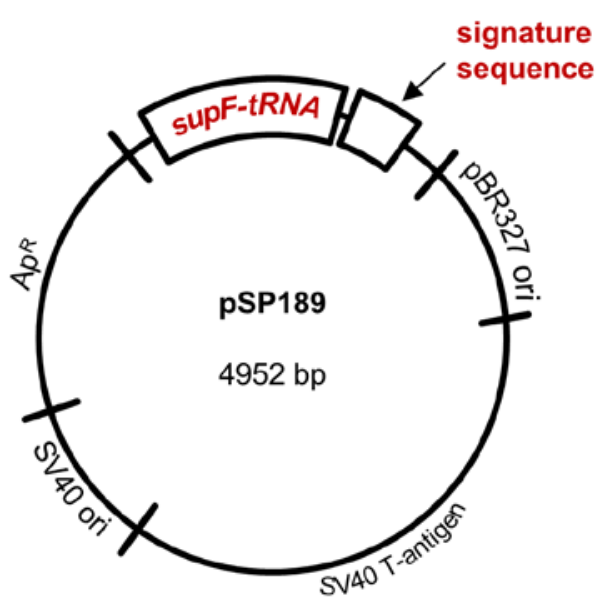

Figure 5: Scheme of the pSP189 plasmid

The plasmid includes an ampicillin resistance $\left(A p^{R}\right)$ for selective growing of successfully transformed bacteria, replication origins (ori) for bacterial and eukaryotic cells (SV40 ori and pBR327 ori, respectively), the supF-tRNA gene, and the signature sequence as most important units (after information given in Parris and Seidman [146]).

In the first phase of the PSV experiments, the origin of replication (ori) for eukaryotic cells is important. If plasma treatment - regardless of test version - destroys this gene, GM cells will not replicate the pSP189 vector. In the next step, plasmid DNA was isolated from GM cells (cf. 3.4.1). Due to enzymatic digestion with Dpnl (cf. 3.4.5), all plasmids that were originally used for transfection are destroyed. Thus, only plasmids that were replicated in the GM cells and later transformed into MLB100 bacteria, enable them to grow on plates. After transformation bacterial solutions had to be plated on ampicillin, X-Gal, and IPTG containing agar plates (cf. 3.3.6). The essential genetic sites on plasmids for bacterial growth at this point are the $A p^{R}$ and the pBR327ori for prokaryotic cells. Functional impairment of the $A p^{R}$ or the bacterial ori will prohibit the growth of MLB100 cells. X-Gal and IPTG are required for a classification of all grown colonies as mutated or non-mutated bacteria. The supF-tRNA gene (85 bp) enables the transcription of genes that carry the Amber-stop-codon [UAG] within their coding sequence [147]. An Amber-stop-codon mutation is located in the LacZ-gene of MLB100 cells that enables the bacteria to transcribe the gene. Thus, they can express the enzyme $\beta$ galactosidase. This enzyme digests the yellow dye X-Gal. The product of this process is the blue dye 5,5'-Dibromo-4,4'-dichloro-indigo and galactose. Thus, MLB100 cells will grow in blue colored colonies on agar plates containing X-Gal. However, the supF-tRNA is very sensitive; only a single point mutation in this gene may lead to a severely restricted enzyme expression or even to the total loss of the expression function. MLB100 cells with a mutation in the supFtRNA gene will grow in white colonies because the X-Gal dye cannot be digested anymore; this is called blue/white selection. 
Following the blue/white-selection, the plasmid was isolated again and used for sequence analysis. It may happen that white colonies growing in close vicinity are clones carrying the same mutation. To identify such clones the signature sequence located next to the supF-tRNA is required. If the same mutation was found in two colonies with equal signature sequences, this implies that both mutations originated from the same bacterium. In turn, if the same mutations were found, but the signature sequences were different, this indicates an independent manifestation of the same mutation. In other words, this allows for a distinction between sibling and independent mutations.

Originally, the pSP189 vector contains an $8 \mathrm{bp}$ long signature sequence [146]. This sequence is characterized by a highly variable sequence. However, the here used plasmid carries an $18 \mathrm{bp}$ long signature sequence that leads to an even higher sequence variability. Theoretically, $4 \cdot 10^{18}$ different signature sequences are possible and, thus, 68 billion different plasmids can be discriminated from each other. The chance for a false positive classification of two equal mutation events is, therefore, very low. Nonetheless, the variability of the signature sequence was proved by creating a library (cf. appendix II).

The assay was performed in two different versions (Fig. 6) with following plasma treatment durations and according plasma doses: KINPen ${ }^{\circledR}$ MED applications for 10,30 , and $60 \mathrm{~s}(\bumpeq 31$, 92, and $184 \mathrm{~J} / \mathrm{cm}^{2}$ ) and $\mu$ s-pulsed DBD treatments for 10,60 , and $270 \mathrm{~s}(\hat{=} 4,23$, and $103 \mathrm{~J} / \mathrm{cm}^{2}$ ).

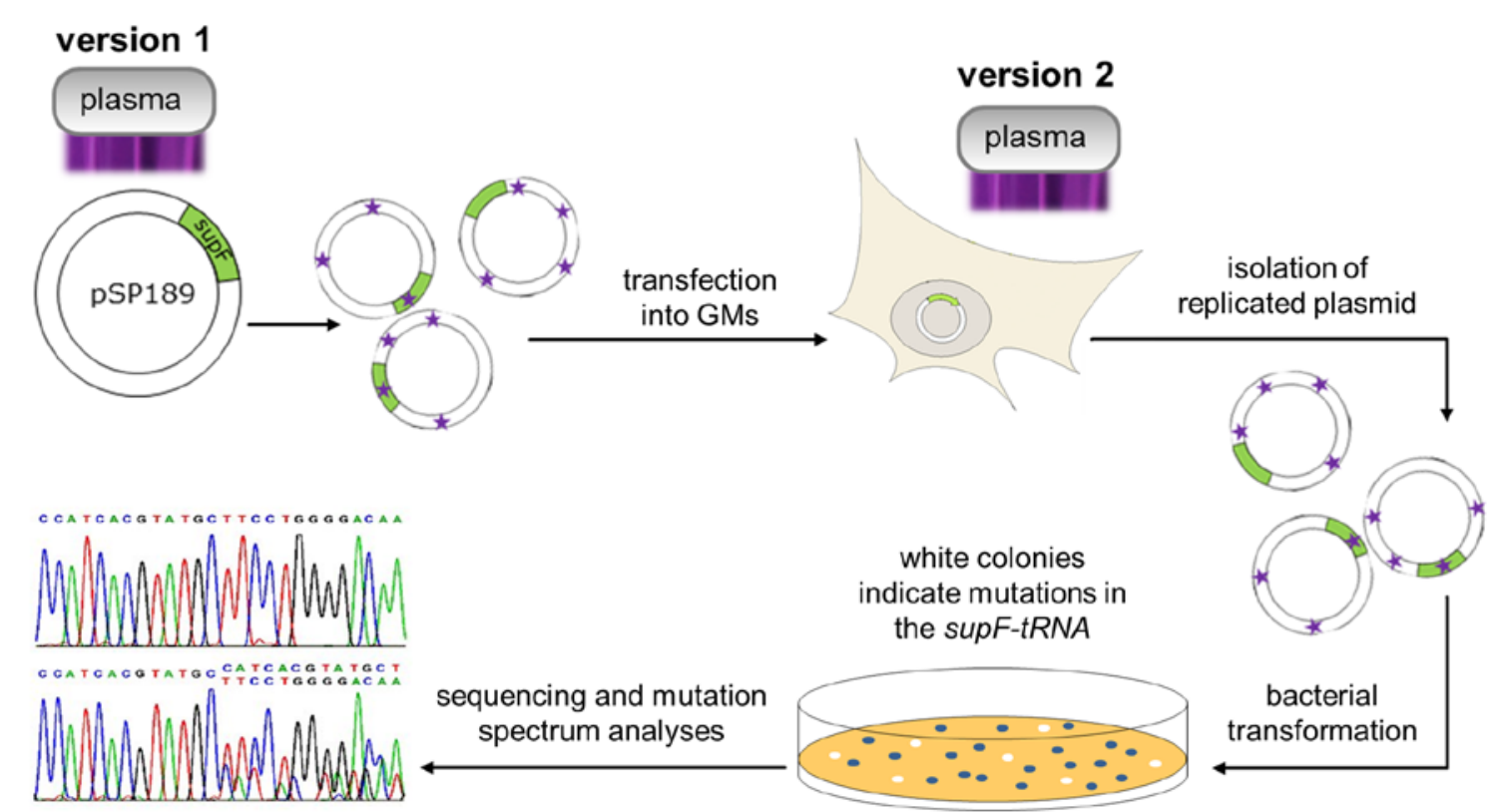

Figure 6: Schematic illustration of the two versions of the PSV assay

In version 1 pSP189 solutions were plasma treated and then transfected into GMs. In version 2, GMs were transfected with untreated pSP189 and then treated with plasma. Following steps were equallyperformed for both versions: Plasmids were isolated from cells and transformed into MLB100. Bacteria carrying a mutation (purple asterisks) in the supF-tRNA gene (marked in green) will grow as white colonies when plated. Blue colonies indicate non-mutated supF-tRNA. In the following analysis steps a mutation spectrum can be generated. 


\section{Version 1}

In this version the plasmid DNA was first treated with APP and, as positive control, with $75 \mathrm{~mJ} / \mathrm{cm}^{2}$ UVC (cf. 3.4.3). Then, pSP189 was transfected into GM cells (cf. 3.2.2), and incubated for $72 \mathrm{~h}\left(37^{\circ} \mathrm{C}, 5 \% \mathrm{CO}_{2}, 90 \%\right.$ humidity). Afterwards, plasmids were isolated from the fibroblasts (cf. 3.4.1) and all following steps performed as described below.

\section{Version 2}

Untreated pSP189 DNA was transfected into GM cells (cf. 3.2.2) and incubated for $72 \mathrm{~h}\left(37^{\circ} \mathrm{C}\right.$, $5 \% \mathrm{CO}_{2}, 90 \%$ humidity). Then, the cells were exposed to the jet and $\mu \mathrm{s}$-pulsed DBD plasma. As positive control, the cells were exposed to UVC radiation at different doses (cf. 3.2.3). Fibroblasts were then incubated for $48 \mathrm{~h}$ before plasmids were isolated (cf. 3.4.1).

\section{Preparation of plasmid DNA and blue/white selection of MLB100}

After isolation of pSP189 from GM cells, the samples had to be digested with Dpnl to degrade all originally transfected plasmid DNA (cf. 3.4.5). Afterwards, transformation of MLB100 cells was carried out using $50 \mathrm{ng}$ of isolated plasmid DNA (cf. 3.3.5). On the next day, all colonies on the agar plates were counted and white colonies picked with toothpicks. $25 \mu \mathrm{L}$ of $\mathrm{ddH}_{2} \mathrm{O}$ were inoculated with a single picked colony by shaking the toothpick in the water. The same toothpick was also tapped once on a new, separate agar plate containing IPTG, X-Gal, and ampicillin to create a backup plate.

\section{Polymerase chain reaction}

The PCR technique was first described by Mullis et al. [148] and used for the amplification of specific DNA sequences. It is based on three steps that are repeated for several times; in so called cycles: 1. denaturation (DNA strand separation), 2. primer annealing, and 3. elongation. Each PCR cycle starts with heating the samples to initiate denaturation of the template DNA from double stranded DNA (dsDNA) to single stranded DNA (ssDNA). Complementary oligonucleotides bind to these templates creating free 3 '-OH ends at ds-ssDNA junctions (annealing). In the last step (elongation) a thermally stable polymerase synthesizes the new DNA strand by adding dNTPs in 5' to 3' direction complementary to the template strand. These steps are repeated about 30-40 times by which the DNA is exponentially amplified after the 2nd cycle. 


\section{Colony PCR premix for one sample $(25 \mu \mathrm{L})$ :}

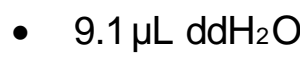

- $4 \mu \mathrm{L}$ of $25 \mathrm{mM} \mathrm{MgCl}_{2}$ (Merck, Darmstadt, DE)

- $1 \mu \mathrm{L}$ of $10 \mathrm{mM}$ dNTPs (Thermo Scientific, Braunschweig, DE)

- $2 \mu \mathrm{L}$ of 10 pmol fPrimer (forward primer; cf. appendix I.8)

- $2 \mu \mathrm{L}$ of 10 pmol rPrimer (reverse primer; cf. appendix I.8)

- $1.5 \mu \mathrm{L}$ DMSO (Sigma-Aldrich, München, DE)

- $\quad 0.4 \mu \mathrm{L}$ Taq DNA polymerase (Thermo Scientific, Braunschweig, DE)

- $5 \mu \mathrm{L} 10 \mathrm{x}$ Buffer with $\mathrm{KCl}$ (supplied with Taq DNA polymerase)

Prior to starting the colony PCR, inoculated bacterial solutions were incubated at $95^{\circ} \mathrm{C}$ for $5 \mathrm{~min}$ to denature the cell material. Then, the PCR premix was added to the samples (total volume: $50 \mu \mathrm{L}$ ) and the following PCR program started (Arktik Thermal Cycler; Thermo Scientific, Waltham, US).

Colony PCR cycler program:

0 . initial denaturation $95^{\circ} \mathrm{C}, 5 \mathrm{~min}$

1. denaturation $95^{\circ} \mathrm{C}, 3 \mathrm{~min}$

2. denaturation $95^{\circ} \mathrm{C}, 30 \mathrm{~s}$

3. primer annealing $55^{\circ} \mathrm{C}, 20 \mathrm{~s}$

4. elongation $72^{\circ} \mathrm{C}, 40 \mathrm{~s}$

5. remaining elongation $72^{\circ} \mathrm{C}, 5 \mathrm{~min}$

To check for successful PCR products, some samples were separated via gel electrophoresis in $1 \%$ agarose gels. For this, $7.5 \mu \mathrm{L}$ of the PCR product and $2.5 \mu \mathrm{L} 6 \mathrm{x}$ DNA loading dye were mixed and loaded into the gel. Simultaneously, $5 \mu \mathrm{L}$ of $100 \mathrm{bp}$ ladder solution were loaded to verify fragmentation sizes. PCR products showing bands at about 500 bp were further used because fPrimer and rPrimer restrict the length of the amplified sequence to $493 \mathrm{bp}$.

\section{Purification of PCR products and sequence analysis}

Cleaning of PCR products from remaining dNTPs and primers was done with Exo-SAP-mix digestion (cf. 3.4.5). Afterwards, another PCR step was done with dideoxyribonucleotide triphosphates (ddNTPs) that are labeled with four different fluorescent dyes. The ddNTPs lack the 3' hydroxyl group, which makes them deficient in polymerization. If one of the four ddNTPS (i.e. ddATP, ddCTP, ddGTP, or ddTTP) is incorporated during the PCR reaction, the chain elongation stops at this point [149]. Consequently, this results in products with different sequence lengths that terminally carry one of the four ddNTP with specific fluorescence markers. The BigDye ${ }^{\circledR}$ Terminator v3.1 Cycle Sequencing Kit (Life technologies, Darmstadt, 
DE) was used according to manufacturer's instructions (except for the volume of Big Dye reaction mix with only $1 \mu \mathrm{L})$.

BigDye reaction mix $(10 \underline{\mu L})$ :

- $7 \mu \mathrm{L}$ digested solution

- $\quad 0.5 \mu \mathrm{L}$ of 5 pmol sPrimer (sequencing primer; cf. appendix I.8)

- $1 \mu \mathrm{L} 10 x$ Buffer (3.1 Seq. Kit)

- $1 \mu \mathrm{L}$ BigDye Ready Reaction Mix (3.1 Seq. Kit)

- $0.5 \mu \mathrm{L} \mathrm{ddH} \mathrm{H}_{2} \mathrm{O}$

\section{Cycling reaction program:}

0 . initiate denaturation

$95^{\circ} \mathrm{C}, 1 \mathrm{~min}$

1. denaturation

$95^{\circ} \mathrm{C}, 15 \mathrm{~s}$

2. primer annealing

$55^{\circ} \mathrm{C}, 20 \mathrm{~s}$

3. elongation

$72^{\circ} \mathrm{C}, 4 \mathrm{~min}$

After this cycling reaction step, the DNA products were purified with sodium acetate. Therefore, $10 \mu \mathrm{L}$ of $3 \mathrm{M}$ sodium acetate $(\mathrm{pH}: 5.6)$ and $250 \mu \mathrm{L}$ ethanol (96\%) were pipetted into a reaction tube. $10 \mu \mathrm{L}$ of the cycling product were mixed with $90 \mu \mathrm{L} d \mathrm{dH}_{2} \mathrm{O}$ and also added to this reaction tube. The solution was vortexed and incubated for $10 \mathrm{~min}$ on ice. Then, products were precipitated by a $30 \mathrm{~min}$ centrifugation at $13000 \mathrm{rpm}$ (Hereaus Megafuge 1.0R; Thermo Scientific, Schwerte, DE). The supernatant was discarded, the pellet dissolved in $300 \mu \mathrm{L} 70 \%$ ethanol, again centrifuged (10 min at $13000 \mathrm{rpm})$, and the supernatant discarded. For drying, the reaction tubes were placed on a thermoblock for 10 to $30 \mathrm{~min}$ at $37^{\circ} \mathrm{C}$. Finally, the products were vortexed with $10 \mu \mathrm{L} \mathrm{Hi-Di} \mathrm{Formamide} \mathrm{(Applied} \mathrm{Biosystems,} \mathrm{Foster} \mathrm{City,} \mathrm{US)} \mathrm{and} \mathrm{stored}$ at $-20^{\circ} \mathrm{C}$. The color codes of all DNA sequences were then analyzed by automatic separation of the products through capillary gel electrophoresis. The four different fluorescent ddNTPs were photometrically measured with a genetic sequence analyzer (3100-Avant Genetic Analyzer; Applied Biosystems, Foster City, US).

\section{Analysis of PSV results}

a) First, the total number of colonies was counted on each agar plate (CFU). The averaged CFU data from negative control plates (bacteria were transformed with untreated plasmid or plasmids were isolated from untreated GM cells) were defined as $100 \%$. All other averaged CFU data from plasma treatments or UVC irradiations were normalized to the negative control. Untreated controls represent the overall transformation efficiency of intact plasmids. Damaged plasmids in which the eukaryotic ori is destructed GM cell are not able to replicate the plasmid leading to the loss of the plasmid for the assay. If the bacterial ori or ampicillin resistance is 
impaired on the plasmid MLB100 cannot grow on agar plates. Therefore, CFU values represent the overall genotoxicity of the respective treatment modality.

b) The ratio between white and total CFU numbers on an agar plate represents the mutation frequency, thus, the mutagenicity of the underlying treatment modality. The spontaneous mutation frequency was calculated with CFU data of negative control plates. For version 1 , the mutation frequency of plasma- or UVC-treated pSP189 DNA solutions were calculated, and for version 2 the mutation frequency of plasma- or UVC-treated GM cells carrying untreated pSP189 plasmids were calculated. Resulting mutation frequencies were averaged over all successful experiments.

c) Mutation spectra were generated with all white colonies that were picked from the agar plates. Sequences were aligned to the original sequence of the supF-tRNA and the signature sequence with the software Chromas Lite 2.1 and the online tool MultAlin to reveal individual changes in genotypes of supF-tRNA and the signature sequence. Calculations of relative CFU values and mutation frequencies for version 1 and 2 of the PSV assay were based on different sample sizes.

Sample sizes of CFU values and mutation frequencies in version 1:

- $\quad$ negative control with $n=12$

- jet applications with $n=13$

- DBD applications with $\mathrm{n}=13$

- UVC $\left(75 \mathrm{~mJ} / \mathrm{cm}^{2}\right)$ with $\mathrm{n}=12$

Sample sizes of CFU values and mutation frequencies in version 2:

- $\quad$ negative control with $\mathrm{n}=14$

- jet applications with $n=8$

- $\quad$ DBD applications with $\mathrm{n}=6$

- UVC $\left(2.5 \mathrm{~mJ} / \mathrm{cm}^{2}\right)$ with $\mathrm{n}=4$

- $\quad$ UVC $\left(5 \mathrm{~mJ} / \mathrm{cm}^{2}\right)$ with $\mathrm{n}=8$

- $\quad$ UVC $\left(7.5 \mathrm{~mJ} / \mathrm{cm}^{2}\right)$ with $\mathrm{n}=10$

SD values were calculated with Excel (Microsoft Office 2010). Statistically significant differences were tested as described before with the SigmaPlot 12.0 software (cf. 3.5.1). 


\subsubsection{Flow cytometry assay}

To study the formation of DSBs induced by plasma treatments, flow cytometric analyses were performed based on phosphorylated H2A.X ( $Y-H 2 A . X)$ stain.

In practice, a cell suspension is swept away with a rapidly streaming liquid through a thin channel inside the flow cytometer. Inside the channel, one cell after another passes a laser, that excites every single cell. The emission is detected by the forward scatter detector. Simultaneously, side scatter detectors record fluorescent emission wavelengths and intensities (Fig. 7).

Thus, every cell in the flow channel, which was detected by the forward scatter detector, will be classified and counted as a distinct event with a specific emission. Furthermore, the liquid stream running through the flow channel is vibrated, which causes the stream to break into single droplets at the end of the channel. Because of this, each droplet carries only one cell in the ideal case. At this point a negative or positive charge is applied to each droplet depending on its fluorescence. Thus, droplets are diverted according to their charges into different vessels.

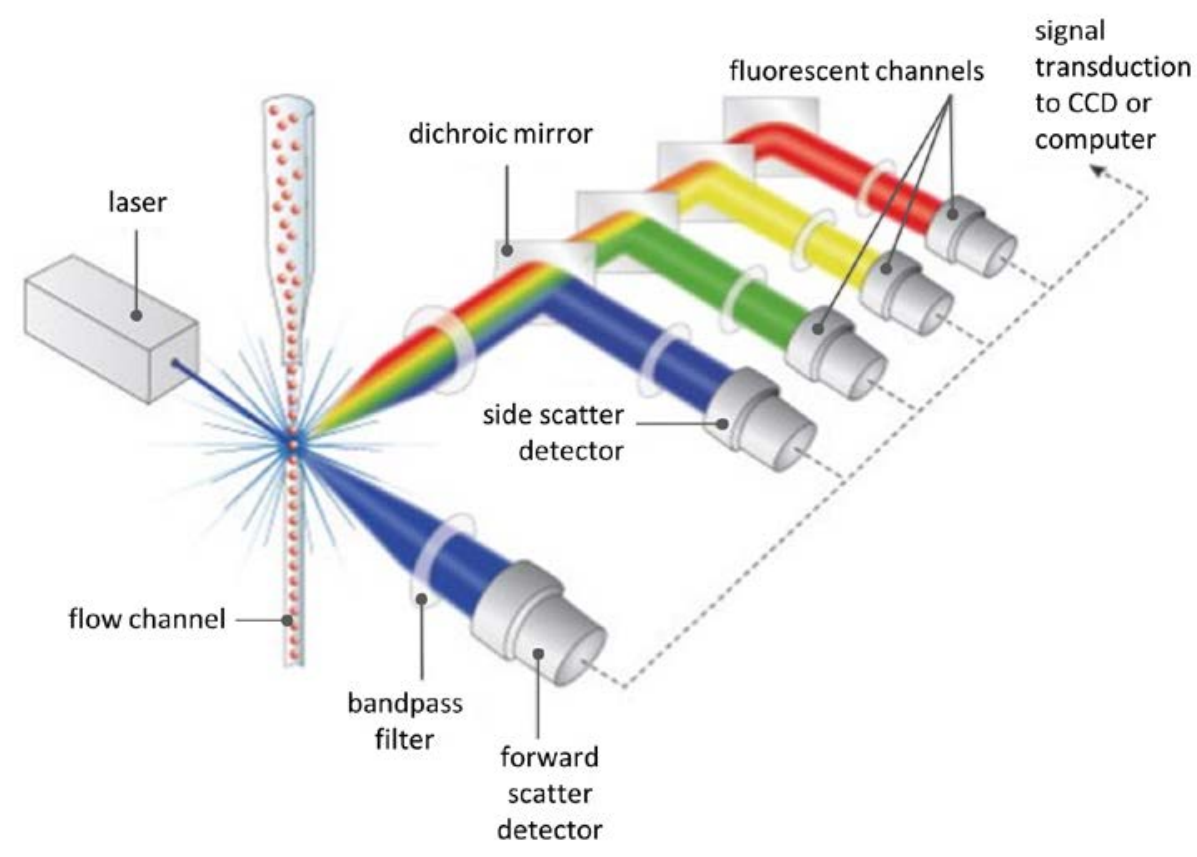

Figure 7: Scheme of laser and light pathways in a flow cytometric device

The scheme shows the laser and light pathways through the flow channel and towards the scatter detectors in a FACS device (modified after https://www.sem rock.com/flow-cytometry.aspx[150]).

\section{Measurements of $\mathrm{Y}-\mathrm{H} 2 \mathrm{~A} . \mathrm{X}$ fluorescence signals}

In these experiments, $Y-H 2 A . X$ histone proteins were detected as DSB markers [151]. The $\mathrm{Y}-\mathrm{H} 2 \mathrm{~A} . \mathrm{X}$ antibody binds to the phosphorylated H2A.X protein that is one variant of the $\mathrm{H} 2 \mathrm{~A}$ histone core protein. Together with other histone core proteins (i.e. $\mathrm{H} 2 \mathrm{~B}, \mathrm{H} 3$, and $\mathrm{H} 4$ ), $\mathrm{H} 2 \mathrm{~A}$ forms the basic element of DNA packaging in eukaryotes, the nucleosome complex [152]. 
Phosphorylation of H2A.X on Ser139 takes place immediately after SSB or DSB events occur and a single DSB can lead to hundreds and thousands of phosphorylated H2A.X proteins [153, 154]. Nevertheless, in normal cells, which are in the G1 phase of their cell cycle, constitutive or intrinsic H2A.X phosphorylation was found. Moreover, cells in their S- and G2/M-phase of the cell cycle exhibit higher levels of $\mathrm{Y}-\mathrm{H} 2 \mathrm{~A} . \mathrm{X}$ than cells in $\mathrm{G} 1$ phase [155].

Cells were first seeded in culture dishes followed by the plasma treatment on the next day (cf. 3.2.3). Afterwards, cells were incubated for $24 \mathrm{~h}\left(37^{\circ} \mathrm{C}, 5 \% \mathrm{CO}_{2}, 90 \%\right.$ humidity) and collected by adding $500 \mu \mathrm{L}$ Accutase to each dish ( $5 \mathrm{~min}, 37^{\circ} \mathrm{C}, 5 \% \mathrm{CO}_{2}, 90 \%$ humidity) and pipetting the cell solution into a new reaction tube. The culture dish was rinsed with $500 \mu \mathrm{L}$ of PBS and this was also transferred to the same reaction tube. The cell solutions were then centrifuged at $1200 \mathrm{rpm}$ (Hereaus centrifuge) for $15 \mathrm{~min}$, the supernatant discarded, and cells re-suspended in $500 \mu \mathrm{L}$ of $3.7 \%$ paraformaldehyde (PFA; cf. appendix I.5) on a vortexer for fixation. Again, the cells were centrifuged ( $2400 \mathrm{rpm}$ for $15 \mathrm{~min}$ ) and the supernatant removed. Then, the cells were permeabilized and unspecific binding sites of the antibody blocked by incubation with $500 \mu \mathrm{L}$ of the Per/Block-solution (cf. appendix 1.5) for $30 \mathrm{~min}$ at $37^{\circ} \mathrm{C}$. The primary antibody, anti-phospho H2A.X (cf. appendix I.6; Dianova, Hamburg, DE), was added to the Per/Block solution at a ratio of 1:4000 (1:100 prediluted in PBS containing 5\% FBS) and incubated for $1 \mathrm{~h}$ at $37^{\circ} \mathrm{C}$. Subsequently, $500 \mu \mathrm{L}$ of PBS-Tween solution (cf. appendix I.5) were added to the cell solution to remove unbound antibody proteins. This was followed by centrifugation (2400 rpm, $15 \mathrm{~min}$ ) and removing of the supernatant. The secondary antibody, Alexa-Fluor $^{\circledR} 488$ (cf. appendix 1.6; Dianova, Hamburg, DE) was diluted to 1:400 in PBS containing $5 \%$ FBS. Cells were then re-suspended in $500 \mu \mathrm{L}$ of the second antibody solution and incubated for $30 \mathrm{~min}$ at $37^{\circ} \mathrm{C}$. Again, $500 \mu \mathrm{L}$ of PBS-Tween solution was added and gently mixed before samples were centrifuged ( $2400 \mathrm{rpm}$ for $15 \mathrm{~min}$ ) and the supernatant discarded. Finally, cells were re-suspended in $500 \mu \mathrm{L}$ PBS and the samples were analyzed with a BD FACS device (BD FACS Canto ${ }^{\mathrm{TM} I l ;}$ BD Bioscience, Heidelberg, DE).

In addition to plasma-treated samples, cell suspensions were prepared for positive and negative controls. Cells were exposed to X-rays with 1, 3, 5, 7, and 9Gy (cf. 3.2.4) as positive control for induced DSB events. Untreated samples were the negative control. Moreover, each experiment included one unstained control, one sample stained with an $\lg _{1}$ isotype antibody (cf. appendix I.6; Dianova, Hamburg, DE) instead of the primary antibody (-1AB), and one sample without the secondary antibody $(-2 A B)$ as control for the binding specificity of the antibodies.

\section{Analysis of flow cytometry results}

The sum of the fluorescent signals of the $-1 A B$ and $-2 A B$ controls was subtracted from the unstained control, which represents the background fluorescence of $\mathrm{Y}-\mathrm{H} 2 \mathrm{~A}$.X proteins in $\mathrm{GM}$ 
cells. This value was also subtracted from all the other recorded values (treated samples with plasma or X-rays) within the same experiment. Data corrected in this way, were then averaged across all experiments and the treated samples normalized to the negative control (defined as 1). Overall, $\mathrm{Y}-\mathrm{H} 2 \mathrm{~A} . \mathrm{X}$ fluorescence signals measured for each sample correspond to the number of DNA strand breaks generated by plasma or X-ray treatments. Data of four experiments with different sample sizes for varying treatment modalities were analyzed:

- $\quad$ negative control with $n=21$

- $\quad$ jet applications with $n=15$

- $\quad$ X-ray irradiations with $\mathrm{n}=6$

SD values were calculated and statistically significant differences tested as described before (cf. 3.5.1). 


\section{Results}

In this study, test systems are presented, which are suitable for a basic evaluation of APP sources regarding their physical and biomedical performances. These will help to assess risk factors of plasma sources intended for medical use. Furthermore, test systems are presented to determine the genotoxic and mutagenic potential of medical plasma devices to assess possible long-term effects. One of the key challenges was to find suitable assays, which can be adjusted to a wide range of different APP devices, to ensure comparability of results. Therefore, two devices, a plasma jet type and a volume DBD device, were used. Moreover, since another focus in this project was on dermatological applications, human skin fibroblasts were chosen as target cells.

The first section of this chapter presents experiments suited for a first, general characterization of medical plasma sources based on our published DIN-SPEC 91315 [11]. This is the first document that defines standards and plasma specific criteria for the general use of plasma devices as medical tool. However, certain data (i.e. measurements of physical efficiencies of the plasma sources, inhibition zone tests, and reactive species generation in PBS) had to be obtained by others during the close collaboration works with the INP and the HAWK. These data are presented in this chapter because they are necessary for comprehensive analyses of plasma-cell interactions.

Descriptions of experimental procedures are only given in the materials and methods part if the respective test systems were established and used by myself. Otherwise, detailed information about methods, techniques, and assays were already published in collaboration with the INP (KINPen ${ }^{\circledR}$ MED source; joint first authorship Mann and Tiede et al. [138]) and with the HAWK ( $\mu$ s-pulsed DBD; joint first authorship Tiede and Hirschberg et al. [47]). Physical performance data and their safety in use are also discussed for both plasma sources in this chapter.

The second part of this chapter presents biological test systems to evaluate the genotoxic and mutagenic potential of APP. This represents an important additional step towards a detailed characterization of medical plasma sources, which may predict their best therapeutic use.

\subsection{Basic characterization of medical plasma sources}

\subsubsection{Physico-technical characterization of APPs and safety in use}

The physico-technical characterization of both APP sources was based on plasma specific parameters described in the DIN-SPEC 91315: electric current, plasma temperature, generation of artificial optical radiation, and emission of potentially unhealthy gases. 


\section{Mean power, maximum and mean discharge current}

Based on previously presented physical parameters of both plasma devices (cf. 3.1) mean power, voltage, and maximum discharge current were measured.

Applications with the kINPen ${ }^{\circledR}$ Med device are usually performed in the way that the tip of the effluent is touching the surface to be treated; that is about $8 \mathrm{~mm}$ from the nozzle of the device to the treatment object. This also represents the application-oriented working distance $[138$, 156]. Consequently, the interaction or exposure area on the treatment object is about $5 \mathrm{~mm}^{2}$ (Fig. 4a). A relatively constant mean power of $145-160 \mathrm{~mW}$ and a current of about $50 \mu \mathrm{A}$ were measured at the tip of the plasma jet [138]. According to the DIN EN 60601-1 (Medical electric equipment - Part 1) the KINPen $^{\circledR}$ MED device was proven to be safe with the here presented configurations $[138,156]$.

For the $\mu \mathrm{s}$-pulsed DBD device a mean power of $274-324 \mathrm{~mW}$ and a maximum discharge current of $470 \mathrm{~mA}$ were measured, the latter of which is only reached for a few nanoseconds. As described in Tiede et al. [47], the mean discharge current averaged across one pulse ('plasma-on' time: $70 \mu \mathrm{s}$ ) is below $10 \mathrm{~mA}$. According to the assumption that no current is flowing during the 'plasma-off' time within one period, the current averaged over one period is $\sim 0.2 \mathrm{~mA}$. In medical therapies electric currents are widely used; e.g. during iontophoresis therapy continues currents of $170 \mathrm{~mA}$ are used [157]. Therefore, the averaged period current of $0.2 \mathrm{~mA}$ is much lower and, thus, no harm is to be expected from discharge current of the DBD device.

In order to achieve comparability on the basis of the energy densities generated by the two sources in addition to the comparison based on treatment durations, energy densities of both sources were calculated for $1 \mathrm{~s}$ of treatment duration. For the kINPen ${ }^{\circledR}$ MED an energy density of about $3.1 \mathrm{~J} / \mathrm{cm}^{2}$ was calculated with $153 \mathrm{~mW}$ mean power and the exposure area of approximately $5 \mathrm{~mm}^{2}$. The energy density of the DBD plasmais about $0.4 \mathrm{~J} / \mathrm{cm}^{2}$ calculated with the mean power of $299 \mathrm{~mW}$ and an exposure area of $78.54 \mathrm{~mm}^{2}$ (diameter of electrode: $10 \mathrm{~mm}$ ). For extended treatment durations these factors were simply multiplied with the according treatment time.

However, it has to be explained, that this comparison is not ideal. During plasma jet treatments of cells or solutions in petri dishes a PBS-free area is generated centrally above the jet device. In addition, a turbulence is produced so that the PBS is moving as swirl in the dish during application. This would mean that exclusively the center of the petri dish will be exposed to an energy density of $3.1 \mathrm{~J} / \mathrm{cm}^{2}$ but the surrounding regions will only be treated indirectly. In case of $\mu$ s-pulsed DBD treatment, the petri dish was horizontally moved in an orbital motion with $40 \mathrm{rpm}$ under the dielectrically covered electrode to obtain the largest exposure area possible. This means that locally seen even less than $0.4 \mathrm{~J} / \mathrm{cm}^{2}$ is applied. 
Since it is very difficult to comprehend which plasma components act with which energy in which area of the petri dish and, thus, the actual energy density applied to cells or solutions cannot be calculated exactly, results of biological assays were compared on the basis of the above calculated, but simplified energy densities.

\section{Gas temperature and thermal output}

For dermatological applications, APP temperature should not exceed $40^{\circ} \mathrm{C}$ since thermal damage of cells, lipids, proteins as well as skin burns should be avoided. The temperature profile of the kINPen ${ }^{\circledR}$ MED plasma was measured using a fiber optic temperature sensor in the axial direction of the visible effluent (Fig. 8). Directly at the nozzle, jet temperature is about $49^{\circ} \mathrm{C}$, but decreases with distance from the nozzle. At the tip of the visible plasmajet $(7-10 \mathrm{~mm}$ from the nozzle), the temperature already fell to around $35-40^{\circ} \mathrm{C}$. Moreover, during medical applications, the device would rather be moved across the treatment area than being held above the same point. Slow movements of the jet decrease heat absorption by the skin. Thus, burns can be completely avoided when the jet is moved across the treatment area at the recommended working distance.

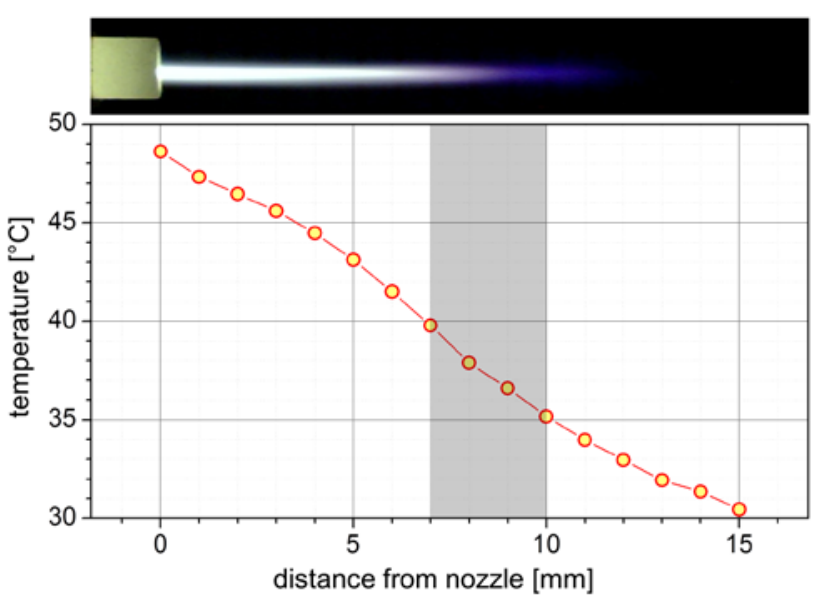

Figure 8: Axial temperature profile of the KINPen ${ }^{\circledR}$ MED

With increasing distance from the nozzle, plasma temperature decreases. At the tip of the effluent (grey area; also: working distance) temperaturesare between 35 and $40^{\circ} \mathrm{C}$ (modified after Bussiahn et al. [156]).

Plasma temperature of the $\mu$ s-pulsed DBD were measured with two different techniques. As for the plasma jet, an optical fiber was held into the discharge for measuring gas temperature. About $300 \mathrm{~K}\left(26.85^{\circ} \mathrm{C}\right)$ could be detected [47]. This technique is sufficient for measuring the temperature of plasma jet devices since the optical fiber does not influence the process of plasmaignition. In the case of a direct DBD, holding a fiber into the discharge gap alters plasma generation. That is why gas temperature was also indirectly determined by optical emission spectroscopy (OES). Maximum and mean gas temperature calculated from the emission spectra were about $380 \mathrm{~K}\left(\sim 107^{\circ} \mathrm{C}\right)$ and $310 \mathrm{~K}\left(\sim 36.85^{\circ} \mathrm{C}\right)$. It has to be mentioned that the maximum gas temperature only is reached for a few microseconds (within a pulse duration: $70 \mu \mathrm{s})$ and also limited to the microdischarge volume [158]. Additionally, within some milliseconds the temperature declines to almost room temperature through heat transfer to the surrounding neutral gas [159]. Furthermore, with another but very similar DBD and a related 
setup, sample heating was analyzed. This revealed that one minute of plasma treatment only marginally increased sample temperatures [160]. Hence, no thermal injury is to be expected from applications with the $\mu$ s-pulsed DBD.

\section{Optical artificial radiation (UV radiation)}

UV radiation generated by plasma represents a serious risk factor since too long exposures of the skin to UV radiation are attributed to aging and wrinkle formation, can cause sunburns or, in the worst cases, skin cancer $[12,13,15,16,161,162]$. With the OES technique, emission bands in the UV range were detected for both sources. The calculation of the effective irradiance produced by the $\mathrm{kINPen}^{\circledR}$ MED was based on measurements with a calibrated optic spectrometer system [138]. The spectral irradiance of the $\mu$-pulsed DBD plasma was calculated after detection of the irradiance with a calibrated radiometer [160].
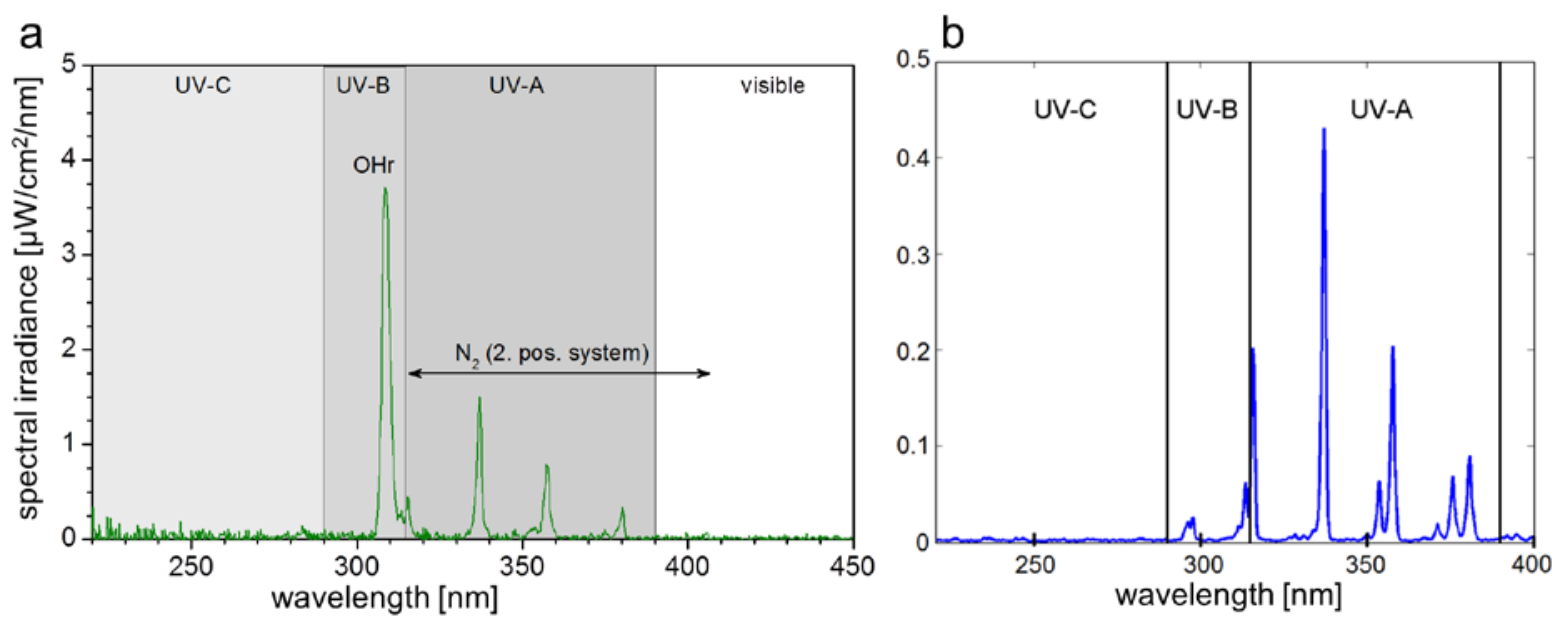

Figure 9: Spectral irradiance of the two plasma sources

The spectral irradiance measured in the UV range is shown for the kINPen ${ }^{\circledR}$ MED (a; modified after Bussiahn etal. [156]) and the $\mu$ s-pulsed DBD (b; after data provided by Joanna Hirschberg). Please note that the $y$-axes are differently scaled in figure (a) and (b).

The results showed that no radiation in the UVC region $(200-280 \mathrm{~nm})$ was generated by either of the two APP devices $[47,138]$. However, the plasma jet produced one emission peak of $\mathrm{OH}$ radicals in the UVB region $\left(\mathrm{OHr}\right.$ at $309 \mathrm{~nm}$; Fig. 9a) and three peaks of $\mathrm{N}_{2}$ molecules in the UVA range (Fig. 9a). In case of the $\mu$ s-pulsed DBD, mainly $\mathrm{N}_{2}$ peaks in the UVA region were detected (at $315.6 \mathrm{~nm}, 337 \mathrm{~nm}$, and $357.6 \mathrm{~nm}$ ) and only small emission peaks in the UVB region (Fig. 9b).

The plasma jet device KINPen $^{\circledR}$ MED driven with argon gas demonstrable generates vacuum UV (VUV) radiation [156]. Due to the jet flow rate of $5 \mathrm{slm}$, an optical light path is produced, through which VUV radiation can likely reach the treatment object. Argon shows two intensive emission lines in the VUV region at $104.8 \mathrm{~nm}$ and 106.7 nm [163]. In Bussiahn et al. [156] the maximum effective irradiance of the kINPen ${ }^{\circledR}$ MED plasma in the range of $100-400 \mathrm{~nm}$ was measured to be $35 \pm 5 \mu \mathrm{W} / \mathrm{cm}^{2}$, thus the two highest resonance lines of argon were taken into 
account. As described in Mann et al. [138], if one imagine that a surface of $1 \mathrm{~cm}^{2}$ should be treated with the plasma jet that has an exposure area of $5 \mathrm{~mm}^{2}$, the jet must be hold onto 20 surface points, separately. For a total treatment duration of $60 \mathrm{~s}$ this would lead to an exposure time of $3 \mathrm{~s}$ for every surface point. Consequently, the effective irradiation for every $3 \mathrm{~s}$ contact point can be calculated and is about $105 \mu \mathrm{J} / \mathrm{cm}^{2}$. The International Commission on Nonlonizing Radiation Protection (ICNIRP) defines a maximum radiation dose of $3 \mathrm{~mJ} / \mathrm{cm}^{2}$ in the range of $180-400 \mathrm{~nm}$ as the daily limit for UV exposure of sensitive skin phototypes [164]. Therefore, the effective irradiance of the plasma jet is lower than the irradiation safety value and, thus, safe regarding UV radiation [138]. The other way round, it can be said that one surface point of $5 \mathrm{~mm}^{2}$ can be treated for about $85 \mathrm{~s}$ before reaching the threshold value of the ICNIRP. Certainly, this should be considered when using the kINPen ${ }^{\circledR}$ MED plasma on human skin.

Helmke et al. [165] presented a study with a very similar DBD device and similar experimental configuration as used during this project, where maximal exposure durations of plasma on the human skin were calculated. Results showed that the ICNIRP limit of $3 \mathrm{~mJ} / \mathrm{cm}^{2}$ was reached after $7 \mathrm{~h}$ of plasma treatment. The effective irradiance of $0.12 \mu \mathrm{W} / \mathrm{cm}^{2} \mathrm{can}$, thus, be calculated. In the practical medical use treatment durations of $7 \mathrm{~h}$ are most unlikely, one would rather expose the skin for some seconds or minutes (e.g. $10 \mathrm{~min} \hat{=} 72 \mu \mathrm{J} / \mathrm{cm}^{2}$ ). Based on this fact, the $\mu \mathrm{s}$-pulsed DBD device can be considered as safe with respect to the production of UV. In addition, no harm is to be expected due to VUV radiation in the DBD plasma since the ignition in air results in the efficient absorption by $\mathrm{N}_{2}(<100 \mathrm{~nm})$ and $\mathrm{O}_{2}(<200 \mathrm{~nm})[166,167]$.

\section{Gas emission}

The generation of APP is always accompanied by ROS and RNS production. The radicals will react with molecules in the ambient air and can lead to the formation of toxic gases like $\mathrm{O}_{3}$, NO. When their concentrations are too high and when these gases are inhaled, the respiratory tract can be harmed. Therefore, it is very important to examine $\mathrm{O}_{3}$ and $\mathrm{NO}_{2}$ as a product of NO not only in the immediate vicinity of the APP but also at further distances to the generated plasma. This can be done with spectroscopic measurement techniques like OES. For both sources, $\mathrm{O}_{3}$ generation in and around the ignited plasma were measured. In addition for the jet $\mathrm{NO}_{2}$ measurements were performed, whereas for the DBD NO concentrations were provided after a model system described elsewhere.

In case of the plasma jet, gas concentrations were not only measured at different working distances but also at three solid angles relative to the effluent $\left(180^{\circ}, 90^{\circ}\right.$, and $\left.45^{\circ}\right)$. Whereas $\mathrm{NO}_{2}$ was not detected near the plasma jet, high ozone concentrations were observed at all solid angles in the very close vicinity of the nozzle; values were between 0.1 and 6 part per million (ppm) at distances below $10 \mathrm{~cm}$. Highest concentrations were found when the jet was 
directed head-on to the sensor ( $180^{\circ}$ solid angle). At distances of $30 \mathrm{~cm}$ or more and angles of $45^{\circ}$ and $90^{\circ}, \mathrm{O}_{3}$ concentrations were lower than $0.055 \mathrm{ppm}=120 \mu \mathrm{g} / \mathrm{m}^{3}$ (Fig. 10a; rough dotted lines). The maximum workplace concentration (MAK) for $\mathrm{O}_{3}$ is defined with $0.1 \mathrm{ppm}$ $\left(=200 \mu \mathrm{g} / \mathrm{m}^{3}\right)$ over $8 \mathrm{~h}$ per day [168]. Furthermore, the EU provides an exposure limit for $\mathrm{O}_{3}$ in directive 2002/3/EG; the value is a daily average of $0.055 \mathrm{ppm}=120 \mu \mathrm{g} / \mathrm{m}^{3}$ over $8 \mathrm{~h}$. When the plasma jet is not frontally directed at the face and one is standing more than $30 \mathrm{~cm}$ away from the jet, $\mathrm{O}_{3}$ concentrations are below these threshold values. Hence, the use of the kINPen ${ }^{\circledR}$ MED under these conditions can be considered as safe.

For the $\mu \mathrm{s}$-pulsed $\mathrm{DBD} \mathrm{O}_{3}$ concentrations were recorded directly within the interelectrode space, i.e. where the plasma is generated, and at different distances to the discharge gap. Inside the discharge 5 ppm were measured. With increasing distances to the plasma $($ at $15 \mathrm{~cm})$, $\mathrm{O}_{3}$ concentration decreased to about $0.042 \mathrm{ppm}$. Concentrations below the safety limits [168] are already reached at a $10 \mathrm{~cm}$ distance from the discharge gap (Fig. 10b). NO concentration was measured within the discharge gap and results showed that 235 to $265 \mathrm{ppm}$ were produced. As for ozone, the concentration in the discharge rapidly declines with increasing distance to the discharge gap. The calculated NO concentration for a lateral distance of $3 \mathrm{~cm}$ is $0.2 \mathrm{ppm}$ which can be considered as harmless for humans which was already described elsewhere [47]. Taken together, no harm is to be expected when the respiratory tract is $10 \mathrm{~cm}$ away from the discharge gap of the $\mu s-$ pulsed DBD.

a

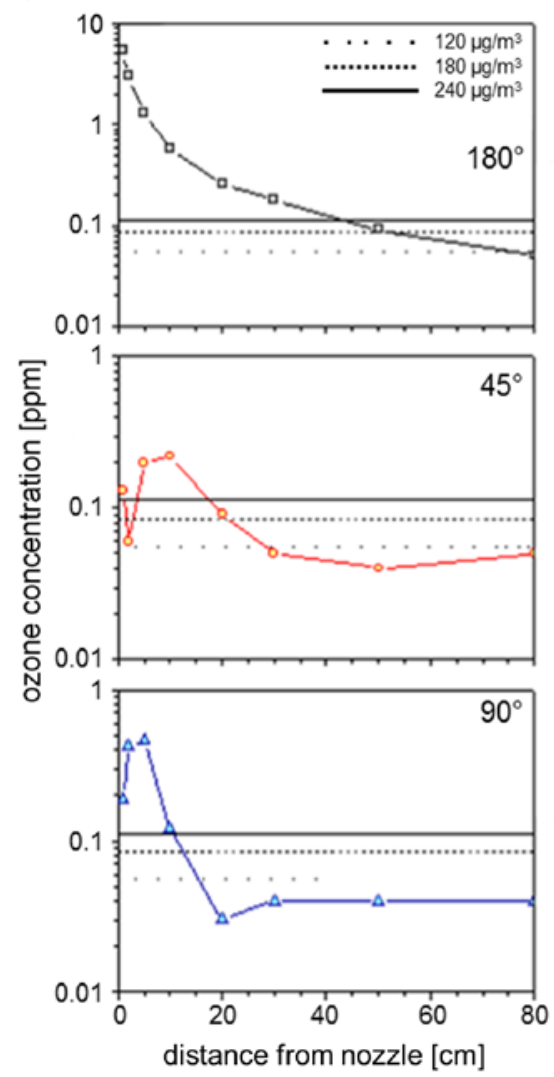

b

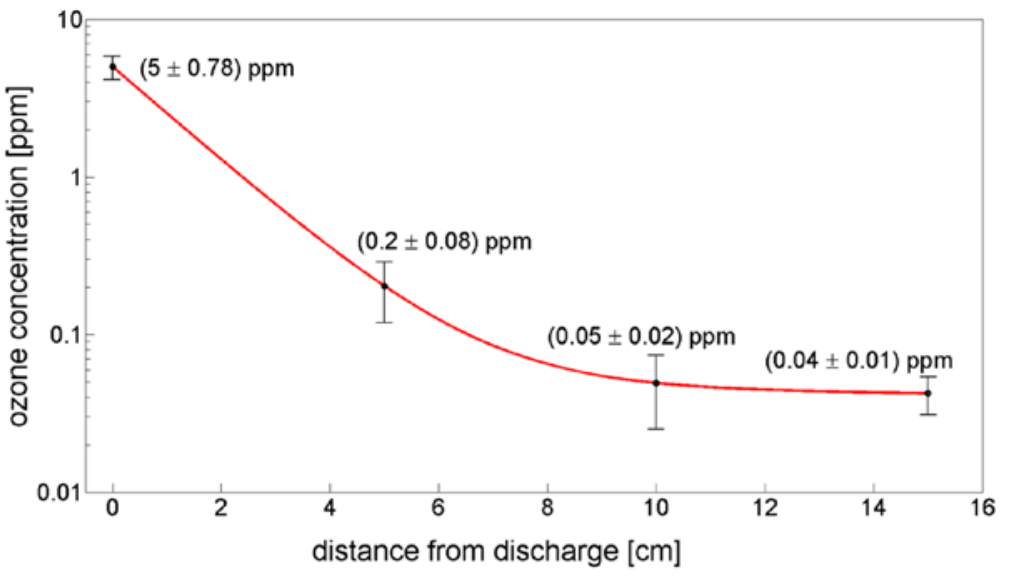

Figure 10: Ozone concentrations generated around the two plasma sources

Ozone concentrations were measured in different distances to the jet (a) and the $\mu$ s-pulsed DBD plasma (b; modified after Tiede et al. [47]). In addition, measurements were performed in varying solid angles for the KINPen ${ }^{\circledR}$ MED (modified after Bussiahn etal. [156]). 


\subsubsection{Biomedical efficiency of APP}

The knowledge about induced biological effects of APPs is required for an appropriate evaluation of their medical potential. The DIN-SPEC 91315 includes descriptions of very easy to perform test systems to study three important aspects of the biomedical efficiency of APP sources: the antimicrobial effect, the cytotoxic effect on human skin cells, and the chemical changes of liquids due to plasma treatments.

\subsubsection{Inactivation efficiency of APP against microorganisms}

One beneficial property of plasma applications is their strong antimicrobial effect. In medicine, this can be used for contact free removal of bacteria from infected wounds.

Investigations of the inactivation capacities using the KINPen $^{\circledR}$ MED were performed in accordance with the DIN-SPEC 91315 using the inhibition zone test and five different microbial strains [138]. The results revealed increasingly larger inhibition zones with extended plasma treatment durations (Fig. 11). This indicates the antimicrobial efficiency of the plasma jet. The test also revealed a strain dependent inactivation capacity of the jet. For example, the fungus strain Candida albicans (C. albicans) is more sensitive to the plasma application than Pseudomonas aeruginosa ( $P$. aeruginosa). Such experiments were not performed with the $\mu s-$ pulsed DBD, but existing data for a similar DBD source were used to evaluate and discuss the inactivation efficiency against microorganisms (cf. 5.1.2.1).

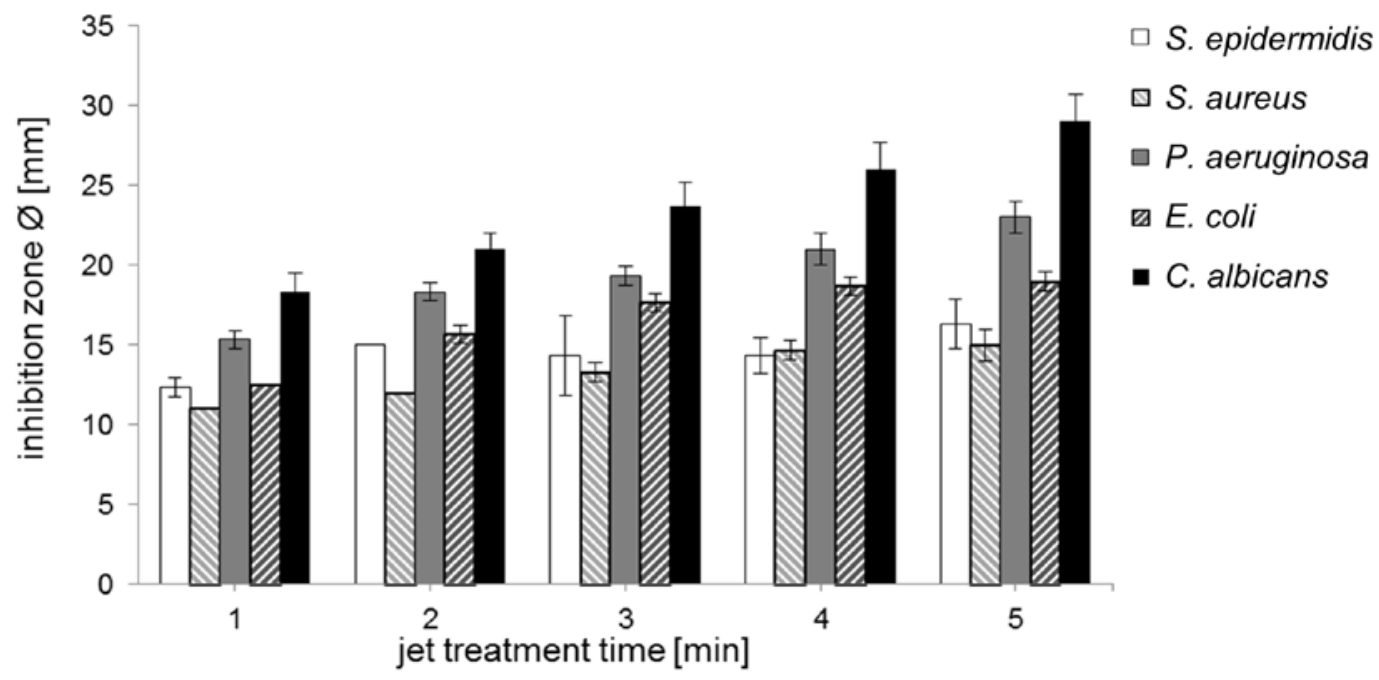

Figure 11: Microbial inhibition zone sizes produced by the plasma jet

The microbial strains (S. epidermidis, S. aureus, $P$. aeruginosa, E. coli, and C. albicans) were punctuallytreated on tryptic soy agar plates with the kINPen ${ }^{\circledR}$ MED (modified after Mann et al. [138]). 


\subsubsection{Cytotoxic effects of APPs on fibroblasts}

The cytotoxicity of the plasma sources were measured with the use of the MTS kit. Quantitative cell viability after plasma exposures were studied on two different fibroblast cell types; GMs and PFs. In addition, two different versions of the assay were performed:

1) Cell viabilities of plasma-treated cells were measured to study direct plasma effects.

2) Plasma-treated PBS was used to study the impact of reactive species formed in the PBS; defined as indirect plasma treatment.

The latter was of interest, because plasma is known to "activate" liquids via interactions of reactive species produced in the plasma with the treated liquid, which in turn generate byproducts that influence cell behavior and response [21, 83, 169]. With the indirect approach of the assay, specific plasma components, like the electric current, UV radiation, and temperature that affect cells were excluded. Thus, only the chemical changes within the PBS solution are responsible for underlying changes in cell viabilities. Such indirect plasma tests were not included in the DIN-SPEC 91315.

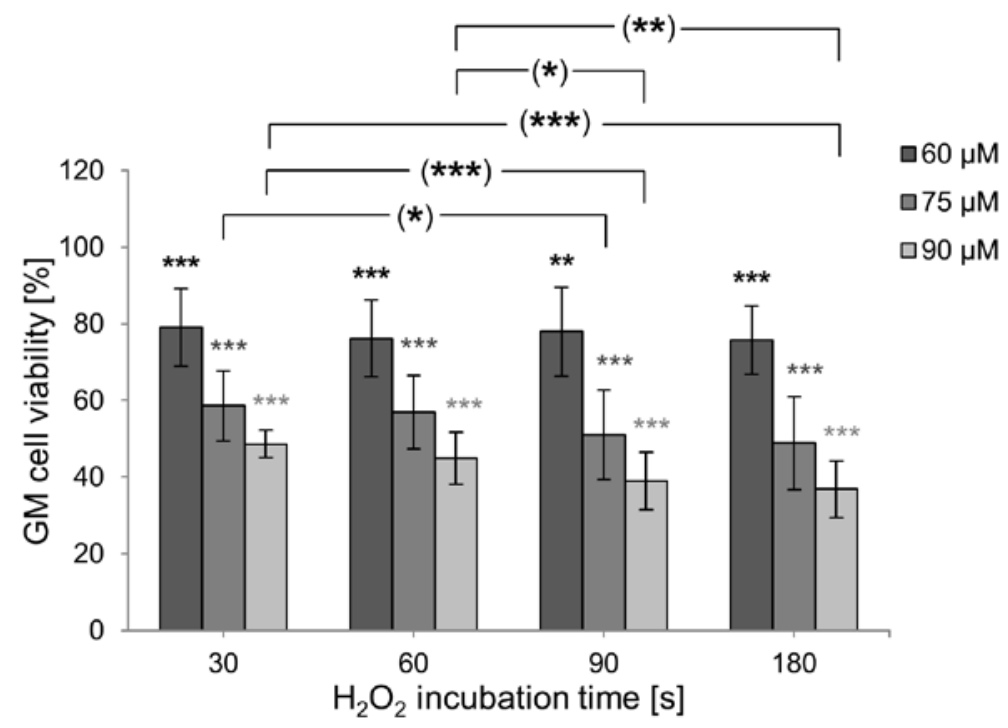

Figure 12: Cell viability of GM cells after $\mathrm{H}_{2} \mathrm{O}_{2}$ treatments

GM viability decreased as a function of varying incubation times with different concentrations of $\mathrm{H}_{2} \mathrm{O}_{2}(60,75, a$ and $90 \mu \mathrm{M})$. Error bars represent SD values and statistically significant differences to the negative control are marked with * $(p \leq 0.05),{ }^{* *}(p \leq 0.01)$, and ${ }^{* * *}(p \leq 0.001)$. Asterisks in brackets show differences between varying incubation times at same concentrations.

To demonstrate the functionality of this method, GM cells were incubated for $30,60,90$, and $180 \mathrm{~s}$ in $\mathrm{H}_{2} \mathrm{O}_{2}$ solutions with different concentrations $\left(60,75,90 \mu \mathrm{M} \mathrm{H}_{2} \mathrm{O}_{2}\right.$ in PBS). Figure 12 shows that cell viability of GM cells significantly reduced with higher concentrations of $\mathrm{H}_{2} \mathrm{O}_{2}$. Extended incubations for $60 \mu \mathrm{M}$ and $75 \mu \mathrm{M} \mathrm{H}_{2} \mathrm{O}_{2}$ solutions caused similar viability reductions, which were significant in only one case (Fig. 12; cf. 30 s and $180 \mathrm{~s}$ at $75 \mu \mathrm{M}$ ). With the strongest 
$\mathrm{H}_{2} \mathrm{O}_{2}$ concentration, significant differences of cell viabilities were found between all incubation times.

\section{1) Direct plasma effects}

Independently from the plasma source used, cell viability of PF or GM cells declined with longer treatment times (Fig. 13). First, cell responses of PF and GM cells are compared considering both plasma sources separately.

Jet applications with the kINPen ${ }^{\circledR}$ MED device led to LD50 values between 30 and $60 \mathrm{~s}(\hat{=} 92$ and $184 \mathrm{~J} / \mathrm{cm}^{2}$ ) for both cell lines. In most cases, GM cells were significantly more susceptible to jet treatments than PFs with only one exception at $30 \mathrm{~s}$ of treatment duration (Fig. 13a).
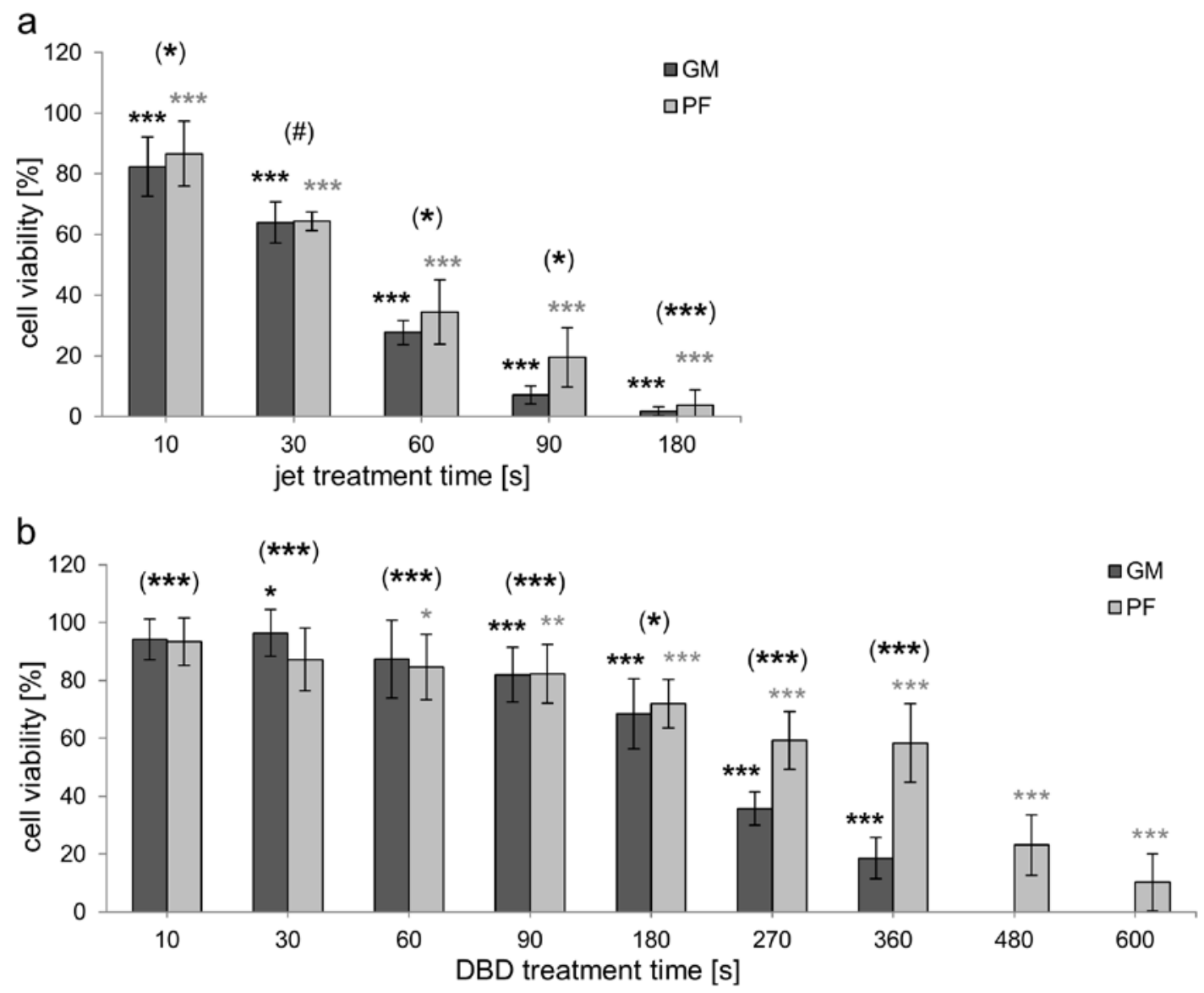

Figure 13: Plasma treatment time dependent cell viability of fibroblasts

With extended plasma applications with the KINPen ${ }^{\circledR}$ MED (a) and the $\mu$ s-pulsed DBD (b; modified after Tiede etal. [47]) cell viabilities of GM and PF cells are decreasing. Error bars represent SDs. Statisticallysignificant differences to the negative control (defined as $100 \%)$ are marked with * $(p \leq 0.05){ }^{* *}(p \leq 0.01)$, and ${ }^{* * *}(p \leq 0.001)$. Asterisks in brackets refer to the comparison between GM and PF cell viability at same treatment duration.

At this point it is important to mention that plasma jet applications also affected cells due to the argon gas flow $(5 \mathrm{slm})$. The gas stream generated a PBS-free center in cell culture dish during treatment. Cells in this area were directly exposed to the stream and plasma components. To determine the impact of the gas flow alone, additional experiments were performed with GM 
cells. On average, the results showed a $17 \%$ reduction of cell viability due to the gas stream (data not shown).

Figure $13 \mathrm{~b}$ shows the results of direct treatments with the $\mu \mathrm{s}$-pulsed DBD. A treatment duration of $180 \mathrm{~s}\left(\triangleq 69 \mathrm{~J} / \mathrm{cm}^{2}\right.$ ) resulted in a cell viability of $68.4 \%$ for GMs and $72 \%$ for PFs. Thus, longer application times than used for jet treatments were necessary to decrease cell viability below $50 \%$. The LD50 value was reached at $180-270 \mathrm{~s}\left(\bumpeq 69-103 \mathrm{~J} / \mathrm{cm}^{2}\right)$ of DBD-treated GMs and at $360-480 \mathrm{~s}\left(\triangleq 137-183 \mathrm{~J} / \mathrm{cm}^{2}\right.$ ) of PF cells. As for $\mathrm{kINPen}^{\circledR}$ MED applications, there was a difference between the sensitivity of PF and GM cells to the DBD plasma. At short treatment durations PFs reacted more sensitive than GMs $\left(10-60 \mathrm{~s} \triangleq 4-23 \mathrm{~J} / \mathrm{cm}^{2}\right)$, whereas DBD applications between $90-360 \mathrm{~s}\left(\hat{=} 34-137 \mathrm{~J} / \mathrm{cm}^{2}\right)$ resulted in lower $\mathrm{GM}$ cell viabilities compared to PFs (Fig. 13b).

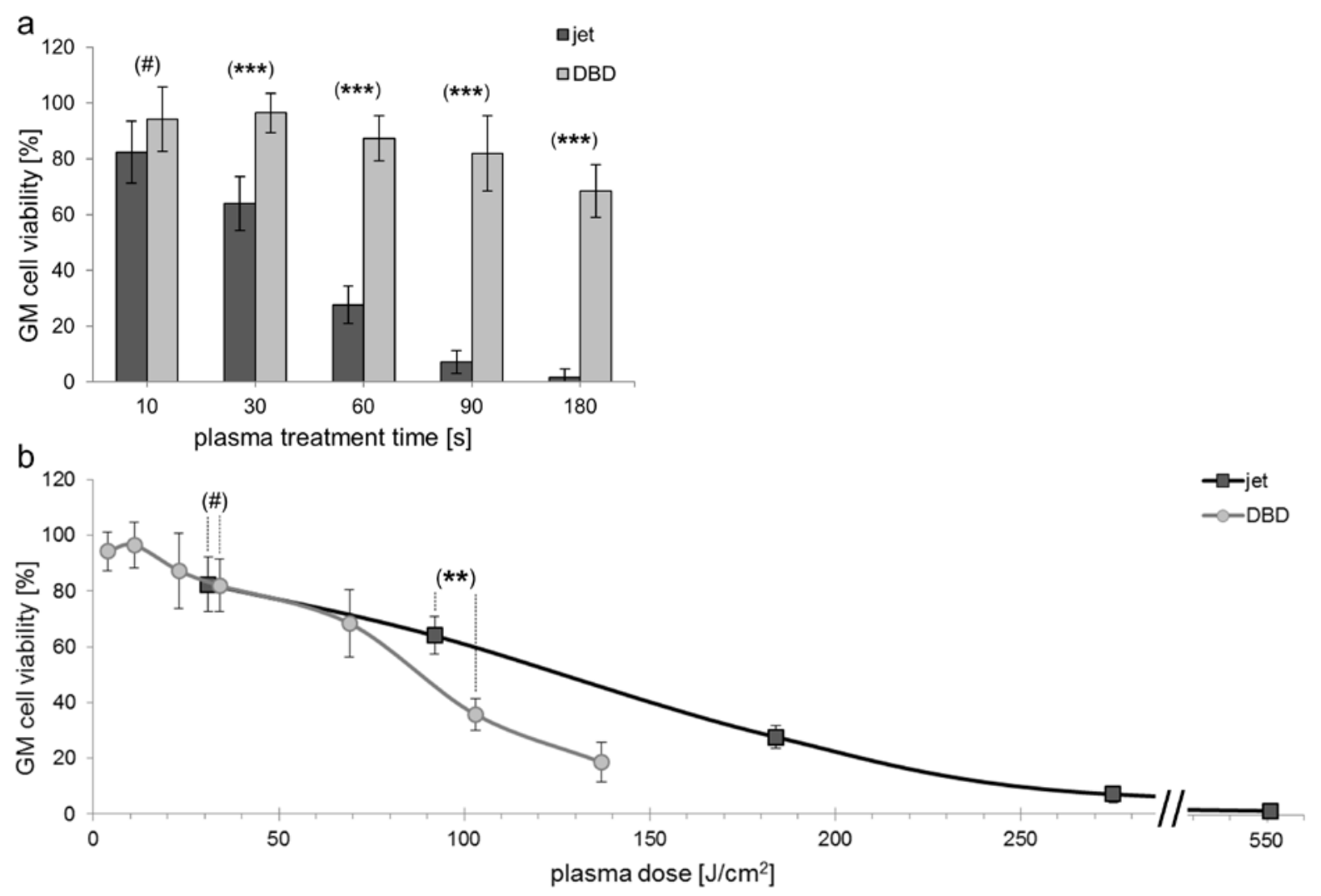

Figure 14: Plasma-type dependent cell viability of GM cells

The cell viability of GM cells is shown as a function of treatment times (a) and as a function of plasma doses (b) applied by KINPen ${ }^{\circledR}$ MED and DBD treatments. GM viability was in almost all cases significantly lower for same treatment durations with the plas majet than the DBD plasma (exception at 10s). In contrast, the DBD plasma tends to induce lower viabilities at similar plasma doses compared to the jet. Error bars represent SDs. Statistically significant difference at same treatment times or similar plasma doses are marked with ${ }^{* *}(p \leq 0.01)$ and $* \star *(p \leq 0.001)$. Non-significant differenced are marked with (\#). 
Based on these results, a direct comparison between cytotoxic effects induced by the two plasma sources was possible. When comparing the cell viability of GMs on the basis of same treatment durations, it is obvious that GM viability decreased faster for jet than DBD applications (Fig. 14a). In addition, if cell viability of GMs is compared the level of plasma doses, the DBD plasma tends to decrease the viability stronger than the plasma jet at energy densities between $7-14 \mathrm{~J} / \mathrm{cm}^{2}$. A closer look shows that e.g. $10 \mathrm{~s} \bumpeq 31 \mathrm{~J} / \mathrm{cm}^{2}$ of jet application approximately corresponds to a $90 \mathrm{~s} \bumpeq 34 \mathrm{~J} / \mathrm{cm}^{2}$ treatment with the DBD plasma, at which cell viability was reduced to about $82 \%$ (Fig. 14b). Another comparison on the basis of similar

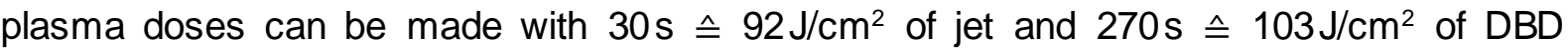
treatments. Here, cell viability of GM cells was significantly lower for DBD (35.8\%) than jet application (63.9\%).

\section{2) Indirect plasma effects}

For the indirect approach, PBS solution was exposed to plasma and then cells were incubated for $5 \mathrm{~min}$ in the PBS. In figure 15 cell viabilities of the two cell lines exposed to the two different plasma sources are presented. Overall, cell viabilities decreased with extended treatment durations with the plasma jet and DBD plasma. As expected, the decrease was lower than in direct plasma treatment tests.

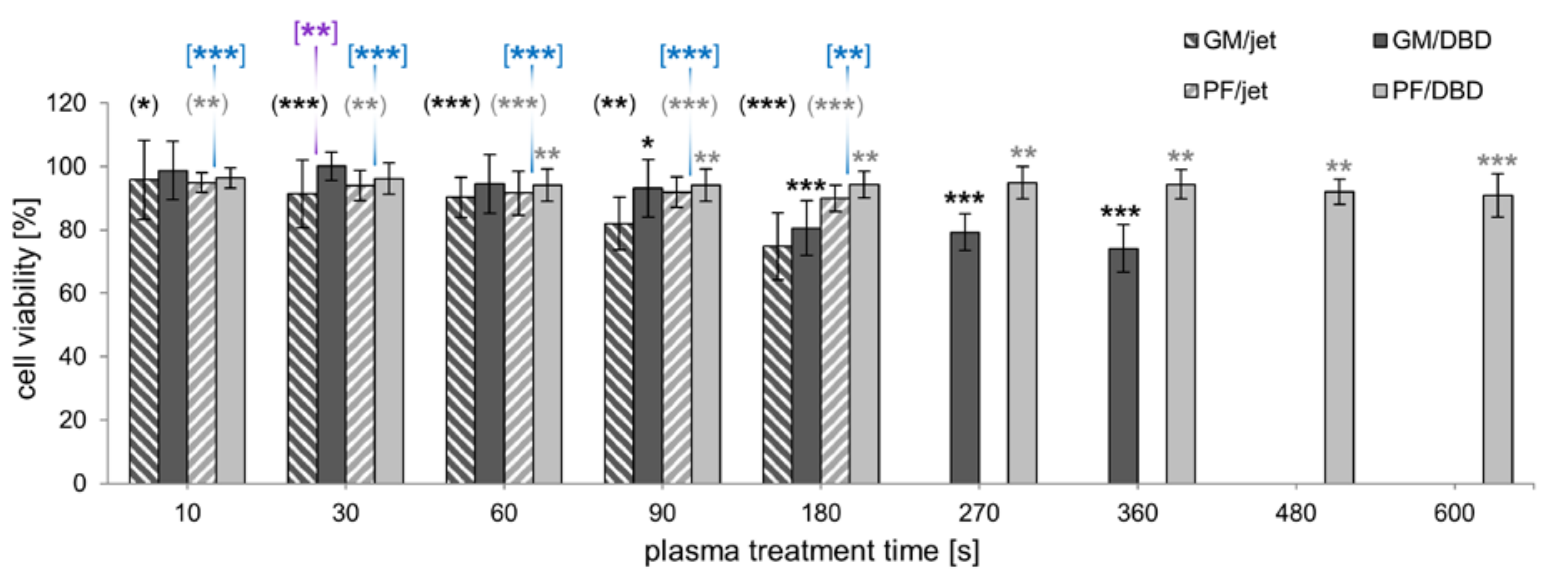

Figure 15: Fibroblast cell viability after indirect plasma treatments

Cell viabilities of GM and PF cells are shown as a function of different treatment durations of PBS with the kINPen ${ }^{\circledR}$ MED plasma (hatched bars) and the $\mu$ s-pulsed DBD plasma (solid bars) following $5 \mathrm{~min}$ cell incubation. Error bars represent SDs. Statistically significant differences to untreated controls (defined as 100\%) are marked with ${ }^{*}(p \leq 0.05),{ }^{* *}(p \leq 0.01)$, and ${ }^{* * *}(p \leq 0.001)$ for indirect jet applications and asterisks in round brackets refer to indirect DBD treatments compared to the untreated control. Asterisks in square brackets mark significant differences between jet-treated and DBD-treated PBS added to GMs (purple) or PFs (blue).

A comparison between GM and PF sensitivity revealed that, in most cases, GMs reacted more sensitive to the plasma-treated PBS than PF cells. As in direct MTS experiments, only short DBD treatments up to 60 s significantly induced stronger viability reductions of PFs compared to GMs. This was the other way round for DBD treatment durations of $90 \mathrm{~s}$ and longer 
(Fig. 15; cf. solid bars). $10 \mathrm{~s}$ of indirect plasma jet treatment also resulted in higher cell viabilities of GMs than PFs, whereas extended treatment durations induced lower GM viabilities compared to PF viabilities (Fig. 15; cf. hatched bars). In all cases these differences were significant (data not shown).

Comparing the effects of both sources on GM cells, only a tendency towards a stronger effect of indirect jet applications was observed (one significant difference at $30 \mathrm{~s}$ in Fig. 15; purple asterisks). In contrast, the plasma jet induced significant lower PF viabilities at all comparable treatment durations than the DBD plasma (Fig. 15; blue asterisks).

After indirect jet treatment for $180 \mathrm{~s} \bumpeq 551 \mathrm{~J} / \mathrm{cm}^{2} \mathrm{GM}$ cell viability was reduced to about $75 \%$. A similar viability value (74\%) was reached with $360 \mathrm{~s} \triangleq 137 \mathrm{~J} / \mathrm{cm}^{2}$ of indirect DBD treatment. This shows that lower DBD than jet doses applied to PBS are necessary to induce the same GM cell viability.

\subsubsection{APP-dependent generation of reactive species and $\mathrm{pH}$ changes}

For a better understanding, which reactive species may contribute to plasma effects, the last test system described in the DIN-SPEC 91315 focused on the generation of ROS and RNS in liquids. As in the MTS assay for indirect effects, PBS was treated with either one of the two plasma sources followed by measurements of $\mathrm{NO}_{2}{ }^{-}$and $\mathrm{NO}_{3}{ }^{-}$concentrations (representative for the production of RNS), and $\mathrm{H}_{2} \mathrm{O}_{2}$ concentration (representative for ROS generation). In addition, the $\mathrm{pH}$ was measured after plasma treatments, because this is another important factor in wound healing and some skin diseases $[115,116]$.

\section{Reactive species production in PBS}

For photometrical measurements of reactive species generated by the $\mathrm{kINPen}^{\circledR}$ MED in PBS the very sensitive Aplex ${ }^{\circledR}$ UltraRed Reagent for $\mathrm{H}_{2} \mathrm{O}_{2}$ (Thermo Fisher, Dreieich DE; lower detection limit: $\sim 0.08 \mu \mathrm{M}$ ) and the Nitrate/Nitrite Colorimetric Assay Kit (Cayman Chemical, Ann Arbor, Michigan, US) for $\mathrm{NO}_{2}{ }^{-}$and $\mathrm{NO}_{3}{ }^{-}$detection (detection range: 5-35 $\mu \mathrm{M}$ ) were used.

A different test system was used for measurements of species produced by the $\mu$ s-pulsed DBD: RQflex 10 and appropriate reflectometric test strips (Merck KGaA, Darmstadt, DE). Detection thresholds of this test system are much higher with $6-588 \mu \mathrm{M}(0.2-20 \mathrm{mg} / \mathrm{L})$ for $\mathrm{H}_{2} \mathrm{O}_{2}$, 11-543 $\mu \mathrm{M}(0.5-25 \mathrm{mg} / \mathrm{L})$ for $\mathrm{NO}_{2}{ }^{-}$, and 48-1452 $\mu \mathrm{M}\left(3-90 \mathrm{mg} / \mathrm{L}^{-}\right.$for $\mathrm{NO}_{3}{ }^{-}$.

In figure 16, concentrations of above mentioned species in plasma-treated PBS are shown. Both plasma sources caused concentrations to rise with longer treatment durations. Limited by the detection thresholds of the RQflex 10 test kit no DBD data exist for applications shorter than $90 \mathrm{~s}$. 


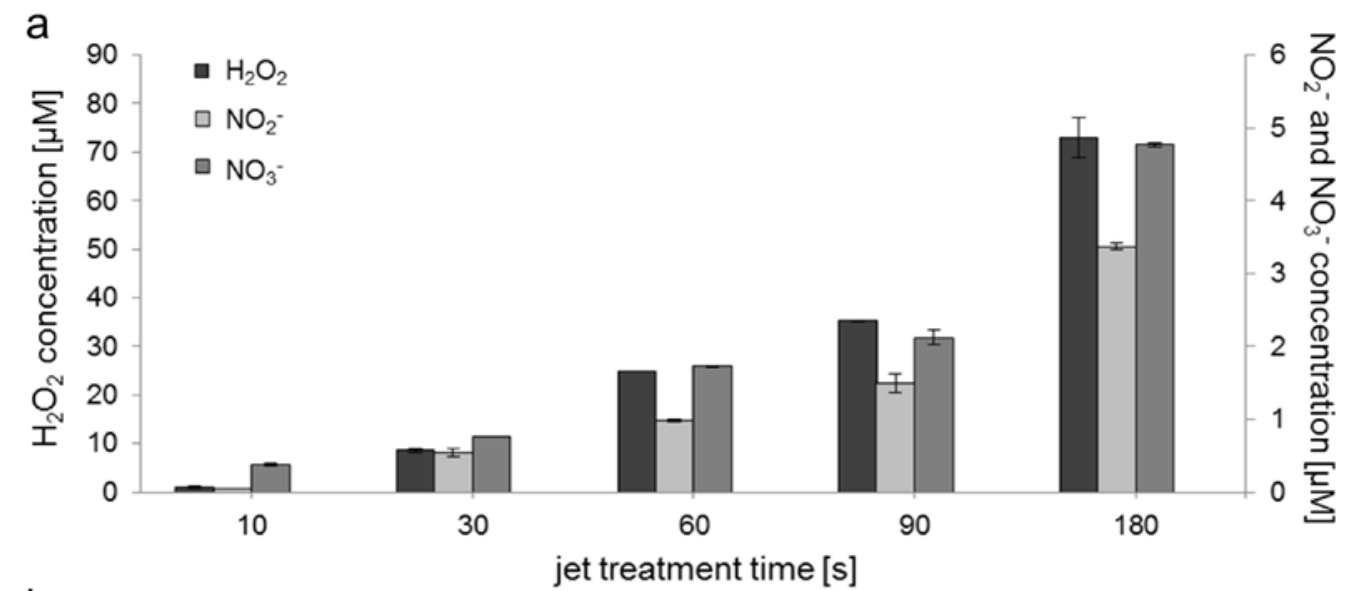

b

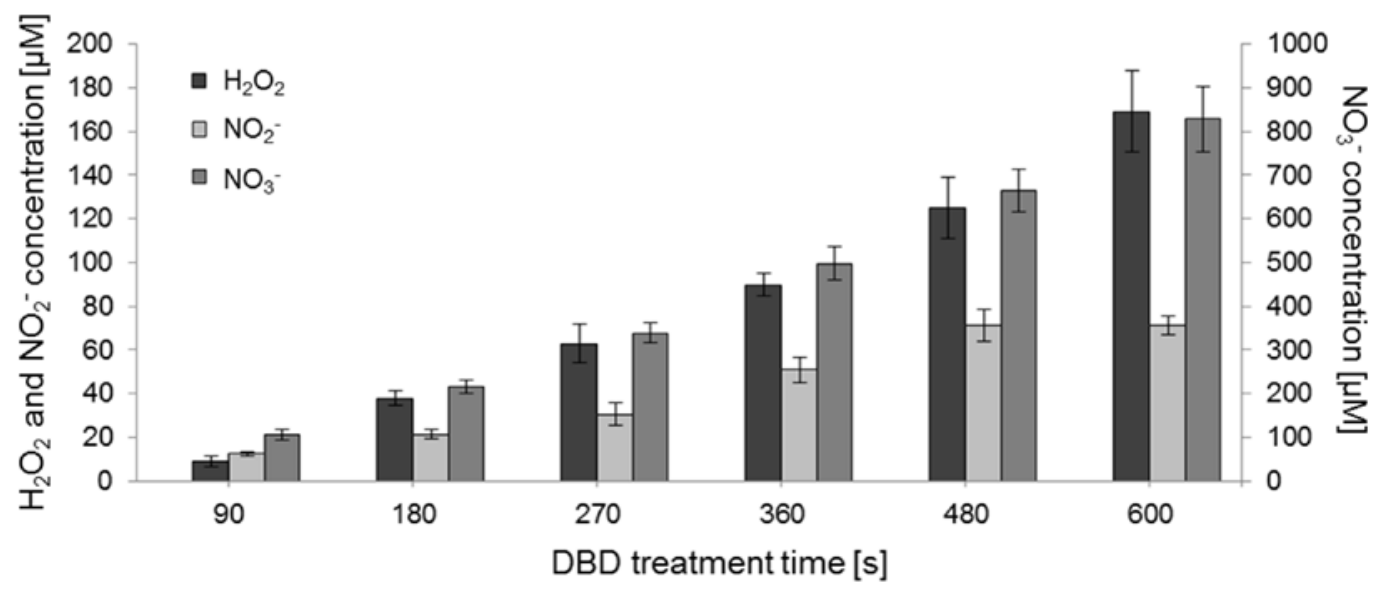

Figure 16: Plasma treatment time dependent generation of reactive species in PBS

$\mathrm{H}_{2} \mathrm{O}_{2}, \mathrm{NO}_{2}^{-}$, and $\mathrm{NO}_{3}{ }^{-}$concentrations were detected in PBS treated with the kINPen ${ }^{\circledR}$ MED (a) and the $\mu$ s-pulsed DBD device (b; modified after Tiede et al. [47]). Error bars represent SDs. Please note the two y-axes in each subfigure.

Maximum concentrations detected after $180 \mathrm{~s} \bumpeq 551 \mathrm{~J} / \mathrm{cm}^{2}$ of the jet application were $73 \mu \mathrm{M}$ for $\mathrm{H}_{2} \mathrm{O}_{2}, 3 \mu \mathrm{M}$ for $\mathrm{NO}_{2}{ }^{-}$, and $5 \mu \mathrm{M}$ for $\mathrm{NO}_{3}^{-}$(Fig. 16a). PBS exposure of $180 \mathrm{~s} \triangleq 69 \mathrm{~J} / \mathrm{cm}^{2}$ to the $\mu$ s-pulsed DBD led to concentrations of $38 \mu \mathrm{M}$ for $\mathrm{H}_{2} \mathrm{O}_{2}, 21 \mu \mathrm{M}$ for $\mathrm{NO}_{2}^{-}$, and $215 \mu \mathrm{M}$ for $\mathrm{NO}_{3}{ }^{-}$ (Fig. 16b). Thus, at same exposure times concentrations of $\mathrm{NO}_{2}{ }^{-}$and $\mathrm{NO}_{3}{ }^{-}$were many times higher after DBD than after jet treatments. In contrast, $\mathrm{H}_{2} \mathrm{O}_{2}$ concentrations were higher in jet treated PBS. Similar $\mathrm{H}_{2} \mathrm{O}_{2}$ concentration were e.g. generated by $30 \mathrm{~s} \triangleq 92 \mathrm{~J} / \mathrm{cm}^{2}$ of jet and $90 \mathrm{~s} \triangleq 34 \mathrm{~J} / \mathrm{cm}^{2}$ of DBD application or by $90 \mathrm{~s} \triangleq 275 \mathrm{~J} / \mathrm{cm}^{2}$ of jet and $180 \mathrm{~s} \triangleq 69 \mathrm{~J} / \mathrm{cm}^{2}$ of DBD treatments.

A comparison of reactive species concentrations produced at similar plasma doses revealed that DBD treatments generated higher concentrations in all cases (table 1). However, the differences in RNS concentrations were greater between the two plasma sources than differences in the ROS concentration of $\mathrm{H}_{2} \mathrm{O}_{2}$. 
Table 1: Reactive species concentrations in plasma-treated PBS at similar plasma doses

Similar plasma doses applied to PBS solution led to higher concentrations of $\mathrm{H}_{2} \mathrm{O}_{2}, \mathrm{NO}_{2}^{-}$, and $\mathrm{NO}_{3}{ }^{-}$when using the DBD source compared to the kINPen ${ }^{\circledR}$ MED device.

\begin{tabular}{lc|ccc}
\multicolumn{2}{l}{$\begin{array}{l}\text { Plasma dose }\left[\mathrm{J}_{\mathbf{c}} \mathbf{c m}^{2}\right] \hat{=} \\
\text { Treatment duration }[\mathbf{s}]\end{array}$} & $\mathrm{H}_{2} \mathrm{O}_{2}[\mu \mathrm{M}]$ & $\mathrm{NO}_{2}^{-}[\mu \mathrm{M}]$ & $\mathrm{NO}_{3}^{-}[\mu \mathrm{M}]$ \\
\hline \hline (jet) & $31 \bumpeq 10$ & 1 & 0.04 & 0.4 \\
$(\mathrm{DBD})$ & $34 \bumpeq 90$ & 9 & 12 & 105 \\
\hline (jet) & $92 \bumpeq 30$ & 9 & 0.6 & 0.8 \\
$(\mathrm{DBD})$ & $103 \bumpeq 270$ & 63 & 30 & 339 \\
\hline (jet) & $184 \bumpeq 60$ & 25 & 1 & 1.7 \\
$(\mathrm{DBD})$ & $183 \bumpeq 480$ & 125 & 71 & 664 \\
\hline
\end{tabular}

\section{Changes of $\mathrm{pH}$ in PBS}

Plasma is also known to have an impact on the $\mathrm{pH}$ of liquids or humid treatment objects [117, 120]. Since in-vitro experiments on fibroblasts were always performed in PBS ( $\mathrm{pH}: 7.4)$, plasma treatment time dependent $\mathrm{pH}$ changes of PBS were recorded. As illustrated in figure 17 both sources slowly decreased $\mathrm{pH}$ values with extended treatment durations. For longest treatment times with the DBD $\left(600 \mathrm{~s} \bumpeq 22.9 \mathrm{~J} / \mathrm{cm}^{2}\right)$ and with the plasma jet source $\left(180 \mathrm{~s} \bumpeq 551 \mathrm{~J} / \mathrm{cm}^{2}\right)$ the $\mathrm{pH}$ was reduced by 0.66 and 0.09 , respectively. Furthermore, DBD plasma led to a slightly stronger shift towards an acidic $\mathrm{pH}$ at same application times than the plasma jet. Comparing $\mathrm{pH}$ changes at similar plasma doses at about $183 \mathrm{~J} / \mathrm{cm}^{2}$ ( $\triangleq 60 \mathrm{~s}$ of jet and $480 \mathrm{~s}$ of DBD treatment in Fig. 17; purple arrowhead) pH decreased by 0.05 for jet treatments and by 0.54 for DBD applications.

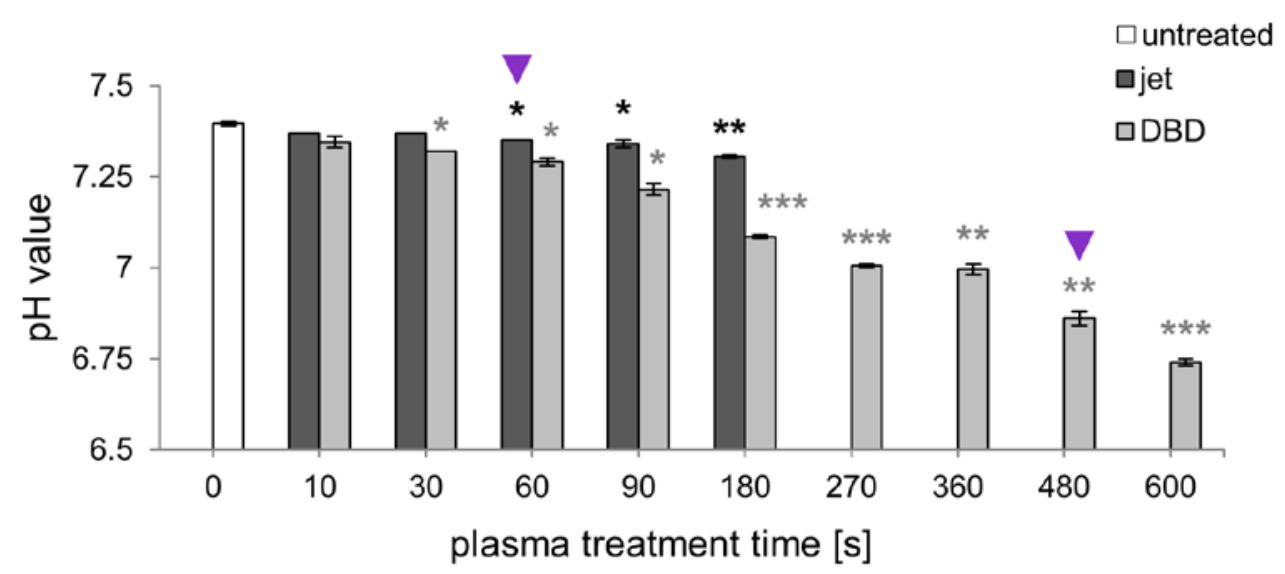

Figure 17: Plasma-type dependent changes of the pH value in PBS

The $\mathrm{pH}$ value of PBS solution treated with the $\mathrm{kINPen}{ }^{\circledR}$ MED or the $\mu$ s-pulsed DBD device slightlydecreased with extended treatment duration. Error bars represent SDs and statisticallysignificant differences to untreated PBS are marked with * $(p \leq 0.05),{ }^{* *}(p \leq 0.01)$, and ${ }^{* * *}(p \leq 0.001)$. Purple arrowheads mark similar plasma doses of about $183 \mathrm{~J} / \mathrm{m}^{2}$. 


\subsection{Evaluation of long-term damages induced by APP}

Based on the general characterization of both APP sources, additional and detailed experiments focus on plasma-induced genotoxic and mutagenic effects. Reproducible and cost-effective assays and experimental procedures were established and evaluated until the most practicable solutions were found. Not only resulting data and effects were of interest but also the ease of use and explanatory power of the assays.

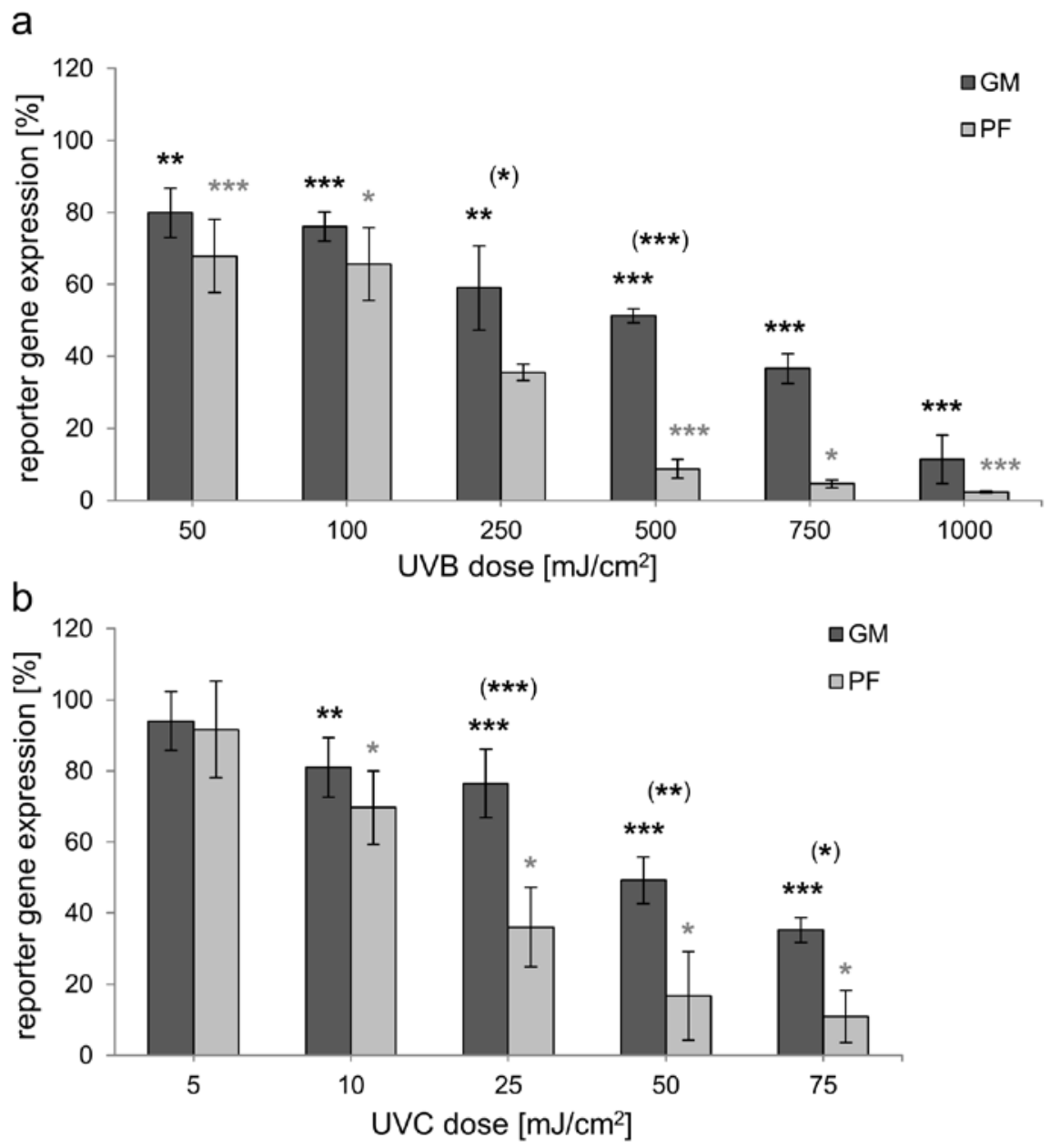

Figure 18: Reporter gene expression of fibroblasts after transfection with UV-irradiated plasmids

GM and PF cells showed lower firefly expression rates as a function of different UVB (a) and UVC (b) doses. Error bars represent SDs. Significant differences to the untreated control (defined as 100\%) are marked with * $(p \leq 0.05)$, $* *(p \leq 0.01)$, and ${ }^{* * *}(p \leq 0.001)$. Asterisks in brackets mark significant differences between the two cell lines exposed to same UV doses.

\subsubsection{Indirectly measured genotoxicity of APP on plasmid DNA}

Usually, the HCR assay is performed to quantify the repair capacity of eukaryotic cells. Here, the properties of this assay were used to indirectly quantify genotoxic effects.

For this assay, plasmid DNA diluted in $\mathrm{dd}_{2} \mathrm{O}$ was exposed to APPs or UV radiations, followed by transfection of plasmids into fibroblast cells. During the incubation time, cells naturally repair 
plasma- or UV-induced damages on plasmids. The reporter gene firefly can then be expressed from intact plasmids and the enzymatic activity of the firefly luciferase is detectable as luminescence in the cell extract. Hence, the luminescence intensity represents the rate of firefly reporter gene expression.

As positive control, plasmid DNA was irradiated with different doses of UVB and UVC (Fig. 18). As expected, expression rates in both cell lines decreased with higher UV irradiation doses; this indicates that the HCR assay was successfully established and performed. However, the expression rates of firefly depended on the used cell type. GM cells expressed higher levels of firefly than PF cells when same UVB or UVC doses were applied. These differences were significant for intermediate doses of UVB and for mediate to high UVC doses (Fig. 18; asterisks in brackets). UVB was additionally selected as positive control for the later discussion about transferability of these in-vitro effects to in-vivo effects of APP applications (cf. 5.2.1).
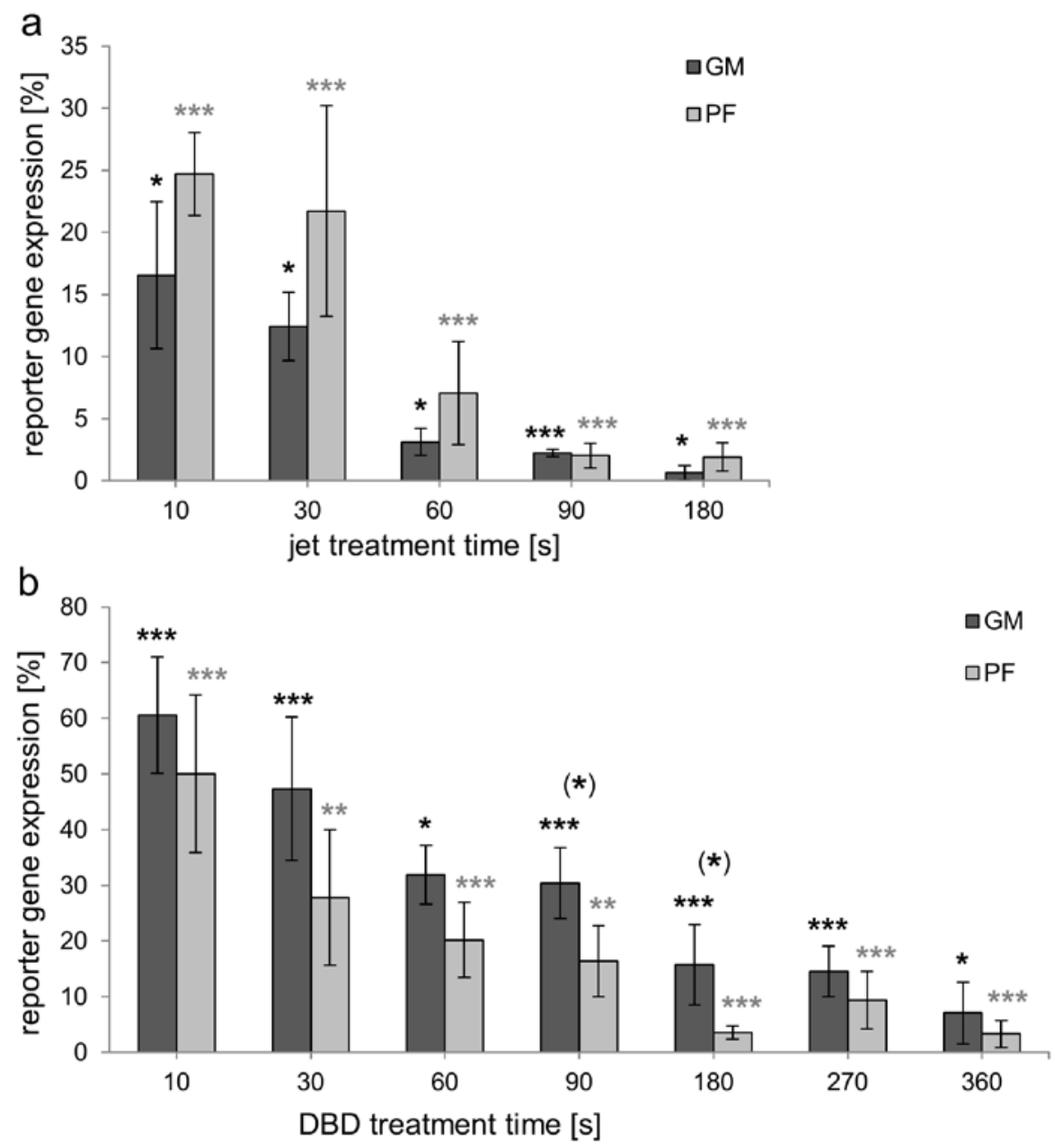

Figure 19: Reporter gene expression of fibroblasts after transfection with plasma-treated plasmids

GM and PF cells showed lower expression rates of fireflyas a function of kINPen ${ }^{\circledR}$ MED (a) and $\mu$ s-pulsed DBD (b) treatment durations. Error bars represent SDs. Statisticallysignificant differences to the negative control (untreated firefly plasmid DNA transfected into fibroblasts, defined as $100 \%)$ are marked with * $(p \leq 0.05)$, ${ }^{* *}(p \leq 0.01)$ and $\star \star \star ~(p \leq 0.001)$. Asterisks in brackets refer to significant differences between different cell lines at same treatment durations. 
Results of APP treatments are given in figure 19. In general, reporter gene expression rapidly decreased after plasmatreatments of the firefly plasmid with the two devices. Applications with the $\mathrm{KINPen}{ }^{\circledR}$ MED device for $10 \mathrm{~s} \triangleq 31 \mathrm{~J} / \mathrm{cm}^{2}$ reduced gene expressions to about $16.5 \%$ for GM cells and $24.7 \%$ for PF cells; they further decreased to $0.6 \%$ (GM) and $1.9 \%$ (PF) at 180 s $\hat{=} 551 \mathrm{~J} / \mathrm{cm}^{2}$. Cell-type dependent expression rates were, however, not significantly different from each other (Fig. 19a). Interestingly, when the DBD device was used, GM cells tend to be more effective in gene expression than PF cells (Fig. 19b). $90 \mathrm{~s} \triangleq 34 \mathrm{~J} / \mathrm{cm}^{2}$ of DBD treatment led to significant different gene expressions of $30.4 \%$ in GMs and $16.4 \%$ in PFs. At 180 s $\triangleq 69 \mathrm{~J} / \mathrm{cm}^{2}$, expression rates were already reduced to about $15.7 \%$ (in GMs) and $3.6 \%$ (in PFs). For the longest treatment duration or highest plasma dose $\left(360 \mathrm{~s} \triangleq 137 \mathrm{~J} / \mathrm{cm}^{2}\right)$ firefly expression declined to $7.1 \%$ (in GMs) and 3.3\% (in PFs).
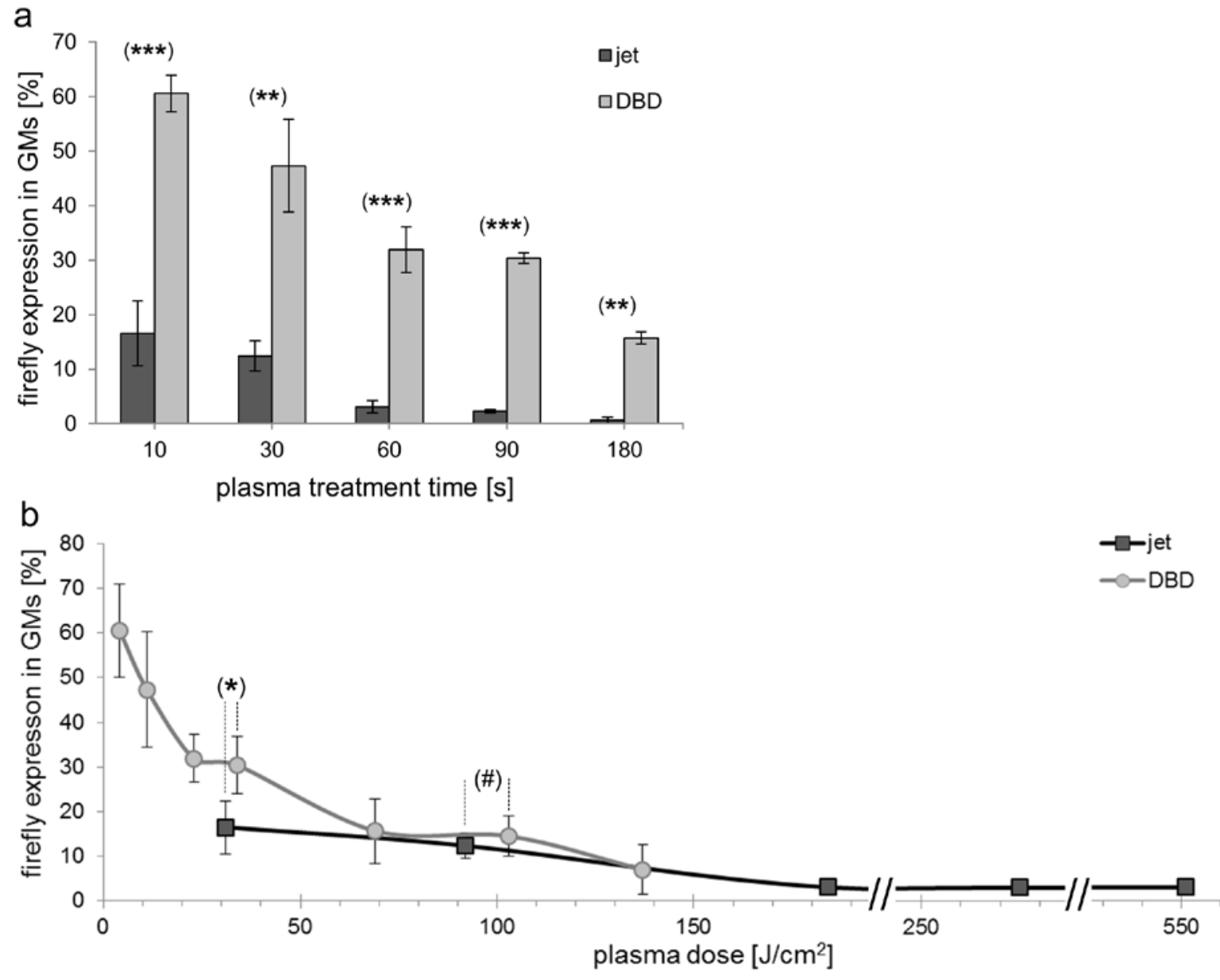

Figure 20: Plasma-type dependent expression rates of firefly in GM cells

The firefly gene expression is shown as a function of treatment durations with the two plasmas (a) and as a function of plasma doses (b). Error bars represent SDs and significant differences between the two sources for same treatment duration or similar plasma doses are marked with * $(p \leq 0.05),{ }^{* *}(p \leq 0.01)$, and ${ }^{* *}(p \leq 0.001)$. Statisticallynon-significant differences are marked with (\#). 
In a direct comparison between the two sources used for same treatment durations, it becomes apparent that the impact on firefly DNA was significantly more pronounced after kINPen ${ }^{\circledR}$ MED than after DBD use (Fig. 20a). A comparison between firefly expression rates in GM cells at similar plasma doses revealed that at around $30 \mathrm{~J} / \mathrm{cm}^{2}$ lower expression rates were detected after jet $\left(31 \mathrm{~J} / \mathrm{cm}^{2}\right)$ than after DBD $\left(34 \mathrm{~J} / \mathrm{cm}^{2}\right)$ applications (Fig. 20b). Other than that, DBD and plasma jet doses between plasma doses of $\sim 70-140 \mathrm{~J} / \mathrm{cm}^{2}$ tend to generate similar gene expression rates.

\subsubsection{DNA fragmentation capacity of APPs}

Since the HCR assay indirectly demonstrated a fast and high genotoxicity of APPs on isolated plasmids, the question of how the DNA is affected by plasma arose. As a first step, fragmentation capacities of the two plasma sources were studied using a very simple method, i.e. gel electrophoretic separation. As in HCR experiments, firefly plasmid DNA was used.

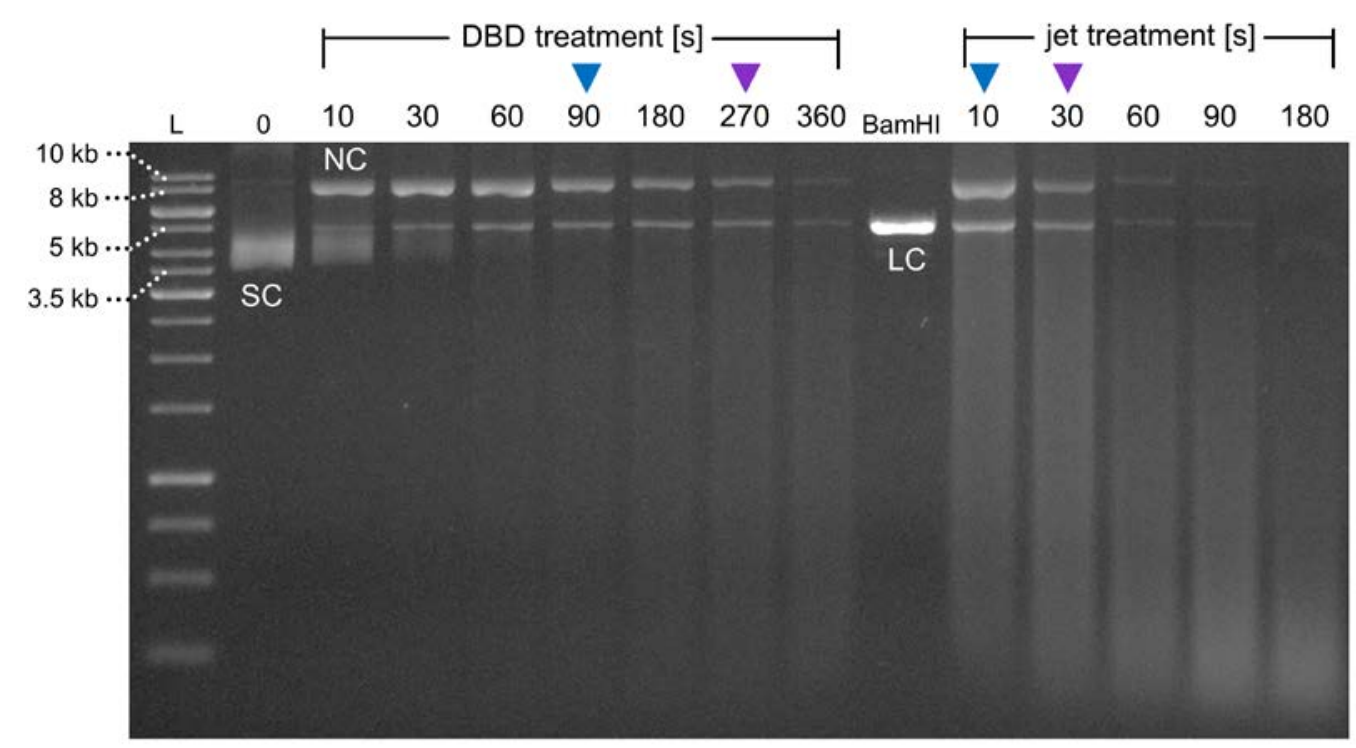

Figure 21: DNA fragmentation capacity of the two plasma sources

The gel picture shows the gel electrophoretic separation of firefly plasmid DNA treated with the $\mu s$-pulsed DBD device (left) or the kINPen ${ }^{\circledR}$ MED (right). $1 \mathrm{~kb}$ weight ladder (L), untreated firefly plasmid DNA (0), and plasmid digested with the restriction enzyme $(\mathrm{BamHI})$ are included. The plasmid is presentin three different conformations: supercoiled conformation (SC), nicked circular conformation (NC), and linearized conformation (LC). Changes in bands intensityand the appearance of greysmear are indicator for the fragmentation capacity. Comparable plasma doses of the two APPs are marked with asterisks of the same color (blue for $\sim 30 \mathrm{~J} / \mathrm{cm}^{2}$ and purple for $\sim 100 \mathrm{~J} / \mathrm{cm}^{2}$ ).

As seen in figure 21, untreated control samples showed a wide band between 5 and $3.5 \mathrm{~kb}$ that represents the very condensed, so called supercoiled conformation (SC) of the plasmid. A second very thin band was visible between 10 and $8 \mathrm{~kb}$ representing the nicked circular conformation (NC). After plasma treatment of firefly plasmid, a third band appeared at $5 \mathrm{~kb}$. Bands at these heights represent the linearized conformation (LC), since the size of the firefly 
plasmid is $4863 \mathrm{bp}$ (cf. appendix I.7; Fig. 28). In addition, BamHI enzyme digestion verified that the linearized form indeed runs at about $5 \mathrm{~kb}$.

Having said this, shortDBD treatments (10 s) induced a decrease in SC yields, higher amounts of NC plasmid, and, simultaneously, the appearance of LC plasmids. After longer treatment durations with the $\mu \mathrm{s}$-pulsed DBD (30-180s) the LC plasmid quantity increased and coincidently the NC yield decreased. With longest DBD exposures (270 and $360 \mathrm{~s}$ ), both bands that represent NC and LC plasmids lost intensity indicating a quantitative decrease. Furthermore, grey, blurred smear occurred below the LC band at $60 \mathrm{~s}$, which were getting brighter with extended treatment durations. Small DNA fragments with variable sizes create such smear when running through the gel and, thus, this smear indicates an excessive fragmentation of the plasmid DNA.

Fragmentation was even more pronounced in $\mathrm{KINPen}^{\circledR}$ MED treated samples. It has to be noted, that in comparison to DBD samples, triple amounts of jet-treated DNA had to be loaded into the gel for visualization of bands (cf. 3.4.4). Applications of $10 \mathrm{~s}$ and longer, led to clearly visible blurred smear. With 60-180 s of APP treatments, they appeared lower and lower in the gel. As for DBD treated samples, two bands representing the NC and LC plasmid conformation were produced; the intensity of both bands decreased with extended treatments until almost no bands were visible after $180 \mathrm{~s}$ of plasma application.

At comparable plasma doses of the DBD and the jet, fragmentation of plasmid DNA was more pronounced for plasma jet treatments (Fig. 21; $\sim 30 \mathrm{~J} / \mathrm{cm}^{2}$ and $\sim 100 \mathrm{~J} / \mathrm{cm}^{2}$ marked with blue and purple arrowheads, respectively).

\subsubsection{Post-plasma mutation analysis of plasmid DNA}

The PSV assay was established to examine the genotoxic and mutagenic effects of plasma treatments on plasmid DNA. Results provide information about mutation frequencies and mutation patterns induced by plasma. The assay was performed for the cell line GM, with three selected treatment durations each for both of the plasmasources, and in two different versions. In the first version, pSP189 plasmid solutions were exposed to either the plasma jet or DBD plasma and then transfected into GM cells. In the second version, cells were directly treated with plasma after transfection with untreated pSP189 plasmids. In addition, version 1 and version 2 experiments always included samples irradiated with UVC as positive control.

\subsubsection{Mutation analysis with the PSV-version 1 assay}

\section{1a) Genotoxic effects of plasma treatments on plasmid DNA}

As illustrated in figure 22, relative CFU values decreased with longer plasma application times or increasing plasma doses. A comparison on the basis of same treatment durations showed that e.g. $10 \mathrm{~s}$ of plasma treatment led to a relative CFU value of $67.5 \%$ for $\mathrm{kINPen}^{\circledR} \mathrm{MED}$ 
applications and to $92.8 \%$ CFU for the use of the $\mu$ s-pulsed DBD. Treatments for 60 s resulted in 60\% CFU for jet and 56.7\% CFU for DBD applications (Fig. 22a). However, in both cases, the relative CFU values were not significantly different from each other. After the longest treatment duration with 270 s of DBD plasma, only a few colonies could grow on plates resulting in a CFU value of $3.1 \%$. The positive control - when plasmid solution was irradiated with a UVC dose of $75 \mathrm{~mJ} / \mathrm{cm}^{2}$ - induced a very high relative CFU of $87.7 \%$. Comparing the plasmatype dependent genotoxic effect based on plasma doses, DBD treatments tend to affect plasmid DNA stronger than jet treatments did. Significant lower CFU values were detected at plasma jet doses of $31 \mathrm{~J} / \mathrm{cm}^{2}\left(\hat{=} 10 \mathrm{~s}\right.$ ) and $92 \mathrm{~J} / \mathrm{cm}^{2}\left(\hat{=} 30 \mathrm{~s}\right.$ ) compared to $23 \mathrm{~J} / \mathrm{cm}^{2}$ ( $103 \mathrm{~J} / \mathrm{cm}^{2}$ (^ $\left.270 \mathrm{~s}\right)$ of DBD plasma (Fig. 22b).

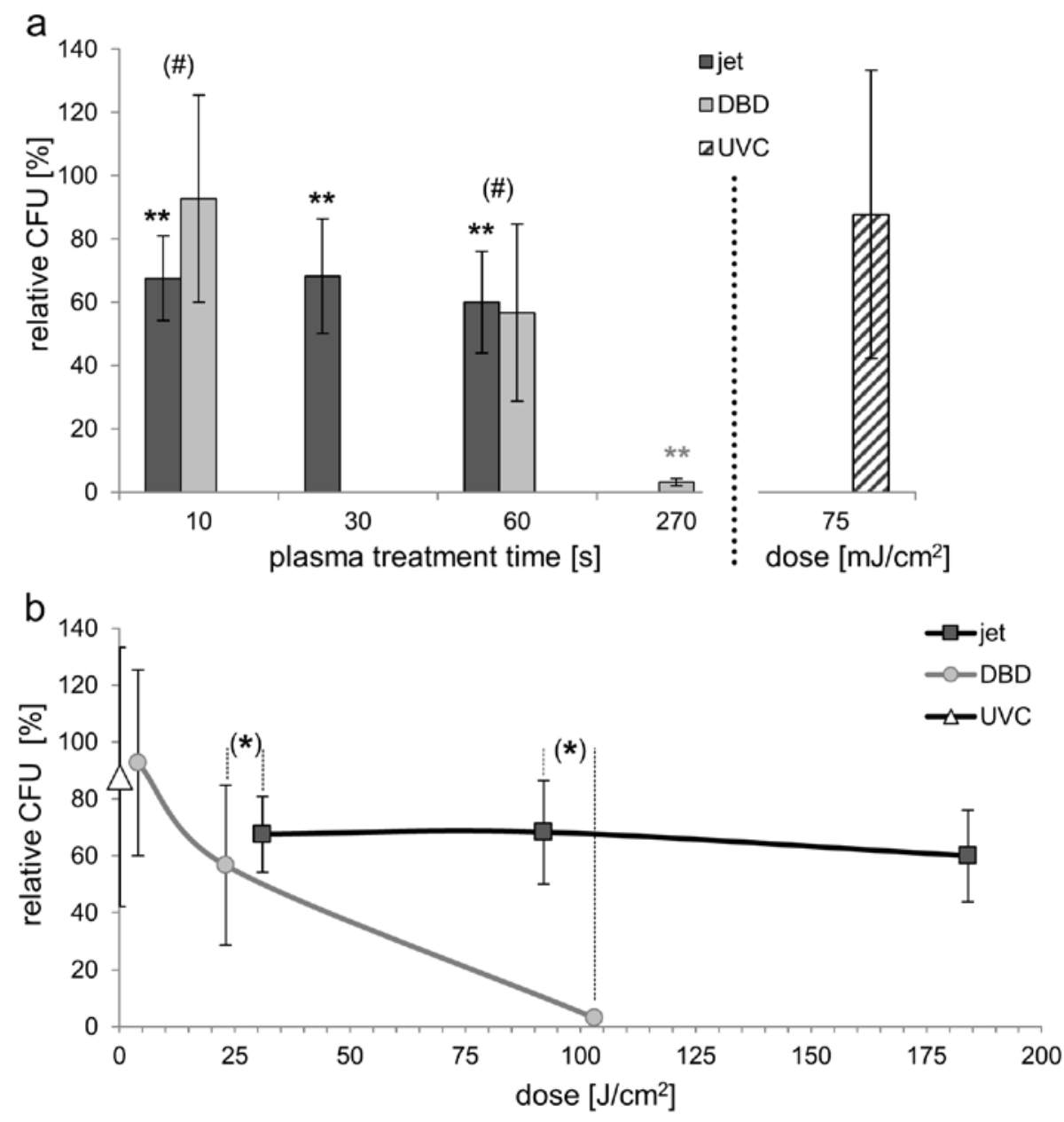

Figure 22: Plasma-type and UVC dependent genotoxicity recorded in the PSV assay-version 1

The relative CFU values are given as a function of plasma treatment times and UVC irradiation (a), as well as a function of different plasma doses (b) for the use of the kINPen ${ }^{\circledR}$ MED and $\mu$ s-pulsed DBD device. In the latter diagram the relative CFU value for the UVC exposure of $75 \mathrm{~mJ} / \mathrm{cm}^{2}$ was also inserted, even though the doses of plasma and UVC are not comparable with each other. Error bars represent SD values. Statistical differences to untreated control samples are marked with ${ }^{* *}(p \leq 0.01)$. Non-significant differences are marked with (\#). Asterisk in brackets refer to the comparison of similar plasma doses around 25 and $100 \mathrm{~J} / \mathrm{cm}^{2}$ marked with * $(p \leq 0.05)$. 


\section{1b) Spontaneous and plasma-induced mutation frequency on plasmid DNA}

For each experiment, the mutation frequency was separately calculated and then values were averaged across experiments. With this, the spontaneous mutation frequency of the pSP189 vector was calculated to be about $0.8 \cdot 10^{-3}$ (Fig. 23). Mutation frequencies steadily increased with expanded treatment durations of the two sources. In case of the plasma jet, 10, 30, and $60 \mathrm{~s}$ of applications resulted in $2.9 \cdot 10^{-3}, 2.1 \cdot 10^{-3}$, and again $2.9 \cdot 10^{-3}$ mutation frequencies, respectively. For DBD treatments mutation frequencies of $0.9 \cdot 10^{-3}(10 \mathrm{~s}), 2 \cdot 10^{-3}(60 \mathrm{~s})$, and $43.3 \cdot 10^{-3}$ (270 s) were calculated. The mutation frequency for $270 \mathrm{~s}$ of DBD application is very striking; it is about 54 times higher than the spontaneous rate and even higher than after plasmid exposure to $75 \mathrm{~mJ} / \mathrm{cm}^{2}$ UVC (mutation frequency: $15 \cdot 4 \cdot 10^{-3}$ ). This high value can be explained by the extremely small number of colonies on ' $270 \mathrm{~s}$ plates' (on average, only about 10 CFUs; i.e. 3.1\% CFU relative to untreated control). Therefore, every single mutation has a high impact on the mutation frequency. Also, it is obvious that the SD values in figure 23 are very high at all treatment conditions. This is due to large differences in colony numbers across, but also within experiments.
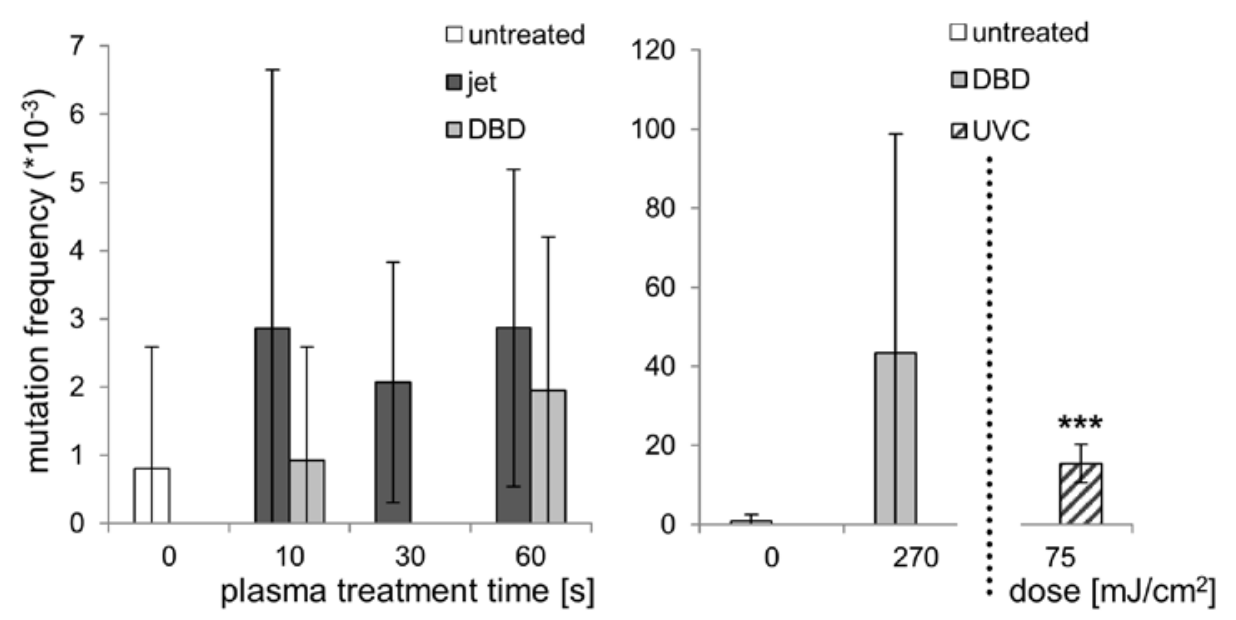

Figure 23: Mutation frequencies of plasma- and UVC-treated plasmid DNA

There is a tendency towards rising mutation frequencies with extended plas ma treatment times using the kINPen $^{\circledR}$ MED and $\mu$ s-pulsed DBD device. For clarity, results of 270s of DBD treatment and UVC irradiation are shown in the right diagram; note that the $y$-axis has a different scale. Error bars represent SDs and the only statistical difference to the untreated control is marked with ${ }^{* * *}(p \leq 0.001)$.

\section{1c) Mutation spectra of plasma-treated plasmid}

The sequences of the supF-tRNA genes on the pSP189 vector were examined for all white colonies that indicated a mutation. In table 2, the mutation spectra are shown for untreated control samples (spontaneous mutations), for UVC irradiation, and for the different plasma sources used. The analysis focused on two general questions: i) what kinds of mutations were induced by different plasma sources/UVC and ii) is there a source/UVC dependent mutation pattern? 


\section{Table 2: Mutation spectra of the supF-tRNA on pSP189 plasmid DNA}

The supF-tRNA sequence (grey) with the complementarystrand (black) is listed and numbered (starting on position 27 in the pSP189 plasmid). Bold and underlined bases mark positions of mutations and the respective mutations are listed below. Every single row represents a single bacterial colony analyzed. Insertions and deletions are marked by vertical lines. Sizes of deletions are provided only if they were countable.

\section{Spontaneous mutations}

\begin{tabular}{llllllll}
27 & 37 & 47 & 57 & 67 & 77 & 87 & 97 \\
CCACCCCAAG & GGCTCGCCGG & TTTCCCTCGT & CTGAGATTTA & GACGGCAGTA & GCTGAAGCTT & CCAAGCTTAG & GAAGGGGGTG \\
\hline GTGG
\end{tabular}

|||||||||| |||||||||| |||||||||| |||||||||| |||||||||| |||||||||| |||||||||| |||||||||| |||||

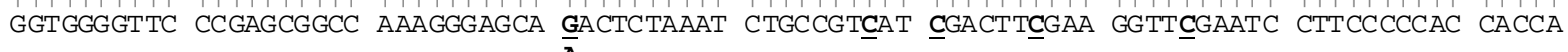
$\bar{A}$

$\mathbf{T} \mathbf{T}$

$\mathbf{T}$
A

UVC irradiation $\left(75 \mathrm{~mJ} / \mathrm{cm}^{2}\right)$

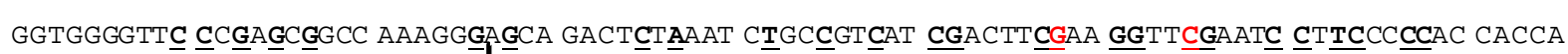

${ }^{T}$

T A

A

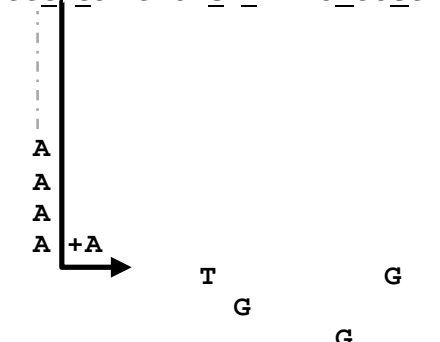

$\mathbf{T}$

A

$\mathbf{T}$
$\mathbf{T}$
$\mathbf{T}$
$\mathbf{T}$
$\mathbf{A}$
$\mathbf{A}$
$\mathbf{A}$
$\mathbf{A}$
$\mathbf{A}$
$\mathbf{A}$
$\mathbf{A}$
$\mathbf{A}$
$\mathbf{A}$

AA

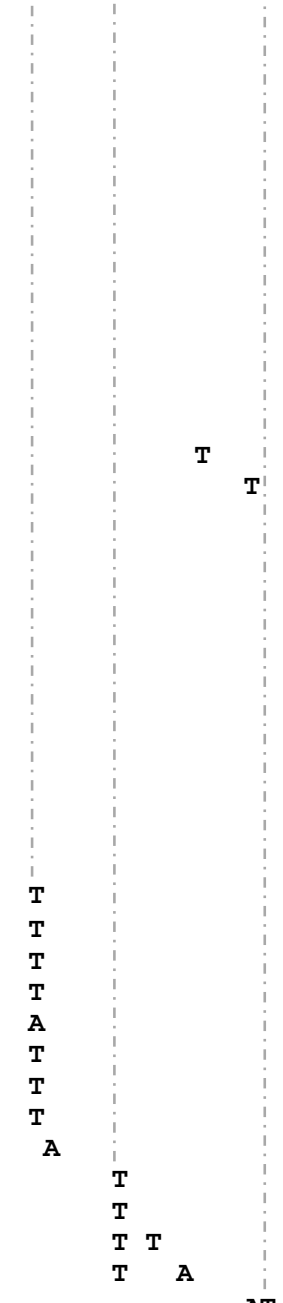

AT

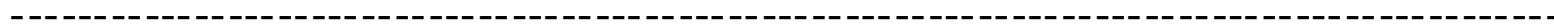

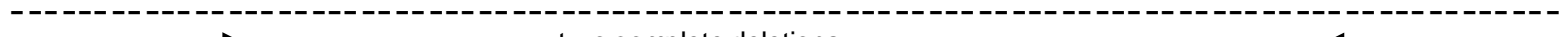

tw o complete deletions 


\section{Jet treatment}

$10 \mathrm{~s}\left(\hat{=} 31 \mathrm{~J} / \mathrm{cm}^{2}\right)$

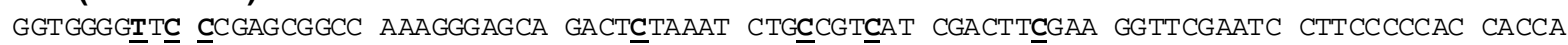
$\bar{A} \frac{T}{T}$

A

G

G

$\begin{array}{ll}\text { T } & \mathbf{T}\end{array}$

A

$30 \mathrm{~s}\left(\bumpeq 92 \mathrm{~J} / \mathrm{cm}^{2}\right)$

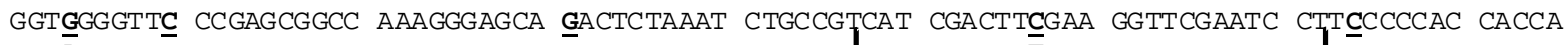
$\bar{A}$

A

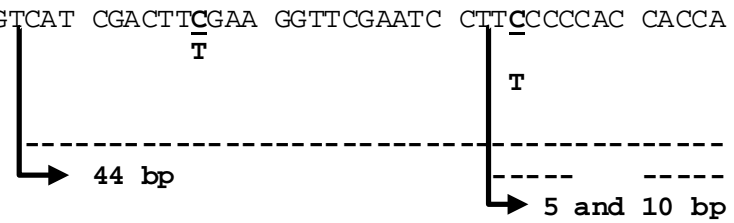

$60 \mathrm{~s}\left(\hat{=} 184 \mathrm{~J} / \mathrm{cm}^{2}\right)$

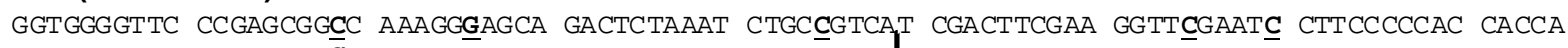
$\overline{\mathbf{G}}$

T

A

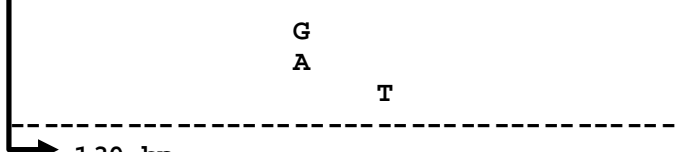

$130 \mathrm{bp}$

DBD treatment

$10 \mathrm{~s}\left(\hat{=} 4 \mathrm{~J} / \mathrm{cm}^{2}\right)$

GGTGGGGTTC CCGAGCGGCC AAAGGGAGCA GACTCTAAAT CTGCCGTCAT CGACTTCGAA GGTTCGAATC CTTCCCCCAC CACCA $\bar{A}$

$60 \mathrm{~s}\left(\hat{=} 23 \mathrm{~J} / \mathrm{cm}^{2}\right)$

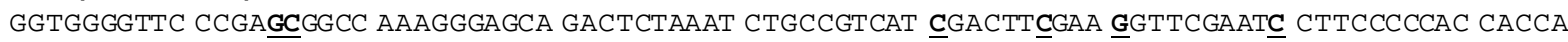
$\mathbf{T}$

A A

A

G

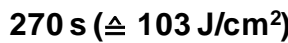

GGTGGGGTTC CCGAGCGGCC AAAGGGAGCA GACTCTAAAT CTGCCGTCAT CGACTTCGAA GGTTCGAATC CTTCCCCCAC CACCA $\bar{A}$

T $\quad$ T

For UVC irradiations in total 53 mutations were detected in 44 bacterial colonies, the majority of which were point mutations of the type pyrimidine and purine transitions. Thus, showing a mutation pattern induced by UV exposure, as expected. More specifically the following mutations were observed: 23 pyrimidine transitions of the type $C \rightarrow T, 19 G \rightarrow A$ purine transitions, one $A \rightarrow G$ purine transition, six transversions $(3 x C \rightarrow A, 1 x C \rightarrow G, 1 x G \rightarrow T$, $1 x T \rightarrow G, 1 x T \rightarrow A$ ), two complete deletions, and one insertion of only one A nucleobase. As expected for UVC irradiation, pyrimidine rich regions in the sequence were most susceptible to generate point mutations; e.g. on position 85 and 91 in the supF-tRNA sequence, seven 
purine and pyrimidine transitions were found $(G \rightarrow A$ and $C \rightarrow T$, respectively; red labeled base positions for UVC irradiation in table 2).

For plasma applications, no clear mutation patterns were obvious. In total 23 (in 18 colonies) and 15 (in 11 colonies) mutated regions were found after treatments with the kINPen ${ }^{\circledR}$ MED and the $\mu \mathrm{s}$-pulsed DBD device, respectively. In more detail, plasma jet treatments for 10,30 , and 60 s led to the formation of 9,5 , and 6 single base substitutions. Deletions were detected for $30 \mathrm{~s}$ (two deletions) and $60 \mathrm{~s}$ (one deletion) of plasma jet application. The DBD plasma induced 5 mutations after $10 \mathrm{~s}, 6$ mutations after $60 \mathrm{~s}$, and 4 mutations after $270 \mathrm{~s}$ of treatment. Only one deletion was found after a 10 s application.

Similar to UVC irradiation, plasma applications more often caused $C \rightarrow T$ and $G \rightarrow A$ transitions than transversions: plasma jet treatments induced $7 x \mathrm{C} \rightarrow \mathrm{T}$ (4 after 10s, 2 after $30 \mathrm{~s}$, and 1 after $60 \mathrm{~s}$ ) and $1 \times \mathrm{G} \rightarrow \mathrm{A}$ (after 30s); DBD plasma induced 6x C $\rightarrow \mathrm{T}$ (3 after 10s, 1 after $60 \mathrm{~s}$, and 2 after $270 \mathrm{~s}$ ) and $4 \times \mathrm{G} \rightarrow \mathrm{A}$ ( 1 after 10s, 1 after $60 \mathrm{~s}$, and 2 after $270 \mathrm{~s}$ ). Spontaneous mutations (total: 5$)$ were of the kind $C \rightarrow T(3 x), G \rightarrow A(1 x)$ transitions and one transversion $(1 \times C \rightarrow A)$.

\subsubsection{Mutation analysis with the PSV-version 2 assay}

\section{2a) Genotoxic effect of APP on untreated pSP189 plasmid DNA within fibroblasts}

In most cases, the relative CFU values decreased with extended plasma treatments or with higher UVC irradiation doses indicating a genotoxic effect due to plasma and UVC on plasmid DNA within fibroblasts (Fig. 24a).

UVC as positive control was applied in different doses than in version 1, because an irradiation dose of $75 \mathrm{~mJ} / \mathrm{cm}^{2}$ would kill most GM cells in the dish. As expected, the relative CFUs decreased as a function of higher UVC doses $\left(2.5 \mathrm{~mJ} / \mathrm{cm}^{2}: 23.3 \%, 5 \mathrm{~mJ} / \mathrm{cm}^{2}: 19.8 \%\right.$, $\left.7.5 \mathrm{~mJ} / \mathrm{cm}^{2}: 9.9 \%\right)$.

CFU values also steadily decreased for plasma jet applications (10s: $85.1 \%$, 30 s: $79.3 \%, 60 \mathrm{~s}$ : $59.6 \%)$. In contrast, applying the DBD plasma for 10 s to GM cells including untreated pSP189 DNA resulted in an even higher CFU (166.3\%) than in untreated control samples. With the longest treatment duration of 270 s the CFU value was reduced to $75.3 \%$.

When comparing the CFU values of same treatment durations for both sources (10 and $60 \mathrm{~s}$ ), only a significant lower CFU was detectable at $10 \mathrm{~s}$ generated by the plasma jet (Fig. 24a). Results of the comparison based on similar plasma doses showed that plasma jet and DBD treatments induced very similar CFUs in the range of about $25-105 \mathrm{~J} / \mathrm{cm}^{2}$. 

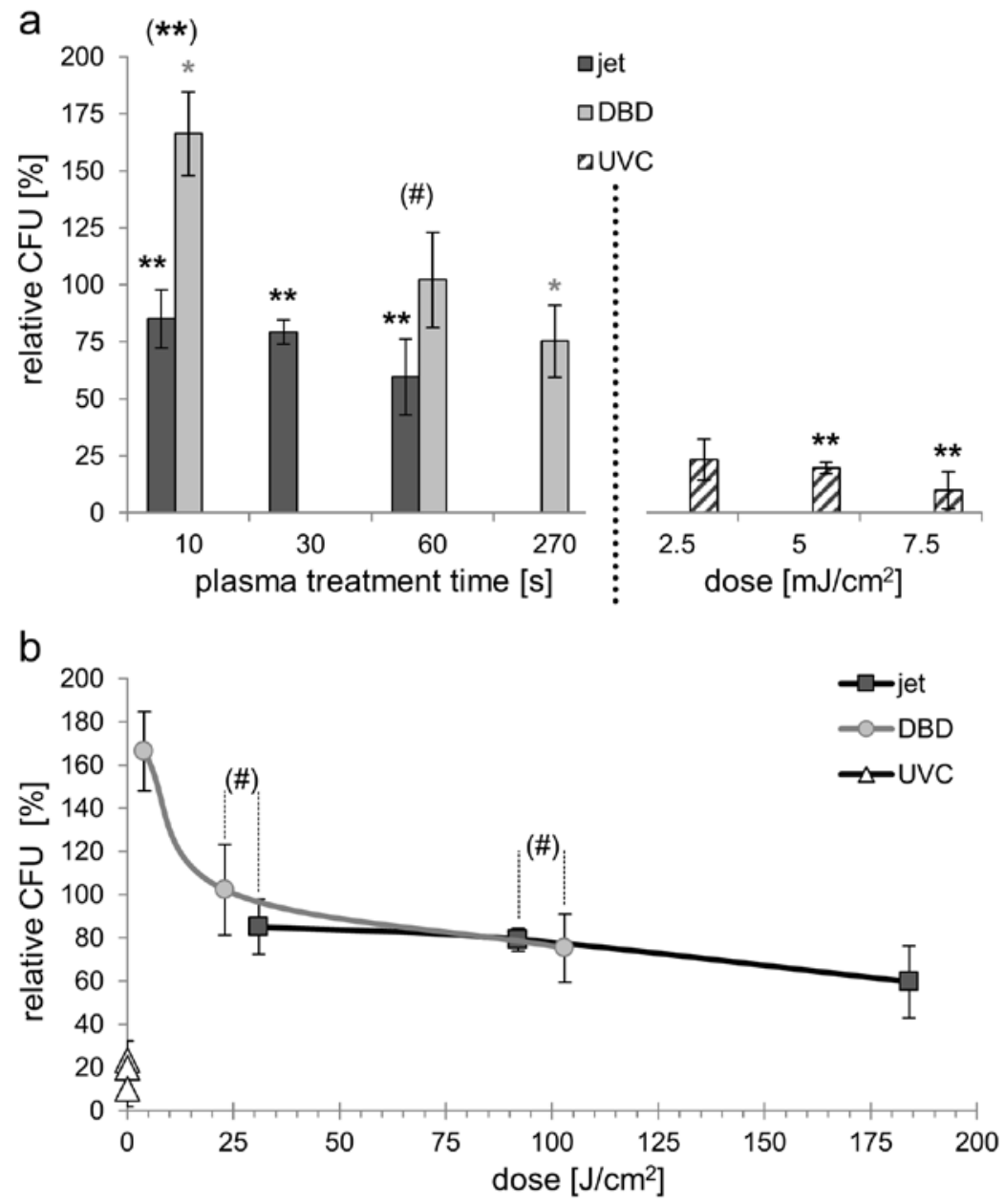

Figure 24: Plasma-type and UVC dependent genotoxicity recorded in PSV assay-version 2

Relative CFU values are shown as a function of plasma treatment durations (a) and plasma doses (b) for the use of the KINPen ${ }^{\circledR}$ MED and the $\mu$ s-pulsed DBD device. In both plots CFU values induced by UVC irradiations are included demonstrating that UVC at these doses had the strongest impact. Error bars represent SDs. Statistical differences to the untreated control samples are marked with * $(p \leq 0.05)$ and ** $(p \leq 0.01)$. Asterisk in bracket refer to the comparis on between the two plasma sources applied for $10 \mathrm{~s}$. Non-significant differences are marked with (\#).

\section{2b) Plasma-induced mutation frequencies of plasmid DNA transfected into fibroblasts}

In this version of the PSV assay no mutated colonies were detectable on untreated control agar plates. In addition, only few mutations were found in treated samples, i.e. only three mutated colonies of 3113 colonies, all of which were induced by DBD plasma with 10 and $60 \mathrm{~s}$ of treatment durations. Hence, the mutation frequency after $10 \mathrm{~s}$ of DBD treatment was calculated to be $1.88 \cdot 10^{-3}\left( \pm 0.81 \cdot 10^{-3}\right)$ and after $60 \mathrm{~s}$ of DBD exposure was $0.84 \cdot 10^{-3}$ $\left( \pm 0.69 \cdot 10^{-3}\right)$. Only the DBD plasma applied for 10 s generated a slightly higher but not significant different mutation frequency than spontaneously evoked (cf. $0.8 \cdot 10^{-3}$ observed in version 1). 


\section{2c) Mutation spectrum}

Only a few point mutations could be detected in DBD treated samples (table 3).

Table 3: Mutations recorded in the PSV assay-version 2

\begin{tabular}{cc} 
DBD treatment & Mutation \\
\hline \hline 1. colony (10s) & $2 \times C \rightarrow T$ \\
& $2 \times C \rightarrow A$ \\
2. colony (10s) & $G \rightarrow A$ \\
3. colony (60s) & $G \rightarrow C$
\end{tabular}

\subsubsection{Flow cytometric analyses of genomic DNA damages in fibroblasts}

Gel electrophoresis, HCR and PSV experiments already indicate genotoxic effects of plasma, which likely involved the formation of DNA strand breaks. To estimate the amount of DSB as a function of plasma treatment time, flow cytometric analyses were carried out with the DSB marker $\mathrm{Y}-\mathrm{H} 2 \mathrm{~A} . \mathrm{X}$ antibody. The antibody binds to the phosphorylated H2A.X histone protein that is known to be formed in high numbers by cells after a single DSB event $[152,154]$. The assay was only performed with the kINPen ${ }^{\circledR}$ MED device and on GM cells.

lonized radiation known to induce DSB events $[152,170]$ was used as positive control. As expected, $\mathrm{Y}-\mathrm{H} 2 \mathrm{~A}$.X signals increased with higher $\mathrm{X}$-ray radiation doses (upper $\mathrm{X}$-axis in Fig. 25). The relative $Y-H 2 A . X$ fluorescence signals also increased with extended jet treatment durations (lower X-axis in Fig. 25). Similar $Y-H 2 A . X$ signals were induced by $30 \mathrm{~s}$ and $1 \mathrm{~Gy}, 60 \mathrm{~s}$ and $3 \mathrm{~Gy}, 90 \mathrm{~s}$ and $5 \mathrm{~Gy}$, or $180 \mathrm{~s}$ and $7 \mathrm{~Gy}$ of plasma and X-ray treatments, respectively.

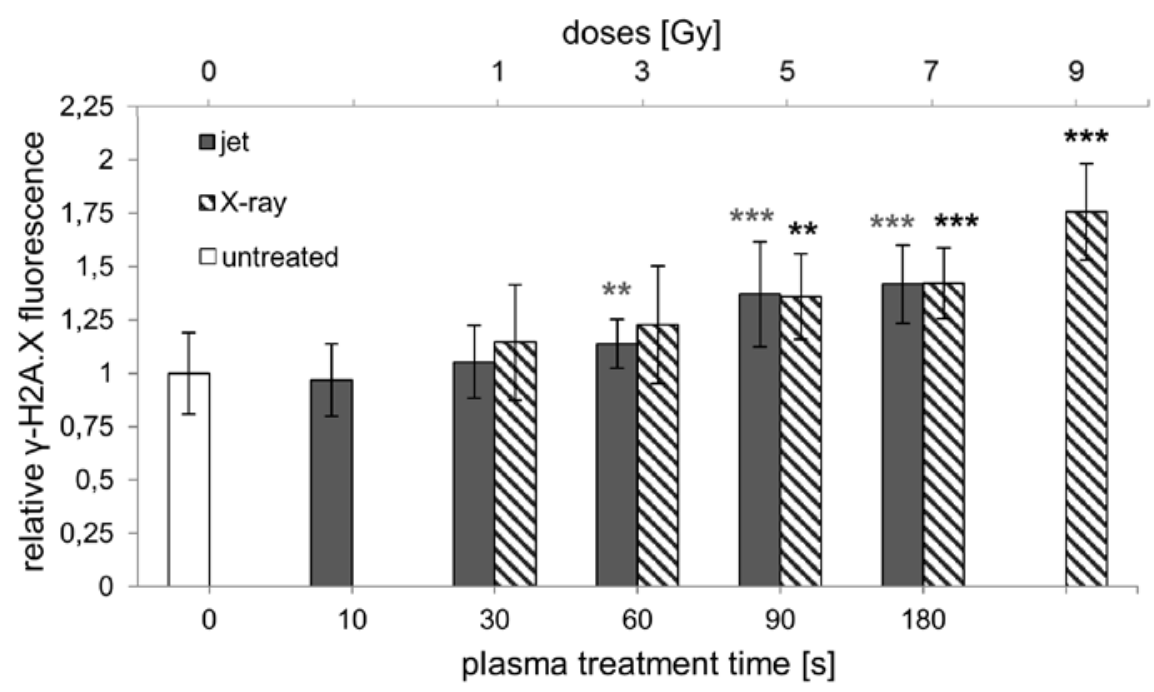

Figure 25: Plasma-and X-ray-induced DSBs measured as relative Y-H2A.X fluorescence

The relative $Y-H 2 A . X$ fluorescence signals generated in GM cells are shown as a function of plasma jet treatments and X-ray irradiations. For a better comparability between kINPen ${ }^{\circledR}$ MED and X-ray treatments, two $x$-axes are illustrated: jet treatment times on the lower X-axis and X-ray doses on the upper $x$-axis. Error bars represent SD values. Statistical differences to the untreated control (defined as 1$)$ are marked with $* *(p \leq 0.01)$ and $\star \star \star ~(p \leq 0.001)$. 


\section{Discussion}

The many advantages of plasma therapy are at present still countered by the necessity of assessing the safety of this promising technique. Even though more and more researchers in the plasma medicine community perform detailed evaluations of risks and side effects, still, plasma specific, official guidelines for medical applications of APPs are missing.

Such guidelines are especially important in dermatology, where the skin of patients is directly exposed to APP. Thus, during application, all plasmacomponents come in contact with human cells and their environments, which may be of advantage but also may lead to detrimental side effects. Several publications already introduced plasma sources as therapeutic tool in dermatology mostly striving to treat highly infected or chronic wounds $[5,25,110,165,171-$ 173]. In most of the studies, the physical properties of the plasma sources were characterized and potential risk factors were named and discussed. However, a comparison of their results is impossible since experimental settings and procedures differ greatly between studies. Furthermore, biomedical efficiency characterizations of the various sources often did not include experiments on genotoxic or mutagenic effects. However, plasma contains a number of biologically active particles, some of which are well known to cause genomic alterations, e.g. reactive species and UV radiation [12, 17, 174-177]. It was demonstrated for several times that plasma applications on isolated DNA induce strand breaks, which lead to DNA fragmentation in a dose dependent manner [178-182]. Moreover, various studies confirmed that genomic DNA inside the nucleus of cells is also modified due to plasma applications [80, 182-185]. This may trigger cells to initiate the apoptotic pathway or it may result in the formation of mutations within the genome. If manifested mutations are induced and changes in the chromatin structure are permanent, the genetic integrity becomes instable and oncogenic transformation of cells may occur [186-189], which is a serious threat to humans.

For these reasons, a complete, detailed characterization of medical plasma sources is of great importance, not only for the patients, but also for nurses, physician assistants, and medical doctors using the device. Furthermore, it is of quite importance that results obtained with different plasma sources or varying efficiency parameters can be compared. With this knowledge physical settings and treatment recommendations may be fine-tuned for a specific source in order to achieve the best application results for desired effects.

In this thesis, test systems were developed and described, which were used for a basic physical characterization of two different plasma sources. Most, but not all test systems described in the first part of this thesis, were published in the DIN-SPEC 91315 [11]. The second, major part of this thesis presents procedures and assays, which were established to 
the use of plasma sources for the assessment of the genotoxic and mutagenic effects. Longterm damages and possible side effects can thereby be discovered.

\subsection{Basic characterization of medical plasma sources}

In cooperation with the INP, the University Medical Center in Greifswald, the IFS ('Institut für anwendungsorientierte Forschung und klinische Studien') in Göttingen, and the TU Berlin (chair of innovation economics) the first document describing the techniques and methods for a basic performance characterization based on defined plasma specific criteria for APP sources was developed and published [11]. Part one of the DIN-SPEC 91315 describes test systems for measuring generally important physical and technical parameters: i.e. plasma temperature, UV radiation, gas emission, and generated currents. In part two, assays to evaluate basic biomedical performance characteristics are introduced: i.e. microbial inactivation efficiency, cytotoxic effect, plasma-liquid interaction. The two APP devices used in this thesis - the KINPen ${ }^{\circledR}$ MED and the $\mu$ s-pulsed volume DBD - were characterized as described in the DIN-SPEC 91315. Minor adjustments had to be made for the use of the DBD device because the assays in the document are based on the use of a plasma jet type, only.

\subsubsection{Physico-technical parameters and medical treatment requirements}

The results of physico-technical capacity measurements of the two APP sources indicate that both devices are safe in the general use. According to already existing guidelines and thresholds (cf. 4.1.1) no risks are to be expected from electric currents, gas temperature, UV radiation, and the emission of $\mathrm{O}_{3}$ and $\mathrm{NO}$.

Nevertheless, the general physical characterization also revealed that during treatments with the KINPen ${ }^{\circledR}$ MED device certain requirements have to be complied with. The distance between the nozzle and treated object should be at least $7 \mathrm{~mm}$ to avoid burns on the skin. As already mentioned, the recommended working distance for the kINPen ${ }^{\circledR}$ MED is 7-10 mm [138], which is in agreement with the safety aspect regarding temperature. UV radiation generated in this plasma should be considered in more detail. According to ICNIRP guidelines [164], thresholds for irradiation are reached with $85 \mathrm{~s}$ of a spot treatment. To avoid health risks due to UV irradiation spot treatments, therefore, must not exceed $85 \mathrm{~s}$, or the jet must be constantly moved across the treatment area. The latter would also reduce the actual supplied temperature onto the skin. Still, the detrimental impact of highly energetic VUV radiation should not be neglected. Even though the effective irradiance of the plasma jet was measured in a wide range from 100-400 nm, VUV below $100 \mathrm{~nm}$ were not included. VUV radiation can induce strand breaks or damage proteins in cells by breaking covalent bonds between $\mathrm{C}-\mathrm{C}$ or $\mathrm{C}-\mathrm{H}$ chemical compounds [190]. However, there are no sophisticated data or studies that determine 
exactly VUV emission in the kINPen ${ }^{\circledR}$ MED device, wherefore no reasonable statement can be given regarding VUV specific health risks.

The only limit for applications with the $\mu$ s-pulsed DBD refers to UV radiation; here, the total exposure duration of $7 \mathrm{~h}$ per day must not be exceeded. In all in-vivo studies where plasma was applied to human or animal skin, advantageous effects were observed after applications for less than $10 \mathrm{~min}$ at a time $[46,109,110,191]$. According to the ICNIRP guidelines, $\mu \mathrm{s}$-pulsed DBD applications of this duration are safe and, thus, no risk is to be expected from UV radiation.

\subsubsection{Biomedical efficiency of APP}

For a general and basic assessment of the medical potential of APP sources three common and easy to perform test systems were chosen. The first test provides information about the antimicrobial strength of APP treatments. In dermatological therapy this is important since various skin diseases are accompanied or the cause of pathogenic colonization. In wounds that go deeper than the epidermis, fibroblasts are uncovered and surrounded by body fluids that leak out of the wound. During APP treatments of such wounds fibroblasts will come in contact with plasma components wherefore the second test system, namely the MTS assay, investigates the cytotoxic effect of APPs on skin fibroblasts. The wound liquid will also be affected by plasma. Therefore, the last analysis deals with chemical changes of plasma-treated physiological solution.

\subsubsection{Plasma inactivation efficiency against microorganisms}

As already mentioned, the same inactivation experiments were not performed with the $\mu \mathrm{s}$ pulsed DBD. However, various sophisticated studies examined the antimicrobial effect of volume DBDs in similar settings [106, 192]. In Mertens et al. [192] a bactericidal effect on E. coli, $P$. aeruginosa, and C. albicans was already detectable after $2 \mathrm{~s}$ of plasma application, which corresponds to a low plasma dose of $0.17-0.18 \mathrm{~J} / \mathrm{cm}^{2}$. Similarly, in the comprehensive work by Daeschlein et al. [106], an effective inactivation of 13 different bacterial and fungal wound pathogens was achieved within $3 \mathrm{~s}$. Comparing the bactericidal effect of the kINPen ${ }^{\circledR}$ Med device with results presented in Daeschleinet al. [106], antimicrobial elimination efficiency was stronger for the use of the DBD source. $1 \mathrm{~min}\left(\hat{=} 184 \mathrm{~J} / \mathrm{cm}^{2}\right)$ of jet application, e.g. generated an inhibition zone of about $113 \mathrm{~mm}^{2}$ in $S$. epidermidis samples (calculated from Fig. 11), whereas $3 \mathrm{~s}\left(\bumpeq 0.193 \mathrm{~J} / \mathrm{cm}^{2}\right)$ of treatment with the DBD plasma induced an inhibition area of about $240 \mathrm{~mm}^{2}$ [106]. It must be noted that in Daeschlein et al. [106] two different plasmasources were used; the kINPen09 plasmajet and a volume DBD. The kINPen09 device is only in some parts comparable to the kINPen ${ }^{\circledR}$ MED due to different physical settings. Nevertheless, the comparison of inhibition zones generated by the two devices also showed - in most cases - higher inactivation efficiencies induced by DBD treatments, which is in 
agreement with the comparison made above. Since the here used $\mu$ s-pulsed DBD is comparable with the one used in Daeschlein et al. [106], it can be assumed that similar inactivation efficiencies can be obtained. Moreover, a modified version of this DBD (PlasmaDerm ${ }^{\circledR}$ VU-2010) was used in a clinical trial on chronic wounds of the type venous ulcus cruris [110]. This study revealed a significant reduction of bacterial loads in the wounds and a slightly enhanced wound healing when plasma was applied in addition to standard wound care. However, detailed analysis of the $\mu$ s-pulsed DBD inactivation efficiency is required, before this device can be considered as effective antimicrobial toll in dermatological therapies.

\section{Suitability of inhibition zone tests}

The inhibition zone test is a simple technique to evaluate antimicrobial effects of different plasmas and, therefore, is appropriate for an uncomplicated assessment of inactivation efficiencies of APPS. However, in the DIN-SPEC 91315 we recommend to perform another method to estimate the inactivation efficiency. For this test, microorganisms grown in suspension must be exposed to plasma before plating. Then, colonies growing on these plates are counted and the reduction rate calculated in $10^{-x} \log$ steps. Disinfection is achieved when the CFU value was reduced at least by a factor of $10^{-5}$ and sterilization level is achieved when the germ reduction is at least $10^{-6}$. These definitions should be considered as rough guidelines for inactivation efficiency tests with plasma because even if a single plasma application of an infected wound does not reduce bacteria to disinfection or sterilization levels, in the practical medical use, multiple treatments over days or weeks will restrict bacterial overgrowth and, thus, continuously improve wound healing.

\subsubsection{Cytotoxic effects of APPs on human skin fibroblasts}

The in-vitro MTS assay was performed to quantify the cytotoxic effects of the two plasma sources on two different types of human skin fibroblast: i.e. immortalized GMs and PFs isolated from healthy skin samples. The results revealed decreasing fibroblast viabilities with extended application times or increasing plasma doses (Fig. 13).

As mentioned before, reactive species generated by plasmas are most likely the main mediators for cell responses, followed by UV radiation and electric currents (this refers to biomedical APP sources only). In the same manner as ROS and RNS, UV radiation, and electric excitation elicit dose or power dependent effects, APP was also found to cause different cell responses depending on the treatment duration and on how the plasma was produced $[21,23,182,193]$. This is because these parameters determine the composition of the plasma and the plasma dose. In the next two subsections, major mechanisms are presented, all of which are likely to contribute to the cytotoxic effect observed in this thesis. 


\section{Cell membrane damage and elevated endogenous ROS level}

The first target of plasma components in MTS experiments was the PBS covering the cells during treatments. PBS has a buffering property via the balanced chemical Eq. 23 that efficiently consume $\mathrm{OH}^{-}$and $\mathrm{H}^{+}$ions:

$$
\mathrm{H}_{2} \mathrm{PO}_{4}^{-} \leftrightarrow \mathrm{HPO}_{4}^{2-}+\mathrm{H}^{+}
$$

In this way, the pH of PBS is effectively stabilized at about 7.4, which was verified by measurements of $\mathrm{pH}$ changes in plasma-treated PBS (Fig. 17). The same buffering system, in addition to some others, stabilizes the $\mathrm{pH}$ in intra- and extracellular fluids [194]. Nevertheless, if concentrations of $\mathrm{OH}^{-}$and $\mathrm{H}^{+}$are too high and the buffering capacity is depleted, these ions will react with other molecules in the PBS buffer.

Both devices, the $\mathrm{KINPen}^{\circledR}$ MED and $\mu$ s-pulsed DBD, generate high concentrations of different ROS ( $\left.\mathrm{ROOH}, \mathrm{OH}^{\bullet}, \mathrm{O}_{2}{ }^{-}\right)$and $\mathrm{RNS}\left(\mathrm{NO}, \mathrm{NO}_{2}^{-}, \mathrm{NO}_{3}{ }^{-}\right)$. Short-lived and highly reactive radicals like $\mathrm{OH}^{\bullet}$ will preferentially react with nearby molecules at the point of generation and may then be transformed into long-lived species like $\mathrm{O}_{3}, \mathrm{H}_{2} \mathrm{O}_{2}, \mathrm{NO}_{2}$, and $\mathrm{O}_{2}$. These long-lived species then diffuse through the PBS solution, reach cells and induce oxidative stress in a number of different ways. They can for example directly affect the cell membrane. The lipid bilayer that constitutes the cell membrane can be oxidized by such long-lived species or other ROS like alkoxyl radicals $\left(\mathrm{RO}^{\bullet}\right)$ or peroxyl radicals (ROO*), which degrade the membrane [195]. It has already been confirmed that plasma applications cause lipid peroxidation of cell membranes [196] and, thus, induces transient pores [178], which affect the fluidity and transport properties of the membrane. Plasma application may also lead to gaps in the lipid layer by charging the lipids $[73,178]$ due to the electric current flowing across the cells. However, pores in the cell membrane enhance the diffusion rate of reactive species into the cell and then, they can react with other cell components. UV radiation is also known to affect cell membranes. It can directly disrupt the lipids, which leads to the formation of pores, and/or it can oxidize lipids via photogenerated ROS (e.g. $\mathrm{H}_{2} \mathrm{O}_{2}, \mathrm{OH}^{\bullet}, \mathrm{O}_{3}$, and singlet molecular oxygen $\left(\mathrm{O}_{2}\left({ }^{1} \Delta_{\mathrm{g}}\right)\right.$ ) in aqueous solutions [197]. The following equation shows the transformation of $\mathrm{O}_{3}$ and water to $\mathrm{H}_{2} \mathrm{O}_{2}$, which can be induced by UV light shorter than $330 \mathrm{~nm}$ (Eq. 24) [198]:

$$
\mathrm{O}_{3}+\mathrm{H}_{2} \mathrm{O}+h v \rightarrow \mathrm{H}_{2} \mathrm{O}_{2}+\mathrm{O}_{2} \text {. }
$$

$\mathrm{H}_{2} \mathrm{O}_{2}$ itself can be excited by UV light below $300 \mathrm{~nm}$ to form $\mathrm{OH}^{\bullet}$ radicals (Eq. 25) [198, 199]:

$$
\mathrm{H}_{2} \mathrm{O}_{2}+h \mathrm{v} \rightarrow 2 \mathrm{OH}^{\bullet}
$$

Nevertheless, most researchers are certain that reactive species, especially ROS are responsible for plasma-induced cell responses affecting the viability of cells $[21,83,86,184$, 200]. Not only does the plasma-mediated formation of ROS in the extracellular space play a 
central role in triggering cellular oxidative stress, but it also causes elevated endogenous ROS levels $[21,114,201]$. One of the main sources of ROS in cells is the mitochondrial respiratory pathway, which produces nearly $90 \%$ of the cellular energy by oxidative phosphorylation of adenosine diphosphate (ADP) to form adenosine triphosphate (ATP) [202-204]. Mitochondrial dysfunction due to significantly increased ROS levels can trigger mitochondria-mediated apoptosis [205]. The study of Ahn et al. [88] demonstrated that plasma treatment depolarized the membrane potential of mitochondria, which is an early event of apoptosis. Other studies confirmed that mitochondria-mediated apoptosis is one effect of plasma applications [80, 200].

\section{DNA damages}

UV radiation produced by plasma sources was assumed to rather play a minor role; at least regarding its decontamination and sterilization efficiency against microorganisms $[18,206$, 207]. Even though this assumption is based on prokaryotic inactivation studies, the hypothesis that UV may be of minor importance in plasma-cell interactions is, unfortunately, somehow generally accepted. Still, since UV radiation has been shown to be a cellular stressor, potential medical risks and benefits of this plasma component should also be considered and explored. UV radiation does not only affect genomic DNA directly, but is also known to trigger the intracellular release and production of $\operatorname{ROS}[208,209]$. Especially $\mathrm{ROS}$, like $\mathrm{O}_{2}{ }^{\bullet}$ or $\mathrm{OH}^{\bullet}$ can oxidize DNA molecules and give rise to numerous different DNA lesions or strand breaks via reactions with DNA bases or sugar moieties [17-19, 182].

UV radiation also affects DNA because photons can be directly absorbed by nucleic acids, which leads to the generation of photoproducts (CPD and/or 6,4PP). Especially photons from UVC radiation produce significant amounts of severe CPD and 6,4PP photolesions. However, both plasma devices used in this project do not generate emission bands in the UVC region, but UVB and UVA radiations. UVB radiation can directly induce CPD and 6,4PP DNA damages, but also other modifications of nucleobases, e.g. the oxidized form of guanine 7,8-dihydro-8-oxoguanine (8-oxoG) $[13,16]$. In contrast, UVA irradiation is thought to mainly indirectly evoke DNA lesions or modifications via secondary photoreactions producing ROS. Interestingly, some studies found evidence that UVA may also generate photoproducts directly $[13,16]$. UV-induced injury of skin cells is attributed to aging, wrinkle formation, sunburn, and, in the worst, causes skin cancer $[12,13,16,161,162]$.

Taken together, all these described influences of separate plasma components can reinforce one another during plasma treatments of cells, which results in an overall synergistically enhanced effect.

\section{Cell-type dependent cytotoxic effects}

The results of the MTS assay demonstrate that cell viability of both types of fibroblasts (GM and PF) decreased in a cell-type dependent manner with extended plasma treatment times. 
When using the $\mathrm{kINPen}^{\circledR}$ MED device, in all cases GM cells reacted more sensitive to treatments than PFs, seen as lower viability values induced after same treatment durations. In contrast, at short and direct DBD applications of up to one minute, PFs were more sensitive than GMs (Fig. 13b). This indicates that such short DBD treatments somehow are better compensated by GMs than PFs.

One possible explanation could be based on the cellular nature of the two cell types. GM00637 is a SV40 transformed and, therefore, immortalized cell line. As a consequence, these cells divide more frequently than normal cells due to deregulated p53 tumor suppressor proteins [210]. The normal cell cycle arrest at checkpoints (i.e. G1/S and G2/M phase) is bypassed, which leads to abnormal proliferation behavior comparable to cancer cells. It can be assumed that PF cells with normal cell cycle will arrest at checkpoints due to DNA damages induced by short DBD plasma application whereas GM cells will proliferate further on until a certain threshold of damage or cellular stress. This may explain that treatment durations of up to $60 \mathrm{~s}$ caused higher cell viabilities of GMs compared to PF cells.

Extended DBD treatment times of $60 \mathrm{~s}$ and longer or plasma doses of $23 \mathrm{~J} / \mathrm{cm}^{2}$ and higher resulted in lower viability values of GMs compared to PFs, which might be also explained by the fact that the proliferation behavior of GM and cancer cells is similar. Cancer cells are known to have defects in several signaling pathways, resulting in oncogenic stimulation, increased metabolic activity due to apoptosis inhibition, mitochondrial malfunction, and impaired repair mechanisms. This leads to an accumulation of defects in the cell, and moreover to a higher intracellular ROS level than normal [211-213]. As already stated, plasma applications can induce and increase exogenous and endogenous ROS stress for cells. Upon a certain plasma dose cancer cells may reach the apoptosis threshold faster than normal cells due to the induced ROS stress in addition to the already higher basis level of intracellular ROS [184, 212, 214]. It might be suggested that GM cells also comprise higher basis ROS levels as a consequence of immortalization. Moreover, in the study of Ma et al. [184], cancer cells that lack functional p53 showed an exceptionally high sensitivity to repetitive plasma treatments compared to p53-proficient cancer cell lines. It is, therefore, quite likely that plasma treatments of GM cells led to a stronger cytotoxic effect upon a certain threshold compared to normal and intact PF cells. Another explanation can be based on the higher division rate of GMs, wherefore cells are more often in the S-phase of their cell cycle. DNA is generally more susceptible to genetic modifications in this phase of the replication process [187, 189, 215]. Hence, reactive species and UV radiation produced in the plasma may induce more DNA damages in GM cells than in PFs. Accumulation of DNA lesions, failure in repairing damages, and resulting genomic instability will force the cell to initiate apoptosis or it may degenerate [186, 189].

In consistence with these hypotheses, plasma jet treatments with doses of $31 \mathrm{~J} / \mathrm{cm}^{2}(\hat{=} 10 \mathrm{~s})$ and higher induced stronger reductions of $\mathrm{GM}$ viabilities compared to PF viabilities. In 
conclusion, this would mean that induced cell damages with low plasma doses (up to about $30 \mathrm{~J} / \mathrm{cm}^{2}$ ) do not force GM cells to arrest at cell cycle checkpoints; they proliferate further on, while PF proliferation is slowed down in the first instance. At doses $\geq 30 \mathrm{~J} / \mathrm{cm}^{2}$ the induced ROS stress might be high enough that the threshold of initiating apoptosis is reached earlier in GM cells than in PFs. Due to the abnormal proliferation behavior of GMs the cells presumably accumulate more damage. This would lead to a more sensitive reaction of GM cells when they are exposed to such high plasma doses.

\section{Source dependent decrease of cell viability}

When comparing the source dependent cytotoxic effect on fibroblasts on the basis of treatment durations, the results clearly evidence that the plasma jet has a faster detrimental impact on these cells than the DBD plasma (Fig. 14a). For jet applications, the LD50 value was already reached with treatment durations of 30-60 s. With the DBD plasma 180-270 s and 360-480 s were necessary to drop GM and PF viabilities to about $50 \%$, respectively.

It could be assumed that the VUV emission in the plasma jet is responsible for its stronger cytotoxic effect. However, this can be disproved by the following experimental circumstance: Due to the gas flow of the plasma jet, a PBS-free area in the middle of the cell culture dish was produced. Consequently, middle centered cells were not covered by PBS and, thus, they quickly dehydrated during treatments. Even if cells were exposed to significant VUV emission in this area, they will eventually die anyway. Cells growing at the edge of the PBS-free area were likely to be directly exposed to plasma components like UV, aggressive unstable ROS, and other radicals, but not VUV. As soon as the effluent mixes up with air, which is at the peripheral region around the whole effluent, VUV photons will be efficiently absorbed by $\mathrm{N}_{2}$ or $\mathrm{O}_{2}[166,167]$. All cells at the very outside of the petri dish are only indirectly treated by the jet, so rather come in contact with long-lived species produced by interactions of PBS and the plasma.

In contrast, cells treated with the DBD plasma were constantly covered with PBS. Hence, the PBS layer above the cells can buffer short-lived species and, thus, cells rather interact with long-lived species. Of course cells will also be exposed to UVA and UVB radiation generated by the DBD plasma.

Nevertheless, since fibroblasts in the center of the petri dish will be in any case eliminated during jet applications there is always a certain cell reduction of cells in jet-treated samples. This difference in the treatment conditions may be in part one reason for the lower viability values after jet applications.

Following the hypothesis that reactive species, especially ROS, are mainly responsible for plasma-induced effects, another explanation could be that the plasma jet device generates higher concentrations of reactive species in same time periods as the DBD plasma, which then 
would lead to a stronger cytotoxic effect. Looking at the indirect plasma treatment experiments, this might be true; indirect plasma jet applications decreased PFs viability values significantly stronger in comparison to indirect DBD treatments (Fig. 15; blue asterisks).

Concentration measurements of specific ROS and RNS $\left(\mathrm{H}_{2} \mathrm{O}_{2}, \mathrm{NO}_{2}^{-}\right.$, and $\left.\mathrm{NO}_{3}^{-}\right)$in plasmatreated PBS revealed that the plasma jet generated higher concentrations of $\mathrm{H}_{2} \mathrm{O}_{2}$ but extremely lower concentrations of $\mathrm{NO}_{2}^{-}$and $\mathrm{NO}_{3}{ }^{-}$than the DBD plasma after same time durations (Fig. 16; cf. $90 \mathrm{~s}$ and $180 \mathrm{~s}$ ). This affirms that the plasma jet is more cytotoxic because of a higher ROS production. That long-lived species such as $\mathrm{H}_{2} \mathrm{O}_{2}$ indeed greatly influence cell viability was evidenced in positive control experiments; here, slightly increasing $\mathrm{H}_{2} \mathrm{O}_{2}$ concentrations already significantly decreased cell viability of GM cells (Fig. 12). $\mathrm{H}_{2} \mathrm{O}_{2}$ can diffuse across cell membranes and in aqueous solutions it can react to form strongly oxidizing $\mathrm{OH}^{\bullet}$. Therefore, already small changes in $\mathrm{H}_{2} \mathrm{O}_{2}$ concentrations have a strong impact on oxidative stress levels of cells. Moreover, in the close vicinity to and at further distances from the plasma jet, higher $\mathrm{O}_{3}$ concentrations were detected than near the DBD plasma. At a distance of $15 \mathrm{~cm}$ away from the ignited plasma, the DBD device produced $0.042 \mathrm{ppm} \mathrm{O}_{3}$. In contrast, at the same distance the plasma jet produced less than $0.2 \mathrm{ppm}$ for $45^{\circ}$ of solid angle and more than $0.1 \mathrm{ppm}$ for $90^{\circ}$ of solid angle (Fig. 10). $\mathrm{O}_{3}$ can react with water to form $\mathrm{OH}^{\bullet}$ (Eq. 26) or $\mathrm{H}_{2} \mathrm{O}_{2}$ (Eq. 27) and, thus, increase oxidative stress on and in cells:

$$
\begin{aligned}
& \mathrm{O}_{3}+\mathrm{H}_{2} \mathrm{O} \rightarrow 2 \mathrm{OH}^{\bullet}+2 \mathrm{O}_{2}, \\
& \mathrm{O}_{3}+\mathrm{H}_{2} \mathrm{O} \rightarrow \mathrm{H}_{2} \mathrm{O}_{2}+2 \mathrm{O}_{2} .
\end{aligned}
$$

As previously mentioned, UVB and UVA radiation can trigger apoptosis via direct and indirect damages of cell components, like the cell membrane, proteins, or DNA. In both plasma sources, emission lines in the UVA and UVB region were measured showing that the plasma jet comprises higher UVA and UVB spectral irradiances than the DBD (Fig. 9). Thus, the power input of UV radiation generated by the plasma jet is much higher than in the DBD plasma. This could also explain why plasma jet application led to faster cell viability reductions compared to DBD.

When comparing GM cell viabilities on the basis of applied plasma doses, it is obvious that between $30-70 \mathrm{~J} / \mathrm{cm}^{2}$ jet and DBD plasma induced similar GM damages. At $10 \mathrm{~s} \triangleq 31 \mathrm{~J} / \mathrm{cm}^{2}$ of plasma jet and $90 \mathrm{~s} \bumpeq 34 \mathrm{~J} / \mathrm{cm}^{2}$ of DBD application a comparable cell viability of about $82 \%$ was detected (Fig. 14b). Interestingly, at higher doses $\left(>70 \mathrm{~J} / \mathrm{cm}^{2}\right)$ DBD plasma showed a tendency towards a stronger cytotoxic impact on GMs than the plasma jet; at around $90 \mathrm{~J} / \mathrm{cm}^{2}$ one significantly lower DBD-induced GM viability was detected. At such high doses the amount of deposited reactive species is tremendously higher in DBD-treated PBS than in jet-treatedPBS (table 1), which possibly is responsible for the stronger cytotoxic effect of the DBD plasma. This assumption is further strengthened by statistical analysis of indirect MTS results. When 
comparing PF viabilities at similar plasma doses of the plasma jet and DBD plasma (i.e. $10 \mathrm{~s}$ vs. $90 \mathrm{~s} \hat{=}-33 \mathrm{~J} / \mathrm{cm}^{2}$, $30 \mathrm{~s}$ vs. $270 \mathrm{~s} \hat{=}-98 \mathrm{~J} / \mathrm{cm}^{2}$, and $60 \mathrm{~s}$ vs. $480 \mathrm{~s} \hat{=} \sim 184 \mathrm{~J} / \mathrm{cm}^{2}$ ) the DBD plasma always showed a significantly stronger cytotoxic effect (data not shown).

\section{Suitability of the MTS assay to investigate cytotoxic APP effects}

The MTS assay is a common cytotoxic test system and provides a simple way to gain fundamental information about suitable plasma treatment durations or dose ranges to be applied for desired biomedical effects. Based on the results, a comparison of cytotoxic effects on different cell types can be done quickly. Furthermore, results obtained with various physical settings of the same device (e.g. pulse repetition rate or voltage), as well as different plasma sources can be compared with each other.

However, it should be emphasized that this in-vitro method, in which human fibroblasts were treated, constitutes an artificial environment and does not represent an experimental model for the human skin. Thus, the results cannot be completely transferred to plasma-induced effects on human skin. It is likely, though, that cytotoxic effects tested in-vitro are stronger than effects on cells growing in skin tissue, because the uppermost layers of the skin composed of dead, flatted keratinocytes will protect the proliferative fibroblasts below. It was, for example, demonstrated that penetration of reactive species into the skin is limited to the upper layers of the stratum corneum [191]. In addition, for the kINPen09 plasma jet - which is a previous laboratory version of the kINPen ${ }^{\circledR}$ MED -, low effective tissue penetration depths (at most: $60 \mu \mathrm{m}$ ) were determined in pancreatic cancer tissue [216].

On the other hand, if one imagines a plasma application of a wound, which is deep enough that the dermis is exposed, proliferative fibroblasts will be directly hit by the plasma. Therefore, basic experiments on fibroblast responses to plasmas on the in-vitro level are necessary to gain relevant information about effective dose ranges of plasma sources.

In addition, ex-vivo or in-vivo investigations of tissue-plasma interactions that are more close to the natural situation mostly require expensive and more complicated equipment, animal farming, or skin models. Therefore, the MTS assay is a good choice to evaluate cytotoxic effects of plasma sources on a basic level.

\subsubsection{APP-induced chemical changes (choice of treatment solution)}

The choice of the medium or liquid that surrounds the cells during plasma treatment is of tremendous importance for the outcome of plasma-cell interaction experiments. Depending on the buffering property of the treatment solution, different concentrations of ROS and RNS are formed due to plasma application and, thus, cell responses can vary. In the study of Oehmigen et al. [117], for example, plasma inactivation efficiency against bacteria depended on the dilution liquid. Bacteria suspended in non-buffered physiological $\mathrm{NaCl}$ solution $(0.85 \%)$ were more efficiently inactivated by plasma applications compared to bacteria suspended in PBS. 
This study further showed that bacterial elimination efficiency was heavily influenced by the $\mathrm{pH}$ value of the solution. It was suggested that enhanced formation of ROS and RNS in non-buffered solutions significantly reduced the $\mathrm{pH}$ of bacterial solutions, which resulted in higher inactivation rates. Mammalian cell viability also depends on the treatment solution used during plasma application. In a study of Wende et al. [83], HaCaT keratinocytes diluted in different cell culture media were treated with a plasma jet. After the same treatment times, smaller cell numbers were found in plasma-treated RPMI medium than in IMDM medium. This implies that the composition of cell culture medium - that differ in organic molecules such as vitamins, buffer systems, sugars, and amino acids - has a strong impact on resulting plasma-medium interaction chemistry. However, the adherent cell line in this study was treated in suspension, which is not a healthy and natural condition for these cells. Therefore, one can assume that the HaCaT cells in general were more sensitive to the plasma jet treatment than under naturally adherent conditions. Another study compared cell responses of mammalian epithelial breast cells incubated in different plasma-treated solutions [21]. For this, serum-containing medium, serum-free medium, PBS supplemented with BSA, and PBS alone were exposed to plasma prior to cell contact. The results revealed DNA damages in the cells in all cases, except for plasma-treated PBS. To further analyze, which components of the different solutions were responsible for cell damages, 11 amino acids dissolved in PBS were treated with plasma and added to the cells. It was found that the peroxidation effectiveness of the tested amino acids directly correlates with DNA damaging rates. This strongly indicates the formation of organic peroxides due to reactions of plasmaand culture medium compounds. UV radiation from the DBD plasma as well as ions and electrons were excluded as reasons for DNA damages [21].

The test systems established during this project should meet the requirements of comparability of results obtained by using different devices and/or different cell types. As the compositions of different cell culture media are highly variable, a comparison of plasma-induced effects in different cell lines would be more difficult when the appropriate cell culture media were used. Here, PBS was chosen as cell solution during plasma treatments to avoid culture medium-mediated effects on cells and to guarantee the best possible basis for comparability.

For both sources, pH measurements of plasma-treated PBS solutions revealed only slightly reduced values as a function of plasma treatment durations (Fig. 17). In comparison, the DBD plasma induced a stronger shift towards an acidic $\mathrm{pH}$ than the plasma jet for same treatment durations; 180 s of plasma treatment with the KINPen $^{\circledR}$ MED and the DBD plasma led to a $\mathrm{pH}$ of 7.31 and 7.09, respectively. Comparing similar plasma doses applied to the PBS (e.g. at about $184 \mathrm{~J} / \mathrm{cm}^{2}$ ), again a stronger DBD-induced acidification was achieved compared to the plasma jet. This difference can be explained by different gases used to operate the devices. The jet device produces the plasma in argon gas, whereas humid air serves as process gas 
for the DBD plasma. About $78 \%$ of the air consists of $\mathrm{N}_{2}$ molecules that can be transferred to $\mathrm{NO}$ and $\mathrm{NO}_{2}$ (Eq. 4, 13-15) and further to $\mathrm{HNO}_{2}$ and $\mathrm{HNO}_{3}$ in liquid environments (Eq. 17, 20). These inorganic molecules decrease the $\mathrm{pH}$ of solutions. In consistent with this, $\mathrm{NO}_{2}{ }^{-}$and $\mathrm{NO}_{3}{ }^{-}$ concentrations were always higher in DBD-treated PBS for same treatment durations as well as at similar plasma doses (Fig. 16 and table 1). However, even the strongest decrease of about 0.66 found after $600 \mathrm{~s}$ of DBD treatment, can be considered as insignificant regarding the influence on the normal cell physiology [217].

\subsection{Evaluation of long-term damages induced by APPs}

As previously said, plasma has the potential to damage isolated and cellular DNA, which includes strand breaks. Eukaryotic cells have well-developed defense mechanisms against DNA damages and well developed repair pathways that are, for example, triggered by UV radiation or the presence of high ROS concentrations. SSBs are most commonly, indirectly induced by oxidative attack at the sugar-phosphate backbone. They also are indirectly generated during the base excision repair (BER) of oxidative damages on bases, at abasic sites, and other adducts. SSB can be in addition directly formed by disintegration of oxidized sugar [218]. If not repaired, SSBs might lead to the formation of DSBs [219]. UV-induced photolesions, however, are recognized and repaired via proteins of the nucleotide excision repair (NER) mechanism [17, 220]. In mammalian cells, DSBs are primarily repaired via non-homologous end-joining (NHEJ). DSBs that cannot be repaired represent a special danger for eukaryotic cells, for example a single DSB in an essential gene can lead to apoptosis initiation. A detailed review of the different repair pathways and mechanisms of the human genome can be found in Christmann et al. [220]. However, depending on the amount of DNA damages, cells may still be alive but mutated. If the genetic integrity is completely disturbed by a high quantity of mutations or DSBs, cells will eventually die.

In the dermatological use of APP, this might be of advantageous, when the desired effect is e.g. to eliminate skin cancer cells. Treating skin diseases with the purpose to enhance the wound healing process, detrimental effects like DNA alterations and cell destruction are to be excluded. Several groups study the physical and chemical mechanisms underlying plasma-induced DNA damages, because they are of crucial importance for a comprehensive understanding of the mutagenic and genotoxic effects caused by plasma applications. Experiments on isolated DNA (in most cases on plasmid DNA) were conducted to gain information about basic plasma-DNA interactions $[179,180,221-223]$. More application-orientated studies analyzed cellular DNA damages [79, 80, 183, 224-226].

In this thesis, different assays and experimental procedures for the evaluation of DNA damages induced by plasma treatments were tested. In some of the assays, isolated plasmid 
DNA was used as experimental target: HCR, gel electrophoresis, and PSV assay version 1. In others, cellular plasmid DNA in and genomic DNA of fibroblasts were studied: PSV assay version 2 and flow cytometric analysis. The latter test systems are of special interest because they show if APPs generate DNA damages in intact cells and, if so, which types of DNA damages occur. Furthermore, it is discussed if the test systems are appropriate for the assessment of the genotoxic and mutagenic potential of plasmas.

\subsubsection{Genotoxic effect of APP on plasmid DNA}

The HCR assay was used to study the genotoxic effect of APPs on firefly plasmid DNA transfected into fibroblasts. After transfection and an appropriate incubation time, the overall enzymatic activity of firefly luciferases was measured as luminescence intensity in cell extracts. When plasma treatments induce DNA damages in the firefly reporter gene of the plasmid the expression of the enzyme will be impeded and, thus, no luminescence signal is detectable. Hence, the more plasma-induced DNA damages are generated in reporter genes the lower is the relative reporter gene expression, which in turn indicates the genotoxic efficiency. For normalization of data, the base-level gene expression of fibroblasts was determined by co-transfection of untreated renilla plasmid DNA.

The results of the HCR assay indicate that the plasma jet and DBD plasma induce DNA damages in the firefly plasmid. Already the shortest application time (10s) dramatically reduced the expression of the firefly enzyme in both cell lines (Fig. 19). This demonstrates that both plasma sources are highly genotoxic for DNA molecules dissolved in water.

\section{Cell-type dependent reporter gene expression}

Results suggest a difference in reporter gene expression rates between GM and PF cells. In case of using the plasma jet, firefly expression only tends to be higher after transfection into PF than into GM cells (Fig. 19a). In contrast, DBD treatments led to significant increased firefly expression levels in GMs compared to PFs for 90 and $180 \mathrm{~s}$ of treatment durations (Fig. 19b). This might be explained by the altered cell cycle and metabolism of the GM cells. As previously stated, immortalized GM cells will more quickly leave the G1- and enter the S-phase of their cell cycle than healthy cells. This is due to their artificially induced genetic modifications of the tumor suppressor protein p53, which speeds-up the DNA replication in GM cells. Since repair mechanisms are still functional in these cells [227] and they are more often passing cell cycle checkpoints this might result in higher repair rates within the same time period. In addition, the elevated proliferation behavior of GM cells can lead to higher transcriptional activity and, thus, to higher enzyme expressions. The expression yields of renilla enzyme suggest that these assumptions could be true. Indeed, higher renilla RFUs were detected in GM compared to PF cells in all individual experiments (data not shown). Furthermore, plasmid DNA exposed to intermediate doses of UVB or to intermediate up to high UVC doses also expressed 
significantly more reporter genes in GM cells than in PFs (Fig. 18), which is in agreement with the explanation presented above.

\section{Source dependent reporter gene expression}

Treatments with the kINPen ${ }^{\circledR}$ MED device reduced firefly expression in GM cells stronger than DBD application (Fig. 20a). This indicates a stronger genotoxic effect of the plasma jet after same treatment durations.

Most probably, the same stressors, which are responsible for plasma-type dependent differences in cell cytotoxicity, also induce differences in reporter gene expressions in fibroblast cells. As introduced before, direct and extensive exposure of DNA molecules to ROS and UV radiation can result in DNA lesions, including strand breaks and various kinds of nucleobase

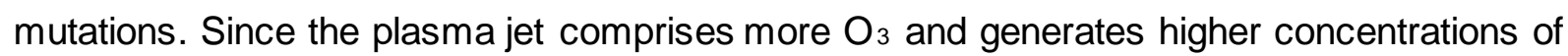
$\mathrm{H}_{2} \mathrm{O}_{2}$ in aqueous solution after same treatment durations, this could lead to higher amounts of $\mathrm{OH}^{\bullet}$ formed in water. Besides the direct alteration of bases in the DNA via oxidation, $\mathrm{OH}^{\bullet}$ can directly damage the deoxyribose of the DNA backbone, remove hydrogen from a deoxyribose carbon, and, thus, generate a base release, which further can lead to a strand break [228]. In addition to these oxidative damages, UVB irradiation produced in the plasmas can penetrate through water and, therefore, affects plasmid DNA. Since spectral irradiance measurements confirmed that the plasma jet comprises higher UVB radiation than the DBD plasma, CPD and 6,4PP photolesions are probably induced in higher amounts by plasma jet treatments. This supports the assumption that the plasma jet acts more detrimental to DNA dissolved in water. Looking at the expression rates induced by similar energy densities of the sources it is obvious that around $30 \mathrm{~J} / \mathrm{cm}^{2}$ the plasma jet acts more genotoxic, whereas at doses between $70-140 \mathrm{~J} / \mathrm{cm}^{2}$ expression rates seem to be similar for the use of both sources (Fig. 20b). Gel electrophoretic separations of plasma-treated firefly plasmid DNA demonstrated that the plasma jet stronger and faster fragments plasmid DNA compared to DBD plasma. Such damaged plasmid DNA is lost for the HCR assay because the fibroblasts are not able to repair small DNA fragments, whereas other plasma-induced damages like oxidative lesions have a chance to be repaired after transfection into cells. However, since the impact of reactive species would have to be stronger in DBD-treated samples - because they are generated in a considerably larger amount by DBD treatments - the question arises why doses between $70-140 \mathrm{~J} / \mathrm{cm}^{2}$ resulted in similar genotoxic effects. It would be conceivable that the plasma jet, due to its high spectral irradiance and low reactive species production, causes similar amounts of oxidative and other damages as the DBD plasma by the generation of high reactive species concentrations but low irradiation intensities. 


\section{Suitability of the HCR test system to evaluate genotoxicity of APPs}

The experimental procedure of this test system is not very complex and well reproducible. For the performance of the assay a luminometer device and a HCR kit is required. The assay is often used for investigations of repair capacities of deficient cells, e.g. of fibroblasts with mutations in xeroderma pigmentosum (XP) genes [229, 230]. XP is an autosomal recessive genetic disorder leading to an impaired NER pathway wherefore UV-induced DNA damages cannot be efficiently repaired anymore. A comparison of the reporter gene expression rates of XP-deficient cells and healthy fibroblasts after defined UV-induced DNA damages is, therefore, indicative for the severity of a specific XP mutation [230]. However, in this thesis the HCR assay was performed to analyze the genotoxic effect of APPs on plasmids. Since healthy cells with normal repair capacities were used decreasing relative reporter gene expressions indirectly indicate the genotoxicity of plasmas without knowing which DNA damages are exactly generated. Therefore, this assay is probably better suited to examine the repair capacities of deficient cells after induction of defined DNA lesions. Other test systems may be more appropriate to obtain detailed information about genotoxic effects of medical plasma sources.

It should be emphasized again, that these in-vitro results are not transferable to in-vivo effects caused by APP application. As already declared, isolated DNA is more susceptible to direct APP treatments or UV irradiations than genomic DNA. In addition, similar UVB doses as applied in this thesis (Fig. 18a), are also used for phototherapeutic treatments of some skin diseases such as eczema or psoriasis [231, 232]. Hence, even though the results clearly demonstrate high UVB-mediated genotoxicity, these doses were defined as tolerable for the human skin.

\subsubsection{DNA fragmentation due to APP treatment}

A very simple way to test the fragmentation capacity of APP is to separate isolated, plasma-treated DNA via gel electrophoresis. Several research groups already used this convenient method [178-181, 223, 233, 234]. In conformity with their results, both, the jet and the DBD plasma caused strand breaks in plasmid DNA in a dose dependent manner (Fig. 21). A stronger fragmentation capacity was observed for the plasma jet compared to the DBD plasma after same treatment durations. The same was observed when similar plasma doses of the two devices were compared (at doses of $\sim 30 \mathrm{~J} / \mathrm{cm}^{2}$ and $\sim 100 \mathrm{~J} / \mathrm{cm}^{2}$ in Fig. 21). At this point it is worth repeating that triple amounts of plasma jet treated DNA had to be loaded onto the gel to even visualize bands. Taken together, this strongly evidences a plasma-type dependent fragmentation capacity, which is stronger for the $\mathrm{kINPen}^{\circledR} \mathrm{MED}$ compared to the DBD device. 


\section{Suitability of the gel electrophoresis to study the fragmentation capacity of APP}

As said before, gel electrophoresis is the easiest way to test for plasma-mediated DNA degradation and is, therefore, recommended if a rapid assessment of the fragmentation capacity is desired. For a more precise quantitative analysis of SSBs or DSBs induced by plasma more complex techniques such as the comet assay, immunofluorescence microscopy of cells based on $\mathrm{Y}-\mathrm{H} 2 \mathrm{~A}$.X, immunoblotting, or flow cytometry should be performed $[185,225$, 226].

However, additional experiments based on this method should be conducted in different solutions, in this case especially in PBS. This is because the DNA degradation rates strongly depend on the medium or solution, in which the DNA is dissolved during plasma treatments $[178,180]$. Cell culture medium and PBS for example protect DNA better from severe damages than water, while DNA damages in culture medium was less pronounced than in PBS. It was assumed that both, PBS and culture medium, have equal buffering potentials and that due to specific medium components radicals may be inactivated to a greater extent than in PBS [178]. Another study, demonstrated that small amounts of amino acids like glycine and arginine are sufficient to reduce DSB formation in plasma-treated DNA [233].

\subsubsection{Post-plasma mutation analysis of plasmid DNA}

To guarantee the absolute safety of plasma treatments in medical applications regarding harmful long-term effects, experiments on the mutagenic effects of APP sources were conducted.

Quickly performable and widely used, the Ames test, developed by Bruce Ames in the early 1970s [235], is a convenient test system to examine the mutagenicity of substances, mostly chemicals. It is based on Salmonella typhimurium strains that are deficient in producing the amino acid histidine due to modified genes, which are essential for the histidine biosynthesis. These bacteria, therefore, require histidine presence to grow. If the test substance is mutagenic, previously modified genes may be re-mutated so that they regain their function and, thus, the bacteria will grow on histidine free medium. Such salmonella are then called revertants and the number of revertants correlates with the mutagenic strength of the tested substance. However, this assay might not be suitable to assess the mutagenic potential of APP sources because the strong antimicrobial effect of plasma might rather eliminate salmonella than induce manifested mutations.

In this thesis the PSV assay was chosen and established to test the mutagenic potential of medical plasma sources on human skin fibroblasts. Based on the plasmid pSP189 including the mutation reporter gene supF-tRNA mutation spectra following plasma applications can be generated. Simultaneously, the test system provides information about the genotoxic effect. 
Two versions of the assay were designed: In the first version, pSP189 plasmid DNA was exposed to plasma and afterwards transfected into GM cells to examine mutations directly evoked in isolated DNA. The second version is more application-oriented. Here, untreated plasmid DNA was first transfected into fibroblast and afterwards the transfected cells were treated with plasma. This was done to test if plasma still alters the plasmid DNA although it is protected by the components and the repair system of the eukaryotic cells.

\subsubsection{Mutation analysis with the PVS assay-version 1}

\section{1a) Genotoxic effect of plasma-treated plasmid DNA}

For both tested APP sources, the relative CFU values decreased in a treatment time and dose dependent manner (Fig. 22). This again demonstrates the genotoxic effect of APP applications on isolated DNA.

After same treatment durations (i.e. 10 and $60 \mathrm{~s}$ ) jet and DBD applications resulted in similar CFU values, although the plasma jet tend to induce a smaller CFU value after $10 \mathrm{~s}$ of treatment than the DBD plasma. Most of the jet and DBD treated samples tend to be stronger genotoxic than UVC irradiation with $75 \mathrm{~mJ} / \mathrm{cm}^{2}$; the only exception was $10 \mathrm{~s}$ of DBD treatment (Fig. 22a). This is similar to HCR results, where UVC exposure with the same irradiation dose generated a lower genotoxic effect than most APP applications (cf. Fig. 18b and 20b).

The comparison of CFU values on the basis of plasma doses applied by the jet and DBD device revealed significantly lower DBD-induced CFUs at around 25 and $100 \mathrm{~J} / \mathrm{cm}^{2}$ (Fig. 22b) indicating stronger damaged plasmids by DBD treatments. This is in contrast to HCR results, where doses around $30 \mathrm{~J} / \mathrm{cm}^{2}$ showed a stronger jet-induced genotoxicity and around $100 \mathrm{~J} / \mathrm{cm}^{2}$ a comparable effect (Fig. 20b).

For the firefly plasmids, severe plasmid fragmentation directly leads to the reduction of the firefly expression rate. In case of the pSP189 fragmented vectors are lost for the assay because they will likely be degraded in GM cells during incubation. Since the plasma jet showed a stronger and faster fragmentation capacity than the DBD plasma, it can be assumed that a considerable amount of pSP189 plasmids are not included in the resulting data of plasma jet treatments in the PSV assay. For transformation of MLB100 bacteria with the isolated plasmids from GMs always 50 ng DNA were used. Since at similar plasma doses reactive species are produced in higher concentrations by the DBD plasma, these might destroy essential genes for bacterial growth - i.e. the ori for bacterial replication and antibiotic resistance - to higher extents compared to the use of the jet device. 


\section{1b) Spontaneous and plasma-induced mutation frequencies of plasmid DNA}

The spontaneous mutation frequency was calculated to be $0.8 \cdot 10^{-3}$ for the supF-tRNA gene in GM cells. Considering the length of the supF-tRNA with $85 \mathrm{bp}$, a spontaneous mutation frequency of approximately $0.9 \cdot 10^{-5}$ mutations per base pair (mut/bp) was calculated. Accordingly, similar mutation frequencies were e.g. generated by jet application of $30 \mathrm{~s}$ $\left(2.5 \cdot 10^{-5} \mathrm{mut} / \mathrm{bp}\right)$ and $60 \mathrm{~s}$ of DBD treatment $\left(2.4 \cdot 10^{-5} \mathrm{mut} / \mathrm{bp}\right)$. Plasma treatments in general resulted in higher mutation frequencies for all treatment durations in comparison to the untreated control, but none of which were significantly different from the untreated control (Fig. 23). Hence, no precise statement can be made about the mutagenicity of the plasma sources.

However, if one compare jet and DBD induced mutation frequencies after same treatment durations, it seems like the DBD plasma acts less mutagenic than the plasma jet $\left(3.4 \cdot 10^{-5} \mathrm{mut} / \mathrm{bp}\right.$ for 10 and $60 \mathrm{~s}$ of jet treatments vs. $1.1 \cdot 10^{-5}$ and $2.4 \cdot 10^{-5} \mathrm{mut} / \mathrm{bp}$ for 10 and $60 \mathrm{~s}$ DBD treatments, respectively).

The highest mutation frequency resulted from $270 \mathrm{~s}$ of DBD exposure $\left(51 \cdot 10^{-5} \mathrm{mut} / \mathrm{bp}\right)$. This frequency is even $\sim 3$ times higher than UVC exposure to $75 \mathrm{~mJ} / \mathrm{cm}^{2}\left(18 \cdot 10^{-5} \mathrm{mut} / \mathrm{bp}\right)$. As already explained in the results part, this high value resulted from small numbers of CFUs with a very high standard deviation (cf. 4.2.3). In general, very high deviations in colony numbers were observed in this assay, which is why at this state of knowledge, precise assumptions regarding the mutagenicity are not possible.

\section{1c) Mutation spectra of plasma-treated plasmid DNA}

Mutation types and mutation patterns were analyzed only within the sequence of the supF-tRNA gene. Three types of mutations, i.e. single base substitution, deletion, and insertion were detected, the majority of which were single base substitutions.

\section{$\underline{\text { Point mutations }}$}

For a better understanding, some definitions and comments regarding point mutation are provided. Point mutations can be induced on both strands of the DNA equally. In theory 12 different base substitutions are possible, namely transitions of the kind $C \rightarrow T, G \rightarrow A, T \rightarrow C$, $A \rightarrow G$, and transversions of the kind $A \rightarrow T, T \rightarrow A, G \rightarrow C, C \rightarrow G, C \rightarrow A, G \rightarrow T, A \rightarrow C$, and $T \rightarrow G$. If a DNA lesion at some point leads to a manifested point mutation, e.g. a $C \rightarrow T$ transition, this will eventually lead to a $G \rightarrow A$ mutation at the same location on the complementary strand. It is however, not possible to identify the exact position of the premutagenic lesion that happened. This is why a detected $C \rightarrow T$ mutation represents a $G \rightarrow A$ mutation and vice versa (Fig. 26). The same applies to the other point mutations, too. Therefore, hereinafter the following designations are used only: $C / G \rightarrow T / A, C / G \rightarrow A / T, C / G \rightarrow G / C, A / T \rightarrow T / A, A / T \rightarrow C / G$, and $A / T \rightarrow G / C$. 


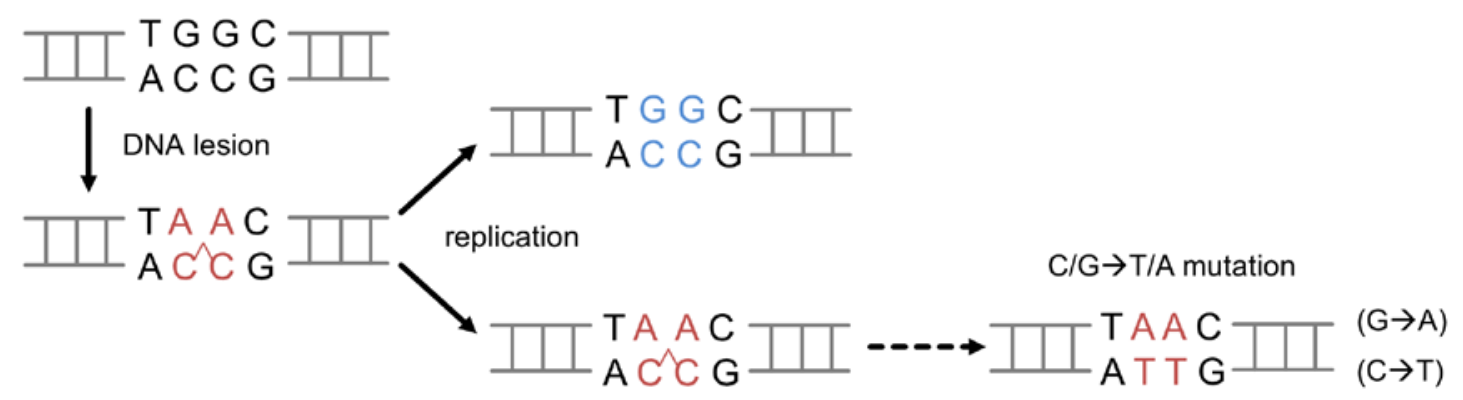

Figure 26: Scheme of how a $C \rightarrow T$ transition simultaneously represents a $G \rightarrow A$ transition

The starting point is a single DNA lesion in the form of a C-C dimer that is induced by e.g. UV radiation. After replication of the damaged strand, $A$ bases might be placed opposite from the $C-C$ dimer. After further replications $T$ bases will be correctly paired with $A$ bases. Now, depending on the DNA strand which is sequenced, either a $C \rightarrow T$ or $G \rightarrow A$ mutation is visible.

The current understanding of the probabilities of spontaneous appearances of specific point mutation types in humans is presented in figure 27 . The frequency of spontaneously generated mutations in the PSV assay match this information; the majority of point mutations were of the kind $C / G \rightarrow T / A$ transitions followed by $C / G \rightarrow A T$ transversions. $C / G \rightarrow T / A$ transitions are characteristic for UVC and UVB irradiated DNA, which most commonly resulted from misincorporation of an A on the opposite site of a pyrimidine dimer [176, 236-238]. In total, the highest number of such mutations was found in the UVC mutation spectrum as expected; about $84 \%$ of all base substitutions were $C / G \rightarrow T / A$ transitions that included one characteristic tandem double $\mathrm{CC} \rightarrow$ TT mutation and one GG $\rightarrow$ AA mutation (table 4).

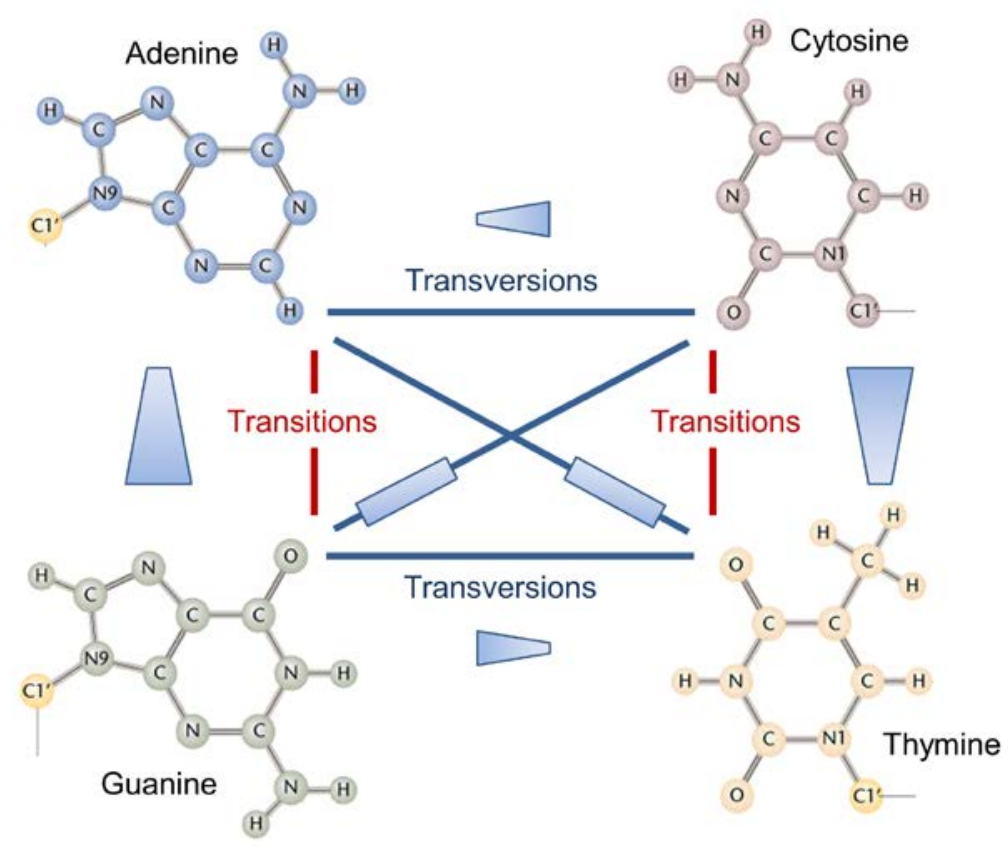

Figure 27: Scheme of the probability of spontaneously occurring mutations in humans

In decreasing order: $C / G \rightarrow T / A$ transitions are mostcommon, followed by $C / G \rightarrow A T$ transversions. $C / G \rightarrow G / C$ and $A / T \rightarrow T / A$ substitutions rarelyoccur, and transversions of the type $A T \rightarrow C / G$ and $A T \rightarrow G / C$ are extremely rare (after information given in Albrecht-Buehler [239]). 


\section{Table 4: Plasma- or UVC-induced point mutations}

The induced base substitutions after UVC or APP treatments are presented as percent values of all base substitutions found for according treatment modality; that are 50 for UVC and 34 for APP applications (nd: not detected).

\begin{tabular}{cccc}
\multicolumn{2}{c}{ Type of lesion } & UVC & APP \\
\hline \hline $\mathrm{C} / \mathrm{G} \rightarrow \mathrm{T} / \mathrm{A}$ & transition & $84 \%$ & $59 \%$ \\
$\mathrm{C} / \mathrm{G} \rightarrow \mathrm{A} / \mathrm{T}$ & transversion & $8 \%$ & $23 \%$ \\
$\mathrm{C} / \mathrm{G} \rightarrow \mathrm{G} / \mathrm{C}$ & transversion & $2 \%$ & $15 \%$ \\
$\mathrm{~A} / \mathrm{T} \rightarrow \mathrm{T} / \mathrm{A}$ & transversion & $2 \%$ & $3 \%$ \\
$\mathrm{~A} \mathrm{~T} \rightarrow \mathrm{C} / \mathrm{G}$ & transversion & $2 \%$ & $\mathrm{nd}$ \\
$\mathrm{A} \mathrm{T} \rightarrow \mathrm{G} / \mathrm{C}$ & transition & $2 \%$ & $\mathrm{nd}$ \\
\hline
\end{tabular}

UVC and plasma generated mutation spectra were different from each other. Although across all plasma treatment durations and both plasma sources used, base substitutions of the type $\mathrm{C} / \mathrm{G} \rightarrow \mathrm{T} / \mathrm{A}$ accounted for the majority as seen in UVC mutation spectrum, transversions of the kind $C / G \rightarrow A / T$ and $C / G \rightarrow G / C$ were also induced in a considerable amount (table 4).

UVB radiation generated in the two plasma sources is likely to produce photoproducts that are the cause for $C$ to $T$ transitions. However, $G$ to $A$ transitions also indicate for oxidative lesions. In addition, the high number of $\mathrm{C} / \mathrm{G} \rightarrow \mathrm{A} / \mathrm{T}$ can also be explained by oxidative DNA damage probably mediated by ROS produced in the plasma. Furthermore, plasma generated UV radiation also may trigger the intracellular release and production of ROS in cells. The base $\mathrm{G}$ is a major target of ROS like e.g. $\mathrm{H}_{2} \mathrm{O}_{2}, \mathrm{O}_{2}$, or $\mathrm{OH}^{\bullet}$. Of the many oxidative damages that modify guanine, the mutagenic 8-oxoG is known to most frequently cause C/G $\rightarrow$ AT mutations [240, 241], whereas $\mathrm{OH}^{\bullet}$ oxidization products of 2'-deoxyguanosine lead to $C / G \rightarrow G / C$ transversions [242]. Therefore, the substantial amount of both mutations detected in plasma-treated samples in addition to the high yields of $C / G \rightarrow T / A$ transitions may be explained by high numbers of oxidative damaged plasmid DNA.

\section{Insertions and deletions}

Induced or spontaneously generated INDELs can be a severe threat to the genomic stability in cells when not repaired. Furthermore, when an insertion or deletion includes only one base pair or $3 n \pm 1$ bp within a coding sequence of a protein this leads to a shift in the translational reading frame resulting in synthesis failure of a functional protein.

In UVC exposed samples three of 54 mutations were INDEL events (one insertion of an A base and two complete deletions of the supF-tRNA). In comparison to that, in plasma jet exposed samples three deletions of 23 mutations were found; this corresponds to about $13 \%$ of all mutations. The DBD plasma produced only one deletion in 15 mutations ( $6.7 \%$ deletions). 
The higher percentage of deletions in jet-treated samples might suggest that deletions were rather plasma-induced than spontaneously generated. This would be in consistent with gel electrophoresis analysis, where plasma jet treatments led to much stronger fragmentation of plasmid DNA than the DBD plasma.

In summary, mutations induced by UVC exposure of isolated DNA mainly generated C/G $\rightarrow$ T/A transitions presumably due to CPD and 6,4PP formations of adjacent pyrimidines. C/G $\rightarrow A V T$ transversions and other base substitutions and INDELs were produced to a much lesser extent. APP applications showed a different mutation pattern. The high yield of $C / G \rightarrow T / A$ transitions can be explained by the combination of induced oxidative DNA lesions via ROS formed in APPs and UVB triggered mutations. The intermediate amount of C/G $\rightarrow$ AVT and $C / G \rightarrow G / C$ transversions were likely induced by oxidative DNA damage. The same factor may be responsible for deletion events in plasma-treated samples. Hence, the mutation spectra for plasma treatment mainly suggest oxidative DNA damage but also UVB induced DNA modifications. The results are, therefore, in agreement with expected DNA alterations due to UV or plasma treatments.

\subsubsection{Mutation analysis with the PSV assay-version 2}

Version 2 of the PSV assay was used to gain more information about genotoxic and mutagenic effects on plasmid DNA, which was already transfected in cells. For control experiments, lower UVC irradiation doses $\left(2.5,5\right.$, and $\left.7.5 \mathrm{~mJ} / \mathrm{cm}^{2}\right)$ were used because $75 \mathrm{~mJ} / \mathrm{cm}^{2}$ eliminated most of the cultured cells (data not shown).

\section{2a) Genotoxic effect of plasma on untreated pSP189 plasmid DNA within fibroblasts}

A lower genotoxic effect was expected in this version of the PSV assay, because in version 1 isolated DNA dissolved in water was directly exposed to plasma, whereas in this version plasmid DNA transfected into GMs should have been protected by cell components during plasma applications. Moreover, plasmid DNA in GM cells might be damaged in other ways due to environmental differences of the intracellular space compared to DNA dissolved in water. The tendency to increased CFU values might indicate a lower genotoxicity in version 2 than in version 1 for the use of both plasma sources (table 5).

Slightly decreasing CFUs after GM exposure to different low doses of UVC indicate increasing genotoxicity. Even the lowest UVC dose $\left(2.5 \mathrm{~mJ} / \mathrm{cm}^{2}\right)$ induced stronger damage of the plasmid in the GMs than the longest plasma application. Since GM cells that were eliminated during plasma application are not included in PSV results and the transformation of MLB100 bacteria were always carried out with $50 \mathrm{ng}$ of plasmid DNA, it can be assumed that plasma-induced genotoxicity of DNA in the cells might be very low. 
However, it is very striking that higher relative CFU values were detected for $10 \mathrm{~s}$ of DBD applications in comparison to untreated samples. This cannot be explained. Here, again additional experiments are necessary to review this result.

Table 5: Comparison of the genotoxic effect recorded in version 1 and 2 of the PSV assay

Relative CFU values caused byplasma or UVC treatment for version 1 and version 2 of the PSV test are presented to quantitatively compare genotoxic effects ( \pm SD).

\begin{tabular}{|c|c|c|c|}
\hline \multicolumn{2}{|c|}{ Treatment } & \multirow{2}{*}{$\frac{\text { Version } 1}{67.5 \%( \pm 13.4)}$} & \multirow{2}{*}{$\begin{array}{c}\text { Version } 2 \\
85.1 \%( \pm 12.7)\end{array}$} \\
\hline Jet & $10 \mathrm{~s}$ & & \\
\hline & $30 \mathrm{~s}$ & $68.3 \%( \pm 18.1)$ & $79.3 \%( \pm 5.3)$ \\
\hline & $60 \mathrm{~s}$ & $60 \%( \pm 16.1)$ & $59.6 \%( \pm 16.6)$ \\
\hline \multirow[t]{3}{*}{ DBD } & $10 \mathrm{~s}$ & $92.8 \%( \pm 32.7)$ & $166.3 \%( \pm 18.3)$ \\
\hline & $60 \mathrm{~s}$ & $56.7 \%( \pm 28)$ & $102.2 \%( \pm 20.9)$ \\
\hline & $270 s$ & $3.1 \%( \pm 1.1)$ & $75.3 \%( \pm 15.9)$ \\
\hline \multirow[t]{4}{*}{ UVC } & $75 \mathrm{~mJ} / \mathrm{cm}^{2}$ & $87.7 \%( \pm 45.5)$ & \\
\hline & $2.5 \mathrm{~m} \mathrm{~J} / \mathrm{cm}^{2}$ & & $23.3 \%( \pm 8.9)$ \\
\hline & $5 \mathrm{~mJ} / \mathrm{cm}^{2}$ & & $19.8 \%( \pm 2.5)$ \\
\hline & $7.5 \mathrm{~m} \mathrm{~J} / \mathrm{cm}^{2}$ & & $9.9 \%( \pm 8.2)$ \\
\hline
\end{tabular}

\section{2b) Plasma-induced mutation frequencies of plasmid DNA within fibroblasts}

With this version of the PSV assay, no spontaneous mutation events could be detected. Since the experimental procedures for the untreated samples were equal in version 1 and 2, the previously calculated spontaneous mutation frequency of $0.9 \cdot 10^{-5} \mathrm{mut} / \mathrm{bp}$ should, in theory, apply to this version, too. Therefore, this value was also used for the mutation frequency comparisons in this section. Only in three colonies mutations were found in the supF-tRNA region of the pSP189 plasmid, all of which were found after DBD treatments. For $10 \mathrm{~s}$ and $60 \mathrm{~s}$ of plasma application the mutation frequencies were $2.2 \cdot 10^{-5}\left( \pm 0.95 \cdot 10^{-5}\right) \mathrm{mut} / \mathrm{bp}$ and $1 \cdot 10^{-5}\left( \pm 0.8 \cdot 10^{-5}\right) \mathrm{mut} / \mathrm{bp}$, respectively. The latter is comparable to the spontaneous mutation frequency and can be neglected. Therefore, only 10s of DBD application induced mutations on plasmid DNA in GM cells, however, this value depends on the enormously high CFU value presented above.

\section{2c) Mutation spectra of plasma-treated plasmid DNA within fibroblasts}

As previously reported only a few mutations were detected in this version of the test system (table 3). The mutations were typical for plasma-induced mutations also found in version 1. A closer look at the first single colony in table 3 shows that at a time four base substitutions were 
detected, and this at a short DNA sequence of only $85 \mathrm{bp}$. This is surprising and seems very unlikely. Since only the mutation frequency of $10 \mathrm{~s}$ DBD application is different from the spontaneous mutation frequency and this calculation depended on both, the surprisingly high CFU value generated by such treatments and the unlikely multiple mutations found in one colony, it is, therefore, rather assumed that plasma applications generally do not induce mutations in plasmid DNA within fibroblasts. More likely the plasma treatments lead to cell damages that trigger apoptosis.

\section{Suitability of the PSV assay to investigate genotoxic and mutagenic potential of APPs}

The adjustment of this test system to the kINPen MED and $\mu$ s-pulsed DBD plasma sources was very difficult, but finally the establishment was achieved with the presented experimental procedure. In general, it can be said that this assay is time-consuming and complex. Every single step must be carried out with greatest care in order to avoid the slightest deviations. This could be a disadvantage, since even small variations in the experimental procedure can lead to high deviations of the data. Hence, this experiment should be repeated very often.

However, the major advantage of this test is that various detailed information about genetic alterations can be simultaneously gained, i.e. genotoxicity rates, mutation frequencies, and mutation patterns.

\subsubsection{Flow cytometric analysis of DNA damages in human fibroblasts}

Flow cytometric analysis was performed based on $\mathrm{Y}-\mathrm{H} 2 \mathrm{~A} . \mathrm{X}$ staining to investigate DSB formation. For experiments, GMs were exposed to either the $\mathrm{kINPen}^{\circledR} \mathrm{MED}$ device or to X-ray radiation, the latter of which is known to induce DSBs in genomic DNA [243]. The damages were measured $24 \mathrm{~h}$ after plasma or X-ray treatments to study late cell responses and residual DNA damages after repair. One of the earliest events following DNA damages in eukaryotic cells is the phosphorylation of the histone protein H2A.X [151]. Even a single DSB event causes immediate formation of $\mathrm{Y}-\mathrm{H} 2 \mathrm{~A}$.X proteins in the close vicinity. The phosphorylation then propagates from the site of damage to surrounding chromatin domains. By that, hundreds or even thousands of $\mathrm{Y}-\mathrm{H} 2 \mathrm{~A} . \mathrm{X}$ proteins are induced within minutes and, thus, producing a distinct focus within the nucleus $[154,244,245]$, which can be visualized by immunofluorescence techniques. There is a close one-to-one relationship between DSBs and $\mathrm{Y}-\mathrm{H} 2 \mathrm{~A} . \mathrm{X}$ foci formation [154, 243]. This is why $\mathrm{Y}-\mathrm{H} 2 \mathrm{~A} . \mathrm{X}$ fluorescence is generally accepted as a sensitive marker for DNA DSBs [151, 152, 154]. Nevertheless, during specific cell cycle phases, cells naturally exhibit a significant amount of $\mathrm{Y}-\mathrm{H} 2 \mathrm{~A}$.X; higher levels of $\mathrm{Y}-\mathrm{H} 2 \mathrm{~A}$.X were found in $\mathrm{S}$ - and G2/M-phase compared to G1-phase [155]. Moreover, DNA fragmentation during apoptosis, which includes the generation of many SSBs and DSBs, also leads to high levels of phosphorylated H2A.X proteins [246-248]. In cancer cells plasma treatment activate the apoptotic pathway, which often led to cell cycle arrest in the sub-G1 phase or the G2/M phase, 
which in turn caused increased phosphorylation of H2A.X [79-81, 90, 226]. In healthy cells, plasma exposure led to higher number of cells in the G2/M phase [82, 83]. It was suggested that reactive species play a major role in inducing DNA damages that led to cell cycle checkpoint arrests as natural repair response of cells [83, 90, 184, 185].

In this thesis, $\mathrm{Y}-\mathrm{H} 2 \mathrm{~A}$.X fluorescence signals increased in GM cells with exposure to extended plasma treatment times $\left(10-180 \mathrm{~s} \triangleq 31-551 \mathrm{~J} / \mathrm{cm}^{2}\right)$. Due to measurements of untreated control samples, the background fluorescence signal of phosphorylated H2A.X histones in a GM population including 10,000 cells was quantified and data of treated samples (same number of cells included) were normalized to this untreated control. Thus, resulting data represent the relative amount of plasma-induced $\mathrm{Y}-\mathrm{H} 2 \mathrm{~A} . \mathrm{X}$ fluorescence above thresholds for untreated controls, which further indicate DSB formation in the genomic DNA. However, with these flow cytometric measurements it is not possible to discriminate if plasma directly or indirectly induce DSBs or if DSBs were produced due to other cellular processes like initiation of apoptosis or mitosis.

A study on human epithelial cells (HeLa) claimed that DSBs were indirectly induced by APP applications [183]. The cells were exposed for $30 \mathrm{~s}$ to a DBD source (plasma dose: $\sim 7.94 \mathrm{~J} / \mathrm{cm}^{2}$ ) and DSBs were visualized by immunocytochemical staining of $\mathrm{Y}-\mathrm{H} 2 \mathrm{~A} . \mathrm{X}$. While immediately fixed and analyzed cells showed almost no $Y-H 2 A$.X fluorescent signals, extended incubations ( $4 \mathrm{~h}$ and $24 \mathrm{~h}$ after plasma treatment) led to increased yields of $\mathrm{Y}-\mathrm{H} 2 \mathrm{~A} . \mathrm{X}$ foci. In addition, it was suggested that stronger fluorescent signals detected $24 \mathrm{~h}$ after plasma treatments were a consequence of mitosis. This would indicate for the activation of cell proliferation due to $30 \mathrm{~s}$ plasma application [183]. Another study used primary human fibroblasts for same analyses [84]. It was again verified that $\mathrm{Y}-\mathrm{H} 2 \mathrm{~A} . \mathrm{X}$ foci formation increased with extended treatment duration and indirect mechanisms were attributed to DSB formation. More precisely, the authors suggest that DSBs were generated during the repair processes of directly-induced SSBs and base damages via plasma treatments, i.e. during the BER process. This is in accordance with another study where increasing $\mathrm{Y}-\mathrm{H} 2 \mathrm{~A}$.X fluorescent signals were also suspected to be a consequence of SSBs or replication arrest in mammalian epithelial breast cells [21].

However, in this thesis $\mathrm{Y}-\mathrm{H} 2 \mathrm{~A} . \mathrm{X}$ fluorescence of plasma and X-ray exposed GM cells were compared showing that e.g. $1 \mathrm{~Gy}$ and $30 \mathrm{~s}\left(\hat{=} 92 \mathrm{~J} / \mathrm{cm}^{2}\right)$ or $7 \mathrm{~Gy}$ and $180 \mathrm{~s}\left(\hat{=} 551 \mathrm{~J} / \mathrm{cm}^{2}\right)$ induced similar signals, which were about $1 \%$ and $42 \%$ higher than the untreated control, respectively. Considering X-ray doses applied in radiation therapy, daily exposure to about 1.8-2 Gy are commonly used; they are called fractions. During therapy, these fractions are repeated until the desired total dose is reached. For the treatment of e.g. epithelial tumors the total dose is about 60-80 Gy [249]. With these doses controlled apoptosis via the direct induction of DSBS 
is triggered in cancer cells. If GM cells used in this thesis are similar to cancer cells and comparable amounts of $\mathrm{Y}-\mathrm{H} 2 \mathrm{~A} . \mathrm{X}$ signals were induced by $1 \mathrm{~Gy}$ and $30 \mathrm{~s}$ of plasma jet treatments or $3 \mathrm{~Gy}$ and $60 \mathrm{~s}$, it might be suggested that such short plasma jet applications induce similar apoptotic cell numbers via presumably indirectly generated DSBs in cells.

\section{Suitability of flow cytometric analysis to study APP-induced DNA damages}

Beside flow cytometric analysis of DNA damages based on $\mathrm{Y}-\mathrm{H} 2 \mathrm{~A} . \mathrm{X}$ staining, immunocytochemistry and Western blot analysis were also widely used to examine cellular DSB formations after plasma treatments [81, 185, 226, 250, 251].

The immunofluorescence method provides the benefit of detecting single $\mathrm{Y}-\mathrm{H} 2 \mathrm{~A} . \mathrm{X}$ focus formation in cells. However, with increasing focus numbers it is getting more and more difficult to discriminate between distinct foci within the cell nucleus due to variations in the intensity and the size. For ionized radiation the immunofluorescence method is, therefore, limited to doses below 2-3Gy. In addition, manually more than 50 cells have to be recorded per sample to get valid data [252]. This is why flow cytometry is the better choice for studying ionized radiation doses higher than $2 \mathrm{~Gy}$ even though single focus formation cannot be distinguished from each other. Moreover, additional cell staining with propidium iodide in flow cytometric performance would allow for quantitative analysis of the cell distribution according to their cell cycle and annexin- $V$ staining would clarify, if DNA damages were the cause of apoptosis induced by plasma treatment of the cells. Therefore, the experimental protocol presented in this thesis could be improved in this way. Of course, it is also necessary to perform this test method with the $\mu \mathrm{s}$-pulsed DBD source and with PF cells to enable a direct comparison between different plasma types, as well as between immortalized and primary skin fibroblasts 
$-100-$ 


\section{Conclusion}

The innovative field of plasma medicine develops very rapidly, which is why more and more plasma devices flood the health-care markets. Various devices that were developed for skin applications can be purchased from a number of vendors. The kINPen ${ }^{\circledR}$ MED source, for example, which was used in this thesis, or plasma sources from the product family PlasmaDerm ${ }^{\circledR}$ (CINOGY GmbH, Duderstadt, DE). Currently, the leading German research groups in the field of plasma medicine, which are associated in a network called 'Nationales Zentrum für Plasmamedizin', work with public health insurance companies to establish plasma applications in a wider range in medicine. However, many research groups still develop their own unique plasma sources and, so far, the medical use of these devices is only limited by the acquisition of a CE certification as a medical tool. The two sources, KINPen $^{\circledR}$ MED and PlasmaDerm ${ }^{\circledR}$, both purchased the CE certification class lla. However, this does not guarantee a risk-free application. Therefore, it depends solely on the engineers, biologists, physicists, and medical doctors, who develop new devices, to ensure that they are well suited for the target applications and that they pose no short and/or long-term health risks.

For this reason, it is necessary to develop test systems that allow a comprehensive assessment of the risks associated with the practical use of any medical plasma source. Likewise, an evaluation of the medical potential of a plasma source is important in order to more reliably predict possible application fields.

\section{Appropriate test systems for the evaluation of medical APP sources and creation of a comparability basis}

In this thesis, various testsystems were evaluated with regard to their applicability and usability for the assessment of medical plasma sources. It was very important that all the test systems could be easily adjusted for the use with different plasma sources. Furthermore, basic parameters were identified, which allow a quantitative comparison. On the one hand, plasma treatment duration was chosen to compare plasma-induced effects and on the other hand results were compared on the basis of the applied plasma doses. For this safety and efficiency analysis, two different devices were chosen, namely the kINPen ${ }^{\circledR}$ MED as a plasma argon jet device and a $\mu$ s-pulsed volume DBD, which ignites in air. Because this study was aimed at dermatological applications of APPs, in-vitro experiments were performed using human skin fibroblasts. 


\section{Basic characterization of medical APP sources}

The first part of the thesis introduces test systems that enable a basic characterization of the physico-technical performances, as well as some bio-medically relevant efficiencies of plasma sources that are designed for medical use. Most of them were already published during my thesis in the first official German safety document, the DIN-SPEC 91315 [11]. This document is a milestone for the plasma medicine community because it represents the initial step towards consistent standards and scientifically defined, plasma specific safety and medical application criteria.

Based on the physico-technical characterization the two plasma sources are safe for general use, i.e. with regard to electric currents, gas temperature and resulting thermal output, UV radiation, and emission of $\mathrm{O}_{3}$ and $\mathrm{NO}$. However, this is only the case under certain conditions. For medical application with the kINPen ${ }^{\circledR}$ MED, the distance from the nozzle to the treatment object must be larger than $7 \mathrm{~mm}$. In addition, spot treatment duration with the jet must not exceed $85 \mathrm{~s}$. Thus, it is recommended to move the plasma jet device at constant speed across the surface of the treated object. Furthermore, the potential risk due to the VUV radiation emitted in the plasma jet needs to be quantified in more detail, since VUV radiation represents a health hazard for humans that cannot be underestimated. When using the DBD device for medical treatments, exposure must not exceed $7 \mathrm{~h}$. However, such long applications are very unlikely, since APP treatment durations usually are in the range of only a few minutes [108$110,253,254]$.

Three test systems were used for a basic assessment of the bio-medically relevant plasma parameters.

The first of three tests is the inactivation efficiency against defined microorganisms. This plasma parameter is especially relevant for dermatological therapies because various skin diseases are accompanied by bacterial or fungal colonization, e.g. chronic wounds, seborrhoeic dermatitis, or acne inversa. For the kINPen ${ }^{\circledR}$ MED device, these experiments could only be done during the cooperation with the INP; the results show that the plasmajet efficiently eliminates pathogens. Such experiments could not be done with the $\mu$ s-pulsed DBD device. However, a similar, if not stronger, inactivation efficiency is to be expected by DBD treatments. This is because a very similar DBD device was proven to more efficiently inactivate pathogens compared to a very similar plasma jet device.

With the use of second test system, i.e. the MTS assay cytotoxic investigations on two different skin fibroblast cell lines were performed and revealed a cell-type dependent decrease of viability due to plasma treatment. In most cases, immortalized GM fibroblasts reacted more sensitive to direct plasma applications than primary fibroblasts. Interestingly, PFs were more sensitive than GMs to short DBD treatment of up to $60 \mathrm{~s}$ that comprise a low plasma dose (up 
to $23 \mathrm{~J} / \mathrm{cm}^{2}$ ). The GM cells have an impaired p53 suppressor protein expression and, thus, a deregulated cell cycle. Therefore, these cells might accelerate higher levels of cell damages at low DBD applications in comparison to healthy PFs. Above a plasma dose of $23 \mathrm{~J} / \mathrm{cm}^{2}$, GMs may reach the threshold to initiate apoptosis faster than PFs; probably, this is due to ROS stress induced by plasma treatments in addition to their increased intracellular basis ROS levels. This interpretation is in accordance with some experimental results. Jet applications of $10 \mathrm{~s}$ and longer, which comprise plasma doses $\geq 31 \mathrm{~J} / \mathrm{cm}^{2}$, caused stronger reductions of GM viabilities compared to PF viabilities, in almost all cases.

Plasma-type dependent effects on GM viability were initially compared based on treatment duration. This revealed significantly lower cell viability induced by the plasma jet. This can be explained by two facts: i) a higher jet-induced ROS stress via $\mathrm{H}_{2} \mathrm{O}_{2}$ and ii) stronger UV irradiances of UVA and UVB, which induced more DNA damages. In indirect MTS experiments, i.e. when only plasma-induced chemical changes were the reasons for changes in cell viability, the plasma jet reduced PF viabilities more strongly than DBD plasma at same treatment times, which is in agreement with the assumption of a higher ROS production in the jet. Thus, ROSmediated damages are likely responsible for the observed differences in plasma-type dependent cell viabilities.

Next, APP-mediated cytotoxicity was compared on the basis of similar plasma doses. Here, it was apparent that for doses around $98 \mathrm{~J} / \mathrm{cm}^{2}$, DBD plasma acted more detrimental on cells than the plasma jet. Probably, this is because DBD plasma induced about 7 times higher concentrations of $\mathrm{H}_{2} \mathrm{O}_{2}, 50$ times higher $\mathrm{NO}_{2}{ }^{-}$and 424 times higher $\mathrm{NO}_{3}{ }^{-}$concentrations than the plasma jet at the same dose. The results of indirect MTS experiments further supported these data, because at similar plasma doses, i.e. at around 33,98 , and $184 \mathrm{~J} / \mathrm{cm}^{2}$, indirect DBD applications induced stronger PF cell reductions than indirect jet treatments.

The third test system describes the analysis of plasma-induced chemical changes of liquids. In this thesis, PBS was used since in-vitro experiments were performed in PBS solution. The plasma-liquid interactions were studied by measuring differences in $\mathrm{H}_{2} \mathrm{O}_{2}, \mathrm{NO}_{2}^{-}$, and $\mathrm{NO}_{3}{ }^{-}$ concentrations. Together with the other test systems, reliable statements and assumptions were made about mechanisms which cause cellular effects or genomic alterations, e.g. the cytotoxic effect as shown above.

Chemical analysis of plasma-treated PBS also included the measurement of pH changes. Only slightly reduced $\mathrm{pH}$ values were demonstrated after treatment with both sources. The largest $\mathrm{pH}$ reduction from 7.4 to 6.74 was induced by a $600 \mathrm{~s}\left(\hat{=} 229 \mathrm{~J} / \mathrm{cm}^{2}\right)$ long DBD treatment. Such $\mathrm{pH}$ changes may inhibit cell growth but barely affect cell physiology [217]. However, at plasma doses of about $184 \mathrm{~J} / \mathrm{cm}^{2}$ (60 s of jet and $480 \mathrm{~s}$ of DBD treatment), acidification was stronger 
for DBD treatments. This is, of course, due to the fact that DBD plasma generates higher concentrations of $\mathrm{NO}_{2}^{-}$and $\mathrm{NO}_{3}{ }^{-}$.

All of the test systems for the basic characterization of medical plasma sources were well adaptable to both types of APP devices used in this thesis. In addition, the test systems are easily reproducible without major effort.

\section{Evaluation of long-term damages of medical APP sources}

The second major part of the thesis focused on potential long-term damages induced by plasma applications on human skin fibroblasts. This is of special interest, because in dermatology, plasma applications will most likely be repeated in regular sessions over the course of some days or even weeks and months, to achieve an improvement of the symptoms or cure of a skin disease $[109,110]$. However, regular treatments with mutagenic or genotoxic substances increase the risk of dramatic consequences such as tumorigenesis.

The nature of the genotoxic effects of APP sources on isolated plasmid DNA, which is dissolved in water was examined with three different methods: the HCR assay, gel electrophoretic separation of plasma-treated plasmid DNA, and the PSV assay in version 1. All assays revealed that genotoxicity increased as a function of plasma treatment times and plasma doses. HCR results indicate a very strong and fast detrimental effect of APP treatments, which, at same treatment durations, was more pronounced for the jet device than for the DBD source. Together with the stronger and faster fragmentation capacity demonstrated via gel electrophoresis, this leads to the assumption that the plasma jet induced significantly more DNA strand breaks. Besides that, other types of plasmid DNA damages due to plasma treatments are most likely oxidative DNA lesions. In the PSV assay version 1, severely fragmented DNA is lost for the assay and, therefore, not included in results. Nonetheless, CFU values were significantly reduced after plasma treatments. A comparison of plasma doses at around 25 and $100 \mathrm{~J} / \mathrm{cm}^{2}$ showed that the DBD plasma led to stronger reductions of CFU values than the plasma jet. This can, again, be explained by a higher production of reactive species by the DBD. Interestingly, very similar amounts of damages were observed in HCR assays at plasma doses between $70-140 \mathrm{~J} / \mathrm{cm}^{2}$. Here, it can be hypothesized that the higher fragmentation capacity of the plasma jet leads to similarly high damage rates as the high concentrations of reactive species of the DBD. Therefore, the overall damages induced at theses doses are similar in their severity.

Calculations of mutation frequencies revealed only a tendency towards rising mutation frequencies, even at the longest treatment duration and, thereby, highest plasma dose (270 s $\triangleq 103 \mathrm{~J} / \mathrm{cm}^{2}$ of DBD treatment). Still, the mutation spectra generated after plasma applications showed that APPs modify plasmid DNA. For treatments with both devices, various point mutations and deletions were found. The majority of these changes were $C / G \rightarrow T / A$ transitions, 
which are characteristic for UV-induced photoproducts, i.e. CPD and 6,4PP but also for oxidative DNA lesions. This indicates that UV radiation and ROS produced in the plasmas have a significant impact on DNA alterations. In addition, noticeable amounts of $C / G \rightarrow A T$ and $C / G \rightarrow G / C$ transversions were generated; again, these indicate oxidative damage through ROS attack. A closer look on mutation types generated after same treatment durations revealed a higher number of $C / G \rightarrow A T$ and $C / G \rightarrow G / C$ transversions in the plasma jet than in the DBD mutation spectrum (10s caused 3 vs. 0 and 60 s led to 5 vs. 4 transversions, respectively). This suggests, again, a stronger genetic impact of the plasmajet, which probably is mediated by higher ROS concentrations generated by the jet plasma. At same plasma doses, a higher rate of UV-characteristic and oxidative $\mathrm{C} / \mathrm{G} \rightarrow \mathrm{T} / \mathrm{A}$ mutations and more deletions were observed in plasma jet treated samples than in DBD treated samples. Both of these facts point to a considerable impact by UV radiation.

Again, all three test methods are well adaptable to different plasma sources. Gel electrophoresis is particularly easy to perform. Adjusting the HCR assay was simple too. However, this test is actually better suited to examine repair mechanisms in cells, as it only represents an indirect measure for studying the genotoxic potential of plasma sources. In addition, better statements can be made if induced damages are known and definable. With version 1 of the PSV assay, three aspects of genetic modifications can simultaneously be revealed. Therefore, the PSV assay is generally better suited for genotoxic and mutagenic studies. But, the implementation is more complicated and requires a higher effort.

For a more detailed analysis of how plasma acts on DNA, which is inside of cultured cells, the PSV assay in version 2 and flow cytometry of $\mathrm{Y}-\mathrm{H} 2 \mathrm{~A} . \mathrm{X}$ stained DSBs in GM cells were performed. In most cases, lower genotoxic effects were observed in version 2 compared to version 1 of the PSV assay, which was expected, because cell structures like the cell membrane and membrane of the nucleus, as well as the cytoplasm protect the DNA against direct modifications by plasma. Surprisingly, the shortestDBD application induced significantly higher CFU values than the untreated control, which can, so far, not be explained. However, point mutations were detected only in DBD treated samples, which is why mutation frequencies and a mutation spectrum were exclusively listed for DBD applications. Even though the 10 and $60 \mathrm{~s}$ of DBD treatments induced a higher mutation frequency, both were not different from the spontaneously generated mutation frequency. The induced point mutations were of the type $\mathrm{C} / \mathrm{G} \rightarrow \mathrm{T} / \mathrm{A}$ and $\mathrm{C} / \mathrm{G} \rightarrow \mathrm{A} / \mathrm{T}$ and, thus, not different from mutations found in version 1 of the test. It has to be explicitly mentioned once again that the mutations observed here were due to an unlikely phenomenon: four mutations occurred at the same time in a single colony. Taken together, it is therefore suggested that APP sources do not induce higher mutation frequencies in plasmid DNA which was transfected into human fibroblasts and thus, no mutagenic effect was detected based on these preliminary results. 
The flow cytometric experiments of genomic DNA from fibroblasts demonstrated elevated $\mathrm{Y}-\mathrm{H} 2 \mathrm{~A} . \mathrm{X}$ fluorescence signals, because of an increased number of DSB events due to plasma applications. The results were correlated with X-ray irradiations, which are known to directly cause DSBs and, consequently, activate apoptosis. Other plasma studies suggest that APP induced DSBs in cells via indirect mechanisms. However, together with the cytotoxic effects of plasma jet applications observed in this study, it may be hypothesized that comparable Y-H2A.X signals induced by e.g. $1 \mathrm{~Gy}$ and $30 \mathrm{~s}$ of plasma jet treatments or $7 \mathrm{~Gy}$ and $180 \mathrm{~s}$ caused similarly high numbers of apoptotic cells. It would be very interesting to repeat and improve these experiments to test if plasma jet and X-ray applications really induce similar apoptotic cell numbers.

Although the last two assays could only be repeated a few times, which led to large standard deviations, both of these tests are very well suited to study plasma-induced genomic DNA damages. The flow cytometry test could be significantly improved when combined with annexin- $\mathrm{V}$ and propidium iodide staining.

\section{Final note to APP applications in medicine}

The test methods used in this thesis only included in-vitro experiments and, therefore, the results obtained here cannot be directly transferred to dermatological applications of the human skin. Nevertheless, this newly developed set of test systems provides reliable information about plasma treatment durations and plasma dose ranges that can be used to obtain the desired biomedical effect. In dermatological applications, e.g. in chronic wound therapy, detrimental cell and/or DNA effects mustbe avoided. In contrast, if detrimental effects are desired, for example in the cancer therapy, the test systems presented here can be used as well to work out the perfect plasma dose and appropriate treatment duration. The results from this study cannot exclude mutagenic effects induced by APP sources. Therefore, it has to be emphasized that plasma applications must be carefully adapted to the severity of the clinical picture of the disease being treated, because the potential risks of plasma treatment cannot and should not be neglected. 


\section{Summary}

APP sources have a great potential to be used for a variety of therapeutic purposes in medicine. This is because APPs comprise a number of different components that induce a unique mixture of biological effects. Because plasma medicine is rapidly developing and simultaneously gaining huge interest worldwide, the necessity of clear, official guidelines and criteria for medical APP sources is indispensable. It is exactly because of these high number of biological active components that a certain degree of risk for the human health has to be taken into account. To avoid or at least to limit such risks, while still achieving reliable bio-medical effects, test systems are necessary that allow detailed assessments of the physico-technical and biomedical properties of APP sources.

In this thesis, test systems are presented, which provide a basis for testing APP sources with regard to both, their medical potential and their possible side effects. At the same time, comparability of plasma-induced effects of different sources were realized on the basis of the treatment duration and the plasma dose. Thereby, it is possible to fine tune APP devices so that they induce a desired biomedical effect within an appropriate treatment time.

In addition to the essential physico-technical characterization of plasma sources, direct plasma-cell interactions and plasma-mediated long-term damages of cells and their components were studied. Moreover, it was demonstrated that the following test systems are suited for dermatology related applications. All of the tests can be easily adapted to two different APP types; i.e. plasma jet devices and volume DBDs.

Direct plasma-cell interactions:

A) Inhibition zone tests: wound related microorganisms

B) Cytotoxicity tests: MTS assay on human skin fibroblasts

C) Chemical changes in PBS: $\mathrm{H}_{2} \mathrm{O}_{2}, \mathrm{NO}_{2}^{-}, \mathrm{NO}_{3}^{-}$, and $\mathrm{pH}$ measurements

\section{Long-term damages:}

D) Plasmid fragmentation capacity: gel electrophoresis

E) Genotoxic and mutagenic investigations: PSV assay on DNA in two versions; i.e. 1. plasma-treated plasmid DNA transfected into untreated fibroblasts; 2. plasma-treated fibroblasts previously transfected with untreated plasmid DNA

F) Formation of DSBs in genomic DNA: flow cytometry combined with $\mathrm{Y}-\mathrm{H} 2 \mathrm{~A}$.X staining (ideally combined with quantitative analysis of cell distribution related to cell cycle phases and apoptosis). 
$-108-$ 


\section{Appendix}

\section{Complete list of materials}

\section{I.1 Devices}

Table 6: Devices

\begin{tabular}{|c|c|c|}
\hline Description & Label & Supplier \\
\hline \multicolumn{3}{|l|}{ Agarose gel } \\
\hline (melting) & Microwave NN-5253 & Panasonic, Hamburg, DE \\
\hline (trays) & Blue Marine 200 & Serva, Heidelberg, DE \\
\hline (chambers) & $\begin{array}{l}\text { Special chamber for agarose gel } \\
\text { electrophoresis }\end{array}$ & Hardware \& service, Friedland, DE \\
\hline (power supply) & Mini Power Rack P20 & Biometra, Göttingen, DE \\
\hline Documentation system & Gel iX 20 Imager & Intas, Göttingen, DE \\
\hline Autoclave & DE-65 & Systec, Wettenberg, DE \\
\hline Bacterial culture & Erlenmeyer flask (200 mL, $500 \mathrm{~mL})$ & WWR, Darmstadt, DE \\
\hline \multirow[t]{5}{*}{ Centrifuges } & Mikro 220, Rotor: 1189-A & Hettich, Tuttlingen, DE \\
\hline & $\begin{array}{l}\text { Eppendorf Centrifuge 5415C, Rotor: F } \\
\text { 45-18-11 }\end{array}$ & Sigma, München, DE \\
\hline & Sorvall RC 6+, Rotor: F13S-14x50cy & Thermo Scientific, Waltham, US \\
\hline & Hereaus Megafuge 1.0R & Thermo Scientific, Schwerte, DE \\
\hline & MC 6 centrifuge & Sarstedt, Nümbrecht, DE \\
\hline Counting chamber & Neubauer cell counting chamber & Brand, Wertheim, DE \\
\hline Dish washer & Miele professional & Miele, Gütersloh, DE \\
\hline Dispenser & Multipette ${ }^{\circledR}$ plus & Eppendorf, Hamburg, DE \\
\hline Drier and sterilizer & Memmert SL 50 & Willi Fischer KG, Frankfurt, DE \\
\hline FACS & BD FACS Canto ${ }^{\mathrm{TM}}$ II & BD Bioscience, Heidelberg, DE \\
\hline \multirow{4}{*}{$\begin{array}{l}\text { Refrigerators and } \\
\text { freezers }\end{array}$} & GUS 34420 & Bosch, Stuttgart, DE \\
\hline & Arctis $\left(-20^{\circ} \mathrm{C}\right)$ & AEG, Nürnberg, DE \\
\hline & glassline $\left(+4^{\circ} \mathrm{C}\right)$ & Liebherr, Ochsenhausen, DE \\
\hline & Ultra low MDF-U73V $\left(-80^{\circ} \mathrm{C}\right)$ & Sanyo, München, DE \\
\hline Ice machine & ZBE 30-10 & Ziegra, Isernhagen, DE \\
\hline \multirow[t]{2}{*}{ Incubators } & $\mathrm{CO}_{2}$-Incubator, MCO-18AIC & Sanyo, München, DE \\
\hline & Incubator model 200 & Memmer, Büchenbach, DE \\
\hline Incubator shaker & Shaker Thermotron & Infors, Bottmingen, SZ \\
\hline
\end{tabular}




\begin{tabular}{|c|c|c|}
\hline Description & Label & Supplier \\
\hline Laboratory hood & not specified & $\begin{array}{l}\text { Norddeuts che Laborbau, Quickborn, } \\
\text { DE }\end{array}$ \\
\hline Liquid nitrogen container & Apollo Biosafe & Messer Griesheim, Bad Soden, DE \\
\hline $\begin{array}{l}\text { Luminescence } \\
\text { measurements }\end{array}$ & Glomax ${ }^{\mathrm{TM}} 96$ Microplate Luminometer & Promega, Mannheim, DE \\
\hline \multirow[t]{2}{*}{ Microscopes } & Axiovert 100 fluorescence microscope & Carl Zeiss, Oberkochen, DE \\
\hline & Axiovert Imager.M1 & Carl Zeiss, Oberkochen, DE \\
\hline Mobile pipettor & Pipetboyacu & Integra Biosciences, Fernwald, DE \\
\hline Orbital shaker & Standard 1000 Orbital Shaker & $\begin{array}{l}\text { WR International bvba, } \\
\text { Geldenaakesbaan, BE }\end{array}$ \\
\hline \multirow[t]{2}{*}{ pH-Meter } & digital pH-meter, pH 525 & Schütt, Göttingen, DE \\
\hline & Lab pH Electrode LE438 & $\begin{array}{l}\text { Mettler-Toledo AG, Schwerzenbach, } \\
\mathrm{CH}\end{array}$ \\
\hline Photometer & Elisa Reader & Tecan, Männedorf, DE \\
\hline \multirow[t]{4}{*}{ Pipettes } & $\begin{array}{l}\text { Transferpette }{ }^{\circledR} \mathrm{S}(1000,100,20, \\
10 \mu \mathrm{L})\end{array}$ & Brand, Wertheim, DE \\
\hline & $\begin{array}{l}\text { Eppendor }{ }^{\circledR} \text { Research }^{\circledR}(1000,100, \\
10 \mu \mathrm{L})\end{array}$ & Eppendorf, Hamburg, DE \\
\hline & Gilson Pipetman $(1000,200,100 \mu \mathrm{L})$ & ABiMED, Langenfeld DE \\
\hline & Multipipette ${ }^{\circledR}$ plus & Eppendorf, Hamburg, DE \\
\hline \multirow[t]{3}{*}{ Plasma devices } & KINPen $^{\circledR}$ MED & $\begin{array}{l}\text { INP Greifswald/neoplas GmbH, } \\
\text { Greifswald, DE }\end{array}$ \\
\hline & $\mu s$-pulsed DBD & HAWK, Göttingen, DE \\
\hline & Power Supply 3045/15 & EA-Electronic, Essen, DE \\
\hline \multirow[t]{2}{*}{ Scales } & MC1 AC210S & Sartorius, Göttingen, DE \\
\hline & Analytic balance BP2100 & Sartorius, Göttingen, DE \\
\hline Sequence analyzer & 3100-Avant Genetic Analyzer & Applied Biosystems, Foster City, US \\
\hline \multirow[t]{2}{*}{ Spectrophotometer } & DU $640^{\circledR}$ Spectrophotometer & Beckmann, München, DE \\
\hline & NanoVuePlus $^{\circledR}$ & GE Healthcare, Buckinghamshire, UK \\
\hline Sterile bench & Heraeus Instruments NF X 44-201 & Schütt, Göttingen, DE \\
\hline Tamping machine & Tecnomara, Tecnoplug & Integra Bioscience, Fernwald, DE \\
\hline Thermal cycler & Arktik Thermal Cycler & Thermo Scientific, Waltham, US \\
\hline Thermal block & Thermomixer 5436 & Eppendorf, Hamburg, DE \\
\hline \multirow[t]{2}{*}{ UV-irradiation } & UVC 500 crosslinker & $\begin{array}{l}\text { Amersham Biosciences, Glattburg, } \\
\mathrm{CH}\end{array}$ \\
\hline & BioLink BLX 312 & LTF-Labortechnik, Wasserburg, DE \\
\hline Vortexer & Vibrofix VF1 Electronic & IKA Labortechnik, Staufem, DE \\
\hline Water bath & 1003 & GFL, Großburgwedel, DE \\
\hline X-ray irradiation & RS225X-Ray Box & $\begin{array}{l}\text { Gulmay Medical LTD, Camberley, } \\
\text { Surrey, UK }\end{array}$ \\
\hline
\end{tabular}




\section{I.2 Disposables}

Table 7: Disposables

\begin{tabular}{|c|c|}
\hline Label & Supplier \\
\hline 96 well Glomax ${ }^{\top M} 96$ Microplate & Promega, Mannheim, DE \\
\hline Cell culture flasks $(75,175 \mathrm{~cm} 3)$ & Greiner bio-one, Frickenhausen, DE \\
\hline Cell culture dish (Falcon 35 × $10 \mathrm{~mm}$ ) & Th. Geyer, Renningen, DE \\
\hline Cell scraper $25 \mathrm{~cm}$ & BD Biosciences, Pharmingen, Oxford, UK \\
\hline Combitips plus $(0.5 \mathrm{~mL}) \&$ advanced $(5,10 \mathrm{~mL})$ & Eppendorf, Hamburg, DE \\
\hline $\begin{array}{l}\text { Conical polypropylene tubes ( } 15 \mathrm{~mL} \text { with and without filter in } \\
\text { cap, } 50 \mathrm{~mL} \text { ) }\end{array}$ & Greiner bio-one, Frickenhausen, DE \\
\hline Cryo boxes & Nunc, Wiesbaden, DE \\
\hline Cryo tubes $2 \mathrm{~mL}$ & Greiner bio-one, Frickenhausen, DE \\
\hline Electroporation cuvette (2, 4 mm gap) & BioRad, Hercules, US \\
\hline Glass cover slips, round, $20 \mathrm{~mm}$ & Carl Roth, Karlsruhe, DE \\
\hline Glass pipettes $(5,10,25 \mathrm{~mL})$ & Brand, Wertheim, DE \\
\hline Kimtech wipes & Kimberley-Clarke Professional, Roswell, US \\
\hline Multiply $\mu$ Strip Pro 8-strip & Sarstedt, Nümbrecht, DE \\
\hline Object slide & Thermo Scientific, Braunschweig, DE \\
\hline Parafilm ${ }^{\circledR}$ & Brand, Wertheim, DE \\
\hline Petri dishes, with vents $(\varnothing 100 \times 20 \mathrm{~mm}, \varnothing 145 \times 20 \mathrm{~mm})$ & Greiner bio-one, Frickenhausen, DE \\
\hline Pasteur pipettes (230 mm) & Brand, Wertheim, DE \\
\hline Pipette tips $(10,200,1000 \mu \mathrm{L})$ & Sarstedt, Nümbrecht, DE \\
\hline $\begin{array}{l}\text { Round-bottom polystyrene tube } 12 \times 75 \mathrm{~mm} \text { (Falcon } 5 \mathrm{~mL} \text { ) no } \\
\text { cap \& snap cap }\end{array}$ & BD Bioscience, Heidelberg, DE \\
\hline Reaction tubes $(0.5,1.5,2 \mathrm{~mL})$ & Eppendorf, Hamburg, DE \\
\hline Scalpel, disposable & Feather, Osaka, JP \\
\hline Syringes, single use $(2,5,10,20 \mathrm{~mL})$ & Braun, Melsungen, DE \\
\hline Sterile filters (pore size $0.2,0.45 \mu \mathrm{m}$ ) filtropur $\mathrm{S}$ (plus) & Sarstedt, Nümbrecht, DE \\
\hline Tissue culture plates (6-, 12-, 24-, 96-well) & Greiner bio-one, Frickenhausen, DE \\
\hline Cupper stripes CFT-25/10M & Conrad Electronic SE, Hirschau, DE \\
\hline Wadding & Brand, Wertheim, DE \\
\hline
\end{tabular}




\section{I.3 Chemicals, reagents, and gas}

Table 8: Chemicals, reagents, and gas

Chemical/Reagent/Gas

2-propanol

6x DNA Loading Dye

Agarose Saekem $^{\circledR}$

Accutase

Ammonium chloride $\left(\mathrm{NH}_{4} \mathrm{Cl}\right)$

Ampicillin

Argon N46 (purity of 99.996\%)

Bacto Tryptone

Bam HI $10 \mathrm{U} / \mu \mathrm{L}$

Boric acid

Calcium chloride $\left(\mathrm{CaCl}_{2}\right)$

Dimethyl sulfoxide (DMSO)

Dpnl $10 \mathrm{U} / \mu \mathrm{L}$

dNTP Mix (dATP, dCTP, dGTP, dTTP)

Dulbecco's modified Eagle's medium (DMEM)

Ethanol absolute, $99.8 \%$

Ethylenediaminetetraacetic acid (EDTA)

Exo-SAP PCR Clean-Up Mix

Fetal Bovine Serum (FBS)

Gene Ruler (100 bp \#SM0241, 1 kb \#SM0311) DNA Ladder

Glycerol

HDGreen Plus DNA Stain

Hoechst 33342

Hi-Di Formamide

Hydrochloric acid $(\mathrm{HCl})$

Hydrogen peroxide $\left(\mathrm{H}_{2} \mathrm{O}_{2}\right) 30 \%$

IPTG

Isopropanol $\left(\mathrm{C}_{3} \mathrm{H}_{7} \mathrm{OH}\right)$

Kalium hydrogen phosphate $\left(\mathrm{KH}_{2} \mathrm{PO}_{4}\right)$

LB Agar

LE Agarose

Lennox L Broth Base

Magnesium chloride $\left(\mathrm{MgCl}_{2}\right)$

\section{Supplier}

JT Baker, Deventer, NL

Thermo Scientific, Braunschweig, DE

Fluka Chemie, Neu-UIm, DE

Biochrom AG, Berlin, DE

Merck, Darmstadt, DE

Sigma-Aldrich, München, DE

Air Liquide, Düsseldorf, DE

BD Bioscience, Heidelberg, DE

Thermo Scientific, Braunschweig, DE

Merck, Darmstadt, DE

Merck, Darmstadt, DE

Sigma-Aldrich, München, DE

Thermo Scientific, Braunschweig, DE

Thermo Scientific, Braunschweig, DE

PAA, Cölbe, DE and others

Merck, Darmstadt, DE

Sigma-Aldrich, München, DE

New England Biolabs, Ipswich, US

Biochrom AG, Berlin, DE

Thermo Scientific, Braunschweig, DE

Merck, Darmstadt, DE

Intas, Göttingen, DE

Thermo Fisher, Dreieich, DE

Applied Biosystems, Foster City, US

Merck, Darmstadt, DE

Merck, Darmstadt, DE

Biotech Trade, Kraichtal, DE

Merck, Darmstadt, DE

Merck, Darmstadt, DE

Invitrogen, Karlsruhe, DE

Biozym, Oldendorf, DE

Invitrogen, Karlsruhe, DE

Merck, Darmstadt, DE 
Chemical/Reagent/Gas

Nonidet P40

Paraformaldehyde (PFA)

Penicillin-Streptomycin (100x; P/S)

Potassium Chloride $(\mathrm{KCl})$

Sodium chloride $(\mathrm{NaCl})$

Sodium dodecyl sulfate (SDS)

Sodium hydrogen phosphate $\left(\mathrm{Na}_{2} \mathrm{HPO}_{4} \times 2 \mathrm{H}_{2} \mathrm{O}\right)$

Sodium hydroxide $(\mathrm{NaOH})$

Sucrose

Sulfuric acid $\left(\mathrm{H}_{2} \mathrm{SO}_{4}\right)$

Taq DNA Polymerase, recombinant $(5 \mathrm{U} / \mu \mathrm{L})$

Tango Buffer 10x

Tris-Base

Triton X-100

Trypanblue

Trypsin/EDTA

Tween20

X-Gal

Yeast Extract BioChemica

\section{Supplier}

Sigma-Aldrich, München, DE

Merck, Darmstadt, DE

PAA, Coelbe, DE

Merck, Darmstadt, DE

Merck, Darmstadt, DE

Carl Roth, Karlsruhe, DE

Merck, Darmstadt, DE

Merck, Darmstadt, DE

Sigma-Aldrich, München, DE

Sigma-Aldrich, München, DE

Thermo Scientific, Braunschweig, DE

Thermo Scientific, Braunschweig, DE

Merck, Darmstadt, DE

Merck, Darmstadt, DE

Sigma-Aldrich, München, DE

Biochrom AG, Berlin, DE

Merck, Darmstadt, DE

Thermo Scientific, Braunschweig, DE

Th. Geyer, Renningen, DE

\section{I.4 Ready to use reaction systems}

\section{Table 9: Ready to use reaction systems}

\begin{tabular}{ll} 
Description & Supplier \\
\hline \hline Attractene Transfection Reagent & Qiagen, Hilden, DE \\
BigDye $^{\circledR}$ Terminator V3.1 Cycle Sequencing Kit(3.1 Seq. Kit) & Life Technologies, Darmstadt, DE \\
CellTiter 96 ${ }^{\circledR}$ AQueous One Solution Cell Proliferation Assay & Promega Corporation, Madison, US \\
Dual-Luciferase Reporter AssaySystem & Promega, Mannheim, DE \\
NucleoBond ${ }^{\circledR}$ Xtra MiDi/Maxi Plus & Machery-Nagel, Düren, DE \\
NucleoSpin Mini plasmid & Machery-Nagel, Düren, DE \\
Wizard $^{\circledR}$ PCR Clean-Up Kit & Promega, Fitchburg, US \\
\hline
\end{tabular}




\section{I.5 Buffers and solutions}

Buffers and solutions were prepared in autoclaved $\mathrm{ddH}_{2} \mathrm{O}$ or PBS. Percentage data for solutions are given in (v/v). Some liquids had to be additionally sterile filtrated using $0.2 \mu \mathrm{m}$ filters and appropriate syringes.

Table 10: Buffers and solutions

\begin{tabular}{|c|c|}
\hline Designation & Recipe \\
\hline \multicolumn{2}{|l|}{ Cell culture } \\
\hline Freezing medium & $40 \%$ DMEM, $40 \%$ FBS, $20 \%$ DMSO \\
\hline culture DMEM & $89 \%$ DMEM, $10 \%$ FBS, $1 \%$ P/S \\
\hline DMEM-13\%F & $86 \%$ DMEM, $13 \%$ FBS, $1 \%$ P/S \\
\hline 10x PBS; pH 7.4 & $\begin{array}{l}1.5 \mathrm{M} \mathrm{NaCl}, 30 \mathrm{mM} \mathrm{KCl}, 80 \mathrm{mM} \mathrm{Na}_{2} \mathrm{HPO}_{4} \times 2 \mathrm{H}_{2} \mathrm{O}, 10 \mathrm{mM} \mathrm{KH}_{2} \mathrm{PO}_{4} \\
\text { diluted in dd } \mathrm{H}_{2} \mathrm{O}\end{array}$ \\
\hline PBS & 10x PBS diluted $1: 10$ in $\mathrm{dd} \mathrm{H}_{2} \mathrm{O}$ \\
\hline \multicolumn{2}{|l|}{ Bacterial culture } \\
\hline Ampicillin stock solution & $100 \mathrm{~g} / \mathrm{L}$ in $\mathrm{ddH}_{2} \mathrm{O}$, sterile filtered \\
\hline IPTG stock solution & $24 \mathrm{~g} / \mathrm{L}$ in $d d H_{2} \mathrm{O}$, sterile filtered \\
\hline X-Gal stock solution & $20 \mathrm{~g} / \mathrm{L}$ in DMSO, sterile filtered \\
\hline $\mathrm{CaCl}_{2}$-glycerol solution & $50 \mathrm{mM} \mathrm{CaCl}_{2}, 15 \%$ glycerol \\
\hline dYT & $16 \mathrm{~g} / \mathrm{L}$ Bacto Tryptone, $10 \mathrm{~g} / \mathrm{L}$ yeast extract, $5 \mathrm{~g} / \mathrm{L} \mathrm{NaCl}$ in $d_{d d H_{2} \mathrm{O}}$ \\
\hline LB medium & $20 \mathrm{~g} / \mathrm{L}$ Lennox L Broth Base, $5 \mathrm{~g} / \mathrm{L} \mathrm{NaCl}$ diluted in $\mathrm{ddH}_{2} \mathrm{O}$, autoclaved \\
\hline LB agar plates with ampicillin & $\begin{array}{l}20 \mathrm{~g} / \mathrm{L} \text { Lennox } \mathrm{L} \text { Broth Base, } 15 \mathrm{~g} / \mathrm{L} \text { Agar, } 0.5 \mathrm{~g} / \mathrm{L} \mathrm{NaCl} \text { diluted in } \mathrm{ddH}_{2} \mathrm{O} \text {, } \\
\text { autoclaved, when cooled under } 60^{\circ} \mathrm{C} 1 \mathrm{~mL} / \mathrm{L} \text { ampicillin stock solution } \\
\text { added }\end{array}$ \\
\hline $\begin{array}{l}\text { LB agar plates with ampicillin, } \\
\text { IPTG, and X-Gal }\end{array}$ & $\begin{array}{l}20 \mathrm{~g} / \mathrm{L} \text { Lennox } \mathrm{L} \text { Broth Base, } 15 \mathrm{~g} / \mathrm{L} \text { Agar, } 5 \mathrm{~g} / \mathrm{L} \mathrm{NaCl} \text { diluted in } \mathrm{ddH}_{2} \mathrm{O} \text {, } \\
\text { autoclaved, when cooled under } 60^{\circ} \mathrm{C} 1 \mathrm{~mL} / \mathrm{L} \text { ampicillin, } 1 \mathrm{mg} / \mathrm{L} \mathrm{IPTG} \text {, and } \\
2 \mathrm{~mL} / \mathrm{L} \text { X-Gal stock solution added }\end{array}$ \\
\hline SOC medium, $\mathrm{pH} 7.0$ & $\begin{array}{l}20 \mathrm{~g} / \mathrm{L} \text { Bacto Tryptone, } 5 \mathrm{~g} / \mathrm{L} \text { yeast extract, } 1 \mathrm{M} \mathrm{NaCl}, 1 \mathrm{M} \mathrm{KCl} \text { diluted in } \\
\mathrm{ddH}_{2} \mathrm{O} \text {, autoclaved, } \mathrm{Mg}^{2+} \text {-and } 2 \mathrm{M} \text { glucose-stock solutions were added to } \\
\text { a final concentration of } 20 \mathrm{mM} \text { each, sterile filtered }\end{array}$ \\
\hline $2 \mathrm{M}$ glucose stock solution & $360 \mathrm{~g} / \mathrm{L}$ diluted in $\mathrm{ddH}_{2} \mathrm{O}$, sterile filtered \\
\hline $\mathrm{Mg}^{2+}$ stock solution & $1 \mathrm{M} \mathrm{MgCl}_{2} \times 6 \mathrm{H}_{2} \mathrm{O}, 1 \mathrm{M} \mathrm{MgSO}_{4} \times 7 \mathrm{H}_{2} \mathrm{O}$ diluted in dd $\mathrm{H}_{2} \mathrm{O}$, sterile filtered \\
\hline \multicolumn{2}{|l|}{ Agarose gel electrophoresis } \\
\hline $\begin{array}{l}\text { Running buffer TBE (1x oder } \\
\text { 10x) }\end{array}$ & $89 \mathrm{mM}$ TRIS, $89 \mathrm{mM}$ Boric acid, $2 \mathrm{mM}$ EDTA in $\mathrm{ddH}_{2} \mathrm{O}$ \\
\hline \multicolumn{2}{|l|}{ Fow cytometry assay } \\
\hline Paraformaldehyde (PFA) & $3.7 \%$ in dd $\mathrm{H}_{2} \mathrm{O}$ (pre-dissolved using $1 \mathrm{M} \mathrm{NaOH}$ ) \\
\hline Per/Block-solution & $0.1 \%$ Triton $\mathrm{X}-100,10 \%$ FBS in PBS \\
\hline PBS-Tween & $0.05 \%$ Tween 20 in PBS \\
\hline
\end{tabular}




\section{I.6 Antibodies}

Table 11: Antibodies

\begin{tabular}{lll} 
Antibody & Supplier & Dilution \\
\hline \hline Alexa-Fluor ${ }^{\circledR}$ 488 goat anti-mouse & Dianova, Hamburg DE & $1: 400$ \\
Anti-phospho H2A.X & Dianova, Hamburg DE & $1: 4000$ \\
Mouse IgG1 Isotype Control & Dianova, Hamburg DE & $1: 4000$ \\
\hline
\end{tabular}

\section{I.7 Plasmids}

\section{pUC19 plasmid}

The pUC19 cloning vector purchased from Carl Roth (Karlsruhe, DE) was used to determine the transformation efficiency in E. coli. It is a small plasmid, $2686 \mathrm{bp}$ in length, and has a high copy number.

\section{Firefly and renilla luciferase plasmid}

The firefly plasmid (pCMMuc; Fig. 28) was a generous gift from Kenneth H. Kraemer, National Cancer Institute, Bethesda, MD, USA. Renilla plasmid (pRL-CMV) was purchased from Promega (Mannheim, DE). Both plasmids were used in the HCR assay (cf. 3.5.3). Firefly plasmid was in addition used in gel electrophoretic separations of plasma-treated DNA (cf. 3.4.4).

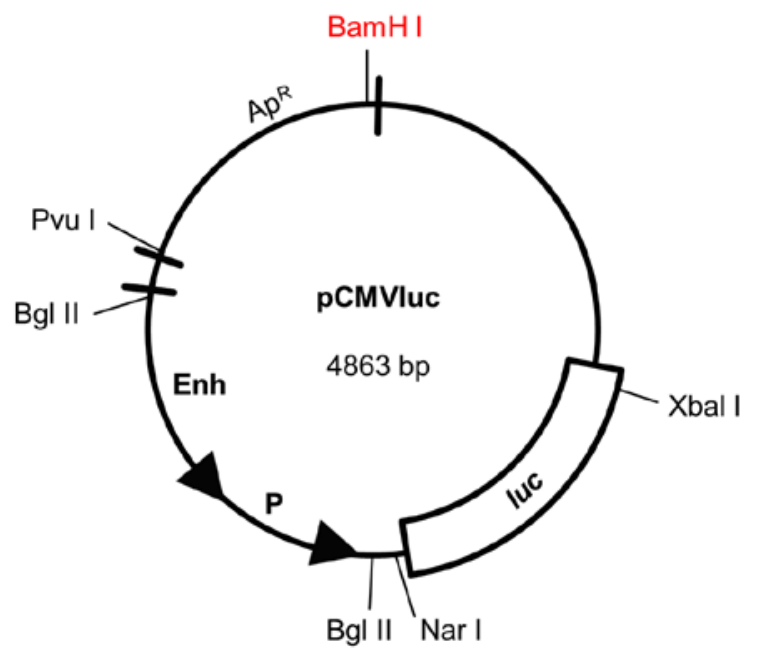

Figure 28: Scheme of the firefly (pCMVluc) plasmid The firefly plasmid includes an ampicillin resistance $\left(A p^{R}\right)$, restriction sites for different enzymes, and the enhancer site and promoter site for the luciferase gene (after information given in Qiao et al. [144]).

\section{pSP189 used for PSV experiments}

This low-copy plasmid was first described by [146]. It includes an ampicillin resistance $\left(A p^{R}\right)$, replication origins for bacterial and eukaryotic cells (SV40 ori and pBR327 ori, respectively), the supF-tRNA gene, and the signature sequence as most important units. This vector was used in this project for mutation analysis based on the blue/white-selection of MLB100 bacteria (cf. 3.8.4). 


\section{I.8 Primer}

The primers used for PCR in the course of the PSV assay are presented in table 12. fPrimer and rPrimer were used in colony PCR for amplification of the sequence region of interest; that is $493 \mathrm{bp}$ of length due to primer choice. The sPrimer was used for sequence PCR with ddNTPs to further analyze sequences of the pSP189 supF-tRNA gene and signature sequence (cf. 3.4.5).

\section{Table 12: Primer}

\begin{tabular}{lll} 
Primer & Supplier & Sequence \\
\hline \hline PL_pSP189_for (fPrimer) & Sigma-Aldrich, München DE & 5'-CACCCAACTGATCTTCAGCA \\
PL_pSP189_rev(rPrimer) & Sigma-Aldrich, München DE & 5'-GGGAAACGCCTGGTATCTTT \\
PL_pSP189_seq (sPrimer) & Sigma-Aldrich, München DE & 5'-GGCGACACGGAAATGTTGAA \\
\hline
\end{tabular}

\subsection{Software and online tools}

- BD FACS Diva Software from BD Bioscience

- Dual Luciferase Reporter Gene Assay: Glomax ${ }^{\mathrm{TM}}$ Software from Promega

- ELISA reader: Magellan ${ }^{\mathrm{TM}}$ data analysis software from TECAN

- Fluorescence microscope: Axiovert Axiovision 100 from Karl Zeiss

- Sequence alignment: http://multalin.toulouse.inra.fr/multalin/

- Sequence analysis: Chromas Lite 2.1, Technelysium

- Statistical analysis: SigmaPlot 12.0

- Text processing, table calculations, etc.: Microsoft Office (Word, Excel, PowerPoint) 


\section{Library of the signature sequence in the pSP189}

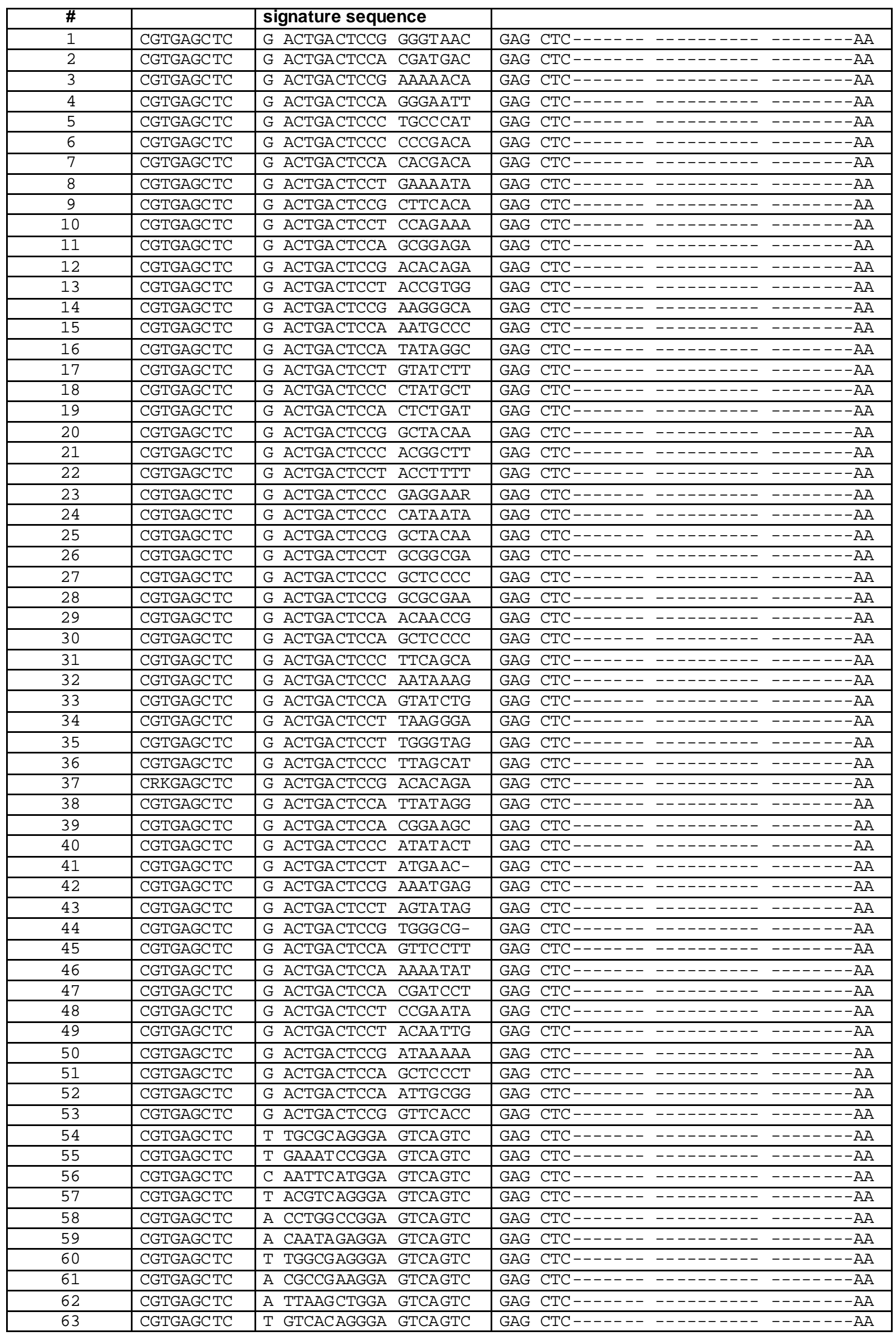




\begin{tabular}{|c|c|c|c|c|c|}
\hline 64 & CGTGAGCTC & A GCGGATTGGA GTCAGTC & GAG CTC $\cdots \cdots$ & 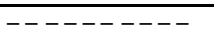 & $---A A$ \\
\hline 65 & CGTGAGCTC & G AGCGGGTGGA & GAG CTC $\cdots \cdots$ & $-\cdots-\cdots$ & $\cdots-\cdots$ AA \\
\hline 66 & CGTGAGCTC & T AACTTTTGGA GTCAGTC & GAG CTC $\cdots \cdots$ & 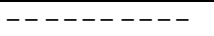 & $\cdots-\cdots$ AA \\
\hline 67 & CGTGAGCTC & T ACGAAGGGGA GTCAGTC & GAG CTC $\cdots \cdots$ & $-\ldots-\ldots$ & $-\cdots-A A$ \\
\hline 68 & CGTGAGCTC & T GCCGCGAGGA GTCAGTC & GAG CTC $\cdots-\cdots$ & -------- & $-\cdots-\cdots$ AA \\
\hline 69 & CGTGAGCTC & C CCAGCTCGGA GTCAGTC & GAG CTC - - - - & -------- & $-\cdots-\cdots-A A$ \\
\hline 70 & CGTGAGCTC & T TCGATTAGGA GTCAGTC & CTC - - - - - & $-\cdots-\cdots-\cdots$ & $\cdots \cdots-\cdots$ AA \\
\hline 71 & CGTGAGCTC & C GCTGTTAGGA & CTC $-\cdots-\cdots$ & $-\cdots--\cdots--$ & $\cdots \cdots-\cdots A$ \\
\hline 72 & CGTGAGCTC & T AGAATTTGGA GTCAGTC & GAG CTC $\cdots-\cdots--$ & ---------- & $-\cdots-\cdots-A A$ \\
\hline 73 & CGTGAGCTC & A GGGGTTTGGA GTCAGTC & GAG CTC - - - - & 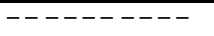 & $\cdots--A A$ \\
\hline 74 & CGTGAGCTC & A ATGAAAAGGA GTCAGTC & GAG CTC $\cdots \cdots$ & $-\cdots-\cdots-\cdots$ & $-\cdots-\cdots$ AA \\
\hline 75 & CGTGAGCTC & T CAGCAACGGA GTCAGTC & GAG CTC $\cdots \cdots$ & -------- & $-\cdots-\cdots A$ \\
\hline 76 & CGTGAGCTC & T TACTGCTGGA GTCAGTC & GAG CTC - - - - - & -------- & $-\cdots-\cdots-A A$ \\
\hline 77 & CGTGAGCTC & A TCTTATTGGA GTCAGTC & CTC - - - - - & $-\cdots--\cdots---$ & $-\cdots-\cdots$ AA \\
\hline 78 & CGTGAGCTC & T ATCCCAGGGA GTCAGTC & GAG CTC $\cdots \cdots$ & --------- & $-\cdots---A A$ \\
\hline 79 & CGTGAGCTC & A GACCTCAGGA GTCAGTC & GAG CTC $\cdots \cdots-\cdots$ & --------- & $\cdots-\cdots-\cdots A$ \\
\hline 80 & CGTGAGCTC & G CGTCGCAGGA GTCAGTC & GAG CTC - - - - - & ---------- & $-\cdots---A A$ \\
\hline 81 & CGTGAGCTC & G GAGGCGTGGA GTCAGTC & GAG CTC $\cdots \cdots$ & -------- & $-\cdots-\cdots-A A$ \\
\hline 82 & CGTGAGCTC & T ATTTATGGGA GTCAGTC & GAG CTC $\cdots \cdots$ & 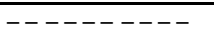 & $-\cdots--A A$ \\
\hline 83 & CGTGAGCTC & T TCATCAAGGA GTCAGTC & GAG CTC $\cdots \cdots$ & $-\cdots--\cdots--$ & $\cdots \cdots-\cdots A$ \\
\hline 84 & CGTGAGCTC & A ATACCCTGGA & CTC - - - - - & --------- & $\cdots-\cdots-\cdots A A$ \\
\hline 85 & CGTGAGCTC & T TCTTCGTGGA GTCAGTC & GAG CTC $\cdots \cdots$ & 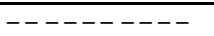 & $-\cdots--A A$ \\
\hline 86 & CGTGAGCTC & A GCCTGGGGGA GTCAGTC & GAG CTC $\cdots \cdots$ & $-\cdots-\cdots-\cdots$ & $\cdots-\cdots$ A \\
\hline 87 & CGTGAGCTC & A TCTGGGTGGA GTCAGTC & GAG CTC $\cdots \cdots$ & -------- & $\cdots---A A$ \\
\hline 88 & CGTGAGCTC & T AAGCGCCGGA GTCAGTC & GAG STC ------ & ---------- & $-\cdots-\cdots-A A$ \\
\hline 89 & CGTGAGCTC & T TAGGTCGGGA GTCAGTC & GAG CTC $\cdots \cdots$ & $-\cdots-\cdots-\cdots$ & $\cdots \cdots-\cdots$ AA \\
\hline 90 & CGTGAGCTC & T AGGTGGGGGA GTCAGTC & GAG CTC $\cdots \cdots$ & --------- & $-\cdots-\cdots-\cdots A$ \\
\hline 91 & CGTGAGCTC & T AATTCCTGGA & GAG CTC $\cdots \cdots-\cdots$ & - - - - - - - & $\cdots \cdots-\cdots$ AA \\
\hline 92 & CGTGAGCTC & T MGGTCTTGGA GTCAGTC & GAG CTC - - - - & -------- & $-\cdots-\cdots-A A$ \\
\hline 93 & CGTGAGCTC & G TGACGGGGGA GTCAGTC & GAG CTC $\cdots \cdots$ & $-\cdots-\cdots-\cdots$ & $-\cdots-\cdots$ AA \\
\hline 94 & CGTGAGCTC & G CGTGTCAGGA GTCAGTC & GAG CTC $\cdots \cdots$ & ---------- & $\cdots \cdots-\cdots$ AA \\
\hline 95 & CGTGAGCTC & A CCGGAACGGA GTCAGTC & GAG CTC $\cdots-\cdots--$ & -- - - - - - & $-\cdots-\cdots-A A$ \\
\hline 96 & CGTGAGCTC & C TTCGGTCGGA GTCAGTC & GAG CTC $\cdots-\cdots--$ & -------- & $-\cdots---A A$ \\
\hline 97 & CGTGAGCTC & A TGGCGGTGGA GTCAGTC & GAG CTC $\cdots \cdots-\cdots$ & $-\cdots-\cdots-\cdots$ & $\cdots \cdots-\cdots$ AA \\
\hline 98 & CGTGAGCTC & T AGAGCGTGGA & GAG CTC $\cdots \cdots$ & -- - - - - - & $\cdots \cdots-\cdots$ AA \\
\hline 99 & CGTGAGCTC & A CGGATTAGGA GTCAGTC & GAG CTC $\cdots-\cdots--$ & --------- & $-\cdots-\cdots-A A$ \\
\hline 100 & CGTGAGCTC & A TCAGTTAGGA GTCRGTC & GAG CTC $\cdots \cdots$ & $-\cdots---\cdot-\cdot$ & $-\cdots--A_{A}$ \\
\hline 101 & CGTGAGCTC & C AAACATGGGA GTCAGTC & GAG CTC $\cdots \cdots$ & ------- & $\cdots---\mathrm{AA}$ \\
\hline 102 & CGTGAGCTC & C TCGTATTGGA GTCAGTC & GAG CTC $\cdots \cdots-\cdots$ & --------- & $-\cdots-\cdots-A A$ \\
\hline 103 & CGTGAGCTC & A CGGAGAGGGA GTCAGTC & RAG YTC - - - - - & --------- & $-\cdots---\mathrm{AA}$ \\
\hline 104 & CGTGAGCTC & A TTACGCAGGA GTCAGTC & GAG CTCGACTGAC & TCC-ATGCTA & A-GAGCTCAA \\
\hline 105 & CGTGAGCTC & A CGCCTTCGGA GTCAGTC & GAG CTCTGATGGC & TGG-AGTCAG & TCGAGCTCAA \\
\hline 106 & CGTGAGCTC & G ACTGACTCCC & GAG CTCGACTGAC & TCC-СACTCT & CAGAGCTCAA \\
\hline 107 & CGTGAGCTC & G GGTACCGGGA GTCAGTC & GAG CTCCTAATTC & GGGGAGTCAG & TCGAGCTCAA \\
\hline 108 & CGTGAGCTC & C CAGCGTTGGA GTCAGTC & GAG CTC $\cdots \cdots-\cdots$ & ---------- & $-\cdots-\cdots-\cdots A$ \\
\hline 109 & CGTGAGCTC & A ATGGGTAGGA GTCAGTC & GAG CTC $\cdots \cdots$ & $-\cdots-\cdots-\cdots$ & $\cdots \cdots-\cdots$ AA \\
\hline 110 & CGTGAGCTC & A TACTAACGGA GTCAGTC & GAG CTC $-\cdots-\cdots$ & -------- & $\cdots \cdots-\cdots A$ \\
\hline 111 & CGTGAGCTC & T ATTGTTCGGA GTCAGTC & GAG CTC $\cdots-\cdots--$ & ---------- & $-\cdots-\cdots-A A$ \\
\hline 112 & CGTGAGCTC & G TCCCTAAGGA STCAGTC & GAG CTC $\cdots \cdots$ & $-\cdots-\cdots-\cdots$ & $\cdots \cdots-\cdots$ AA \\
\hline 113 & CGTGAGCTC & G ACTGACTCCA CATCATT & GAG CTC $\cdots \cdots$ & --------- & $-\cdots----A A$ \\
\hline 114 & CGTGAGCTC & 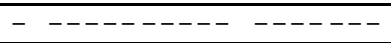 & $----\cdots--\cdots--$ & -- - - - - - & $-\cdots-\cdots-A A$ \\
\hline 115 & CGTGAGCTC & -------- & $-------\cdots--$ & 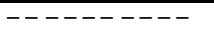 & $\cdots--A_{A}$ \\
\hline 116 & CGTGAGCTC & R ACTGACTCCT GGSTCCG & GAG CTC $\cdots \cdots-\cdots$ & $-\cdots-\cdots-\cdots$ & $-\cdots-\cdots-A A$ \\
\hline 117 & CGTGGACTG & A TWAGGACCTW MKAAGTC & CST GAC $\ldots \ldots$ & 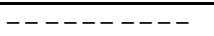 & $-\ldots---G G$ \\
\hline 118 & CGTGGAAGG & A ATTGAATCTT CGGACTC & GAT GAC - - - - - & --------- & $-\cdots----R G$ \\
\hline reference & CGTGAGCTC & $\mathrm{N}$ NNNNNNNNNN NNNNNNN & GAG CTC $\cdots \cdots-\cdots$ & $\overline{--------}$ & $-\cdots----A A$ \\
\hline
\end{tabular}




\section{Bibliography}

1. Glover JL, Bendick PJ, Link WJ (1978) The use of thermal knives in surgery: Electrosurgery, lasers, plasma scalpel. Current Problems in Surgery, 15:1-78. doi:10.1016/S00113840(78)80017-3

2. Farin G, Grund KE (1994) Technology of argon plasma coagulation with particular regard to endoscopic applications. Endoscopic Surgery and Allied Technologies, 2:71-77.

3. Vargo JJ (2004) Clinical applications of the argon plasma coagulator. Gastrointestinal Endoscopy, 59:81-88. doi:10.1016/S0016-5107(03)02296-X

4. Raiser J, Zenker M (2006) Argon plasma coagulation for open surgical and endoscopic applications: state of the art. Journal of Physics D: Applied Physics, 39:3520-3523. doi:10.1088/0022-3727/39/16/S10

5. Lademann J, Richter H, Alborova A, Humme D, Patzelt A, Kramer A, Weltmann K-D, Hartmann B, Ottomann C, Fluhr JW, Hinz P, Hübner G, Lademann O (2009) Risk assessment of the application of a plasma jet in dermatology. Journal of Biomedical Optics, 14:054025 (6pp). doi:10.1117/1.3247156

6. Heinlin J, Morfill G, Landthaler M, Stolz W, Isbary G, Zimmermann JL, Shimizu T, Karrer S (2010) Plasma medicine: possible applications in dermatology. JDDG: Journal der Deutschen Dermatologischen Gesellschaft, 8:968-976. doi:10.1111/j.1610-0387.2010.07495.x

7. Heinlin J, Isbary G, Stolz W, Morfill G, Landthaler M, Shimizu T, Steffes B, Nosenko T, Zimmermann J, Karrer S (2011) Plasma applications in medicine with a special focus on dermatology. Journal of the European Academy of Dermatology and Venereology, 25:1-11. doi:10.1111/j.1468-3083.2010.03702.x

8. von Woedtke T, Reuter S, Masur K, Weltmann K-D (2013) Plasmas for medicine. Physics Reports, 530:291-320. doi:10.1016/j.physrep.2013.05.005

9. Tiede R, Hirschberg J, Daeschlein G, von Woedtke T, Vioel W, Emmert S (2014) Plasma Applications: A Dermatological View. Contributions to Plasma Physics, 54:118-130. doi:10.1002/ctpp.201310061

10. Park GY, Park SJ, Choi MY, Koo IG, Byun JH, Hong JW, Sim JY, Collins GJ, Lee JK (2012) Atmospheric-pressure plasma sources for biomedical applications. Plasma Sources Science and Technology, 21:043001 (21pp). doi:10.1088/0963-0252/21/4/043001

11. (2014) DIN SPEC 91315: General requirements for plasma sources in medicine. Beuth-Verlag

12. Sinha RP, Häder D-P (2002) UV-induced DNA damage and repair: a review. Photochemical \& Photobiological Sciences, 1:225-236. doi:10.1039/b201230h 
13. Mouret S, Baudouin C, Charveron M, Favier A, Cadet J, Douki T (2006) Cyclobutane pyrimidine dimers are predominant DNA lesions in whole human skin exposed to UVA radiation. Proceedings of the National Academy of Sciences of the United States of America, 103:1376513770. doi:10.1073/pnas.0604213103

14. Cadet J, Sage E, Douki T (2005) Ultraviolet radiation-mediated damage to cellular DNA. Mutation Research/Fundamental and Molecular Mechanisms of Mutagenesis, 571:3-17. doi:10.1016/j.mrfmmm.2004.09.012

15. Jiang Y, Rabbi M, Kim M, Ke C, Lee W, Clark RL, Mieczkowski PA, Marszalek PE (2009) UVA Generates Pyrimidine Dimers in DNA Directly. Biophysical Journal, 96:1151-1158. doi:10.1016/j.bpj.2008.10.030

16. Girard PM, Francesconi S, Pozzebon M, Graindorge D, Rochette P, Drouin R, Sage E (2011) UVA-induced damage to DNA and proteins: direct versus indirect photochemical processes. Journal of Physics: Conference Series, 261:012002 (10pp). doi:10.1088/1742$6596 / 261 / 1 / 012002$

17. COOKE MS (2003) Oxidative DNA damage: mechanisms, mutation, and disease. The FASEB Journal, 17:1195-1214. doi:10.1096/fj.02-0752rev

18. Gaunt LF, Beggs CB, Georghiou GE (2006) Bactericidal action of the reactive species produced by gas-discharge nonthermal plasma at atmospheric pressure: A review. IEEE Transactions on Plasma Science, 34:1257-1269. doi:10.1109/TPS.2006.878381

19. Cadet J, Wagner JR (2013) DNA Base Damage by Reactive Oxygen Species, Oxidizing Agents, and UV Radiation. Cold Spring Harbor Perspectives in Biology, 5:a012559-a012559. doi:10.1101/cshperspect.a012559

20. Lee JK, Kim MS, Byun JH, Kim KT, Kim GC, Park GY (2011) Biomedical Applications of Low Temperature Atmospheric Pressure Plasmas to Cancerous Cell Treatment and Tooth Bleaching. Japanese Journal of Applied Physics, 50:08JF01 (7pp). doi:10.1143/JJAP.50.08JF01

21. Kalghatgi S, Kelly CM, Cerchar E, Torabi B, Alekseev O, Fridman A, Friedman G, AzizkhanClifford J (2011) Effects of Non-Thermal Plasma on Mammalian Cells. PLoS ONE, 6:e16270(11pp). doi:10.1371/journal.pone. 0016270

22. Helmke A, Grünig P, Fritz U-M, Wandke D, Emmert S, Petersen K, Viöl W (2012) Lowtemperature Plasma -a Prospective Microbicidal Tool. Recent Patents on Anti-Infective Drug Discovery, 7:223-230. doi:1574-891X12

23. von Woedtke T, Metelmann HR, Weltmann K-D (2014) Clinical Plasma Medicine: State and Perspectives of in Vivo Application of Cold Atmospheric Plasma. Contributions to Plasma Physics, 54:104-117. doi:10.1002/ctpp.201310068 
24. Haertel B, von Woedtke T, Weltmann K-D, Lindequist U (2014) Non-thermal atmosphericpressure plasma possible application in wound healing. Biomolecules and Therapeutics, 22:477-490. doi:10.4062/biomolther.2014.105

25. Bekeschus S, Schmidt A, Weltmann K-D, von Woedtke T (2016) The plasma jet kINPen - A powerful tool for wound healing. Clinical Plasma Medicine1-10. doi:10.1016/j.cpme.2016.01.001

26. Crookes W (1879) On Radiant Matter. Journal of the Franklin Institute, 111:305-316. doi:10.1016/0016-0032(81)90167-8

27. Langmuir I (1928) Sci., 14, 317 (1928). 2. Proceedings of the National Academy of Sciences of the United States of America, 14:627-637.

28. Tendero C, Tixier C, Tristant P, Desmaison J, Leprince $\mathrm{P}$ (2006) Atmospheric pressure plasmas: A review. Spectrochimica Acta Part B: Atomic Spectroscopy, 61:2-30. doi:10.1016/j.sab.2005.10.003

29. Heberlein JVR (1992) Generation of thermal and pseudo-thermal plasmas. Pure and Applied Chemistry, 64:629-636. doi:10.1351/pac199264050629

30. Fauchais P (2004) Understanding plasma spraying. Journal of Physics D: Applied Physics, 37:R86-R108. doi:10.1088/0022-3727/37/9/R02

31. Nemchinsky VA, Severance WS (2006) What we know and what we do not know about plasma arc cutting. Journal of Physics D: Applied Physics, 39:R423-R438. doi:10.1088/0022$3727 / 39 / 22 / R 01$

32. Murphy AB, Tanaka M, Yamamoto K, Tashiro S, Sato T, Lowke JJ (2009) Modelling of thermal plasmas for arc welding: the role of the shielding gas properties and of metal vapour. Journal of Physics D: Applied Physics, 42:194006 (20pp). doi:10.1088/0022-3727/42/19/194006

33. Kogelschatz U, Eliasson B, Egli W (1997) Dielectric-barrier discharges. Principle and applications. Journal De Physique Iv, 7:47-66. doi:10.1051/jp4:1997405

34. Kogelschatz U (2003) Dielectric-barrier Discharges: Their History, Dlscharge Phyics, and Industrial Application. Plasma Chemistry and Plasma Processing, 23:1-46. doi:10.1023/A:1022470901385

35. Rajasekaran $P$ (2011) Atmospheric pressure dielectric barrier (DBD) in air: Plasma characterization for skin therapy. Ruhr-Universität Bochum

36. Park GY, Hong YJ, Lee HW, Sim JY, Lee JK (2010) A Global Model for the Identification of the Dominant Reactions for Atomic Oxygen in $\mathrm{He}_{2} \mathrm{O}_{2}$ Atmospheric-Pressure Plasmas. Plasma Processes and Polymers, 7:281-287. doi:10.1002/ppap.200900084

37. Uhm HS, Lim JP, Li SZ (2007) Sterilization of bacterial endospores by an atmospheric-pressure argon plasma jet. Applied Physics Letters, 90:88-91. doi:10.1063/1.2747177 
38. Reuter S, Winter J, Schmidt-Bleker A, Tresp H, Hammer MU, Weltmann K-D (2012) Controlling the Ambient Air Affected Reactive Species Composition in the Effluent of an Argon Plasma Jet. IEEE Transactions on Plasma Science, 40:2788-2794.

39. Bekeschus S, Iseni S, Reuter S, Masur K, Weltmann K-D (2015) Nitrogen Shielding of an Argon Plasma Jet and Its Effects on Human Immune Cells. IEEE Transactions on Plasma Science, 43:776-781. doi:10.1109/TPS.2015.2393379

40. Schmidt-Bleker A, Winter J, Bösel A, Reuter S, Weltmann K-D (2016) On the plasma chemistry of a cold atmospheric argon plasma jet with shielding gas device. Plasma Sources Science and Technology, 25:015005 (24pp). doi:10.1088/0963-0252/25/1/015005

41. Kolb JF, Mohamed A-AH, Price RO, Swanson RJ, Bowman A, Chiavarini RL, Stacey M, Schoenbach $\mathrm{KH}$ (2008) Cold atmospheric pressure air plasma jet for medical applications. Applied Physics Letters, 92:241501 (4pp). doi:10.1063/1.2940325

42. Ehlbeck J, Schnabel U, Polak M, Winter J, von Woedtke T, Brandenburg R, von dem Hagen T, Weltmann K-D (2011) Low temperature atmospheric pressure plasma sources for microbial decontamination. Journal of Physics D: Applied Physics, 44:013002 (18pp). doi:10.1088/0022$3727 / 44 / 1 / 013002$

43. Sosnin EA, Stoffels E, Erofeev MV, Kieft IE, Kunts SE (2004) The Effects of UV Irradiation and Gas Plasma Treatment on Living Mammalian Cells and Bacteria: A Comparative Approach. IEEE Transactions on Plasma Science, 32:1544-1550. doi:10.1109/TPS.2004.833401

44. Kalghatgi S, Friedman G, Fridman A, Clyne AM (2010) Endothelial Cell Proliferation is Enhanced by Low Dose Non-Thermal Plasma Through Fibroblast Growth Factor-2 Release. Annals of Biomedical Engineering, 38:748-757. doi:10.1007/s10439-009-9868-x

45. Hoentsch M, von Woedtke T, Weltmann K-D, Nebe BJ (2012) Time-dependent effects of lowtemperature atmospheric-pressure argon plasma on epithelial cell attachment, viability and tight junction formation in vitro. Journal of Physics D: Applied Physics, 45:025206 (9pp). doi:10.1088/0022-3727/45/2/025206

46. Arndt $\mathrm{S}$, Unger P, Wacker E, Shimizu T, Heinlin J, Li Y-F, Thomas HM, Morfill GE, Zimmermann JL, Bosserhoff A-K, Karrer S (2013) Cold Atmospheric Plasma (CAP) Changes Gene Expression of Key Molecules of the Wound Healing Machinery and Improves Wound Healing In Vitro and In Vivo. PLoS ONE, 8:e79325 (9pp). doi:10.1371/journal.pone.0079325

47. Tiede R, Hirschberg J, Viöl W, Emmert S (2016) A $\mu$ s-Pulsed Dielectric Barrier Discharge Source: Physical Characterization and Biological Effects on Human Skin Fibroblasts. Plasma Processes and Polymers, 13:775-787. doi:10.1002/ppap.201500190 
48. Tresp H, Hammer MU, Weltmann K-D, Reuter S (2013) Effects of Atmosphere Composition and Liquid Type on Plasma-Generated Reactive Species in Biologically Relevant Solutions. Plasma Medicine, 3:45-55. doi:10.1615/PlasmaMed.2014009711

49. Meiners A (2011) Entwicklung, Charakterisierung und Anwendung nichtthermischer LuftPlasmajets. Georg-August-Universität Göttingen

50. Sakiyama Y, Graves DB, Chang H-W, Shimizu T, Morfill GE (2012) Plasma chemistry model of surface microdischarge in humid air and dynamics of reactive neutral species. Journal of Physics D: Applied Physics, 45:425201 (19pp). doi:10.1088/0022-3727/45/42/425201

51. Moll I (2016) Duale Reihe Dermatologie, 8th ed. Thieme Verlag

52. Welsch $\cup(\mathbf{2 0 1 4})$ Lehrbuch Histologie, 4th ed. Urban Fisher

53. Green KJ, Jones JCR (1996) Desmosomes and hemidesmosomes: structure and function of moleculr components. The FASEB Journal, 10:871-881.

54. Borradori L, Sonnenberg A (1999) Structure and function of hemidesmosomes: More than simple adhesion complexes. Journal of Investigative Dermatology, 112:411-418. doi:10.1046/j.15231747.1999.00546.x

55. Raymond A-A, Gonzalez de Peredo A, Stella A, Ishida-Yamamoto A, Bouyssie D, Serre G, Monsarrat B, Simon M (2008) Lamellar Bodies of Human Epidermis. Molecular \& Cellular Proteomics, 7:2151-2175. doi:10.1074/mcp.M700334-MCP200

56. Robson MC (1997) Wound infection: A failure of wound healing caused by an imbalance of bacteria. Surgical Clinics of North America, 77:637-650. doi:10.1016/S0039-6109(05)70572-7

57. Broughton IG, Janis JE, Attinger CE (2006) The basic science of wound healing. Plastic and Reconstructive Surgery, 117:12-34. doi:10.1097/01.prs.0000225430.42531.c2

58. Hart CA, Scott LJ, Bagley S, Bryden AA, Clarke NW, Lang SH (2002) Role of proteolytic enzymes in human prostate bone metastasis formation: in vivo and in vitro studies. British Journal of Cancer, 86:1136-1142. doi:10.1038/sj.bjc.6600207

59. Artuc M, Hermes B, Steckelings UM, Grützkau A, Henz BM (1999) Mast cells and their mediators in cutaneous wound healing - active participants or innocent bystanders? Experimental Dermatology, 8:1-16. doi:10.1111/j.1600-0625.1999.tb00342.x

60. Diegelmann RF, Evans MC (2004) Wound healing: An overview of acute, fibrotic and delayed healing. Frontiers in Bioscience, 9:283-289. doi:10.2741/1184

61. Diegelmann RFPD, Cohen IKMD, Kaplan AMPD (1981) The Role of Macrophages in Wound Repair: A Review. Plastic \& Reconstructive Surgery, 68:107-113. 
62. Peranteau WH, Zhang L, Muvarak N, Badillo AT, Radu A, Zoltick PW, Liechty KW (2008) IL-10 Overexpression Decreases Inflammatory Mediators and Promotes Regenerative Healing in an Adult Model of Scar Formation. The Journal of Investigative Dermatology, 128:1852-1860. doi:10.1038/sj.jid.5701232

63. Knighton D, Hunt T, Scheuenstuhl H, Halliday B, Werb Z, Banda M (1983) Oxygen tension regulates the expression of angiogenesis factor by macrophages. Science, 221:1283-1285. doi:10.1126/science.6612342

64. Dissemond J (2006) Wann ist eine Wunde chronisch? Der Hautarzt, 57:55. doi:10.1007/s00105005-1048-9

65. Dissemond J (2006) Moderne Wundauflagen für die Therapie chronischer Wunden. Hautarzt, 57:881-887. doi:10.1007/s00105-005-1054-y

66. Halbert AR, Stacey MC, Rohr JB, Jopp-Mckay A (1992) THE EFFECT OF BACTERIAL COLONIZATION ON VENOUS ULCER HEALING. Australasian Journal of Dermatology, 33:7580. doi:10.1111/j.1440-0960.1992.tb00083.x

67. Edwards R, Harding KG (2004) Bacteria and wound healing. Current Opinion in Infectious Diseases, 17:91-96.

68. Menke NB, Ward KR, Witten TM, Bonchev DG, Diegelmann RF (2007) Impaired wound healing. Clinics in Dermatology, 25:19-25. doi:10.1016/j.clindermatol.2006.12.005

69. Nwomeh BC, Liang HX, Diegelmann RF, Cohen IK, Yager DR (1998) Dynamics of the matrix metalloproteinases MMP-1 and MMP-8 in acute open human dermal wounds. Wound Repair and Regeneration, 6:127-134. doi:10.1046/j.1524-475X.1998.60206.x

70. Cooper DM, Yu EZ, Hennessey P, Ko F, Robson MC (1994) Determination of Endogenous Cytokines in Chronic Wounds. Annals of Surgery, 219:688-692. doi:10.1097/00006534199510000-00073

71. Laroussi M (1996) Sterilization of contaminated matter with an atmospheric pressure plasma. IEEE Transactions on Plasma Science, 24:1188-1191. doi:10.1109/27.533129

72. Stoffels E, Kieft IE, Sladek REJ (2003) Superficial treatment of mammalian cells using plasma needle. Journal of Physics D: Applied Physics, 36:2908-2913. doi:10.1088/0022$3727 / 36 / 23 / 007$

73. Stoffels E, Sakiyama Y, Graves DB (2008) Cold atmospheric plasma: Charged species and their interactions with cells and tissues. IEEE Transactions on Plasma Science, 36:1441-1457. doi:10.1109/TPS.2008.2001084 
74. Kieft IE, Kurdi M, Stoffels E (2006) Reattachment and apoptosis after plasma-needle treatment of cultured cells. IEEE Transactions on Plasma Science, 34:1331-1336. doi:10.1109/TPS.2006.876511

75. Kieft IE, Broers JL V, Caubet-Hilloutou V, Slaaf DW, Ramaekers FCS, Stoffels E (2004) Electric discharge plasmas influence attachment of cultured CHO K1 cells. Bioelectromagnetics, 25:362368. doi:10.1002/bem.20005

76. Kieft IE, Darios D, Roks AJM, Stoffels E (2005) Plasma treatment of mammalian vascular cells: A quantitative description. IEEE Transactions on Plasma Science, 33:771-775. doi:10.1109/TPS.2005.844528

77. Ngo M-HT, Liao J-D, Shao P-L, Weng C-C, Chang C-Y (2014) Increased Fibroblast Cell Proliferation and Migration Using Atmospheric N2/Ar Micro-Plasma for the Stimulated Release of Fibroblast Growth Factor-7. Plasma Processes and Polymers, 11:80-88. doi:10.1002/ppap.201300098

78. Ratovitski EA, Cheng X, Yan D, Sherman JH, Canady J, Trink B, Keidar M, Canady J (2014) Anti-Cancer Therapies of 21st Century: Novel Approach to Treat Human Cancers Using Cold Atmospheric Plasma. Plasma Processes and Polymers, 11:1128-1137. doi:10.1002/ppap.201400071

79. Yan X, Zou F, Zhao S, Lu X, He G, Xiong Z, Xiong Q, Zhao Q, Deng P, Huang J, Yang G (2010) On the Mechanism of Plasma Inducing Cell Apoptosis. IEEE Transactions on Plasma Science, 38:2451-2457. doi:10.1109/TPS.2010.2056393

80. Kim GJ, Kim W, Kim KT, Lee JK (2010) DNA damage and mitochondria dysfunction in cell apoptosis induced by nonthermal air plasma. Applied Physics Letters, 96:021502 (4pp). doi:10.1063/1.3292206

81. Volotskova O, Hawley TS, Stepp MA, Keidar M (2012) Targeting the cancer cell cycle by cold atmospheric plasma. Scientific Reports, 2:636 (10pp). doi:10.1038/srep00636

82. Blackert $\mathrm{S}$, Haertel $\mathrm{B}$, Wende $\mathrm{K}$, von Woedtke $\mathrm{T}$, Lindequist $\mathrm{U}$ (2013) Influence of non-thermal atmospheric pressure plasma on cellular structures and processes in human keratinocytes (HaCaT). Journal of Dermatological Science, 70:173-181. doi:10.1016/j.jdermsci.2013.01.012

83. Wende K, Straßenburg S, Haertel B, Harms M, Holtz S, Barton A, Masur K, von Woedtke T, Lindequist $U$ (2014) Atmospheric pressure plasma jet treatment evokes transient oxidative stress in HaCaT keratinocytes and influences cell physiology. Cell Biology International, 38:412-425. doi:10.1002/cbin. 10200

84. Lazović S, Maletić D, Leskovac A, Filipović J, Puač N, Malović G, Joksić G, Petrović ZL (2014) Plasma induced DNA damage: Comparison with the effects of ionizing radiation. Applied Physics Letters, 105:124101 (6pp). doi:10.1063/1.4896626 
85. Sensenig R, Kalghatgi S, Cerchar E, Fridman G, Shereshevsky A, Torabi B, Arjunan KP, Podolsky E, Fridman A, Friedman G, Azizkhan-Clifford J, Brooks AD (2011) Non-thermal plasma induces apoptosis in melanoma cells via production of intracellular reactive oxygen species. Annals of Biomedical Engineering, 39:674-687. doi:10.1007/s10439-010-0197-x

86. Ishaq M, Kumar S, Varinli H, Han ZJ, Rider AE, Evans MDM, Murphy AB, Ostrikov K (2014) Atmospheric gas plasma-induced ROS production activates TNF-ASK1 pathway for the induction of melanoma cancer cell apoptosis. Molecular Biology of the Cell, 25:1523-1531. doi:10.1091/mbc.E13-10-0590

87. Babington P, Rajjoub K, Canady J, Siu A, Keidar M, Sherman JH (2015) Use of cold atmospheric plasma in the treatment of cancer. Biointerphases, 10:029403 (5pp). doi:10.1116/1.4915264

88. Ahn HJ, Kim K II, Kim G, Moon E, Yang SS, Lee JS (2011) Atmospheric-pressure plasma jet induces apoptosis involving mitochondria via generation of free radicals. PLOS ONE, 6:6-12. doi:10.1371/journal.pone.0028154

89. Iseki S, Nakamura K, Hayashi M, Tanaka H, Kondo H, Kajiyama H, Kano H, Kikkawa F, Hori M (2012) Selective killing of ovarian cancer cells through induction of apoptosis by nonequilibrium atmospheric pressure plasma. Applied Physics Letters, 100:113702 (4pp). doi:10.1063/1.3694928

90. Vandamme M, Robert E, Lerondel S, Sarron V, Ries D, Dozias S, Sobilo J, Gosset D, Kieda C, Legrain B, Pouvesle JM, Pape A Le (2012) ROS implication in a new antitumor strategy based on non-thermal plasma. International Journal of Cancer, 130:2185-2194. doi:10.1002/ijc.26252

91. Jiang C, Chen M-T, Gorur A, Schaudinn C, Jaramillo DE, Costerton JW, Sedghizadeh PP, Vernier PT, Gundersen MA (2009) Nanosecond Pulsed Plasma Dental Probe. Plasma Processes and Polymers, 6:479-483. doi:10.1002/ppap.200800133

92. Rupf S, Idlibi AN, Marrawi F Al, Hannig M, Schubert A, von Mueller L, Spitzer W, Holtmann H, Lehmann A, Rueppell A, Schindler A (2011) Removing Biofilms from Microstructured Titanium Ex Vivo: A Novel Approach Using Atmospheric Plasma Technology. PLoS ONE, 6:e25893 (9pp). doi:10.1371/journal.pone.0025893

93. Lee HW, Nam SH, Mohamed A-AH, Kim GC, Lee JK (2010) Atmospheric Pressure Plasma Jet Composed of Three Electrodes: Application to Tooth Bleaching. Plasma Processes and Polymers, 7:274-280. doi:10.1002/ppap.200900083

94. Foster WK, Moy RL, Fincher EF (2008) Advances in plasma skin regeneration. Journal of Cosmetic Dermatology, 7:169-179. doi:10.1111/j.1473-2165.2008.00385.x

95. Kono T, Groff WF, Sakurai H, Yamaki T, Soejima K, Nozaki M (2009) Treatment of traumatic scars using plasma skin regeneration (PSR) system. Lasers in Surgery and Medicine, 41:128130. doi:10.1002/lsm.20723 
96. Chutsirimongkol C, Boonyawan D, Polnikorn N, Techawatthanawisan W, Kundilokchai T (2014) Non-Thermal Plasma for Acne and Aesthetic Skin Improvement. Plasma Medicine, 4:79-88. doi:10.1615/PlasmaMed.2014011952

97. Laroussi M (2008) The biomedical applications of plasma: A brief history of the development of a new field of research. IEEE Transactions on Plasma Science, 36:1612-1614. doi:10.1109/TPS.2008.917167

98. Emmert S, Brehmer F, Hänßle H, Helmke A, Mertens N, Ahmed R, Simon D, Wandke D, MausFriedrichs W, Däschlein G, Schön MP, Viöl W (2013) Atmospheric pressure plasma in dermatology: Ulcus treatment and much more. Clinical Plasma Medicine, 1:24-29. doi:10.1016/j.cpme.2012.11.002

99. Venezia RA, Orrico M, Houston E, Yin S, Naumova YY (2008) Lethal Activity of Nonthermal Plasma Sterilization Against Microorganisms. Infection Control and Hospital Epidemiology, 29:430-436. doi:10.1086/588003

100. Daeschlein G, Scholz S, von Woedtke T, Niggemeier M, Kindel E, Brandenburg R, Weltmann KD, Junger M (2011) In Vitro Killing of Clinical Fungal Strains by Low-Temperature AtmosphericPressure Plasma Jet. IEEE Transactions on Plasma Science, 39:815-821. doi:10.1109/TPS.2010.2063441

101. Zimmermann JL, Dumler K, Shimizu T, Morfill GE, Wolf A, Boxhammer V, Schlegel J, Gansbacher B, Anton M (2011) Effects of cold atmospheric plasmas on adenoviruses in solution. Journal of Physics D: Applied Physics, 44:505201 (9pp). doi:10.1088/0022-3727/44/50/505201

102. Klämpfl TG, Isbary G, Shimizu T, Li YF, Zimmermann JL, Stolz W, Schlegel J, Morfill GE, Schmidt HU (2012) Cold atmospheric air plasma sterilization against spores and other microorganisms of clinical interest. Applied and Environmental Microbiology, 78:5077-5082. doi:10.1128/AEM.00583-12

103. Daeschlein G, Scholz S, Arnold A, von Podewils S, Haase H, Emmert S, von Woedtke T, Weltmann K-D, Jünger M (2012) In Vitro Susceptibility of Important Skin and Wound Pathogens Against Low Temperature Atmospheric Pressure Plasma Jet (APPJ) and Dielectric Barrier Discharge Plasma (DBD). Plasma Processes and Polymers, 9:380-389. doi:10.1002/ppap.201100160

104. Daeschlein G, von Woedtke T, Kindel E, Brandenburg R, Weltmann K-D, Jünger M (2010) Antibacterial Activity of an Atmospheric Pressure Plasma Jet Against Relevant Wound Pathogens in vitro on a Simulated Wound Environment. Plasma Processes and Polymers, 7:224-230. doi:10.1002/ppap.200900059

105. Maisch T, Shimizu T, Li YF, Heinlin J, Karrer S, Morfill G, Zimmermann JL (2012) Decolonisation of MRSA, S. aureus and E. coli by cold-atmospheric plasma using a porcine skin model in vitro. PLOS ONE, 7:1-9. doi:10.1371/journal.pone.0034610 
106. Daeschlein G, Napp M, von Podewils S, Lutze S, Emmert S, Lange A, Klare I, Haase H, Gümbel D, von Woedtke T, Jünger M (2014) In Vitro Susceptibility of Multidrug Resistant Skin and Wound Pathogens Against Low Temperature Atmospheric Pressure Plasma Jet (APPJ) and Dielectric Barrier Discharge Plasma (DBD). Plasma Processes and Polymers, 11:175-183. doi:10.1002/ppap.201300070

107. Joaquin JC, Kwan C, Abramzon N, Vandervoort K, Brelles-Marino G (2009) Is gas-discharge plasma a new solution to the old problem of biofilm inactivation? Microbiology, 155:724-732. doi:10.1099/mic.0.021501-0

108. Isbary G, Morfill G, Schmidt HU, Georgi M, Ramrath K, Heinlin J, Karrer S, Landthaler M, Shimizu T, Steffes B, Bunk W, Monetti R, Zimmermann JL, Pompl R, Stolz W (2010) A first prospective randomized controlled trial to decrease bacterial load using cold atmospheric argon plasma on chronic wounds in patients. British Journal of Dermatology, 163:78-82. doi:10.1111/j.13652133.2010.09744.x

109. Isbary G, Heinlin J, Shimizu T, Zimmermann JL, Morfill G, Schmidt H-U, Monetti R, Steffes B, Bunk W, Li Y, Klaempfl T, Karrer S, Landthaler M, Stolz W (2012) Successful and safe use of 2 min cold atmospheric argon plasma in chronic wounds: results of a randomized controlled trial. British Journal of Dermatology, 167:404-410. doi:10.1111/j.1365-2133.2012.10923.x

110. Brehmer F, Haenssle HA, Daeschlein G, Ahmed R, Pfeiffer S, Görlitz A, Simon D, Schön MP, Wandke D, Emmert S (2015) Alleviation of chronic venous leg ulcers with a hand-held dielectric barrier discharge plasma generator (PlasmaDerm ${ }^{\circledR}$ VU-2010): results of a monocentric, twoarmed, open, prospective, randomized and controlled trial (NCT01415622). Journal of the European Academy of Dermatology and Venereology, 29:148-155. doi:10.1111/jdv.12490

111. Wende K, Landsberg K, Lindequist U, Weltmann K-D, von Woedtke T (2010) Distinctive Activity of a Nonthermal Atmospheric-Pressure Plasma Jet on Eukaryotic and Prokaryotic Cells in a Cocultivation Approach of Keratinocytes and Microorganisms. IEEE Transactions on Plasma Science, 38:2479-2485. doi:10.1109/TPS.2010.2052835

112. Kim PY, Kim Y-S, Koo IG, Jung JC, Kim GJ, Choi MY, Yu Z, Collins GJ (2011) Bacterial Inactivation of Wound Infection in a Human Skin Model by Liquid-Phase Discharge Plasma. PLoS ONE, 6:e24104 (6pp). doi:10.1371/journal.pone.0024104

113. Dobrynin D, Fridman G, Friedman G, Fridman A (2009) Physical and biological mechanisms of direct plasma interaction with living tissue. New Journal of Physics, 11:115020 (26pp). doi:10.1088/1367-2630/11/11/115020

114. Steinbeck MJ, Chernets N, Zhang J, Kurpad DS, Fridman G, Fridman A, Freeman TA (2013) Skeletal Cell Differentiation Is Enhanced by Atmospheric Dielectric Barrier Discharge Plasma Treatment. PLOS ONE, 8:e82143 (9pp). doi:10.1371/journal.pone.0082143 
115. Schneider LA, Korber A, Grabbe S, Dissemond J (2007) Influence of pH on wound-healing: A new perspective for wound-therapy? Archives of Dermatological Research, 298:413-420. doi:10.1007/s00403-006-0713-x

116. Schreml S, Szeimies RM, Karrer S, Heinlin J, Landthaler M, Babilas P (2010) The impact of the $\mathrm{pH}$ value on skin integrity and cutaneous wound healing. Journal of the European Academy of Dermatology and Venereology, 24:373-378. doi:10.1111/j.1468-3083.2009.03413.x

117. Oehmigen K, Hähnel M, Brandenburg R, Wilke C, Weltmann K-D, von Woedtke T (2010) The Role of Acidification for Antimicrobial Activity of Atmospheric Pressure Plasma in Liquids. Plasma Processes and Polymers, 7:250-257. doi:10.1002/ppap.200900077

118. Liu F, Sun P, Bai N, Tian Y, Zhou H, Wei S, Zhou Y, Zhang J, Zhu W, Becker K, Fang J (2010) Inactivation of Bacteria in an Aqueous Environment by a Direct-Current, Cold-AtmosphericPressure Air Plasma Microjet. Plasma Processes and Polymers, 7:231-236. doi:10.1002/ppap.200900070

119. von Woedtke $\mathrm{T}$, Oehmigen $\mathrm{K}$, Brandenburg $\mathrm{R}$, Hoder T, Wilke C, Hähnel M, Weltmann K-D (2012) Plasma for Bio-Decontamination, Medicine and Food Security. Plasma BioDecontamination, Med Food Secur. doi:10.1007/978-94-007-2852-3

120. Helmke A, Hoffmeister D, Mertens N, Emmert S, Schuette J, Vioel W (2009) The acidification of lipid film surfaces by non-thermal DBD at atmospheric pressure in air. New Journal of Physics, 11:115025 (10pp). doi:10.1088/1367-2630/11/11/115025

121. Barton A, Wende K, Bundscherer L, Hasse S, Schmidt A, Bekeschus S, Weltmann K-D, Masur K (2013) Nonthermal Plasma Increases Expression of Wound Healing Related Genes in a Keratinocyte Cell Line. Plasma Medicine, 3:125-136.

122. Negrão R, Costa R, Duarte $D$, Gomes $T$, Azevedo I, Soares R (2013) Different effects of catechin on angiogenesis and inflammation depending on VEGF levels. Journal of Nutritional Biochemistry, 24:435-444. doi:10.1016/j.jnutbio.2011.12.011

123. Ślusarz R, Gadomska G, Biercewicz M, Grzelak L, Szewczyk MT, Rość D, Beuth W (2012) The influence of selected demographic factors and wound location on the concentration of vascular endothelial growth factor (VEGF-A) in the wound healing process after neurosurgery: Brief report. Wound Repair and Regeneration, 20:667-675. doi:10.1111/j.1524-475X.2012.00821.x

124. Chen W, Tang Q, Gonzales MS, Bowden GT (2001) Role of p38 MAP kinases and ERK in mediating ultraviolet-B induced cyclooxygenase-2 gene expression in human keratinocytes. Oncogene, 20:3921-3926. doi:10.1038/sj.onc.1204530

125. Zhan P, Qian Q, Yu LK (2013) Prognostic value of COX-2 expression in patients with non-small cell lung cancer: a systematic review and meta-analysis. Journal of Thoracic Disease, 5:40-47. doi:10.3978/j.issn.2072-1439.2013.01.02 
126. Braunstein S, Kaplan G, Gottlieb AB, Schwartz M, Walsh G, Abalos RM, Fajardo TT, Guido LS, Krueger JG (1994) GM-CSF Activates Regenerative Epidermal Growth and Stimulates Keratinocyte Proliferation in Human Skin In Vivo. Journal of Investigative Dermatology, 103:601604. doi:10.1111/1523-1747.ep12396936

127. Breuhahn K, Mann A, Müller G, Wilhelmi A, Schirmacher P, Enk A, Blessing M (2000) Epidermal overexpression of granulocyte-macrophage colony-stimulating factor induces both keratinocyte proliferation and apoptosis. Cell Growth \& Differentiation: the Molecular Biology Journal of the American Association for Cancer Research, 11:111-121.

128. Fang Y, Shen J, Yao M, Beagley KW, Hambly BD, Bao S (2010) Granulocyte-macrophage colony-stimulating factor enhances wound healing in diabetes via upregulation of proinflammatory cytokines. British Journal of Dermatology, 162:478-486. doi:10.1111/j.13652133.2009.09528.x

129. Feng J, El-Assal ON, Besner GE (2005) Heparin-binding EGF-like growth factor (HB-EGF) and necrotizing enterocolitis. Seminars in Pediatric Surgery, 14:167-174. doi:10.1053/j.sempedsurg.2005.05.005

130. Johnson NR, Wang Y (2013) Controlled delivery of heparin-binding EGF-like growth factor yields fast and comprehensive wound healing. Journal of Controlled Release, 166:124-129. doi:10.1016/j.jconrel.2012.11.004

131. Martin P (1997) Wound Healing--Aiming for Perfect Skin Regeneration. Science, 276:75-81. doi:10.1126/science.276.5309.75

132. Santoro MM, Gaudino G (2005) Cellular and molecular facets of keratinocyte reepithelization during wound healing. Experimental Cell Research, 304:274-286. doi:10.1016/j.yexcr.2004.10.033

133. Radek KA, Taylor KR, Gallo RL (2009) FGF-10 and specific structural elements of dermatan sulfate size and sulfation promote maximal keratinocyte migration and cellular proliferation. Wound Repair and Regeneration, 17:118-126. doi:10.1111/j.1524-475X.2008.00449.x

134. Fridman G, Friedman G, Gutsol A, Shekhter AB, Vasilets VN, Fridman A (2008) Applied Plasma Medicine. Plasma Processes and Polymers, 5:503-533. doi:10.1002/ppap.200700154

135. Awakowicz P, Bibinov N, Born M, Busse B, Gesche R, Helmke A, Kaemling A, Kolb-Bachofen V, Kovacs R, Kuehn S, Liebmann J, Mertens N, Niemann U, Oplaender C, Porteanu HE, Scherer J, Suschek C, Vioel W, Wandke D (2009) Biological stimulation of the human skin applying healthpromoting light and plasma sources. Contributions to Plasma Physics, 49:641-647. doi:10.1002/ctpp.200910068 
136. Rajasekaran $P$, Opländer $C$, Hoffmeister D, Bibinov N, Suschek CV, Wandke D, Awakowicz $P$ (2011) Characterization of Dielectric Barrier Discharge (DBD) on Mouse and Histological Evaluation of the Plasma-Treated Tissue. Plasma Processes and Polymers, 8:246-255. doi:10.1002/ppap.201000122

137. Daeschlein G, Scholz S, Ahmed R, Majumdar A, von Woedtke T, Haase H, Niggemeier M, Kindel $E$, Brandenburg R, Weltmann K-D, Jünger M (2012) Cold plasma is well-tolerated and does not disturb skin barrier or reduce skin moisture. JDDG: Journal der Deutschen Dermatologischen Gesellschaft, 10:509-515. doi:10.1111/j.1610-0387.2012.07857.x

138. Mann MS, Tiede R, Gavenis K, Daeschlein G, Bussiahn R, Weltmann K-D, Emmert S, von Woedtke T, Ahmed R (2016) Introduction to DIN-specification 91315 based on the characterization of the plasma jet kINPen ${ }^{\circledR}$ MED. Clinical Plasma Medicine, 4:35-45. doi:10.1016/j.cpme.2016.06.001

139. Grant SGN, Jessee J, Bloom FR, Hanahan D (1990) Differential plasmid rescue from transgenic mouse DNAs into Escherichia coli methylation-restriction mutants. Proceedings of the National Academy of Sciences of the United States of America, 87:4645-4649. doi:10.1073/pnas.87.12.4645

140. Wiencke JK, Yager JW, Varkonyi A, Hultner M, Lutze LH (1997) Study of arsenic mutagenesis using the plasmid shuttle vector pZ189 propagated in DNA repair proficient human cells. Mutation Research - Reviews in Mutation Research, 386:335-344.

141. Bimboim HC, Doly J (1979) A rapid alkaline extraction procedure for screening recombinant plasmid DNA. Nucleic Acids Research, 7:1513-1523. doi:10.1093/nar/7.6.1513

142. Zeugin JA, Hartley JL (1985) Ethanol Precipitation of DNA. Focus, 7:1-2. doi:10.1108/eb015969

143. Green MR, Sambrook J (2012) Molecular Cloning, 4th ed. doi:10.3724/SP.J.1141.2012.01075

144. Qiao Y, Spitz MR, Guo Z, Hadeyati M, Grossman L, Kraemer KH, Wei Q (2002) Rapid assessment of repair of ultraviolet DNA damage with a modified host-cell reactivation assay using a luciferase reporter gene and correlation with polymorphisms of DNA repair genes in normal human lymphocytes. Mutation Research - Fundamental and Molecular Mechanisms of Mutagenesisesearch, 509:165-174.

145. Thoms K, Baesecke J, Emmert B, Hermann J, Roedling T, Laspe P, Leibeling D, Truemper L, Emmert S (2007) Functional DNA repair system analysis in haematopoietic progenitor cells using host cell reactivation. Scandinavian Journal of Clinical and Laboratory Investigation, 67:580-588. doi:10.1080/00365510701230481

146. Parris CN, Seidman MM (1992) A signature element distinguishes sibling and independent mutations in a shuttle vector plasmid. Gene, 117:1-5. 
147. Kraemer KH, Seidman MM (1989) Use of supF, An Escherichia coli tyrosine suppressor tRNA gene, as a mutagenic target in shuttle-vector plasmids. Mutation Research, 220:61-72.

148. Mullis K, Faloona F, Scharf S, Saiki R, Horn G, Erlich H (1986) Specific Enzymatic Amplification of DNA In Vitro: The Polymerase Chain Reaction. Cold Spring Harbor Symposia on Quantitative Biology, 51:263-273. doi:10.1101/SQB.1986.051.01.032

149. Sanger F, Nicklen S, Coulson a R (1977) DNA sequencing with chain-terminating inhibitors. Proceedings of the National Academy of Sciences, 74:5463-5467. doi:10.1073/pnas.74.12.5463

150. Semrock Filters for Flow Cytometry. https://www.semrock.com/flow-cytometry.aspx. Accessed 10 August 2017

151. Rogakou EP, Boon C, Redon C, Bonner WM (1999) Megabase Chromatin Domains Involved in DNA Double-Strand Breaks In Vivo. The Journal of Cell Biology, 146:905-915.

152. Kuo LJ, Yang L-X (2008) Gamma-H2AX - a novel biomarker for DNA double-strand breaks. In vivo (Athens, Greece), 22:305-310.

153. Sedelnikova OA, Rogakou EP, Panyutin IG, Bonner WM (2002) Quantitative Detection of 125 IdU-Induced DNA Double-Strand Breaks with Y - H2AX Antibody. Radiation Research, 158:486492.

154. Pilch DR, Sedelnikova OA, Redon C, Celeste A, Nussenzweig A, Bonner WM (2003) Characteristics of gamma-H2AX foci at DNA double-strand breaks sites. Biochemistry and Cell Biology, 81:123-129. doi:10.1139/003-042

155. Huang X, Tanaka T, Kurose A, Traganos F, Darzynkiewicz Z (2006) Constitutive histone H2AX phosphorylation on Ser-139 in cells untreated by genotoxic agents is cell-cycle phase specific and attenuated by scavenging reactive oxygen species. International Journal of Oncology, 29:495-501.

156. Bussiahn R, Lembke N, Gesche R, von Woedtke T, Weltmann K-D (2013) Plasmaquellen für biomedizinische Applikationen. Hygiene \& Medizin, 38:212-216.

157. Herndon CM (2007) Iontophoretic Drug Delivery System: Focus on Fentanyl. Pharmacotherapy, 27:745-754. doi:10.1592/phco.27.5.745

158. Hirschberg J, Omairi T, Mertens N, Helmke A, Emmert S, Viöl W (2013) Influence of excitation pulse duration of dielectric barrier discharges on biomedical applications. Journal of Physics $D$ : Applied Physics, 46:165201 (11pp). doi:10.1088/0022-3727/46/16/165201

159. Kuchenbecker M, Bibinov N, Kaemlimg A, Wandke D, Awakowicz P, Viöl W (2009) Characterization of DBD plasma source for biomedical applications. Journal of Physics $D$ : Applied Physics, 42:045212 (10pp). doi:10.1088/0022-3727/42/4/045212 
160. Hirschberg J, Loewenthal L, Krupp A, Emmert S, Viöl W (2016) Plasma Induced Changes in Human Lipid Composition as Revealed through XPS-Analysis. Natural Science, 8:125-137. doi:10.4236/ns.2016.83016

161. Matsumura $\mathrm{Y}$, Ananthaswamy $\mathrm{HN}$ (2004) Toxic effects of ultraviolet radiation on the skin. Toxicology and Applied Pharmacology, 195:298-308. doi:10.1016/j.taap.2003.08.019

162. Rabe JH, Mamelak AJ, McElgunn PJS, Morison WL, Sauder DN (2006) Photoaging: mechanisms and repair. Journal of the American Academy of Dermatology, 55:1-19. doi:10.1016/j.jaad.2005.05.010

163. Mertmann P, Bibinov N, Halfmann H, Awakowicz $P$ (2010) Determination of argon resonance line emission in an ICP hitting a biological sample. Plasma Sources Science and Technology, 19:015017 (7pp). doi:10.1088/0963-0252/19/1/015017

164. ICNIRP (2004) International Commission on Non-lonized Radiation Protection. Health Phys. doi:10.1097/HP.0b013e318289a611

165. Helmke A, Wandke D, Mahmoodzada M, Weltmann K-D, Viöl W (2013) Impact of Electrode Design, Supply Voltage and Interelectrode Distance on Safety Aspects and Characteristics of a Medical DBD Plasma Source. Contributions to Plasma Physics, 53:623-638. doi:10.1002/ctpp. 201200133

166. Chan WF, Cooper G, Sodhi RNS, Brion CE (1993) Absolute optical oscillator strengths for discrete and continuum photoabsorption of molecular nitrogen (11-200 eV). Chemical Physics, 170:81-97. doi:10.1016/0301-0104(93)80095-Q

167. Yoshino K, Parkinson WH, Ito K, Matsui T (2005) Absolute absorption cross-section measurements of Schumann-Runge continuum of $\mathrm{O}_{2}$ at 90 and $295 \mathrm{~K}$. Journal of Molecular Spectroscopy, 229:238-243. doi:10.1016/j.jms.2004.08.020

168. (2006) The MAK Collection for Occupational Health and Safety.

169. Laroussi M, Mohades S, Barekzi N (2015) Killing adherent and nonadherent cancer cells with the plasma pencil. Biointerphases, 10:029401 (7pp). doi:10.1116/1.4905666

170. Vignard J, Mirey G, Salles B (2013) lonizing-radiation induced DNA double-strand breaks: A direct and indirect lighting up. Radiotherapy and Oncology, 108:362-369. doi:10.1016/j.radonc.2013.06.013

171. Rajasekaran P, Mertmann P, Bibinov N, Wandke D, Viöl W, Awakowicz P (2009) DBD plasma source operated in single-filamentary mode for therapeutic use in dermatology. Journal of Physics D: Applied Physics, 42:225201 (8pp). doi:10.1088/0022-3727/42/22/225201 
172. Isbary G, Stolz W, Shimizu T, Monetti R, Bunk W, Schmidt HU, Morfill GE, Klämpfl TG, Steffes B, Thomas HM, Heinlin J, Karrer S, Landthaler M, Zimmermann JL (2013) Cold atmospheric argon plasma treatment may accelerate wound healing in chronic wounds: Results of an open retrospective randomized controlled study in vivo. Clinical Plasma Medicine, 1:25-30. doi:10.1016/j.cpme.2013.06.001

173. Salehi S, Shokri A, Khani MR, Bigdeli M, Shokri B (2015) Investigating effects of atmosphericpressure plasma on the process of wound healing. Biointerphases, 10:029504 (7pp). doi:10.1116/1.4914377

174. Moriwaki S, Ray S, Tarone RE, Kraemer KH, Grossman L (1996) The effect of donor age on the processing of UV-damaged DNA by cultured human cells: reduced DNA repair capacity and increased DNA mutability. Mutation Research - Fundamental and Molecular Mechanisms of Mutagenesis, 364:117-123. doi:10.1016/0921-8777(96)00029-8

175. de Gruijl FR (1999) Skin cancer and solar UV radiation. European Journal of Cancer, 35:20032009. doi:10.1016/S0959-8049(99)00283-X

176. Perdiz D, Grof P, Mezzina M, Nikaido O, Moustacchi E, Sage E (2000) Distribution and Repair of Bipyrimidine Photoproducts in Solar UV-irradiated Mammalian Cells. The Journal of Biological Chemistry, 275:26732-26742. doi:10.1074/jbc.M001450200

177. Lehnert B, lyer R (2002) Exposure to low-level chemicals and ionizing radiation: reactive oxygen species and cellular pathways. Human \& Experimental Toxicology, 21:65-69. doi:10.1191/0960327102ht212oa

178. Leduc M, Guay D, Leask RL, Coulombe S (2009) Cell permeabilization using a non-thermal plasma. New Journal of Physics, 11:115021 (12pp). doi:10.1088/1367-2630/11/11/115021

179. Ptasińska S, Bahnev B, Stypczyńska A, Bowden M, Mason NJ, Braithwaite NSJ (2010) DNA strand scission induced by a non-thermal atmospheric pressure plasma jet. Physical Chemistry Chemical Physics, 12:7779-77781. doi:10.1039/c001188f

180. O'Connell D, Cox LJ, Hyland WB, McMahon SJ, Reuter S, Graham WG, Gans T, Currell FJ (2011) Cold atmospheric pressure plasma jet interactions with plasmid DNA. Applied Physics Letters, 98:2011-2014. doi:10.1063/1.3521502

181. Alkawareek MY, Gorman SP, Graham WG, Gilmore BF (2014) Potential cellular targets and antibacterial efficacy of atmospheric pressure non-thermal plasma. International Journal of Antimicrobial Agents, 43:154-160. doi:10.1016/j.ijantimicag.2013.08.022

182. Arjunan K, Sharma V, Ptasinska S (2015) Effects of Atmospheric Pressure Plasmas on Isolated and Cellular DNA-A Review. International Journal of Molecular Sciences, 16:2971-3016. doi:10.3390/ijms16022971 
183. Leduc M, Guay D, Coulombe S, Leask RL (2010) Effects of non-thermal plasmas on DNA and mammalian cells. Plasma Processes and Polymers, 7:899-909. doi:10.1002/ppap.201000032

184. Ma Y, Ha CS, Hwang SW, Lee HJ, Kim GC, Lee K-W, Song K (2014) Non-Thermal Atmospheric Pressure Plasma Preferentially Induces Apoptosis in p53-Mutated Cancer Cells by Activating $\begin{array}{llllll}\text { ROS Stress-Response Pathways. PLoS ONE, 9:e91947 (14pp). } & \end{array}$ doi:10.1371/journal.pone.0091947

185. Plewa J-M, Yousfi M, Frongia C, Eichwald O, Ducommun B, Merbahi N, Lobjois V (2014) Lowtemperature plasma-induced antiproliferative effects on multi-cellular tumor spheroids. New Journal of Physics, 16:043027 (20pp). doi:10.1088/1367-2630/16/4/043027

186. Zhivotovsky B, Kroemer G (2004) Apoptosis and genomic instability. Nature Reviews Molecular Cell Biology, 5:752-762. doi:10.1038/nrm1443

187. Aguilera A, Gómez-González B (2008) Genome instability: a mechanistic view of its causes and consequences. Nature Reviews Genetics, 9:204-217. doi:10.1038/nrg2268

188. Willis N, Rhind N (2009) Regulation of DNA replication by the S-phase DNA damage checkpoint. Cell Division, 4:13 (10pp). doi:10.1186/1747-1028-4-13

189. Duch A, de Nadal E, Posas F (2013) Dealing with Transcriptional Outbursts during S Phase to Protect Genomic Integrity. Journal of Molecular Biology, 425:4745-4755. doi:10.1016/j.jmb.2013.08.019

190. Brandenburg R, Lange H, von Woedtke T, Stieber M, Kindel E, Ehlbeck J, Weltmann K-D (2009) Antimicrobial effects of UV and VUV radiation of nonthermal plasma jets. IEEE Transactions on Plasma Science, 37:877-883. doi:10.1109/TPS.2009.2019657

191. Fluhr JW, Sassning S, Lademann O, Danin ME, Schanzer S, Kramer A, Richter H, Sterry W, Lademann J (2012) In vivo skin treatment with tissue-tolerable plasma influences skin physiology and antioxidant profile in human stratum corneum. Experimental Dermatology, 21:130-134. doi:10.1111/j.1600-0625.2011.01411.x

192. Mertens N, Mahmoodzada M, Helmke A, Grünig P, Laspe P, Emmert S, Viöl W (2014) Inactivation of Microorganisms Using Cold Atmospheric Pressure Plasma with Different Temporal Discharge Characteristics. Plasma Processes and Polymers, 11:910-920. doi:10.1002/ppap.201300184

193. Shashurin A, Keidar M, Bronnikov S, Jurjus RA, Stepp MA (2008) Living tissue under treatment of cold plasma atmospheric jet. Applied Physics Letters, 93:181501 (3pp). doi:10.1063/1.3020223

194. Darnell J, Lodish H, Baltimore D (1986) Molecular Cell Biology. Scientific AmericanBooks, New York 
195. Gutteridge JMC (1995) Lipid peroxidation and antioxidants as biomarkers of tissue damage. Clinical Chemistry, 41:1819-1828.

196. Kalghatgi S, Azizkhan-Clifford J (2011) DNA Damage in Mammalian Cells by Atmospheric Pressure Microsecond-Pulsed Dielectric Barrier Discharge Plasma Is Not Mediated Via Lipid Peroxidation. Plasma Medicine, 1:167-177. doi:10.1615/PlasmaMed.2011003798

197. Howland MC, Parikh AN (2010) Model Studies of Membrane Disruption by Photogenerated Oxidative Assault. The Journal of Physical Chemistry B, 114:6377-6385. doi:10.1021/jp10286 $1 \mathrm{v}$

198. Guittonneau S, De Laat J, Duguet JP, Bonnel C, Doré M (1990) Oxidation of Parachloronitrobenzene in Dilute Aqueous Solution by $\mathrm{O}_{3}+\mathrm{UV}$ and $\mathrm{H}_{2} \mathrm{O}_{2}+\mathrm{UV}$ : A Comparative Study. Ozone: Science \& Engineering, 12:73-94. doi:10.1080/01919519008552456

199. Bolton JR, Cotton CA (2008) The Ultraviolet Disinfection Handbook, 1st ed. American Water Works Association, USA

200. Haertel B, Straßenburg S, Oehmigen K, Wende K, von Woedtke T, Lindequist U (2013) Differential Influence of Components Resulting from Atmospheric-Pressure Plasma on Integrin Expression of Human HaCaT Keratinocytes. BioMed Research International, 2013:1-9. doi:10.1155/2013/761451

201. Yan X, Xiong Z, Zou F, Zhao S, Lu X, Yang G, He G, Ostrikov K (2012) Plasma-induced death of HepG2 cancer cells: Intracellular effects of reactive species. Plasma Processes and Polymers, 9:59-66. doi:10.1002/ppap.201100031

202. Thannickal VJ, Fanburg BL (2000) Reactive Oxygen Species and Cell Signaling. American Journal of Physiology - Lung Cellular and Molecular Physiology, 279:L1005-L1028. doi:10.1164/rccm.2206007

203. Trachootham D, Lu W, Ogasawara M a, Valle NR-D, Huang P (2008) Redox Regulation of Cell Survival. Antioxidants \& Redox Signaling, 10:1343-1374. doi:10.1089/ars.2007.1957

204. Alfadda AA, Sallam RM (2012) Reactive Oxygen Species in Health and Disease. Journal of Biomedicine and Biotechnology, 2012:1-14. doi:10.1155/2012/936486

205. Circu ML, Aw TY (2010) Reactive oxygen species, cellular redox systems, and apoptosis. Free Radical Biology and Medicine, 48:749-762. doi:10.1016/j.freeradbiomed.2009.12.022

206. Laroussi M, Leipold F (2004) Evaluation of the roles of reactive species, heat, and UV radiation in the inactivation of bacterial cells by air plasmas at atmospheric pressure. International Journal of Mass Spectrometry, 233:81-86. doi:10.1016/j.ijms.2003.11.016 
207. Boudam MK, Moisan M, Saoudi B, Popovici C, Gherardi N, Massines F (2006) Bacterial spore inactivation by atmospheric-pressure plasmas in the presence or absence of UV photons as obtained with the same gas mixture. Journal of Physics D: Applied Physics, 39:3494-3507. doi:10.1088/0022-3727/39/16/S07

208. Kulms D, Schwarz T (2002) Mechanisms of UV-Induced Signal Transduction. The Journal of Dermatology, 29:189-196. doi:10.1111/j.1346-8138.2002.tb00248.x

209. Birch-Machin MA, Swalwell H (2010) How mitochondria record the effects of UV exposure and oxidative stress using human skin as a model tissue. Mutagenesis, 25:101-107. doi:10.1093/mutage/gep061

210. Xie S, Wang Q, Wu H, Cogswell J, Lu L, Jhanwar-Uniyal M, Dai W (2001) Reactive Oxygen Species-induced Phosphorylation of p53 on Serine 20 Is Mediated in Part by Polo-like Kinase-3. Journal of Biological Chemistry, 276:36194-36199. doi:10.1074/jbc.M104157200

211. Masson N, Ratcliffe PJ (2014) Hypoxia signaling pathways in cancer metabolism: the importance of co-selecting interconnected physiological pathways. Cancer \& Metabolism, 2:1-17. doi:10.1186/2049-3002-2-3

212. Zhu C, Hu W, Wu H, Hu X (2015) No evident dose-response relationship between cellular ROS level and its cytotoxicity - a paradoxical issue in ROS-based cancer therapy. Scientific Reports, 4:5029 (10pp). doi:10.1038/srep05029

213. Boland ML, Chourasia AH, Macleod KF (2013) Mitochondrial Dysfunction in Cancer. Frontiers in Oncology, 3:1-28. doi:10.3389/fonc.2013.00292

214. Kim SJ, Chung TH (2016) Cold atmospheric plasma jet- generated RONS and their selective effects on normal and carcinoma cells. Nature Publishing Group1-14. doi:10.1038/srep20332

215. Bartek J, Lukas C, Lukas J (2004) Checking on DNA damage in S phase. Nature Reviews Molecular Cell Biology, 5:792-804. doi:10.1038/nrm1493

216. Partecke LI, Evert K, Haugk J, Doering F, Normann L, Diedrich S, Weiss F, Evert M, Huebner NO, Guenther C, Heidecke CD, Kramer A, Bussiahn R, Weltmann K-D, Pati O, Bender C, von Bernstorff W (2012) Tissue Tolerable Plasma ( TTP ) induces apoptosis in pancreatic cancer cells in vitro and in vivo. BioMed Central Cancer, 12:1-10.

217. Froehlich JE, Anastassiades TP (1974) Role of $\mathrm{pH}$ in fibroblast proliferation. Journal of Cellular Physiology, 84:253-259. doi:10.1002/jcp.1040840211

218. Caldecott KW (2008) Advances in autism genetics: on the threshold of a new neurobiology. Nature Reviews Genetics, 9:341-355. doi:10.1038/nrg2346 
219. Kuzminov A (2001) Single-strand interruptions in replicating chromosomes cause double-strand breaks. Proceedings of the National Academy of Sciences, 98:8241-8246. doi:10.1073/pnas.131009198

220. Christmann M, Tomicic MT, Roos WP, Kaina B (2003) Mechanisms of human DNA repair: An update. Toxicology, 193:3-34. doi:10.1016/S0300-483X(03)00287-7

221. Yan X, Zou F, Lu XP, He G, Shi MJ, Xong Q, Gao X, Xiong Z, Li Y, Ma FY, Yu M, Wang CD, Wang $Y$, Yang $G$ (2009) Effect of the atmospheric pressure nonequilibrium plasmas on the conformational changes of plasmid DNA. Applied Physics Letters, 95:083702 (3pp). doi:10.1063/1.3212739

222. Bahnev B, Bowden MD, Stypczyńska A, Ptasińska S, Mason NJ, Braithwaite NSJ (2014) A novel method for the detection of plasma jet boundaries by exploring DNA damage. The European Physical Journal D, 68:140 (5pp). doi:10.1140/epjd/e2014-40844-9

223. Han X, Liu Y, Stack MS, Ptasinska S (2014) 3D Mapping of plasma effective areas via detection of cancer cell damage induced by atmospheric pressure plasma jets. Journal of Physics: Conference Series, 565:012011 (6pp). doi:10.1088/1742-6596/565/1/012011

224. Graham WG, Schaper L, Muir M, Currell FJ (2012) The Effect of Electrical Discharges in the Cell Media on Their Viability and DNA Damage and Comparison with the Effect of X-Rays. Plasma Medicine, 2:169-178.

225. Morales-Ramírez $P$, Cruz-Vallejo $V$, Peña-Eguiluz R, López-Callejas R, Rodríguez-Méndez BG, Valencia-Alvarado R, Mercado-Cabrera A, Muñoz-Castro AE (2013) Assessing Cellular DNA Damage from A Helium Plasma Needle. Radiation Research, 179:669-673. doi:10.1667/RR3223.1

226. Chang JW, Kang SU, Shin YS, Kim K II, Seo SJ, Yang SS, Lee JS, Moon E, Baek SJ, Lee K, Kim CH, Un S, Seob Y, II K, Jin S, Sik S, Lee JS, Moon E, Jae S, Lee K, Kim CH (2014) Nonthermal atmospheric pressure plasma induces apoptosis in oral cavity squamous cell carcinoma: Involvement of DNA-damage-triggering sub-G1 arrest via the ATM/p53 pathway. Archives of Biochemistry and Biophysics, 545:133-140. doi:10.1016/j.abb.2014.01.022

227. McLuckie KIE, Crookston RJR, Gaskell M, Farmer PB, Routledge MN, Martin EA, Brown K (2005) Mutation Spectra Induced by a-Acetoxytamoxifen - DNA Adducts in Human DNA Repair Proficient and Deficient (Xeroderma Pigmentosum Complementation Group A) Cells. Biochemistry, 44:8198-8205. doi:10.1021/bi047399e

228. Balasubramanian B, Pogozelski WK, Tullius TD (1998) DNA strand breaking by the hydroxyl radical is governed by the accessible surface areas of the hydrogen atoms of the DNA backbone. Proceedings of the National Academy of Sciences of the United States of America, 95:97389743. 
229. Qiao Y, Spitz MR, Shen H, Guo Z, Shete S, Hedayati M, Grossman L, Mohrenweiser H, Wei Q (2002) Modulation of repair of ultraviolet damage in the host-cell reactivation assay by polymorphic XPC and XPD/ERCC2 genotypes. Carcinogenesis, 23:295-299.

230. Emmert S, Slor H, Busch DB, Batko S, Albert RB, Coleman D, Khan SG, Abu-libdeh B, Digiovanna JJ, Cunningham BB, Lee M, Crollick J, Inui H, Ueda T, Hedayati M, Grossman L, Shahlavi T, Cleaver JE, Kraemer KH (2002) Relationship of Neurologic Degeneration to Genotype in Three Xeroderma Pigmentosum Group G Patients 1. Journal of Investigative Dermatology, 118:972-982.

231. Hölzle E (2003) Praktische UV-Therapie der Psoriasis. Aktuelle Dermatologie, 29:509-516.

232. Gambichler T, Othlinghaus N, Tomi NS, Holland-Letz T, Boms S, Skrygan M, Altmeyer P, Kreuter A (2009) Medium-dose ultraviolet (UV) A1 vs. narrowband UVB phototherapy in atopic eczema: a randomized crossover study. British Journal of Dermatology, 160:652-658. doi:10.1111/j.1365-2133.2008.08984.x

233. Stypczyńska A, Ptasińska S, Bahnev B, Bowden M, Braithwaite NSJ, Mason NJ (2010) The influence of amino acids on DNA damage induced by cold plasma radiation. Chemical Physics Letters, 500:313-317. doi:10.1016/j.cplett.2010.10.016

234. Sousa JS, Niemi K, Cox LJ, Algwari QT, Gans T, O'Connell D (2011) Cold atmospheric pressure plasma jets as sources of singlet delta oxygen for biomedical applications. Journal of Applied Physics, 109:1-8. doi:10.1063/1.3601347

235. Ames BN, Joyce M, Yamasaki E (1975) Methods for Detecting Carcinogens and Mutagens With. Mutation Research, 31:347-363. doi:10.1016

236. Ikehata H, Ono T (2011) The Mechanisms of UV Mutagenesis. Journal of Radiation Research, 52:115-125. doi:10.1269/jrr.10175

237. Rünger TM, Kappes UP (2008) Mechanisms of mutation formation with long-wave ultraviolet light (UVA). Photodermatology, Photoimmunology \& Photomedicine, 24:2-10.

238. Pfeifer GP, Besaratinia A (2012) UV wavelength-dependent DNA damage and human nonmelanoma and melanoma skin cancer. Photochemical \& Photobiological Sciences, 11:90-97. doi:10.1039/C1PP05144J

239. Albrecht-Buehler $G$ (2009) The spectra of point mutations in vertebrate genomes. BioEssays, 31:98-106. doi:10.1002/bies.080081

240. Cheng KC, Cahill DS, Kasai H, Nishimura S, Loeb LA (1992) 8-Hydroxyguanine, an abundant form of oxidative DNA damage, causes $\mathrm{G}$ to $\mathrm{T}$ and $\mathrm{A}$ to $\mathrm{C}$ substitutions. The Journal of Biological Chemistry, 267:166-172. 
241. Epe B (1991) Genotoxicity of singlet oxygen. Chemico-Biological Interactions, 80:239-260. doi:10.1016/0009-2797(91)90086-M

242. Cadet J, Berger M, Douki T, Ravanat J-L (1997) Oxidative damage to DNA: Formation, measurement, and biological significance. In: Reviews of Physiology Biochemistry and Pharmacology. Springer Berlin Heidelberg, 131:1-87.

243. Rothkamm K, Horn S (2009) Gamma-H2AX as protein biomarker for radiation exposure. Annali dell'Istituto Superiore di Sanita, 45:265-271.

244. Rogakou EP, Pilch DR, Orr AH, Ivanova VS, Bonner WM (1998) DNA Double-stranded Breaks Induce Histone H2AX Phosphorylation on Serine 139*. The Journal of Biologica Chemistry, 273:5858-5868.

245. Lowndes NF, Toh GW-L (2005) DNA Repair: The Importance of Phosphorylating Histone H2AX. Current Biology, 15:R99-R102. doi:10.1016/j.cub.2005.01.029

246. Oberhammer F, Wilson JW, Dive C, Morris ID, Hickman JA, Wakeling AE, Walker PR, Sikorska M (1993) Apoptotic death in epithelial cells : cleavage of DNA to 300 and / or $50 \mathrm{~kb}$ fragments prior to or in the absence of internucleosomal fragmentation. European Molecular Biology Organization, 12:3679-3684.

247. Ward IM, Chen J (2001) Histone H2AX Is Phosphorylated in an ATR-dependent Manner in Response to Replicational Stress. Journal of Biological Chemistry, 276:47759-47762. doi:10.1074/jbc.C100569200

248. MacPhail SH, Banáth JP, Yu Y, Chu E, Olive PL (2003) Cell Cycle-Dependent Expression of Phosphorylated Histone H2AX: Reduced Expression in Unirradiated but not X-Irradiated G 1 Phase Cells. Radiation Research, 159:759-767. doi:10.1667/RR3003

249. Cox JD (1990) A Randomized Phase I/II Trial of Hyperfractionated Radiation Therapy With Total Doses of 60.0 Gy to 79.2 Gy. Journal of Clinical Oncology, 8:1543-1555.

250. Kim K, Choi JD, Hong YC, Kim G, Noh EJ, Lee JS, Yang SS (2011) Atmospheric-pressure plasma-jet from micronozzle array and its biological effects on living cells for cancer therapy. Applied Physics Letters, 98:2012-2015. doi:10.1063/1.3555434

251. Wu AS, Kalghatgi S, Dobrynin D, Sensenig R, Cerchar E, Podolsky E, Dulaimi E, Paff M, Wasko K, Arjunan KP, Garcia K, Fridman G, Balasubramanian M, Ownbey R, Barbee KA, Fridman A, Friedman G, Joshi SG, Brooks AD (2013) Porcine intact and wounded skin responses to atmospheric nonthermal plasma. Journal of Surgical Research, 179:e1-e12. doi:10.1016/j.jss.2012.02.039

252. Barber PR, Locke RJ, Pierce GP, Rothkamm K, Vojnovic B (2007) Gamma-H2AX Foci Counting: Image processing and control software for high-content screening. In: Farkas DL, Leif RC, Nicolau DV (eds) in Proc. of SPIE. 6441:64411M (10pp). 
253. Isbary G, Shimizu T, Zimmermann JL, Heinlin J, Al-Zaabi S, Rechfeld M, Morfill GE, Karrer S, Stolz W (2014) Randomized placebo-controlled clinical trial showed cold atmospheric argon plasma relieved acute pain and accelerated healing in herpes zoster. Clinical Plasma Medicine, 2:50-55. doi:10.1016/j.cpme.2014.07.001

254. Isbary G, Morfill G, Zimmermann JL, Shimizu T, Stolz W (2011) Cold Atmospheric Plasma-A Successful Treatment of Lesions in Hailey-Hailey Disease. Archives of Dermatology, 147:388390. doi:10.4172/2161-1122.1000189 
$-142-$ 


\section{List of Figures}

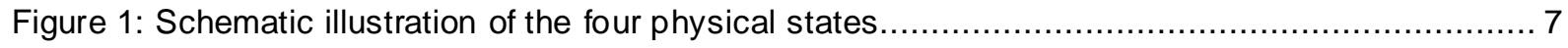

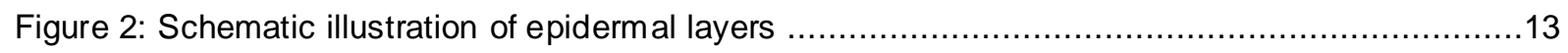

Figure 3: Structural arrangement of the connective tissue in the dermis .....................................14

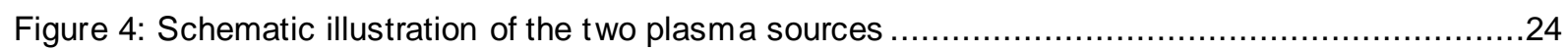

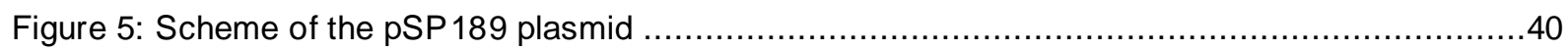

Figure 6: Schematic illustration of the two versions of the PSV assay .......................................

Figure 7: Scheme of laser and light pathways in a flow cytometric device....................................46

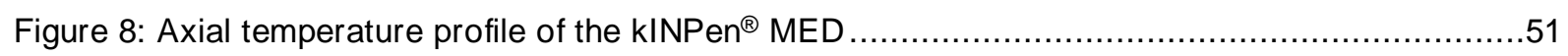

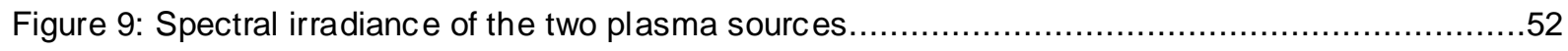

Figure 10: Ozone concentrations generated around the two plasma sources.............................54

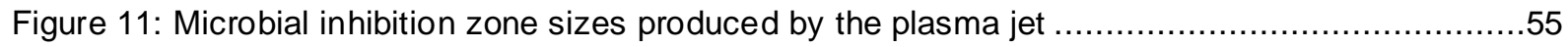

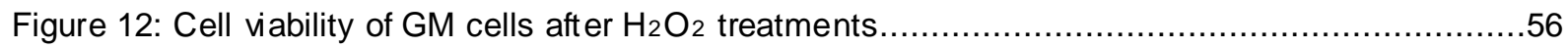

Figure 13: Plasma treatment time dependent cell viability of fibroblasts........................................57

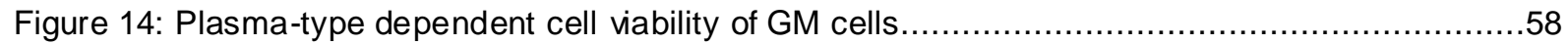

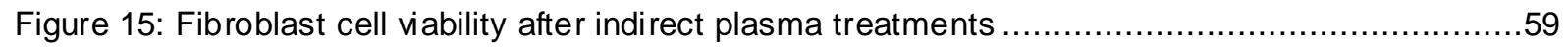

Figure 16: Plasma treatment time dependent generation of reactive species in PBS ......................61

Figure 17: Plasma-type dependent changes of the $\mathrm{pH}$ value in PBS .........................................62

Figure 18: Reporter gene expression of fibroblasts after transfection with UV-irradiated plasmids ......63

Figure 19: Reporter gene expression of fibroblasts after transfection with plasma-treated plasmids ...64

Figure 20: Plasma-type dependent expression rates of firefly in GM cells...................................65

Figure 21: DNA fragmentation capacity of the two plasma sources ...........................................66

Figure 22: Plasma-type and UVC dependent genotoxicity recorded in the PSV assay-version 1 ........68

Figure 23: Mutation frequencies of plasma- and UVC-treated plasmid DNA …..........................69

Figure 24: Plasma-type and UVC dependent genotoxicity recorded in PSV assay-version 2 ...........73

Figure 25: Plasma- and X-ray-induced DSBs measured as relative $\mathrm{Y}$-H2A.X fluorescence ................74

Figure 26: Scheme of how a $C \rightarrow T$ transition simultaneously represents a $G \rightarrow A$ transition ..............93

Figure 27: Scheme of the probability of spontaneously occurring mutations in humans ...................93

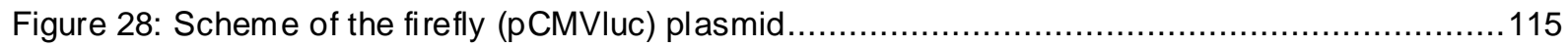




\section{List of Tables}

Table 1: Reactive species concentrations in plasma-treated PBS at similar plasma doses ..............62

Table 2: Mutation spectra of the supF-tRNA on pSP189 plasmid DNA …..................................70

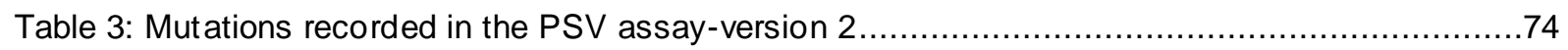

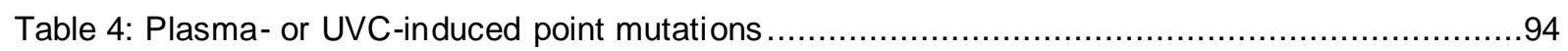

Table 5: Comparison of the genotoxic effect recorded in version 1 and 2 of the PSV assay ..............96

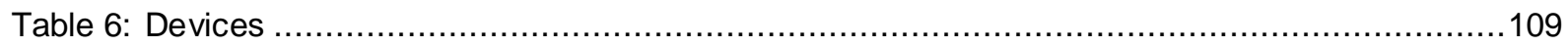

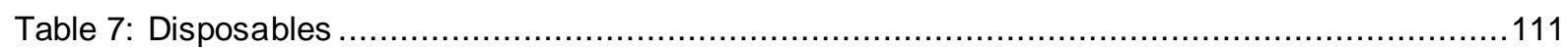

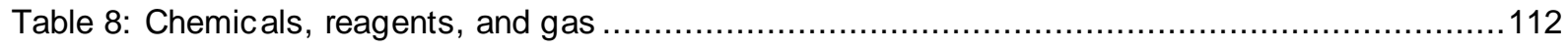

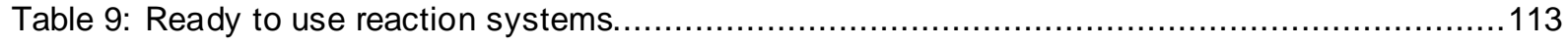

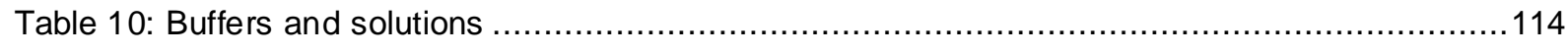

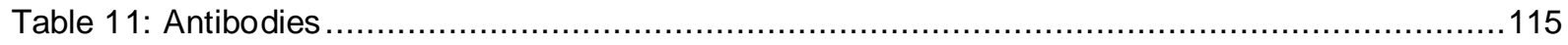

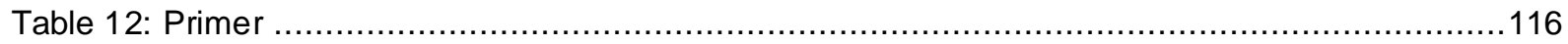




\section{Abbreviations}

\begin{tabular}{|c|c|}
\hline $6,4 \mathrm{PP}$ & pyrimidine-(6-4)-pyrimidone dimer \\
\hline 8-OxoG & 8-oxo-7,8-dihydro-2'-deoxyguanosine \\
\hline A & adenosine \\
\hline APP & atmospheric pressure plasma \\
\hline$A r^{*}$ & excited argon atom \\
\hline BER & base excision repair \\
\hline bp & base pair \\
\hline C & cytosine \\
\hline CFU & colony forming unit \\
\hline CPD & cyclobutane pyrimidine dimer \\
\hline DBD & dielectric barrier discharge \\
\hline $\mathrm{ddH}_{2} \mathrm{O}$ & double-distilled water \\
\hline ddNTP & dideoxyribonucleotide \\
\hline DIN & 'Deutsches Institut für Normung' \\
\hline DMEM & Dulbecco's modified Eagle's medium \\
\hline DMSO & dimethyl sulfoxide \\
\hline DNA & deoxyribonucleic acid \\
\hline dNTP & deoxyribonucleotide \\
\hline DSB & double strand breaks \\
\hline dsDNA & double stranded DNA \\
\hline dYT & double yeast trypton \\
\hline E. coli & Escherichia coli \\
\hline EDTA & ethylenediaminetetraacetic acid \\
\hline EGF & epidermal growth factor \\
\hline eGFP & enhanced green fluorescent protein \\
\hline ELISA & Enzyme Linked Immunosorbent Assay \\
\hline Eq. & equation \\
\hline FACS & fluorescent-activated cell sorting \\
\hline FBS & Fetal Bovine Serum \\
\hline FGF & fibroblast growth factor \\
\hline fPrimer & forward Primer \\
\hline
\end{tabular}




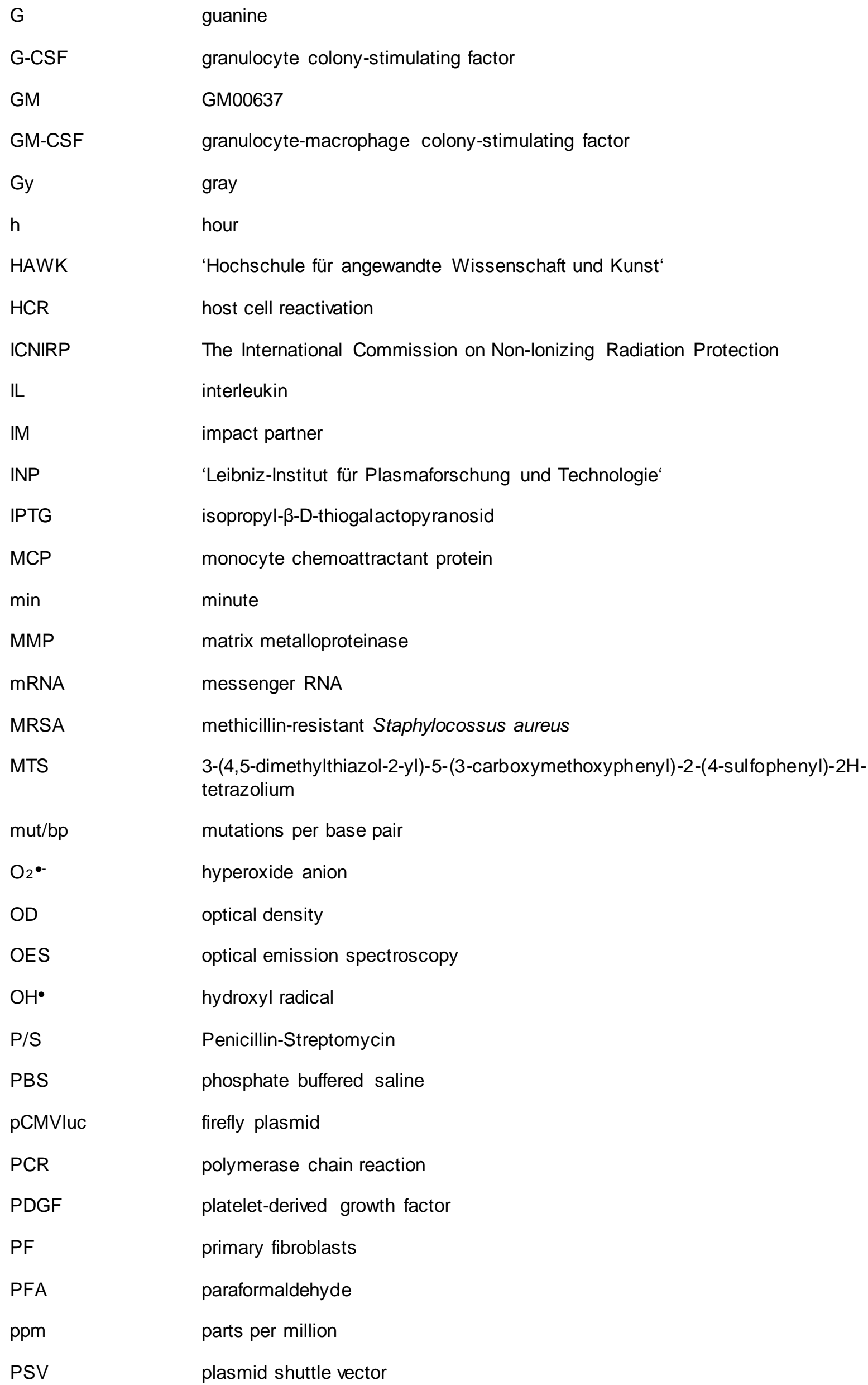


PTGS2

RLU

RNA

RNS

ROS

rPrimer

S. aureus

S. epidermidis

SDS

slm

SOC

sPrimer

SSB

ssDNA

$\mathrm{T}$

TBE

TGF

TNF- $\alpha$

Triton $\mathrm{X}-100$

Tween20

UV

VEGF

VUV

X-Gal

Y-H2A.X prostaglandin-endoperoxide synthase 2

relative light unit

ribonucleic acid

reactive nitrogen species

reactive oxygen species

reverse Primer

Staphylococcus aureus

Staphylococcus epidermidis

sodium dodecyl sulfate

standard liter per minute

Super Optimal Broth

sequencing Primer

single strand break

single stranded DNA

tyrosine

Tris/Borate/EDTA

transforming growth factor

tumor necrosis factor- $\alpha$

Octoxinol 9

Polysorbat 20

ultraviolet

vascular endothelial growth factor

vacuum UV

5-Brom-4-chlor-3-indoxyl- $\beta$-D-galactopyranosid

phosphorylated H2A.X protein 
$-148-$ 


\section{Curriculum vitae}

\section{Personal Data}

Full Name:

Home Address:

\section{Positions}

02/2013 - present

$07 / 2012-12 / 2012$

\section{Education}

10/2009-05/2012

10/2006-9/2009

$10 / 2005-6 / 2006$
Regina Tiede

Bertha-von-Suttner-Straße 18

D-37085 Göttingen

14.01.1986

tiede86@googlemail.com

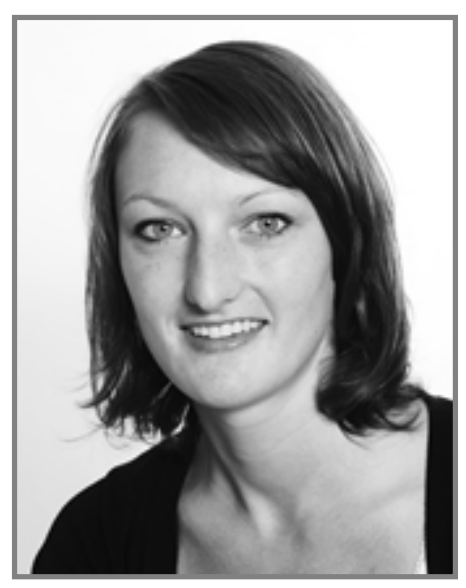

Ph.D.: Evaluation Strategies for Risk Assessment and Usability of Medical Plasma Sources in Dermatology; NormPlas project at the University Medical Center Göttingen

Research associate: Identification, reconstruction and quantitative anatomy of antennal lobe interneurons; Philipps University of Marburg, Germany

Master of Science in Molecular and Cellular Biology with a Neurobiology major, Philipps University of Marburg, Germany

Thesis: 'Development of Methods for Calcium Imaging and Identifying of Imaged Glomeruli in the Antennal Lobe of Manduca sexta L'

Bachelor of Science in Biology with a Neurobiology major, Philipps University of Marburg, Germany

Thesis: 'Pharmacological analysis of the impact of electrical activity on developing olfactory glomeruli of the sphinx moth Manduca sexta L'

Teacher Education in Mathematics and Chemistry, Philipps University of Marburg, Germany 


\section{Research Experiences}

10/2010 - 04/2011 Calcium imaging experiments for the Master Thesis: with Dr. EM Staudacher, West Virginia University, Morgantown, WV, USA

$10 / 2009-12 / 2012$

Identification, reconstruction and quantitative anatomy of antennal lobe interneurons: collaboration with Dr. EM Staudacher - laboratory of Prof. KC Daly - at West Virginia University, Morgantown, WV, USA

08/2008-09/2008

Functional MRI on rat brains (6 week internship) with Dr. F Angenstein, Leibniz Institute for Neurobiology in Magdeburg, Germany

\section{Teaching and other Experiences}

$09 / 15-01 / 16$

Service for the evaluation of the cytotoxicity of a plasma device prototype on behalf of NSF Erdmann Analytics, RhedaWiedenbrück, Germany

$06 / 2014-9 / 2014$

Supervision of the bachelor thesis: 'Bestimmung der in-vivoMutationsspektren von zwei verschiedenen Plasmaquellen mithilfe eines Plasmid-Shuttle-Vektor-Assays`

$04 / 2009-05 / 2009$

Teaching Assistant: laboratory course 'Animal physiology:

and $04 / 2010-05 / 2010$ sensory systems' ('Tierphysiologischer Kurs, Teil: Sinne'), Philipps University Marburg, Germany

$11 / 2009$

Teaching Assistant: laboratory course 'Biology for Medical students' ('Biologie für Mediziner'), Philipps University Marburg, Germany

01/2009 - 09/2009 Research Assistant: maintain laboratory colony of Manduca sexta L., Philipps University Marburg, Germany

02/2006-03/2006 Internship (4 weeks) at day care center 'Pusteblume' in Lübbecke, Germany

\section{Awards}

2015 Innovation Award from 'Stiftung Familie Klee'

2014 Innovation Award from 'Wirtschaftsförderung Region Göttingen'

Founding member of the 'Nationales Zentrum für Plasmamedizin' since 2014 


\section{Short Communications}

Tiede $R^{*}$, Emmert $S$ (2016) Beurteilung und Sicherheit von medizinischen Atmosphärendruckplasmen: Vorstellung der DIN-SPEC 91315. Workshop: PlasmaDerm $^{\circledR}$ zur Wundbehandlung, Rostock, Deutschland 02/2016. (oral presentation; * presenter)

Tiede R, Emmert S (2015) Widespread skin diseases and alternative therapeutic approaches with biocompatible plasma. Atelier Plasma Medicine, Oléans, France 11/2015. (oral presentation; presented by Pouvesle JM)

Tiede $\mathrm{R}^{*}$, Mann MS, von Woedtke T, Daeschlein G, Ahmed R, Viöl W, Laspe P, Apel A, Emmert S (2014) Special test procedures for safety evaluation of plasma devices. 3rd Young Professional Workshop on Plasma Medicine, Zinnowitz, Deutschland 9/2014. (oral presentation; *presenter)

Tiede R* ${ }^{\star}$, Daeschlein G, Mann MS, von Woedtke T, Viöl W, Ahmed R, Emmert S (2015) Evaluierungsstrategien zur Sicherheit von Atmosphärendruckplasmen in der Medizin: Vorstellung der DIN-SPEC 91315. 4. Plasmamedizin-Workshop, Göttingen, Deutschland 6/2015. (oral presentation; *presenter)

Tiede R*, Mann M, Daeschlein G, Ahmed R, von Woedtke T, Emmert S (2015) General Requirements for Medical Plasma Sources [DIN-SPEC 91315]. The 2nd International Workshop on Plasma for Cancer Treatment, Nagoya, Japan 3/2015. (poster; *presenter)

Tiede R, Mann MS, Laspe P, Hirschberg J, Viöl W, von Woedtke T, Emmert S* (2015) Genotoxicity and mutagenicity of a plasma jet and DBD source and alleviation of chronic venous leg ulcers with a DBD plasma generator. The 2nd International Workshop on Plasma for Cancer Treatment, Nagoya, Japan 3/2015 (oral presentation; *presenter).

Mann MS*, Tiede R, Ahmed R, Wandke D, Wurster S, Weltmann K-D, Daeschlein G, Emmert S, von Woedtke T (2014) Standards in Plasma Medicine: Development, Contents and Importance of the first German DIN Specification. 5th International Congress on Plasma Medicine, Nara, Japan 6/2014. (oral presentation; *presenter)

Tiede R* ${ }^{*}$ Emmert S, Daeschlein G, Mann MS, von Woedtke T, Viöl W, Ahmed R (2014) Risikoanalysen von kaltem Atmosphärendruckplasma. Workshop zu Sicherheitsfragen in der Plasmamedizin, Berlin, Deutschland 6/2014. (oral presentation; *presenter) 
Tiede $\mathrm{R}^{*}$, Apel A, Laspe P, Emmert S (2013) Risk Assessment of Plasma Sources in Regard to Biomedical Applications. 2nd Young Professionals Workshop on PlasmaMedicine, Kölpinsee, Deutschland 9/2013. (oral presentation; *presenter)

Tiede $R^{*}$, Seebode $C^{*}$, Georg Daeschlein G, Laspe A, Apel A, Brehmer F, Hänßle F, Helmke A, Mertens N, Viöl W, Maus-Friedrichs W, Schön M, Wandtk D, Emmert S (2013) Topical Workshop: Biomedical Applications of Atmospheric Pressure Plasma Technology, COST Action MP 1101, 05/2013 Kerkrade NL. (oral presentation; *presenter)

Staudacher EM, Tiede R, Schachtner J, Daly KC (2012) Connections between brain and ventral nerve cord play a critical role for pulse tracking in antennal lobe interneurons of Manduca sexta. Program No. 174.05. 2012 Neuroscience Meeting Planner. New Orleans, LA: Society for Neuroscience, 2012. Online

Staudacher EM, Tiede R, Schachtner J, Daly KC (2012) Pulse tracking of antennal lobe neurons is enhanced by input from the thoracic ganglia in Manduca sexta. Huntington Beach, CA. AChemS. \#P86, p. 55

Tiede R, Staudacher EM, Schachtner J, Daly KC (2011) Calcium imaging and subsequent identification of imaged glomeruli in the $\mathrm{AL}$ of the moth Manduca sexta. Program No. 169.03. 2011 Neuroscience Meeting Planner. Washington, DC: Society for Neuroscience, 2011. Online (poster)

Staudacher EM, Tiede R, Schachtner J, Daly KC (2011) Does feed-forward input from the thoracic ganglia mediate antennal lobe pulse tracking in Manduca sexta? Program No. 169.03. 2011 Neuroscience Meeting Planner. Washington, DC: Society for Neuroscience, 2011. Online (poster)

Staudacher EM, Tiede R, Schachtner J, Daly KC (2010) Representations of odor identity and concentration by a virtual ensemble of serially recorded antennal lobe output neurons. Program No. 273.15 2010 Neuroscience Meeting Planner. San Diego, CA: Society for Neuroscience, 2010. Online (poster)

Tiede R, Rulla S, Huetteroth W, Schachtner J (2009) Influence of lanthan chloride and procaine on the development of antennal lobe glomeruli in Manduca sexta. Program No. P NB.20. 2009 DZG Abstractband, Regensburg, Germany: Deutsche Zoologische Gesellschaft, 2009. Online (poster) 